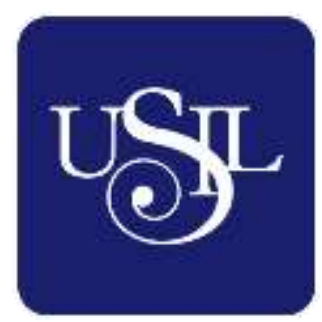

UNIVERSIDAD

SAN IGNACIO

DE LOYOLA

ESCUELA DE POSTGRADO

\title{
PLAN ESTRATÉGICO DE HAMEK INGENIEROS ASOCIADOS S.A.C, PARA LOS AÑOS 2019 AL 2021 (LIMA, PERÚ)
}

Trabajo de Investigación para optar el grado de:

MELISSA KARINA BURGA RUIZ

Maestro en Administración de Negocios - Executive MBA

ERIKA BETTINA CARRILLO ZELAYA

Maestro en Administración de Negocios - Executive MBA

JULIO CESAR CHÁVEZ ENCISO

Maestro en Administración de Negocios - Executive MBA

Asesor:

Mg. Rodolfo Luis González Angulo

Lima - Perú 


\section{Tabla de Contenido}

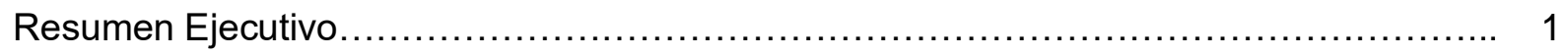

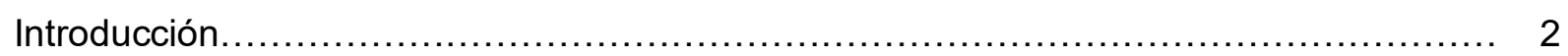

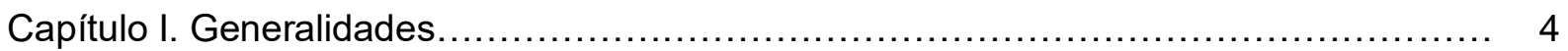

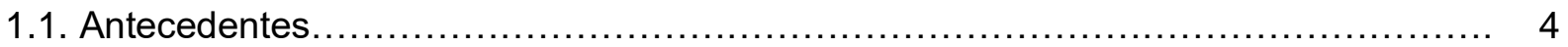

1.2. Determinación del problema u oportunidad........................................ 15

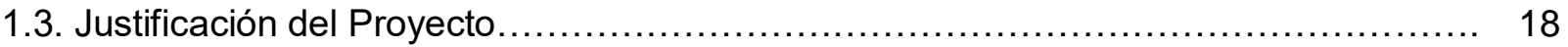

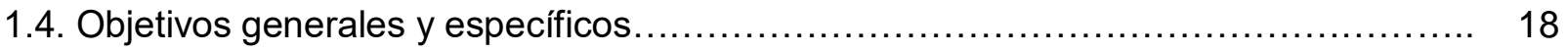

1.4. Alcances y limitaciones de la investigación........................................ 19

Capítulo II. La Empresa................................................................. 20

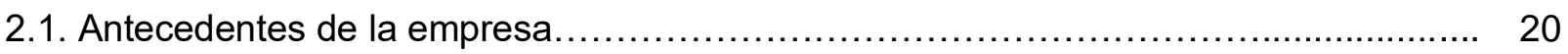

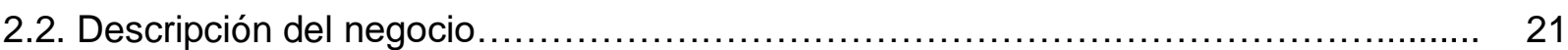

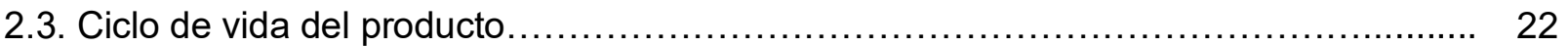

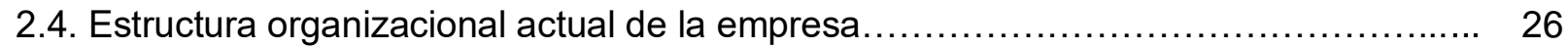

2.5. Situación de Mercado y Financiera actual de la Industria.......................... 36

Capítulo III. Formulación de visión, misión y valores de la empresa...................... 44

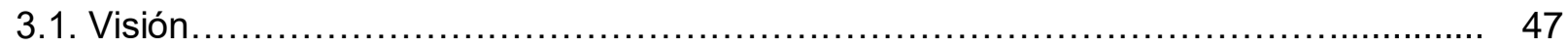

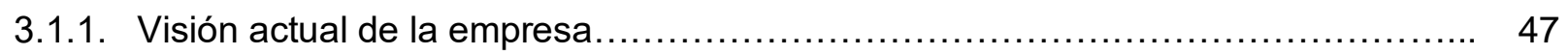

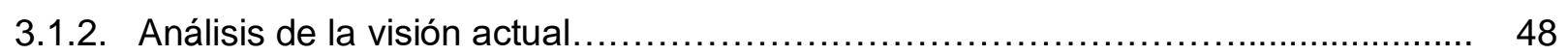

3.1.3. Matriz de la visión propuesta para la empresa.................................. 50

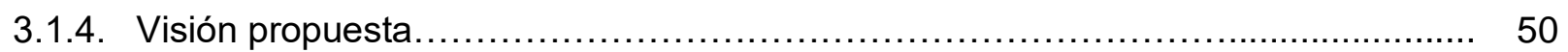

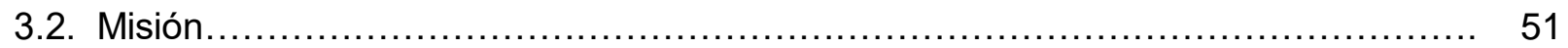

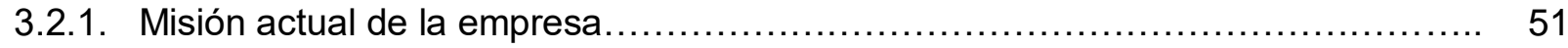

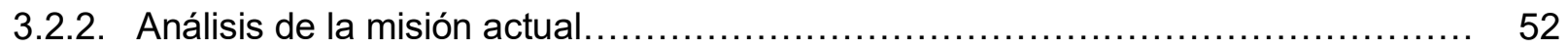

3.2.3. Elementos de la misión propuesta para la empresa........................... 53

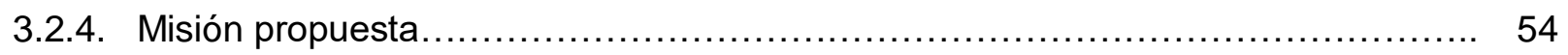

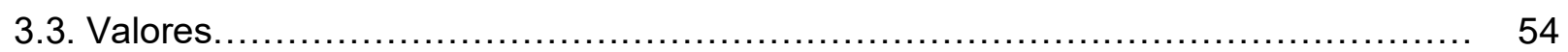

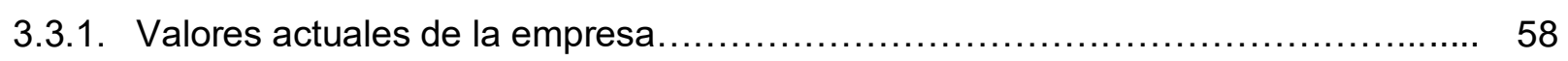

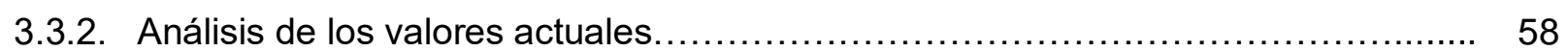

3.3.3. Elementos de los valores propuestos para la empresa........................... 58

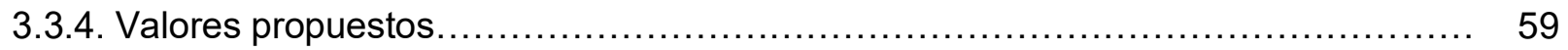

3.4. Alineamiento estratégico de la Visión, Misión y Valores de la empresa................. 60

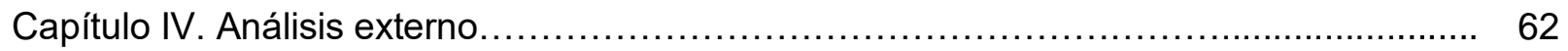

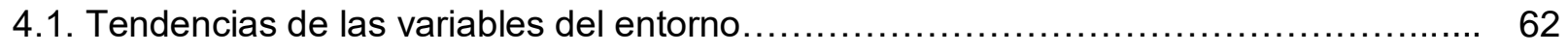




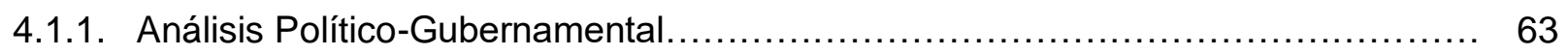

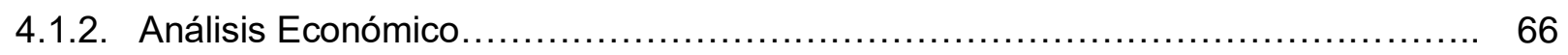

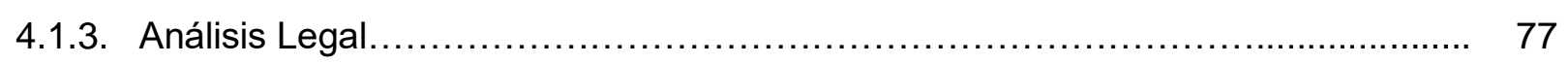

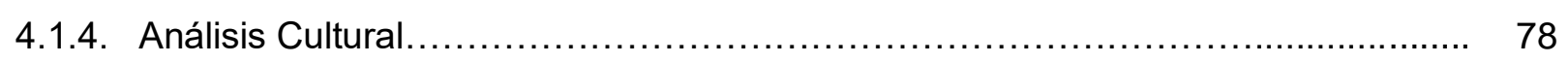

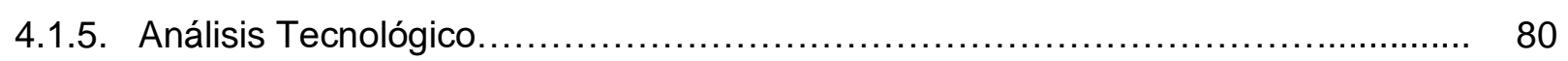

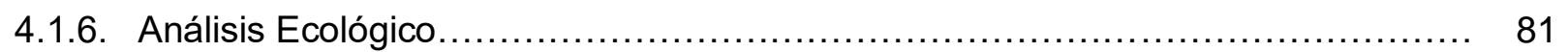

4.2. Impacto en clientes / proveedores de cada una de las variables del entorno........... 83

4.3. Efecto en la empresa de cada una de las variables del entorno...................... 85

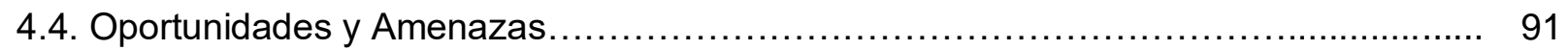

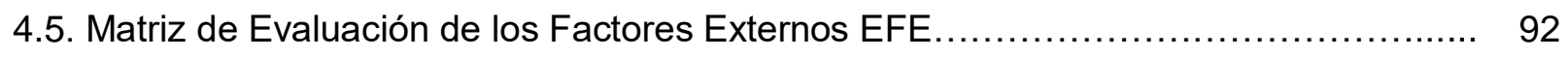

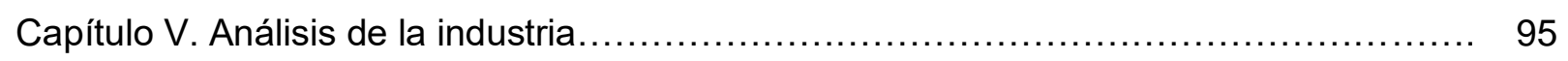

5.1. Descripción del Mercado (demanda) e Industria (oferta) ......................... 95

5.2. Descripción las cinco fuerzas competitivas de la industria............................ 96

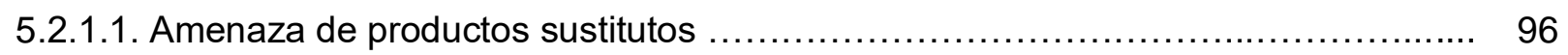

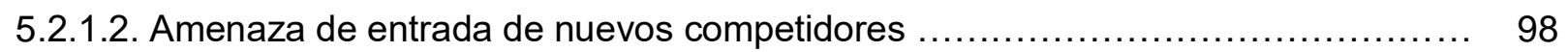

5.2.1.3. Poder de negociación de los clientes ......................................... 99

5.2.1.4.Poder de negociación de los proveedores................................... 99

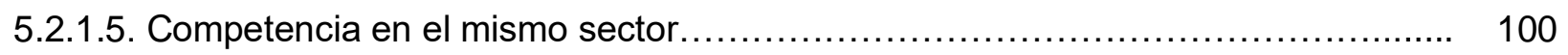

5.3. Matriz de atractividad de cada una de las cinco fuerzas............................ 101

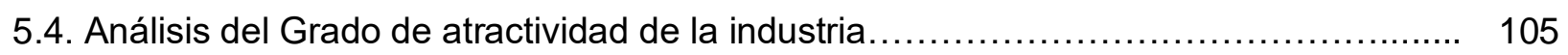

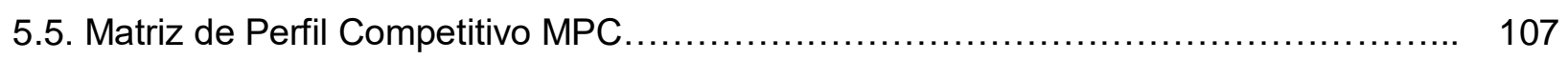

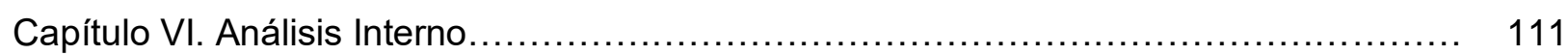

6.1. Descripción de las actividades de la cadena de valor de la empresa: Logística interna, Operaciones, Logística externa, Mercadotecnia, Servicios, Adquisiciones, Recursos Humanos, Tecnología, Infraestructura.

6.2. Indicadores de cada una de las actividades de la cadena de valor.

6.3. Benchmarking y comparación con los líderes de la industria de cada una de las

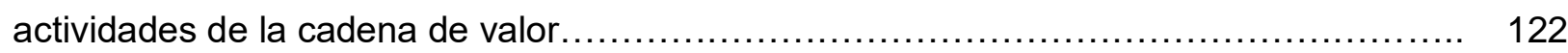

6.4. Determinar las competencias de la empresa................................. 125

6.5. Identificación y determinación de las ventajas competitivas de la empresa............ 126

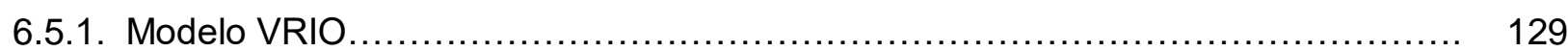

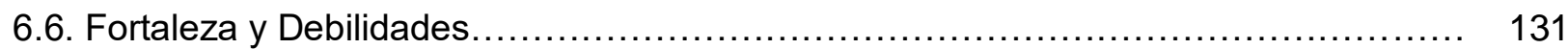

6.7. Matriz de Evaluación de los Factores Internos EFI.................................. 133

Capitulo VII. Formulación de los Objetivos y Diseño de las Estrategias................... 138

7.1. Alcance y planteamiento de los objetivos estratégicos............................. 138

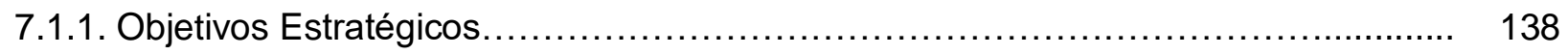




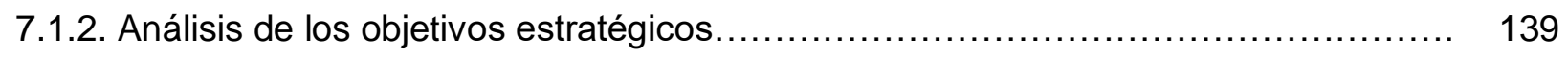

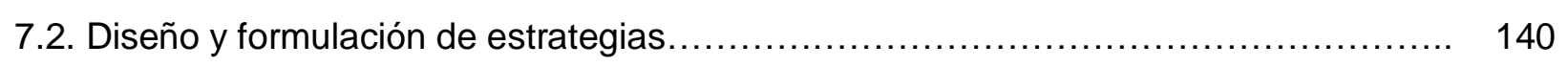

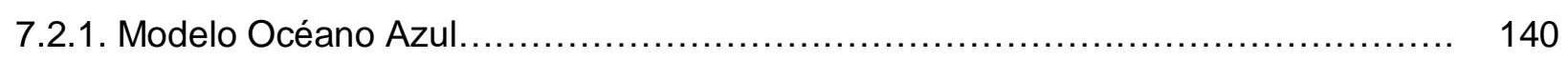

7.2.1.1. Lienzo de la estrategia actual de la empresa.................................. 141

7.2.1.2. Lienzo de la estrategia de la industria..................................... 142

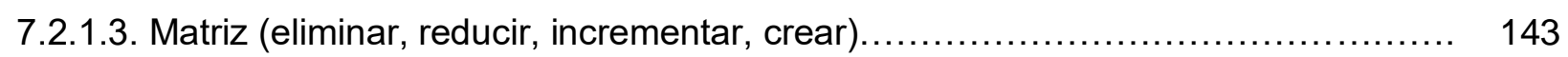

7.2.1.4. Lienzo de la nueva estrategia considerada................................. 144

7.2.2. Matrices de formulación de estrategias......................................... 145

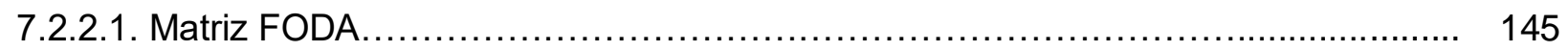

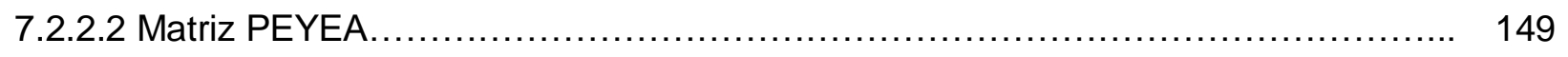

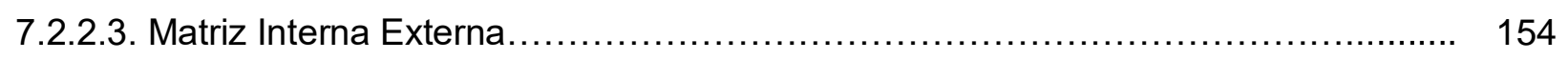

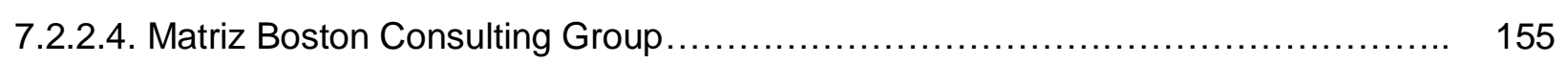

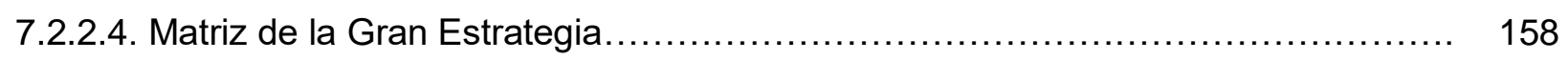

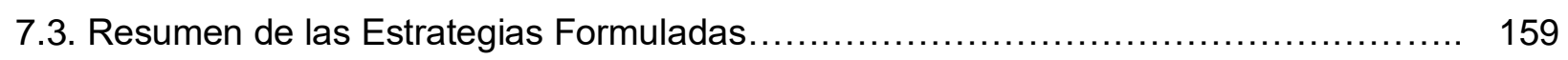

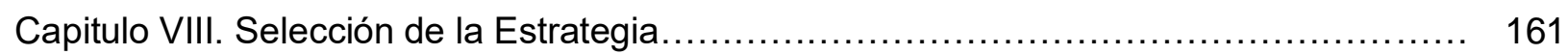

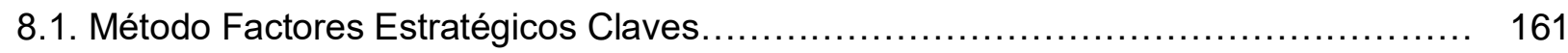

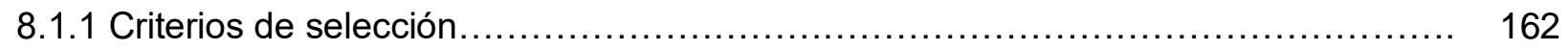

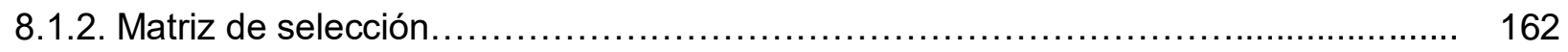

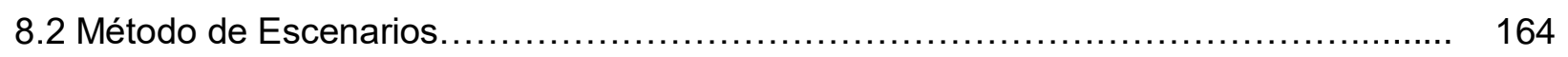

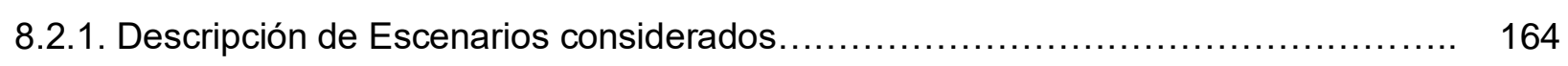

8.2.2. Comparación de estrategias con escenarios..................................... 167

8.3. Matriz de Planeación Estratégica Cuantitativa MPEC .................................. 168

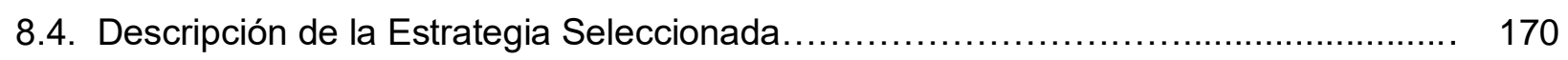

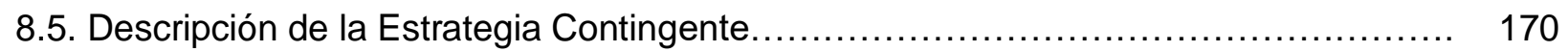

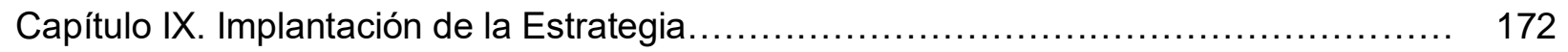

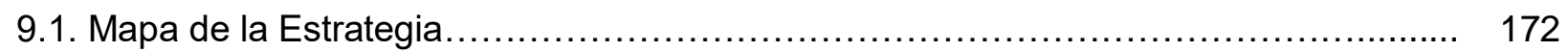

9.2. Objetivos específicos según el mapa de la estrategia........................... 172

9.3. Indicadores para cada uno de los objetivos específicos.............................. 175

9.4. Metas para cada uno de los objetivos específicos.............................. 176

9.5. Iniciativas (acciones a llevar a cabo para cada uno de los objetivos específicos)

Estrategias, programas, políticas, reglas, procedimientos............................. 177

9.6. Responsable de cada una de las iniciativas...................................... 178

9.7. Presupuesto de cada una de las Iniciativas....................................... 179

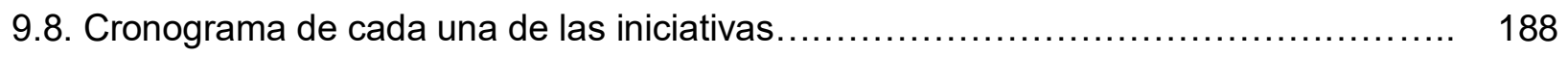

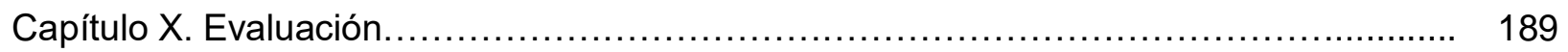

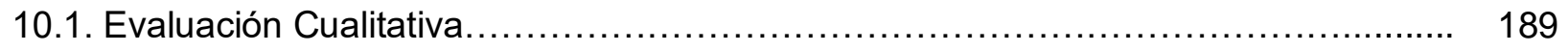


10.1.1. Criterio de Evaluación

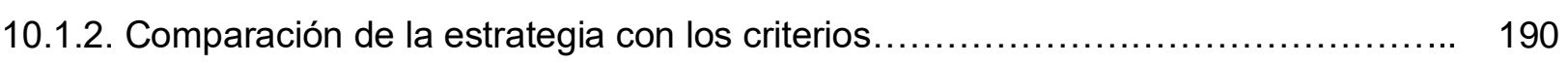

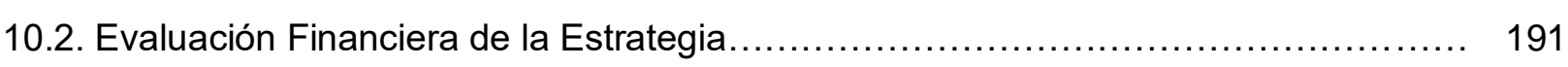

10.2.1. Proyección de estados financieros (situación actual y con nueva estrategia)....... 192

10.2.2. Estado de resultados (situación actual y con nueva estrategia)................... 194

10.2.3. Balance General (situación actual y con nueva estrategia)....................... 199

10.2.4. Flujo de efectivo (situación actual y con nueva estrategia)....................... 204

10.2.5. Proyección de flujos (situación actual y con nueva estrategia) ..................... 204

10.2.6. Evaluación Financiera (VAN, TIR, y ratios financieros) .......................... 209

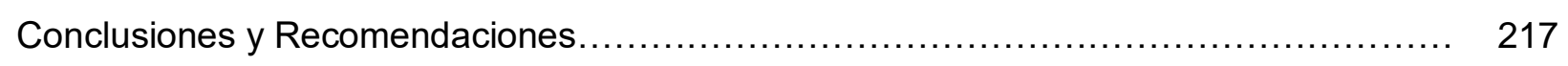

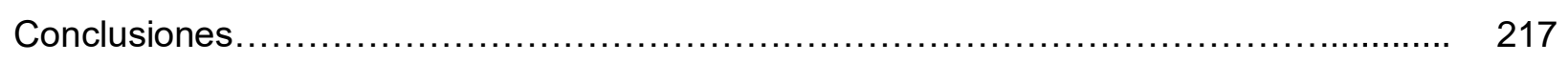

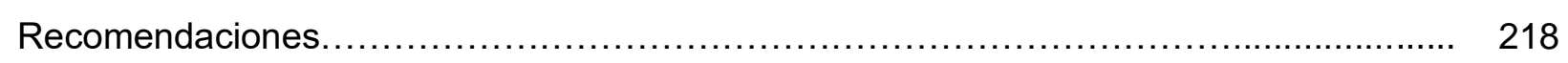

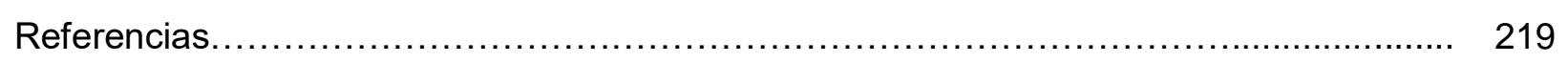

Apéndice.

Apéndice N 1. Entrevista en Profundidad a Gerente General de Hamek Ingenieros y

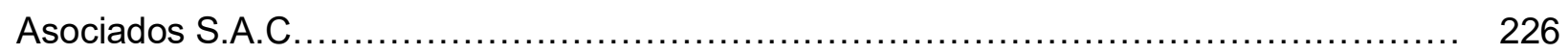

Apéndice N 2. Entrevista en Profundidad a Gerente Administrativo de Hamek Ingenieros

y Asociados S.A.C......................................................................... 234

Apéndice N 3. Entrevista en Profundidad a Experto del Sector Ambiental................... 241

Apéndice N 4. Entrevista en Profundidad a Jefe de Área de Energía de la empresa

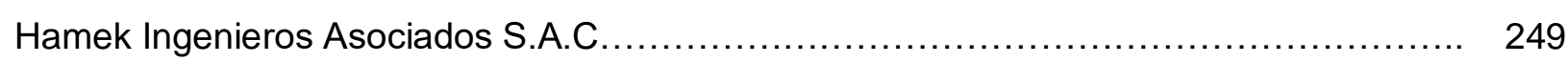

Apéndice N 5. Entrevista en Profundidad a Experto del Sector Energético................. 256

Apéndice N 6. Entrevista en Profundidad al Cliente / No Cliente.............................. 264

Apéndice N 7. Entrevista en Profundidad Especialista Estudios Técnicos / Servicios

Externos para la empresa Hamek Ingenieros Asociados S.A.C...........................

Apéndice N 8. Entrevista en Profundidad a Representante COES ........................... 279

Apéndice N 9. Entrevista de Profundidad a Gerente General d Hamek Ingenieros

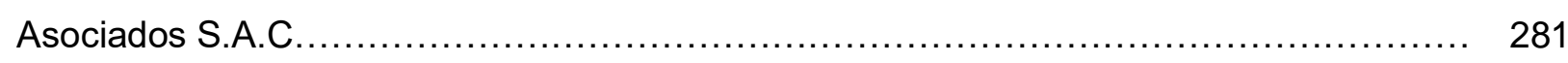

Apéndice N 10. Tabulación Respuestas de Entrevista en Profundidad para

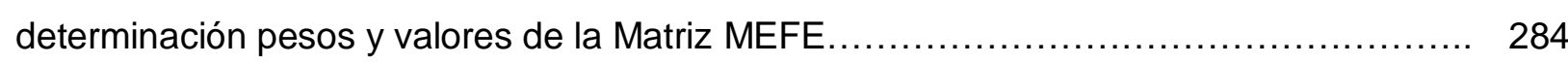

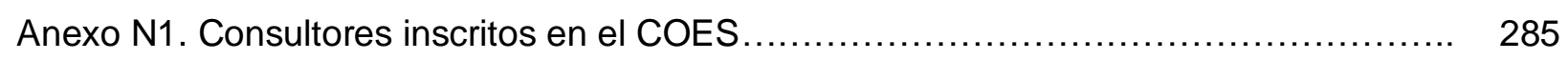

Anexo N2. La empresa está inscrita en la UT Unidad de Transacción de El Salvador....... 286

Anexo N3. Características de las pequeñas empresas en el Perú......................... 288

Anexo N4. Carta de Acreditación del Coes a Hamek Ingenieros Asociados S.A.C......... 289

Anexo N5. Beta por Sector................................................... 290

Anexo N6. Tasa de Mercado y Tasa Libre de Riesgo................................. 291 
Anexo N7. Riesgo Región.

Anexo N8. Inflación Perú e Inflación Estados Unidos. 


\section{Lista de Tablas}

Tabla 1 Tiempo que ha sido cliente de la empresa en los servicios de pruebas de potencia efectiva y rendimiento de las unidades térmicas y/o potencia efectiva de las centrales hidráulicas

Tabla 2 Variación Anual de Ventas de Hamek Ingenieros Asociados S.A.C 25

Tabla 3 Principales Proyectos Mineros en el Perú

Tabla 4 Participación de las Empresas Distribuidoras en el Mercado del Sistema

Eléctrico Interconectado Nacional, 2014.

Tabla 5 Principales proyectos de generación eléctrica a futuro......................... 43

Tabla 6 Acciones Estratégicas Sectoriales.................................................................. 46

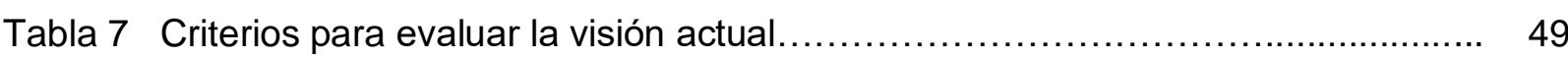

Tabla 8 Descripción de criterios para la evaluación de la visión propuesta.................. 50

Tabla 9 Criterios para evaluar la evaluación de la visión actual........................... 53

Tabla 10 Componentes para la elaboración de la misión................................ 54

Tabal 11 Valores dominantes en la fuerza laboral actual................................ 47

Tabla 12 Factores para el desarrollo de valores............................................... 59

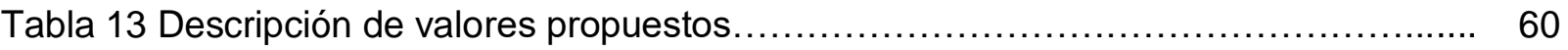

Tabla 14 Relación de valores organizacionales con la misión y visión......................... 61

Tabla 15. Electricidad Gas y Agua: Valor Agregado Bruto....................................... 67

Tabla 16 Lima Metropolitana: Población adecuadamente empleada, según ramas de

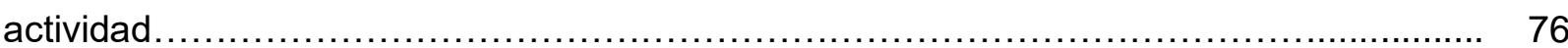

Tabla 17 Impacto de Variables Externas en Clientes y Proveedores...................... 84

Tabla 18 Matriz de Evaluación de Factores Externos (EFE) ........................... 93

Tabla 19 Matriz de atractividad de amenaza frente a productos sustitutos................. 102

Tabla 20. Matriz de atractividad de amenaza frente a nuevos participantes................. 102

Tabla 21. Matriz de atractividad frente a los clientes.......................................... 103

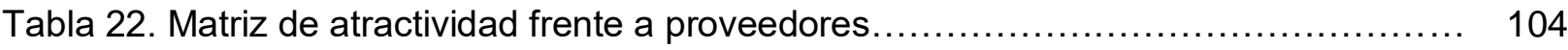

Tabla 23. Matriz de atractividad frente a la rivalidad de competidores..................... 104

Tabla 24. Matriz del grado de Atractividad o Competividad de la Industria........................ 106

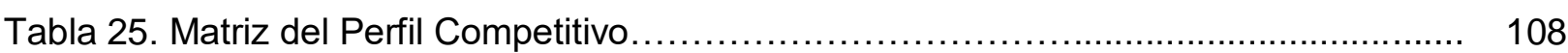

Tabla 26. Relación de Empresas Competidoras en EI Salvador.......................... 110

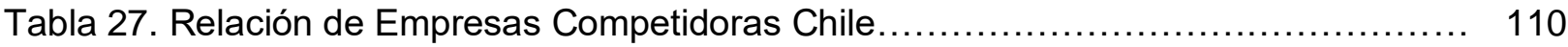

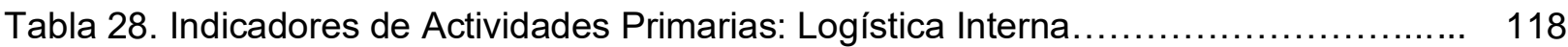

Tabla 29. Indicadores de Actividades Primarias: Producción y Mantenimiento.................. 119

Tabla 30. Indicadores de Actividades Primarias: Servicio y Post Venta........................ 119 
Tabla 31. Indicadores de Actividades de Apoyo: Abastecimiento

Tabla 32. Indicadores de Actividades Primarias: Marketing y Ventas...

Tabla 33. Indicadores de Actividades de Apoyo: Desarrollo de Tecnología.

Tabla 34. Indicadores de Actividades de Apoyo: Recursos Humanos.

Tabla 35. Benchmarking competidores.

Tabla 36. La competencia.

Tabla 37. Participación Ingresos.

Tabla 38. Participación Ingresos Servicios Consultoría....

Tabla 39. Matriz VRIO de la empresa.

Tabla 40. Fortaleza y Debilidades.

Tabla 41. Matriz de Evaluación de los Factores Internos.

Tabla 42. Matriz (eliminar, reducir, incrementar, crear).

Tabla 43. Matriz FODA.

Tabla 44. Factores determinantes Posición Estratégica.

Tabla 45. Análisis Factores determinantes Posición Estratégica.

Tabla 46. Participación de mercado y tasa de crecimiento de la empresa.

Tabla 47. Resumen de Estrategias.

Tabla 48. Matriz de Decisión Estratégica.

Tabla 49. Inversión Proyectada por Estrategia.

Tabla 50. Definición de Contextos.

Tabla 51. Definición de Escenarios.

Tabla 52. Impactos en Principales Variables.

Tabla 53. Impactos en las Estrategias.

Tabla 54. Matriz Cuantitativa de la Planificación Estratégica (MCPE).

Tabla 55. Prioridad de Estrategias Formuladas.

Tabla 56. Objetivos Específicos.

Tabla 57. Indicadores para los Objetivos Específicos de las Estrategias Seleccionadas...

Tabla 58. Meta para los Objetivos Específicos de las Estrategias Seleccionadas......

Tabla 59. Iniciativas para cada uno de los Objetivos

Tabla 60. Responsable por Iniciativa Propuesta.

Tabla 61. Presupuesto en el Plan de Recursos Humanos.

Tabla 62. Presupuesto en plan de aprendizaje y crecimiento.

Tabla 63. Presupuesto en plan de implementación de equipos de medición.

Tabla 64. Presupuesto en Plan Comercial.

Tabla 65. Presupuesto Total de Inversión para los años 2019-2021 - Estrategia Principal

Tabla 66. Presupuesto Total de Inversión para los años 2019-2021-Estrategia 
Contingente.

Tabla 67. Cronograma de cada de las Iniciativas.

Tabla 68. Cuadro Comparativo de Estrategia con Criterios Cualitativos......

Tabla 69. Ingresos Proyectados.

Tabla 70. Crecimiento Proyectado por mercado.

Tabla 71. Crecimiento proyectado por Línea de Asesoría.

Tabla 72. Estado de Pérdidas y Ganancias Actual.

Tabla 73. Estado de Pérdidas y Ganancias Proyectado Sin Implementar Estrategia

Tabla 74. Estado de Pérdidas y Ganancias Proyectado con Estrategia de Penetración de

Mercados

Tabla 75. Estado de Pérdidas y Ganancias Proyectado con Estrategia de Desarrollo de

Producto.

Tabla 76. Balance General Actual.

Tabla 77. Balance General Proyectado sin estrategia

201

Tabla 78. Balance General con Estrategia de Penetración de Mercados

Tabla 79. Balance General con Estrategia de Desarrollo de Productos....

Tabla 80. Flujo de Efectivo Actual.

Tabla 81. Proyección de Flujo Sin Estrategia.

Tabla 82. Inversión en Capex ECE1

Tabla 83. Depreciación de Activos ECE1. 206

Tabla 84. Depreciación de los tres años proyectados ECE1. 206

Tabla 85. Inversiones Working Capital ECE1 206

Tabla 86. Proyección de Flujo con Estrategia de Penetración de Mercados.

Tabla 87. Inversión en Capex ECE2.

Tabla 88. Depreciación de Activos ECE2.

Tabla 89. Depreciación de los Tres Años Proyectados ECE2.

Tabla 90. Inversiones Working Capital ECE2. 208

Tabla 91. Proyección de Flujo con Estrategia de Desarrollo.............................. 209

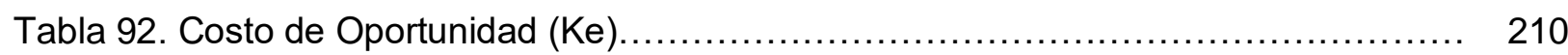

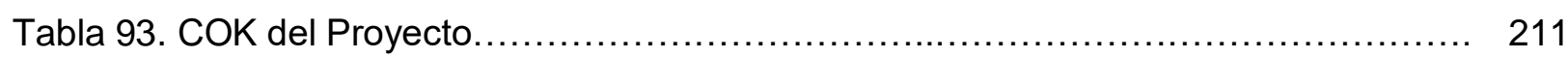

Tabla 94. EI VAN y TIR con Estrategia de Penetración de Mercados...................... 211

Tabla 95. EI VAN y TIR con Estrategia de Desarrollo de Productos........................... 212

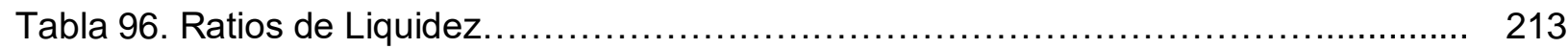

Tabla 97. Ratios de Solvencia...................................................... 214

Tabla 98. Ratios de Rentabilidad ........................................... 216 


\section{Lista de Figuras}

Figura 1. Línea de tiempo de hechos importantes del sector electricidad en el Perú 1884-2016.

Figura 2. Representación de clientes que mantienen relación comercial en años continuos con Hamek.

Figura 3. Metodología de Ishikawa para determinar el Problema Principal...

Figura 4. Ciclo de vida de un producto

Figura 5. Ciclo de vida del producto de la empresa.

Figura 6. Organigrama de la empresa

Figura 7. Diagrama de flujo de proceso del servicio de ensayo de potencia efectiva de

Centrales Hidroeléctrica y Unidades Termoeléctricas.

Figura 8. Importancia de la minería metálica, 2016.

Figura 9. Importancia de la minería metálica, 2016

Figura 10. Proyecciones de demanda de energía entre el año 2014-2024.

Figura 11. Inversiones en Electricidad.

Figura 12. El mercado eléctrico del Perú.

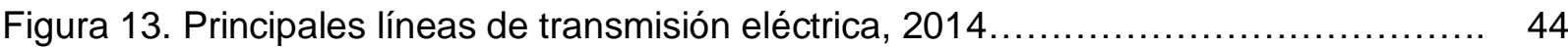

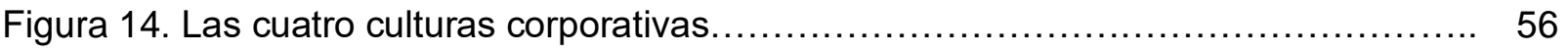

Figura 15. Valores básicos y modelo de la organización de las 7 "s"

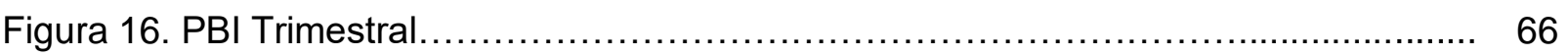

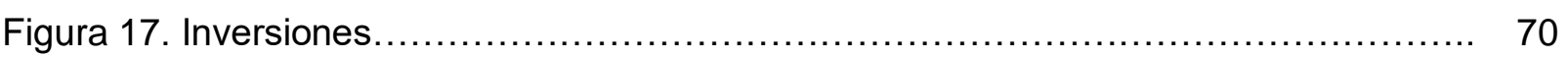

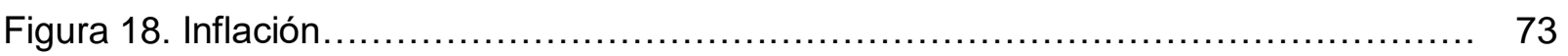

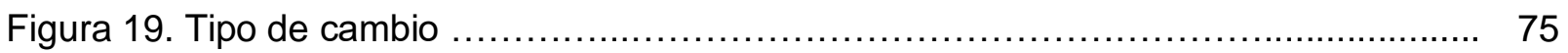

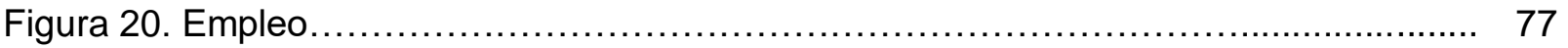

Figura 21. Producto Bruto Interno por Banco Central de Reserva del Perú (BCRP)....... 86

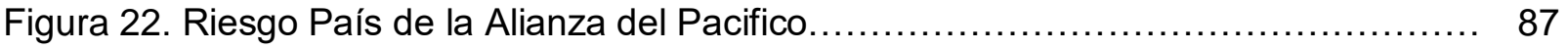

Figura 23. Balance entre Oferta y Demanda de Electricidad............................ 96

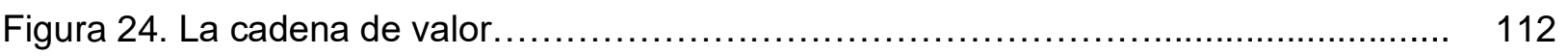

Figura 25. Diagrama de Flujo............................................................ 114

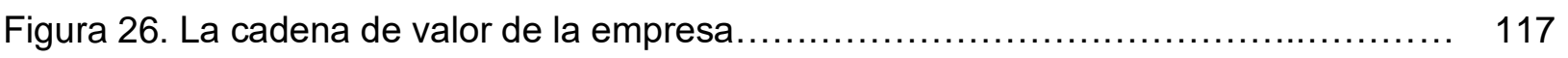

Figura 27. Participación Ingresos en mercado local........................................ 127

Figura 28. Evolución participación ingresos............................................ 129

Figura 29. Lienzo de los atributos de la empresa y sus principales competidores.......... 142

Figura 30. Lienzo de la estrategia de la Industria......................................... 143

Figura 31. Lienzo de la nueva estrategia considerada ................................. 145 


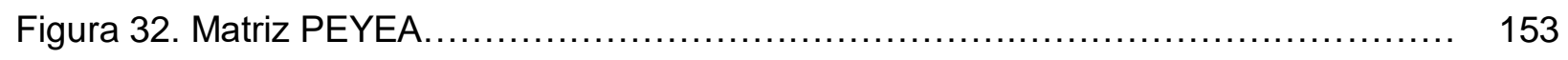

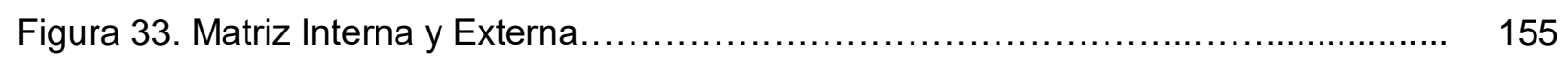

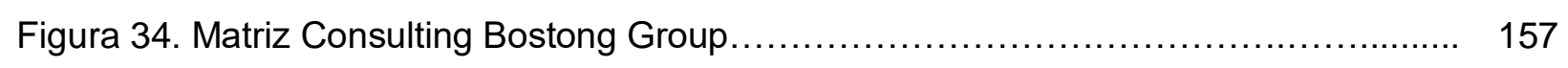

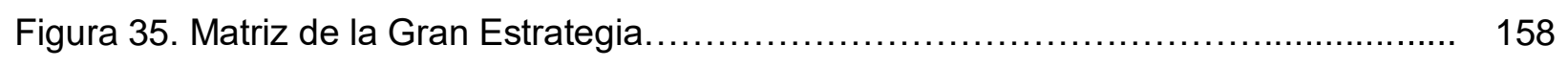

Figura 36. Pronóstico de Ingreso utilizando el método de regresión lineal................... 192 


\section{Resumen Ejecutivo}

El presente trabajo de investigación se desarrolla en base a la necesidad de una pequeña empresa que nació hace 8 años, bajo la dirección del Ing. Amadeo Carrillo, quien después de muchos años de experiencia dirigiendo proyectos destacados en el sector de energía y medio ambiente en el Perú y en el extranjero, decide emprender su propia empresa, en sociedad con su hija Erika Carrillo, así nace Hamek Ingenieros Asociados S.A.C, una empresa familiar que ha conseguido un crecimiento notable en los últimos años, Hamek actualmente es una empresa reconocida a nivel nacional en los servicios que ofrece, con presencia en Chile y el Salvador, este crecimiento se ha ido reflejando en el crecimiento en recursos humanos, tecnológico, en servicios y económicos financieros.

Ante este crecimiento se requiere elaborar un plan estratégico que le permita viabilizar su sostenibilidad y crecimiento en el tiempo, por ello se ha elaborado el Plan estratégico 2018-2020, aprovechando sus oportunidades que implica resolver su problemática actual y aprovechar las oportunidades.

En este momento, existen factores externos que benefician el desarrollo de la empresa, principalmente, que es un sector en constante crecimiento, los servicios que ofrece Hamek no tienen sustitutos pues todos ellos están fijadas por normas y protocolos establecidos por entidades estatales que obligan a todas las generadoras eléctricas a cumplir con las normativas ya establecidas en el sector.

Este plan recomienda una estrategia de penetración de mercado, para ello se desarrolla diez iniciativas, las implementaciones de estas iniciativas están orientadas al fortalecimiento institucional y al incremento de la rentabilidad. Se ha considerado que la implementación en general llegará la cifra aproximada de S/. 810 mil en gastos para los 3 años. El indicador de evaluación financiera arroja un VAN favorable. Los resultados presentan un panorama optimista para la empresa.

Por ello se recomienda la ejecución del Plan Estratégico ante los evidentes beneficios que este genera para la empresa, la estructura organizativa, desempeño y su proyección en el mercado nacional e internacional. La estrategia principal buscará fortalecer su participación en el sector energía en países como Chile y El Salvador, aprovechando las fortalezas del conocimiento en el sector y a la experiencia obtenida a nivel local. 


\section{Introducción}

Hamek Ingenieros Asociados S.A.C., es una firma peruana especializada en servicios para el sector de energía y medio ambiente, desde su fundación en abril 2010 , la organización ha sufrido varios cambios derivados al crecimiento en recursos humanos, en servicios y económicos financieros, así como la expansión en Centro América y Sudamérica, como resultado de estos cambios, Hamek Ingenieros Asociados S.A.C., afronta retos claves de un alto nivel de competitividad, definiendo nuevos modelos de gestión y herramientas que permitan que el crecimiento sea sostenible.

Ante este contexto se ha decidido elaborar un plan estratégico para el periodo 2019 al 2021, todo ello con la finalidad de cambiar las estrategias actuales de la empresa y presentar nuevas estrategias que permitan un crecimiento sostenible.

El proyecto se ha estructurado en diez capítulos descritos a continuación.

En el capítulo I Generalidades, se describe los antecedentes del sector energético en la cual se describen algunos conceptos clave, que son necesarios, para que se tenga un panorama más amplio y claro de la importancia del suministro eléctrico en nuestro país.

Luego se determinará el problema u oportunidad que motivará la elaboración de un plan estratégico para la empresa, posteriormente se detallará la justificación para este plan estratégico y finalmente se mencionará los objetivos generales describiendo la propuesta y enfoque de la investigación, que conllevara a los objetivos específicos que son el desglose de forma cronológica de cada uno de los procesos que se debe llevar a cabo para la consecuencia de los objetivos generales y finalmente dar los alcances y limitaciones que tiene el trabajo de investigación.

En el capítulo II, se describen los antecedentes de la empresa, el giro del negocio, el ciclo de vida de los productos que ofrecen Hamek Ingenieros Asociados S.A.C., así como la estructura organizacional actual, situación del mercado y financiera actual de la industria.

En el Capítulo III, se analizó la visión, misión y valores actuales de la empresa para que en base al desarrollo de una metodología clara se pueda dar lugar a una nueva visión, misión y valores que estén orientadas a que la empresa logre sus objetivos a largo plazo. 
En el Capítulo IV, se presenta el análisis de las variables y factores del entorno externo que afectan e influencian a la empresa, tales como: económico, político, legal, demográfico, cultural, tecnológico y ecológico.

En el Capítulo V, se presentan el análisis de la industria, estudio de la oferta y demanda, descripción de las cinco fuerzas competitivas de la industria, elaboración de la matriz de atractividad de cada una de las cinco fuerzas, grado de atractividad de la industria y elaboración de la matriz de perfil competitivo.

En el Capítulo VI, se presenta el análisis de las variables del entorno interno como un análisis de la cadena de valor de la empresa, Benchmarking y comparación con los líderes de la industria, determinación de las competencias de la empresa, identificación y determinación de las ventajas competitivas de la empresa, elaboración de la matriz de evaluación de los factores internos.

El capítulo VII, se presentan la formulación de los objetivos y diseño de las estrategias, modelo océano azul, elaboración de las matrices de formulación de estrategias y resumen de las estrategias formuladas.

El capítulo VIII, se presentan el estudio y la selección de la estrategia a seguir, elaboración del método de factores estratégicos claves y métodos de escenarios.

El capítulo IX, presentan la implantación de la estrategia, elaboración de la matriz de planeación estratégica cuantitativa, descripción de estrategia seleccionada y estrategia contingente.

El capítulo X, se presenta la evaluación final, que comprendió la evaluación cualitativa y la evaluación financiera de la estrategia. Finalmente se presentan las conclusiones y recomendaciones a las que se ha logrado llegar luego del desarrollo del presente trabajo de estudio. Adicionalmente se presentan anexos, referencias y bibliográficas correspondiente. 


\section{Capítulo I. Generalidades}

En este primer capítulo se describirá algunos conceptos clave, que son necesarios, para que se tenga un panorama más amplio y claro de la importancia del suministro eléctrico, así como dar a conocer el desarrollo que ha tenido el sector a lo largo de su historia y el impacto que tiene en el crecimiento del PBI en nuestro país, para una mejor comprensión se utilizó una línea de tiempo de los hechos importantes del sector electricidad en el Perú desde sus inicios en 1884 hasta el 2016, información tomada del libro titulado "La industria de la electricidad en el Perú: 24 años de aportes al crecimiento económico del país" por el Organismo Supervisor de la Inversión en Energía y Minería (Osinergmin).

En este mismo capítulo se determinará el problema u oportunidad, la justificación para este plan estratégico y finalmente se mencionará los objetivos generales.

Finalmente se revisarán trabajos de planes estratégicos nacionales e internacionales de empresas de similares características a la evaluada en el presente trabajo.

\subsection{Antecedentes}

El suministro de electricidad constituye un servicio público clave para operar procesos industriales y sostener el consumo de los usuarios residenciales. Así, brinda una fuente de energía que impulsa la actividad económica, posibilita el comercio internacional, mantiene el buen funcionamiento de los mercados y genera bienestar al permitir que los ciudadanos tengan altos estándares de calidad de vida. Sin electricidad, el funcionamiento de la economía global sería inviable. Esta relevancia ha determinado que, en todo lugar, en mayor o menor medida, el sector eléctrico se encuentre sujeto a alguna forma de intervención pública por parte del Estado, que se manifiesta vía empresas públicas y regulación de las actividades de las empresas privadas de acuerdo con los mecanismos de mercado. (Tamayo, Salvador, Vásquez, \& Vilches, 2016).

La industria eléctrica en el Perú tuvo su origen a finales del siglo XIX, con la instalación de la primera central hidroeléctrica cerca de la ciudad de Huaraz (región Áncash) y del alumbrado público en el Cercado de Lima.

Como señalan Santibáñez y Sumar (2012) "La Ley General de Electricidad del año 1972, aprobada por Decreto Ley N 19421, fue la norma que reguló durante 20 años el sector eléctrico peruano hasta fines de 1992" (p. 3). 
Fue justamente en el año 1992, como lo señala Duke Energy (2016), que "el gobierno de turno declara en emergencia el Sector Eléctrico Nacional (SEN) y promulga la ley de Concesiones Eléctricas (Decreto Ley №24844), la cual separaría las actividades del sector en: Generación, trasmisión o distribución, cada una con un objeto específico". (p.1). Además, estipuló que las compañías eléctricas sólo podrían desempeñarse en una de estas actividades. Este proceso estuvo acompañado de la creación del Organismo Supervisor de la Inversión en Energía y Minería (OSINERGMIN), como organismo regulador independiente y autónomo del mercado eléctrico, institución que tiene como actividad principal, el administrar un marco normativo y regulatorio estable y transparente, tanto para las empresas concesionarias como para los usuarios.

Otro de los principales objetivos para la creación de OSINERGMIN es la regulación, la necesidad de proteger a los usuarios frente a relaciones asimétricas de contratación, del servicio eléctrico ya que es el sector eléctrico quien suministra un servicio público, como lo señala Tamayo et al. (2016):

Otro problema asociado al sector eléctrico es que suministra un servicio público masivo indispensable para la vida de los ciudadanos y el quehacer de los negocios. Por ello, está expuesto a los riesgos de politización y expropiación de sus activos, razón por la cual la regulación económica necesaria para prevenir estos riesgos y garantizar que los inversionistas en el sector recuperen sus inversiones de forma razonable, necesita ser autónoma e independiente en materia funcional y administrativa de las instancias políticas del Gobierno. (p. 19).

En el contexto institucional vigente desde el 24 setiembre de 2014, que modifica y mejora la regulación de la distribución de electricidad, el Ministerio de Energía y Minas (MEM), como ente perteneciente al Poder Ejecutivo, establece las metas, los objetivos y los principios generales del marco regulatorio aplicable al sector eléctrico. Teniendo como fin superar las fallas de mercado existentes en las actividades energéticas en competencia, la regulación de tarifas, así como la supervisión de la calidad y la seguridad industrial de los sectores con características de monopolio natural.

Los monopolios naturales constituyen situaciones donde es más eficiente que una sola empresa suministre un bien o servicio en un mercado determinado. Esta situación está caracterizada por la existencia de costos medios decrecientes en determinado rango de la demanda. La existencia de monopolios naturales hace necesaria la intervención del Estado para evitar que las empresas abusen de su posición dominante en el mercado, 
estableciendo tarifas elevadas o brindando una calidad de servicio menor al óptimo social.

Otro evento importante de la actividad de transmisión en el Perú fue la creación del Sistema Eléctrico Interconectado Nacional (SEIN), con la entrada en operación de la línea Mantaro-Socabaya, inaugurada en el año 2000. El importante mencionar la introducción de las energías renovables en el país, cuando el 24 de setiembre de 2014 se inauguró la Central Eólica de Marcona con 62 aerogeneradores y una potencia instalada de $22 \mathrm{MW}$.

Desde la década de los noventa el Perú ha experimentado el auge de muchos proyectos de generación de energía eléctrica (ver Figura 1) y el Gobierno ha promulgado distintas normativas y leyes para la regulación del servicio eléctrico. 


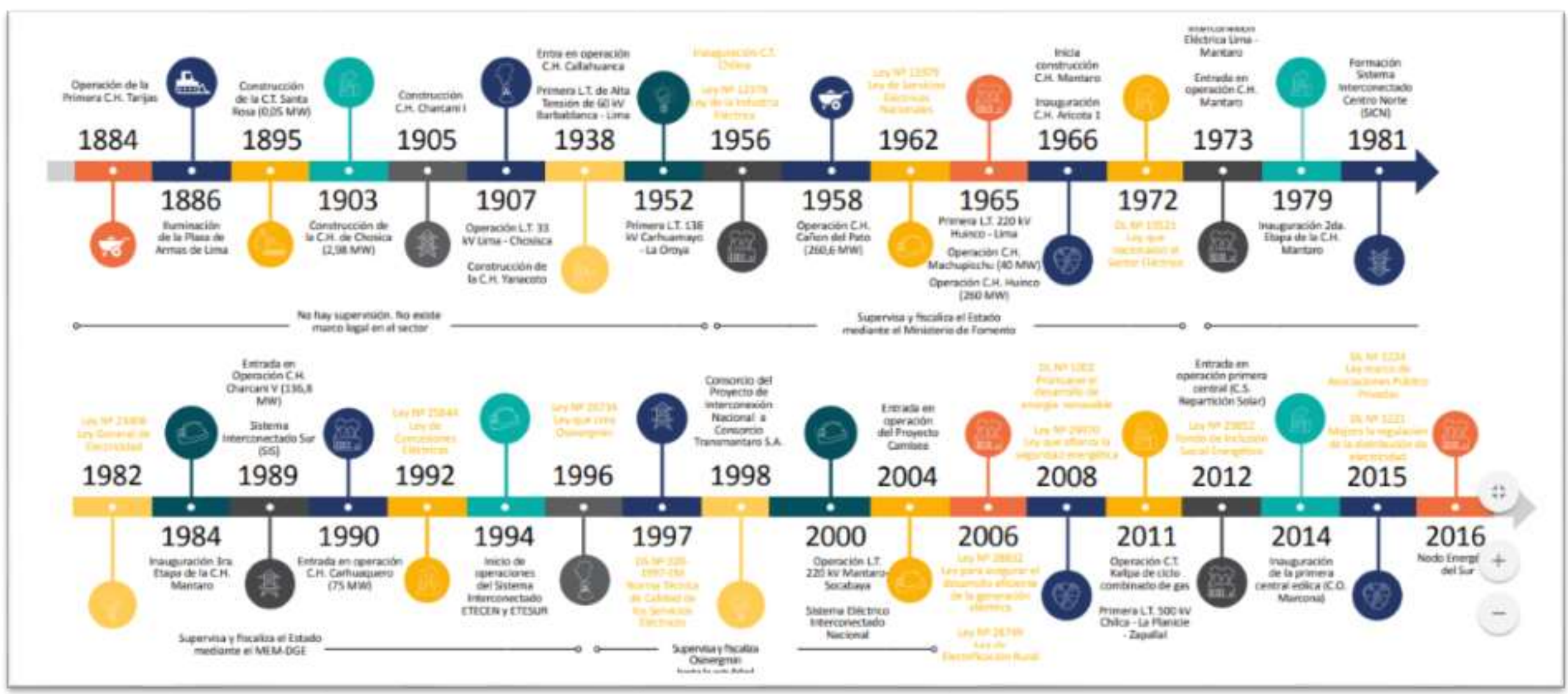

Figura 1. Línea de tiempo de hechos importantes del sector electricidad en el Perú 1884-2016. Adaptado de "La industria de la electricidad en el Perú: 24 años de aportes al crecimiento económico del país” por el Organismo Supervisor de la Inversión en Energía y Minería (Osinergmin), 2016. 
En lo referido a la relación del crecimiento económico y la demanda de energía se puede señalar que sí existe una relación directa como lo señala Ríos (2016):

Existe una estrecha relación entre la demanda de energía y la evolución del PBI y, por tanto, con el crecimiento económico de un país. Por ejemplo, el PBI del Perú entre 2000 y 2013 presentó una tasa promedio anual de crecimiento del $4.8 \%$ y la tasa promedio anual de crecimiento de la demanda de energía fue de $3.7 \%$. (p. 1)

Como lo menciona la Sociedad de Minería, Petróleo y Energía (2008): El Comité de Operación Económica del Sistema Interconectado del Norte (COES NORTE) fue creada en agosto de 1993, para regular las operaciones del Sistema Interconectado Norte, posteriormente en octubre de 1994 se creó el Comité de Operación Económica del Sistema Interconectado del Sur (COES-SUR) con la misma finalidad de su predecesora, pero para la zona sur del país. En octubre de 2000 los Sistemas Centro Norte y Sur se integraron a través de la construcción de la línea de transmisión Mantaro-Socabaya, por lo que ambas instituciones se fusionaron convirtiéndose en lo que hoy en día se conoce como El Comité de Operación Económica del Sistema Interconectado Nacional (COES-SINAC (o simplemente COES). (p. 2)

En la actualidad mantienen los mismos principios de su creación y reúne los esfuerzos de las principales empresas de generación, transmisión y distribución de electricidad, así como de los grandes usuarios libres, contribuyendo a través de su labor al desarrollo y bienestar del país.

En ese escenario, la energía eléctrica, se vuelve vital para el desarrollo de la sociedad y constituye una pieza fundamental para afrontar los principales retos sociales en el camino hacia el desarrollo sostenible, es por ello que debe ser limpia, en el sentido de no impactar negativamente al medio ambiente.

El régimen legal ambiental en el sector eléctrico se da inicio, como lo señalan Kahatt \& Azerrad (2008):

Con la promulgación de la Ley №24844, Ley de Concesiones Eléctricas (LCE), en noviembre de 1992, y un año y medio más tarde, la aprobación de Reglamento de Protección Ambiental en las Actividades Eléctricas (RPAAA o el Reglamento). La LCE contiene disposiciones expresas sobre certificación ambiental para actividades eléctricas, sobre límites máximos permisibles, restos arqueológicos, y otros estándares ambientales. 
Asimismo, se ha determinado que la fiscalización del cumplimiento de las obligaciones ambientales de los titulares de actividades del sector electricidad, recae en el OSINERGMIN.

Mediante la Ley del Sistema Nacional de Evaluación de Impacto Ambiental (Ley № 27446, 2016), se creó un sistema único y coordinado de identificación, prevención, supervisión, control y corrección anticipada de los impactos ambientales negativos derivados de las acciones humanas expresadas por medio del proyecto de inversión, dicha ley busca el establecimiento de un proceso uniforme que comprenda los requerimientos, etapas y alcances de la evaluación del impacto ambiental.

De acuerdo con la Ley General del Ambiente (Ley № 28611, 2004):

Toda actividad humana que implique construcciones, obras, servicios y otras actividades, así como las políticas, planes y programas públicos susceptibles de causar impactos ambientales de carácter significativo, está sujeta, de acuerdo a ley, al Sistema Nacional de Evaluación de Impacto Ambiental (SEIA) el cual es administrado por la Autoridad Ambiental Nacional (ANA).

Gracias a esta normativa es que todas las actividades servicios relacionadas a los diferentes sectores productivos y de servicios del país deben contar con un instrumento de gestión ambiental.

En el campo energético, tomando en cuenta la normativa del sector eléctrico antes mencionado, en principio para atender las necesidades de las empresas generadoras en el marco del cumplimiento de los procedimientos operativos del COES, en mayo del 2014, Hamek Ingenieros Asociados S.A.C. logra formar parte de las consultoras expertas en la ejecución de los ensayos de potencia efectiva y rendimiento de las unidades térmicas y potencia efectiva de las centrales hidráulicas (Ver Anexo 1).

La empresa es considerada como una consultora experta en el sector mencionado por el alto porcentaje que demuestran los clientes en mantener lazos comerciales con Hamek Ingenieros Asociados S.A.C., dato corroborado por las encuestas de reincidencias de servicios, donde el $76 \%$ de las empresas encuestadas han mantenido una relación comercial por más de tres años, este resultado muestra la calidad de los servicios y le da un valor de experto en su especialidad. 
Tabla 1

Tiempo que ha sido cliente de la empresa en los servicios de pruebas de potencia efectiva y rendimiento de las unidades térmicas y/o potencia efectiva de las centrales hidráulicas

\begin{tabular}{lcc}
\hline Variable & Número & Porcentaje \\
\hline De 0 a 1 año & 1 & $6 \%$ \\
De 0 a 2 año & 3 & $18 \%$ \\
De 3 años en adelante & 13 & $76 \%$ \\
Total & 17 & $100 \%$ \\
\hline
\end{tabular}

Nota. Elaboración propia. Representación de clientes que mantienen relación comercial en años
continuos con Hamek

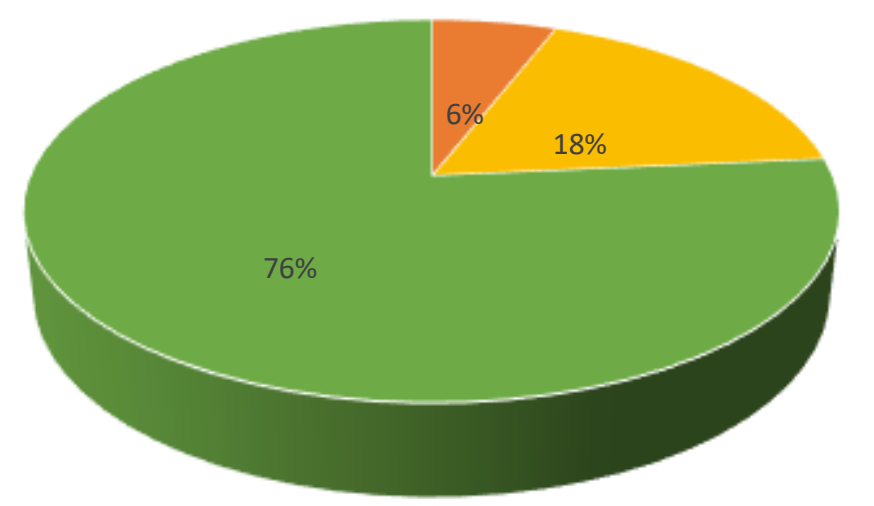

- De 0 a 1 año - De1 a 2 - De 3 años en adelante

Figura 2. Representación de clientes que mantienen relación comercial en años continuos con Hamek. Nota. Elaboración propia.

Así mismo también ofrece otros servicios como diseños, supervisión y ejecución de obras de ingeniería y consultoría aplicados a los campos de energía y medio ambiente.

En los servicios de ejecución de los ensayos de potencia efectiva y rendimiento de las unidades térmicas y potencia efectiva de las centrales hidráulicas Hamek Ingenieros Asociados S.A.C logra posicionarse en el mercado nacional como una empresa consultora especialista, que atiende a todas las generadoras que forman parte de Sistema Eléctrico Interconectado Nacional (SEIN), mismos servicios que le ha valido a la 
empresa a ser reconocidos también en los países de El Salvador y Chile en Sudamérica. (Ver Anexo 2).

En el campo ambiental Hamek Ingenieros Asociados S.A.C., se encuentra inscrita al Servicio Nacional de Certificación Ambiental para las inversiones sostenidas. (SENACE), organismo público técnico especializado que tiene como tarea revisar y aprobar los Estudios de Impacto Ambiental detallados (EIA-d) de mayor envergadura de los proyectos de inversión pública, privada o de capital mixto. Para estudios ambientales de menor envergadura, Hamek Ingenieros Asociados S.A.C., se encuentra registrada en el Ministerio de la Producción, Ministerio de Vivienda, y Construcción, Ministerio de Turismo y Comercio Exterior, Ministerios de Transporte y Comunicaciones, Ministerio de Pesquería y Ministerio de Energía y Minas.

En la revisión de planes estratégicos nacionales e internacionales se han encontrado las siguientes tesis:

\section{A nivel Nacional.}

Mendoza y Vallenas (2018) en el plan de estratégico de empresa EPA S.A.C. empresa ubicada en la ciudad de Arequipa (Perú) busca definir sus objetivos a largo plazo, en el análisis de la organización se ha detectado que tiene deficiencias de orden estratégico y genérico dentro de su organización. Para cubrir los objetivos, los autores tienen como herramienta el análisis del entorno interno y externo, el establecimiento de estrategias de corto y largo plazo y la medición continua de los resultados, que permitirá a EPA S.A.C., dominar la dirección que debe tomar para mejorar las oportunidades identificadas y crear valor para sus accionistas.

Apaza (2017) en la investigación y desarrollo del plan estratégico para la empresa consultora Grupo JICA Ingeniería y Construcción S.A.C, empresa ubicada en la ciudad de Puno (Perú), el autor tiene como objetivo principal, diseñar el plan estratégico para el período 2017-2020, para ello planteó realizar un análisis interno y externo de la empresa con la finalidad de dirigir a la empresa hacia un manejo eficiente de sus recursos y capacidades, buscando alternativas para mejorar la competitividad, desarrollo y posicionamiento de la empresa consultora.

La metodología utilizada en la investigación fue de tipo exploratorio con enfoque cualitativo y cuantitativo.

El análisis situacional de la empresa permitió obtener información relevante del estado actual de los factores internos y externos, utilizando una serie de análisis como la 
matriz FODA, el análisis PEYEA, la matriz BCG, la matriz IE y la matriz GE, lo que permitió redefinir las estrategias para el logro de los objetivos de largo plazo.

Sotomayor, Marticorena, Moses y Valdiviezo (2014), se realiza un planeamiento estratégico para la Constructora San Jorge E. I. R. L., empresa ubicada en la ciudad de Lima, con el único propósito de examinar y determinar las estrategias que le permita a la empresa un crecimiento sostenido, que a la fecha no es favorable, todo ello por la falta de un direccionamiento a largo plazo.

Para el desarrollo del problema detectado se plantea la elaboración de un plan estratégico, utilizar para ello la técnica del análisis interno y externo.

Del análisis interno de la constructora se obtuvieron fortalezas y debilidades que han permitido conocer y comprender el entorno de la Constructora San Jorge E. I. R. L., y plantear estrategias que permiten llegar a la visión de la Constructora. Actualmente no se cuentan con mejoras tecnológicas debido a la carencia de un área de Innovación \& Desarrollo. También se han establecido objetivos de corto plazo, los cuales permitirán realizar la revisión, evaluación, y control de los resultados. El entorno es favorable para Constructora San Jorge E. I. R. L.; sin embargo, en su organización interna resulta necesario contar con áreas importantes, como Recursos Humanos, Marketing, Finanzas, e Investigación y Desarrollo; además de contar con un sistema informático integral que permita mejorar su gestión. Para los objetivos de corto plazo, se asignaron los recursos necesarios para el cumplimiento de los mismos, así como también las políticas para cada una de las estrategias retenidas. Se plantea también una nueva estructura organizacional con la inclusión de áreas necesarias para la mejora de la constructora. Finalmente, en el proceso estratégico, la etapa de evaluación y control se realizará a través del Tablero de Control Balanceado (Balanced Scorecard).

Ortiz, Paredes, Romero y Sánchez (2014), presentan el Plan Estratégico del Sector Eléctrico, logrando evidenciar el potencial de crecimiento del sub sector de generación de energía dada las condiciones favorables referidas a la variedad de recursos naturales y la posición geográfica del Perú para abastecer de energía a toda la región lo que incrementa su atractivo de inversión, adicionalmente el Perú destaca como el tercer país en Latinoamérica con mayor potencial hídrico en Latinoamérica lo que aumenta su atractivo, por otro lado: 
Los proyectos de generación térmica e hídrica en curso, garantizan un abastecimiento interno de energía eléctrica hasta el 2024 y el excedente de aproximadamente 4,000 K permitiría el intercambio con los países limítrofes para la consolidación de un mercado de energía eléctrica de mayor tamaño en toda Latinoamérica, obligando al Sector Eléctrico a repotenciar sus redes de transmisión y reduciendo a su vez sus vulnerabilidades (p. 181)

Se considera muy relevante el estudio del trabajo presentado para elaboración del Plan Estratégico de Hamek Ingenieros Asociados S.A.C. dado la atractividad del sector energético para el desarrollo de las actividades de asesoría y estudios técnicos para el sector.

\section{A nivel Internacional.}

Moll (2017) se enfoca en el Diseño de un Sistema de Control de Gestión para una empresa de Generación de Energía Eléctrica de Fuentes Renovables. El desarrollo de la tecnología y el perfeccionamiento del sistema de evaluación de proyectos, conlleva a la necesidad de desarrollo de un sistema de control de gestión que le permita a la organización alinear y controlar los procesos claves de su estrategia.

El estudio permite a Hamek Ingenieros Asociados S.A.C. comprender mejor el desarrollo del uso de energía renovable en países como Chile, lo cual le permitirá a futuro ampliar el espectro de los servicios de asesoría técnica que brinda actualmente.

Importante precisar que en Chile desde abril del 2008 entró en vigencia la Ley 20.247 que establece la obligación para las empresas eléctricas de comercializar un porcentaje de la energía proveniente de fuentes de energía renovable no convencional (ERNC), al igual que en Perú ello constituye una oportunidad de negocios para Hamek Ingenieros Asociados S.A.C., dado el potencial de crecimiento de uso de la energía renovable no convencional

Finalmente se señala que el estudio se desarrolla sobre una empresa que pertenece a la industria de las pequeñas y medianas empresas de energías renovables, que son emergentes y que cada vez apuestan por el uso de este tipo de energía.

Andrade (2016) presenta el plan estratégico de la empresa BDO Ecuador Cía. Ltda., para el período 2016-2018, El desarrollo de la investigación nace como consecuencia de una necesidad apremiante de la empresa BDO Ecuador por desarrollar un Plan Estratégico para enfrentar un crecimiento mayor luego de cuarenta años en el mercado ecuatoriano, un mercado donde existe mucha competencia y donde se 
empiezan a observar debilidades dado la falta de organización y planificación para sostener este crecimiento.

El desarrollo del estudio plantea un análisis interno para identificar sus fortalezas, normalmente su experiencia en el mercado ecuatoriano y un servicio de calidad mayor, pero además sus debilidades como la falta de organización, objetivos desenfocados entre las áreas, poca capacidad de respuesta a los cambios del mercado (adaptabilidad al cambio), compromiso de la Dirección lo que compromete su crecimiento.

Para Hamek Ingenieros Asociados S.A.C. es muy relevante este estudio pues actualmente atraviesa por una situación similar teniendo como un objetivo en el corto plazo el seguir internacionalizándose en la región ofreciendo un servicio de alto valor para sus clientes en un mercado regional muy competitivo.

Flores, Gonzáles y Lara (2017) desarrolla un plan estratégico para la empresa IPSOMARY S.A., empresa peruana consultora en servicios ambientales y salud ocupacional, ubicado en Guayaquil, Ecuador. El principal problema observado es la reducción de sus niveles de venta en los últimos años, por falta de una adecuada estrategia de comercialización, una baja captación de clientes y la falta de una organización interna.

Se realizó una investigación de tipo exploratorio con un enfoque cuantitativo y cualitativo, la cual finalmente recomienda la constitución de una estructura sólida de ventas para fortalecer la imagen de la compañía.

Aguado y Marín (2014) formulan el plan estratégico del período 2014-2018 de la Empresa Potencia y Tecnologías Incorporadas S.A., comprometida con el medio ambiente, empresa consultora en el sector de energía y telecomunicaciones en Santiago de Cali, Colombia, donde fijan alternativas de crecimiento y desarrollo de ventajas competitivas sostenible de la empresa, con la contribución de sus colaboradores.

Se concluye que la compañía deberá modificar su estructura organizacional y delegar sus tareas a áreas operativas y orientar la cultura organizacional hacia la nueva perspectiva energética. 


\subsection{Determinación del problema u oportunidad}

El principal problema que adolecen las pequeñas empresas (Ver Anexo 3) familiares es la falta de organización que ayuden asegurar y mejorar el gobierno corporativo con un crecimiento sustentable, para ello se hace necesario elaborar un plan estratégico considerando el análisis de las variables internas y externas para formular sus propósitos, sus estrategias y sus planes de acción, como herramienta para mejorar, la estructura organizativa, desempeño y su proyección en el mercado nacional e internacional.

Tal es el caso de la empresa Hamek Ingenieros Asociados S.A.C, cuya actividad en el sector de energía, consiste en la Pruebas y estudios operativos en centrales hidroeléctricas, térmicas, plantas de energía renovable, y líneas de transmisión según procedimientos del Comité de Operaciones Económicas del Sistema (COES-Perú), Coordinador eléctrico Nacional,(CEN- Chile) y Unidad de transacciones (UT-El Salvador), también ofrece los servicios de diseños, supervisión y ejecución de obras de ingeniería y consultoría aplicados a los campos de energía y medio ambiente.

Actualmente tiene una estructura pequeña que sustenta debidamente el desarrollo de sus actividades; sin embargo, los accionistas desean implementar la planeación estratégica, la estructura organizativa, desempeño y su proyección en el mercado nacional e internacional.

El crecimiento de la empresa ha traído consigo un aumento en el recurso humano, tecnológico, en servicios y económico financiero, lo cual ha hecho que Hamek Ingenieros Asociados S.A.C., se convierta en una organización más compleja, exigiendo una mejor planeación, organización y control de sus acciones que le permitan afrontar el futuro aprovechando la coyuntura favorable.

Aunque la empresa es fuerte en cuanto a la calidad de sus servicios y preocupación por la retención de clientes, existen debilidades evidentes en la planeación, pues la ausencia de planes y estrategias limita el logro de sus objetivos y la consecución de sus metas, impactando en su crecimiento y restándole competitividad.

Tomando en cuenta el interés de los accionistas de implementar un plan que oriente su desempeño, resulta adecuado diseñar un plan estratégico partiendo del análisis de factores internos y externos concernientes a la empresa y donde finalmente los objetivos y planes de acción sean acordes con sus posibilidades. 
En una observación inicial, se determina que hasta el momento no se ha realizado ningún diagnóstico organizacional para Hamek Ingenieros Asociados S.A.C. y tampoco se han implementado herramientas administrativas (como planes estratégicos) que orienten su desarrollo. De esta manera, se genera la oportunidad de realizar un aporte a una empresa en crecimiento.

La empresa busca desarrollar una ventaja competitiva diferenciadora en el mercado local e internacional para competir y obtener la mayor rentabilidad, disminuyendo sus debilidades e incrementando sus fortalezas, tomando en cuenta para ello las oportunidades y amenazas del entorno en que se desenvuelve.

En ese sentido, y luego de seguir la metodología de Ishikawa (espina de pescado), determinamos como problema principal, que el negocio no cuenta con un Plan Estratégico definido e implementado.

A continuación, mostramos las causas en detalle del problema principal: 


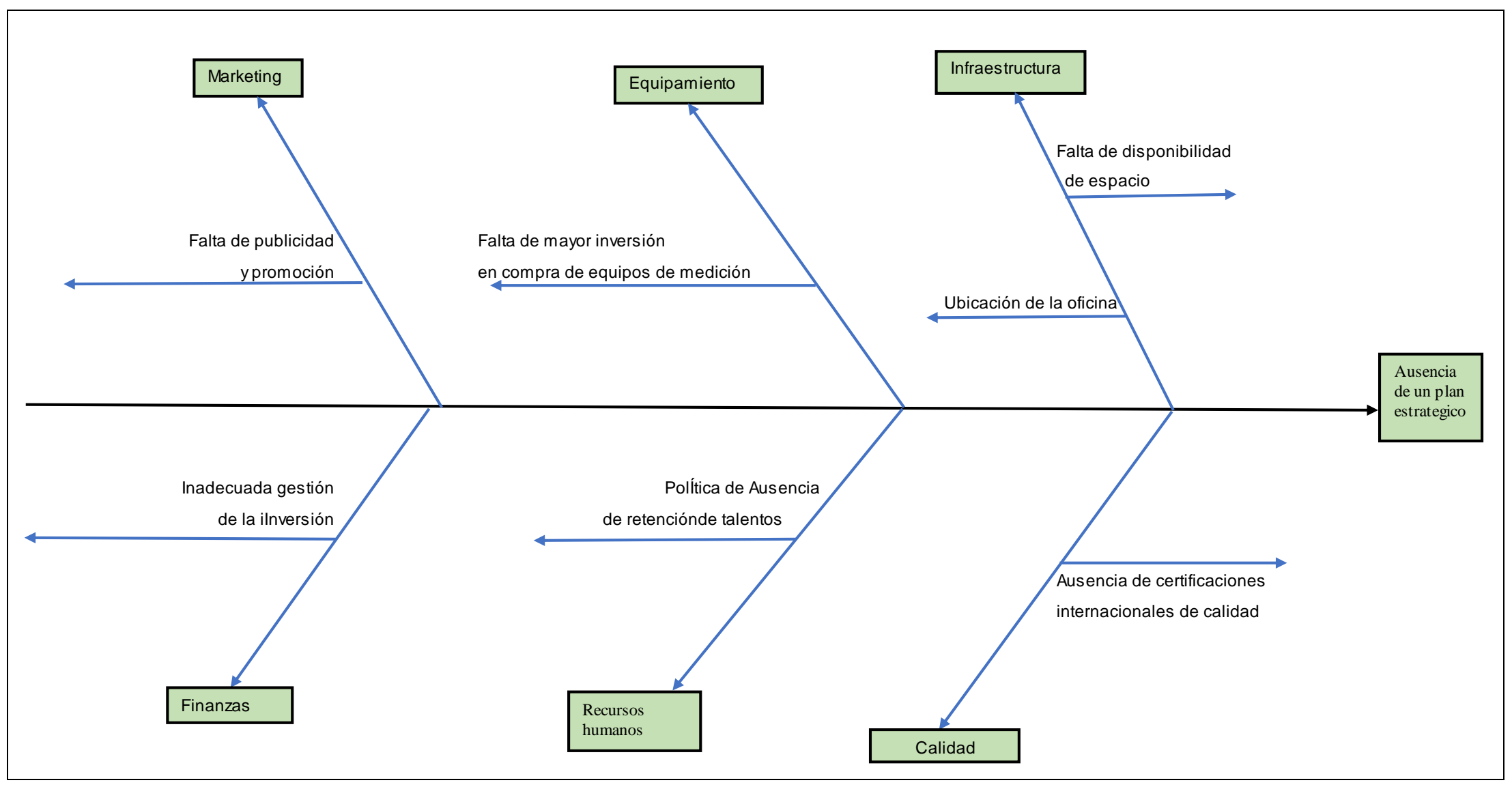

Figura 3. Metodología de Ishikawa para determinar el Problema Principal. Nota. Elaboración propia. 


\subsection{Justificación del Proyecto}

El ambiente competitivo que existe hoy en día, se ha generado en gran parte debido al desarrollo constante de la tecnología, de la sociedad, de la economía y de los conocimientos (informaciones basadas en Internet), esto ha llevado a las empresas a desarrollar nuevas estrategias, para no solamente adaptarse a este ambiente, sino para desarrollar una ventaja competitiva.

Los nuevos cambios que se presentan han impactado fuertemente en las empresas, debido a que, en ocasiones, las mismas no se encuentran preparadas para un cambio en sus procesos de negocio. Por lo tanto, es importante realizar previamente una planeación estratégica que apoyará a la empresa a desarrollar la ventaja competitiva deseada.

El plan estratégico que se realizará para la empresa Hamek Ingenieros Asociados S.A.C., es de gran importancia, porque permitirá identificar variables internas y externas que influirán en su desempeño; brindando la posibilidad de prever situaciones futuras y tomar decisiones acertadas para competir a nivel nacional e internacional logrando suplir las necesidades y cumplir con las expectativas del cliente.

Se realizará una importante contribución a la empresa Hamek Ingenieros Asociados S.A.C., solucionando las necesidades de la gerencia respecto a los temas de administración de la empresa, la planeación y el direccionamiento estratégico, facilitando herramientas que permitan mejorar la estructura organizativa, desempeño y su proyección en el mercado nacional e internacional.

\subsection{Objetivos generales y específicos}

\subsubsection{Objetivos generales.}

Desarrollar un plan estratégico para la empresa Hamek Ingenieros Asociados S.A.C., para el periodo 2019-2021 a fin de mejorar su desempeño, mejorar el gobierno corporativo con un crecimiento sustentable con ello proyectarse en el mercado y obtener una mayor rentabilidad a los accionistas.

\subsubsection{Objetivos específicos.}

- Analizar y formular la visión, misión y valores de la empresa.

- Identificar las oportunidades y amenazas de la empresa (análisis externo) 
- Identificar las fortalezas y debilidades por áreas de la empresa (análisis interno)

- Definir estrategias a implementar en la empresa.

- Identificar las ventajas competitivas que mejoren la imagen de Hamek Ingenieros Asociados S.A.C. y mejoren su posicionamiento.

- Analizar e identificar las variables económicas y financieras de la empresa, con la finalidad de poder identificar donde son los generadores de valor agregado de la compañía, y donde la compañía tiene las oportunidades de mejora, crecimiento y sostenibilidad; con la finalidad de poder trazar un planeamiento que asegure crecimiento de volumen de ventas y el crecimiento en la utilidad del accionista.

\subsection{Alcances y Limitaciones de la Investigación}

\subsubsection{Alcances.}

El Planeamiento estratégico de Hamek Ingenieros Asociados S.A.C. se realizará para un horizonte de tiempo de tres años y comprende el período 2019-2021, el cual abarca las oficinas en Lima.

\subsubsection{Limitaciones.}

La limitación que tiene la presente investigación es el poco acceso a la información sobre las empresas que compiten con Hamek Ingenieros Asociados S.A.C en el Perú, por lo tanto, se circunscribe a competidores locales de Lima. La planificación estratégica se trabajará con información local, dado que no se cuenta con información internacional y que viene ligado a un mayor costo de investigación. 


\section{Capítulo II. La Empresa}

En este capítulo se determinará cuáles son los antecedentes y como se conformó la empresa; se hará una descripción del negocio, destacando de los servicios que ofrece y como fue creciendo en el mercado nacional hasta llegar a posicionarse y expandirse internacionalmente, quienes fueron sus fundadores, se detallará, cuál es el ciclo de vida del servicio de las dos áreas de ingeniería que tiene la empresa, a través de las variaciones anuales de ventas y utilidades en los últimos nueve años, se determinó cual es el ciclo de vida de los productos para su elaboración se consultó, a las publicaciones de Kotler y Armstrong .

En este mismo capítulo se presenta la estructura organizacional actual de la empresa, la cual tiene como finalidad establecer los roles que han de desarrollar los miembros de una organización para trabajar de forma óptima y que se alcancen las metas fijadas en la panificación.

Finalmente se describirá la situación actual de mercado y financiera de la industria.

\subsection{Antecedentes de la Empresa}

Hamek Ingenieros Asociados S.A.C., es una firma peruana especializada en pruebas y estudios operativos en centrales hidroeléctricas, térmicas, plantas de energía renovable, y líneas de transmisión según procedimientos del Comité de Operaciones Económicas del Sistema (COES-Perú), Coordinador eléctrico Nacional,(CEN- Chile) y Unidad de transacciones (UT-El salvador) así como estudios, diseños, supervisión y consultoría aplicados a los campos de energía y medio ambiente para todos los sectores productivos y de servicios del país y de la región.

La empresa se constituye en abril de 2010, como constitución de sociedad anónima cerrada, con registro número 076 del Colegio de Notarios de Lima, siendo los fundadores, los señores Amadeo Carrillo Villena y Erika Carrillo Zelaya, denominados accionistas. La consultora inició sus operaciones en julio de 2010 en la ciudad de Lima, a la fecha ha presentado un crecimiento en dimensión de recursos humanos, tecnológico, en servicios y económicos financieros.

En el campo energético, la empresa se encuentra inscrita como proveedor en las principales empresas y entidades públicas y privadas de Generación Eléctrica del Perú, El Salvador y Chile; así como también en los operadores de los sistemas eléctricos interconectados, que son organizaciones privadas compuestas por generadores, transmisores, distribuidores y usuarios libres, cuya finalidad es coordinar la operación y efectuar la planificación del mercado de corto, mediano y largo plazo de los sistemas 
interconectados al mínimo costo; preservando la seguridad del sistema y el mejor aprovechamiento de los recursos energéticos; tales como: COES en el Perú, Unidad de transacciones - UT en el Salvador, Comisión de Energía de Chile - CEN.

En el 2014, Hamek Ingenieros Asociados S.A.C., se expandió en Centro América, siendo El Salvador el primer país en el que logra ingresar como empresa consultora experta en auditorías en Curvas de consumo de calor y parámetros técnicos y; Costo variable no combustible y Costos de Arranque y Detención de unidades de generación. A la fecha ha participado en los dos tipos de auditorías en siete centrales térmicas.

En el 2016, Hamek Ingenieros Asociados S.A.C., ingreso al mercado chileno, a través del Coordinador Eléctrico Nacional (CEN), habiendo participado en la Auditoría de Potencia Máxima de varias unidades de generación correspondiente a tres centrales térmicas.

En el Sector Ambiental de Hamek Ingenieros Asociados S.A.C., se encuentra inscrita en el registro de consultoras del Servicio Nacional de Certificación Ambiental (SENACE), organismo público técnico especializado, adscrito al Ministerio del Ambiente, la tarea de SENACE consiste en revisar y aprobar los Estudios de Impacto Ambiental detallados (EIA-d) de mayor envergadura de los proyectos de inversión pública, privada o de capital mixto, Hamek Ingenieros Asociados S.A.C., también se encuentra inscrita en el Ministerio de la Producción, Sector MYPE e Industria, Ministerio de la Producción, Ministerio de Transportes, Ministerio de Vivienda y Construcción, Ministerio de Turismo y Comercio Exterior. De igual modo Hamek Ingenieros Asociados S.A.C., ya cuenta con registro en el Ministerio de Medio Ambiente y de Recurso Naturales -MARN en EI Salvador.

Desde sus inicios Hamek Ingenieros Asociados S.A.C., ha evolucionado enfocándose en la entrega y realización de sus servicios con mayor valor, utilizando equipos de última generación acompañados de especialistas con gran trayectoria en el medio.

\subsection{Descripción del Negocio}

Hamek Ingenieros Asociados S.A.C., es una empresa privada especializada en obras de ingeniería y consultoría aplicada a los campos de energía y medio ambiente en todos los sectores productivos y servicios del país: minería, electricidad, hidrocarburos, transporte, industrial, entre otros.

Hamek Ingenieros Asociados S.A.C. está constituida por profesionales de amplia experiencia en sus diferentes campos de acción y cuenta con las autorizaciones 
correspondientes para brindar servicios a las diferentes empresas y entidades públicas y privadas de los diversos sectores productivos, en el ámbito nacional e internacional.

El portafolio de los servicios que ofrecen la empresa Hamek Ingenieros Asociados S.A.C. son:

En el área energética prestan servicio en: (a) Estudios y Pruebas Operativas, (b) Estudios de Gestión Energética, (c) Estudios Económicos y (d) elaboración de Planes, Programas y Estudios de Pre Inversión e Inversión de Proyectos Energéticos.

En el área de medio ambiente los servicios que prestan son: (a) Instrumentos de Gestión Ambiental y servicios especiales, (b) monitoreo y servicios ambientales y (c) servicios generales.

\subsection{Ciclo de vida del producto}

Kotler y Armstrong (2017) señalan que es el curso que siguen las ventas y utilidades de un producto durante su existencia, el cual tiene cinco etapas bien definidas, (ver Figura 4).

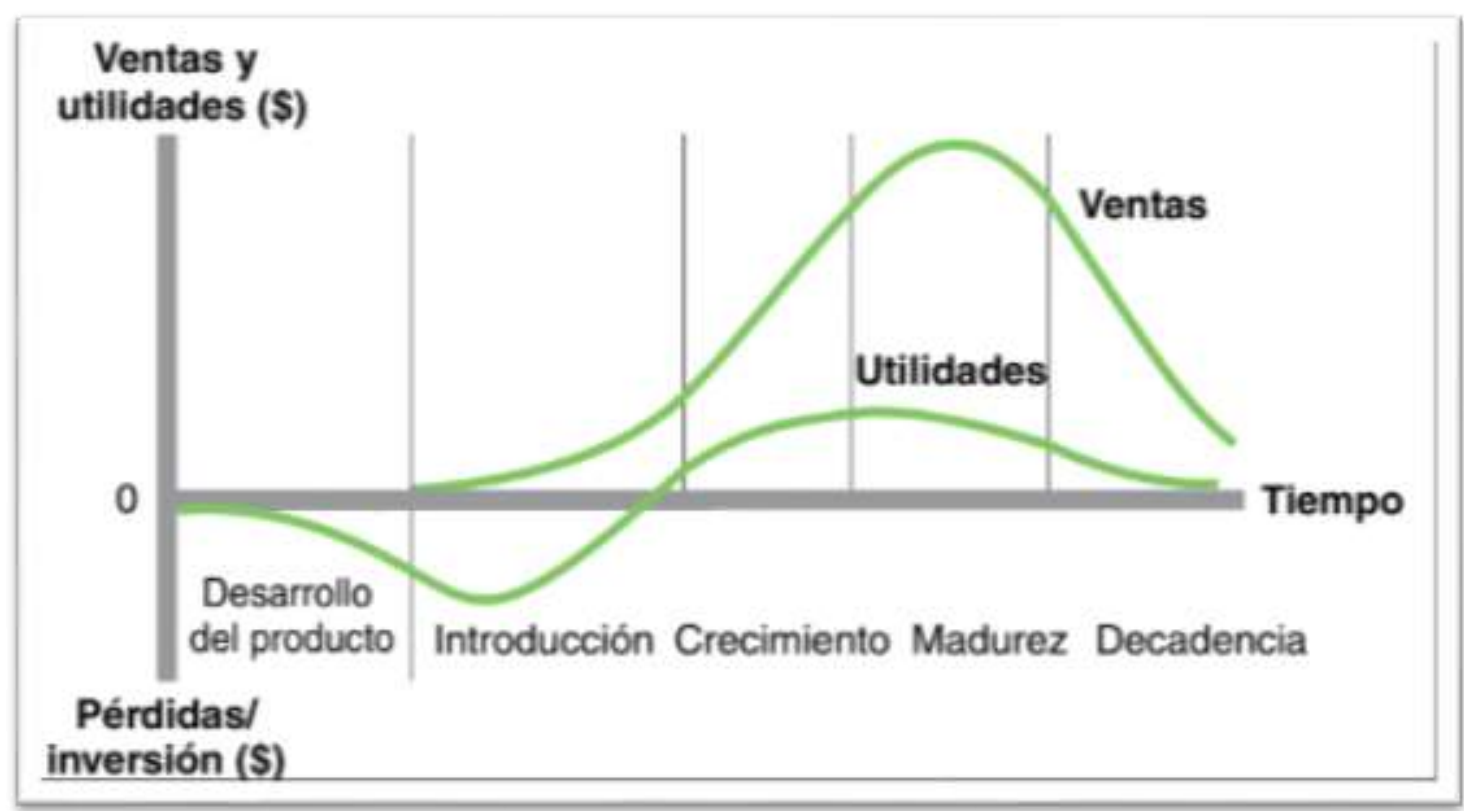

Figura 4. Ciclo de vida de un producto. Adaptado de "Marketing" (p. 282) por Kotler P. Armstrong G., 2017, México: Pearson ISBN: 978-607-32-3860-1.

La empresa Hamek Ingenieros Asociados S.A.C, ofrece servicios a sus clientes, asociado a las áreas de energía y medio ambiente.

Los servicios que ofrece la empresa del área de energía son los siguientes: 
- Estudios y pruebas operativas de potencia efectiva, heat rate, mínimos técnicos pruebas de perfomance (perfomance test) de centrales hidroeléctricas, centrales térmicas, centrales de cogeneración y plantas de energía renovable, según procedimientos de los organismos que coordinan la operación de los sistemas eléctricos interconectados de los distintos países; tales como el COES en el Perú, UT en EI Salvador y CEN en Chile

- Estudios de gestión energética; tales como: estudios de eficiencia energética, uso racional de energía y administración de demanda., calidad de energía, consumo de energía, Sub sistema de Utilización a Tensión de Distribución Primaria en $10 \mathrm{KV}$ y $22,9 \mathrm{KV}$ y; control de pérdidas de energía;

- Estudios económicos; tales como estudio de base para fijaciones tarifarias eléctricas, determinación del precio base de potencia y determinación de costos de generación;

- Planes, Programas y Estudios de pre inversión e inversión de proyectos energéticos; tales como: planes y programas energéticos; balances energéticos, identificación, formulación y evaluación de proyectos de inversión pública y privada a nivel de perfil. estudios de mercado, estudios de pre factibilidad, factibilidad y estudios de ingeniería de detalle, diseño de Banco de Condensadores, filtros de armónicos, compensación de factor de potencia, sistemas de puesta a tierra, subestaciones media y alta tensión, instalaciones eléctricas en baja, media y alta tensión, sistemas de iluminación, sistemas de pararrayos;

- Supervisión de obras de proyectos de generación, transmisión, distribución de energía eléctrica, generación distribuida, cogeneración, energías renovables. electrificación rural y estudios de re potenciamiento de centrales eléctricas.

Los servicios de área de medio ambiente que ofrece la empresa son los siguientes:

- Gestión de riesgos de desastres, pueden revertir la actual tendencia del aumento de los impactos de estos sucesos;

- Estudios de impacto ambiental (EIA), permiten determinar si el proyecto o actividad se hace cargo de los efectos ambientales que genera, mediante la aplicación de medidas de mitigación, reparación y/o compensación;

- Programa de adecuación y manejo ambiental (PAMA), se basan en el diagnóstico ambiental y la priorización de las acciones para incorporar a las operaciones eléctricas los adelantos tecnológicos y/o medidas alternativas que tengan como propósito reducir o eliminar las emisiones y/o vertimientos, a fin 
de poder cumplir con los límites máximos permisibles, establecidos por la autoridad competente;

- $\quad$ Plan de cierre y/o abandono, permiten identificar y cuantificar los impactos ambientales negativos generados en la etapa de cierre o abandono de una actividad minera o eléctrica, así como definir medidas de acción presente y futuras para prevenirlas, minimizar o mitigarlos;

- Evaluación de calidad de agua, aire, ruido, suelo y campo electromagnético, realizan los estudios y proyectos para el tratamiento de aguas servidas, tratamiento de aguas ácidas, gestión y manejo de residuos sólidos y diseño y ejecución de campañas de sensibilización ambiental;

- Consultoría en formalización minera (IGAFOM), se basan en formalizar la minería informal, que opera cumpliendo criterios y normas, remediación de las áreas destruidas y degradadas y persecución de la minería ilegal;

- Auditorías ambientales, se caracterizan en evaluar la eficacia del sistema de gestión ambiental de la organización.

El ciclo del producto, es el servicio que la brinda la empresa al mercado, en el sector energético y medio ambiente.

Para poder analizar el ciclo del producto que ofrece la empresa Hamek Ingenieros Asociados S.A.C., de los servicios en energía y medio ambiente, se revisa la información de las ventas anuales de la empresa; desde el año 2011 al año 2018, los que se detallan a continuación: 


\section{Tabla 2}

Variación Anual de Ventas de Hamek Ingenieros Asociados S.A.C

Tiempo Dic-11 Dic-12 Dic-13 Dic-14 Dic-15 Dic-16 $\quad$ Dic-17 $\quad$ Dic-18

Variación Variación Variación Variación Variación Variación Variación Servicio del

Área

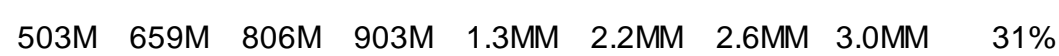

2012-2011 2013-2012 2014-2013 2015-2014 2016-2015 2017-2016 2018-2017

Área

Servicio del

Área

$101 M \quad 123 M \quad 179 M \quad 258 M \quad 319 M \quad 244 M \quad 282 M \quad 295 M \quad 22 \%$

$22 \%$

$12 \%$

$44 \%$

$73 \%$

$16 \%$

$15 \%$

$46 \%$

$44 \%$

$24 \%$

$-23 \% \quad 15 \% \quad 5 \%$

Ambiente

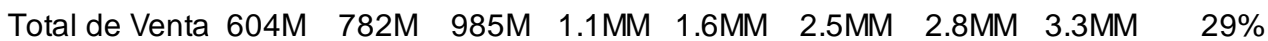

$26 \%$

$18 \%$

$39 \%$

$53 \%$

$16 \%$

$18 \%$

Nota. Elaboración propia 
El ciclo de vida del servicio en el área energética, se encuentra en la etapa de crecimiento, siendo sus ventas una muestra representativa y por su incremento de utilidades (ver Tabla 2), en dicha etapa el producto busca posicionamiento definitivo de tal manera que se consolide y empiece aumentar su participación en el mercado.

El ciclo de vida del servicio que se ofrece en el área del medio ambiente, se encuentra en la etapa de madurez de su ciclo de vida, tiene como característica la estabilización de las ventas (ver Tabla 2), pero con beneficio alto, ya que dicho servicio se consolido en el mercado.

A continuación, se presenta el gráfico el ciclo de vida del producto, representado por la evolución de los servicios del sector de energía y medio ambiente, con datos de sus ventas (ver Figura 5).

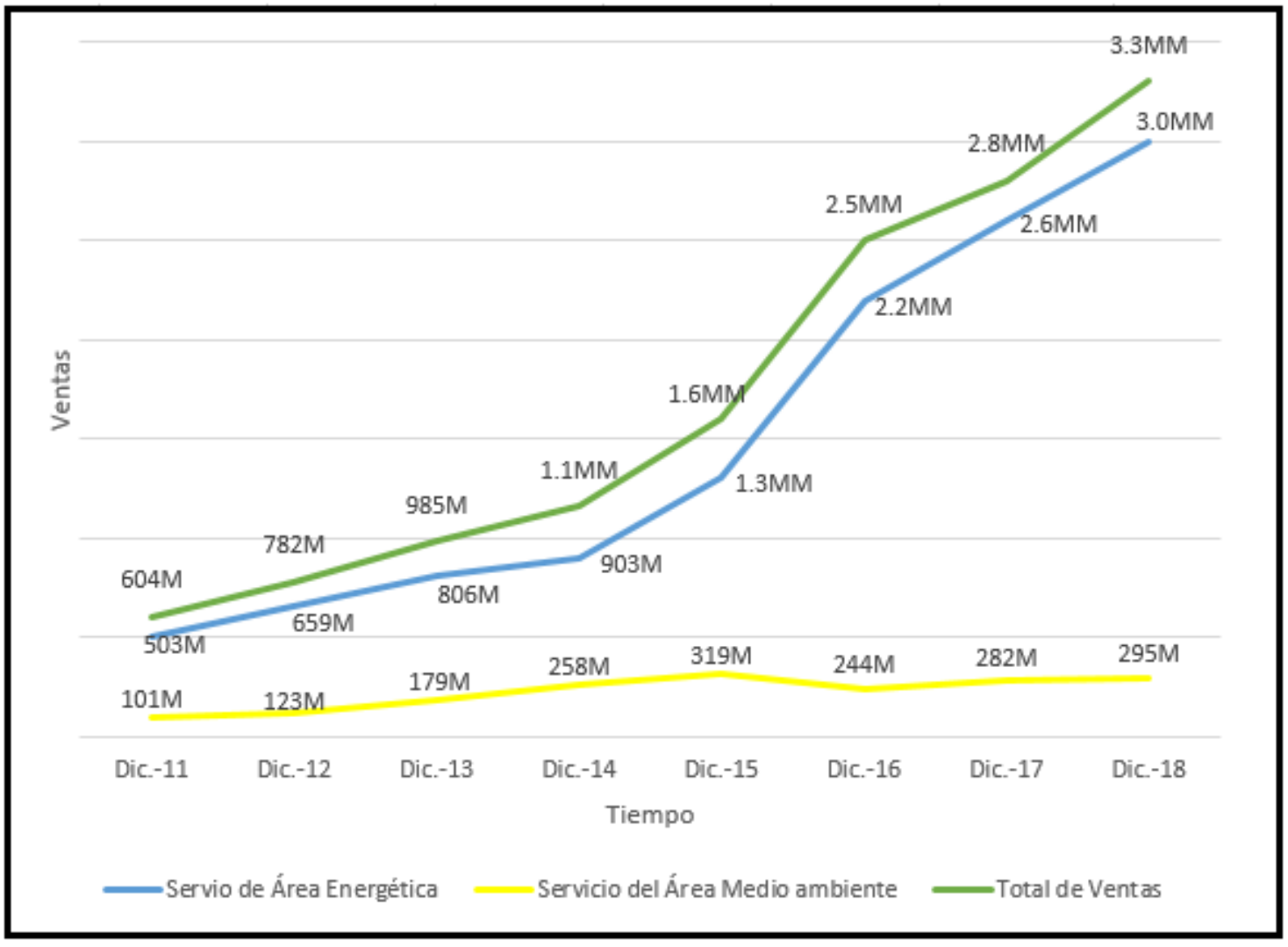

Figura 5. Ciclo de vida del producto de la empresa. Elaboracion propia.

\subsection{Estructura organizacional y actual de la empresa}

De acuerdo con Robbins y Coulter (1996) la estructura organizativa es el "marco formal de la organización de acuerdo con el cual las tareas se dividen, agrupan y coordinan" (p.98). 
Hamek Ingenieros Asociados S.A.C es una empresa familia que basa sus decisiones y responsabilidades en la gerencia general y la gerencia administrativa, la cual es manejada por los accionistas. La figura №06 muestra la estructura organizacional actual de la empresa, basado en una estructura simple, estructura que se mantenido desde los inicios de sus actividades.

El organigrama está compuesto por dos gerencias y dos áreas técnicas. La gerencia administrativa está a cargo de la hija del Gerente General y accionista, esto debido a la sensibilidad de la información que se maneja en esta área, que comprende actividades administrativas, contables y financieras, además del manejo del presupuesto e información reservada de la empresa. Los servicios contables con realizados por un estudio contable externo.

Hamek Ingenieros Asociados S.A.C desde sus inicios determino las funciones, cargos y responsabilidades que deben cumplir los colaboradores y que actualmente no se alinean con los objetivos trazados. Así mismo se ha determinado que el Manual de Organización y Funciones se actualizado en el año 2014 sin embargo a Junio del 2018 no se ha realizado su difusión, esta deficiencia podría ocasionar que los colaboradores no ejecuten un patrón de conducta organizacional. Del Manual de funciones de la empresa se determinan que existen dos áreas de gerencia, la gerencia general representada por el Sr. Amadeo Carrillo y la Gerencia administrativa a cargo de la Sra. Erika Carrillo.

En el siguiente grafico se muestra el organigrama actual de la empresa. Mostrando un total de 8 colaboradores que actualmente forman parte de la organización. 


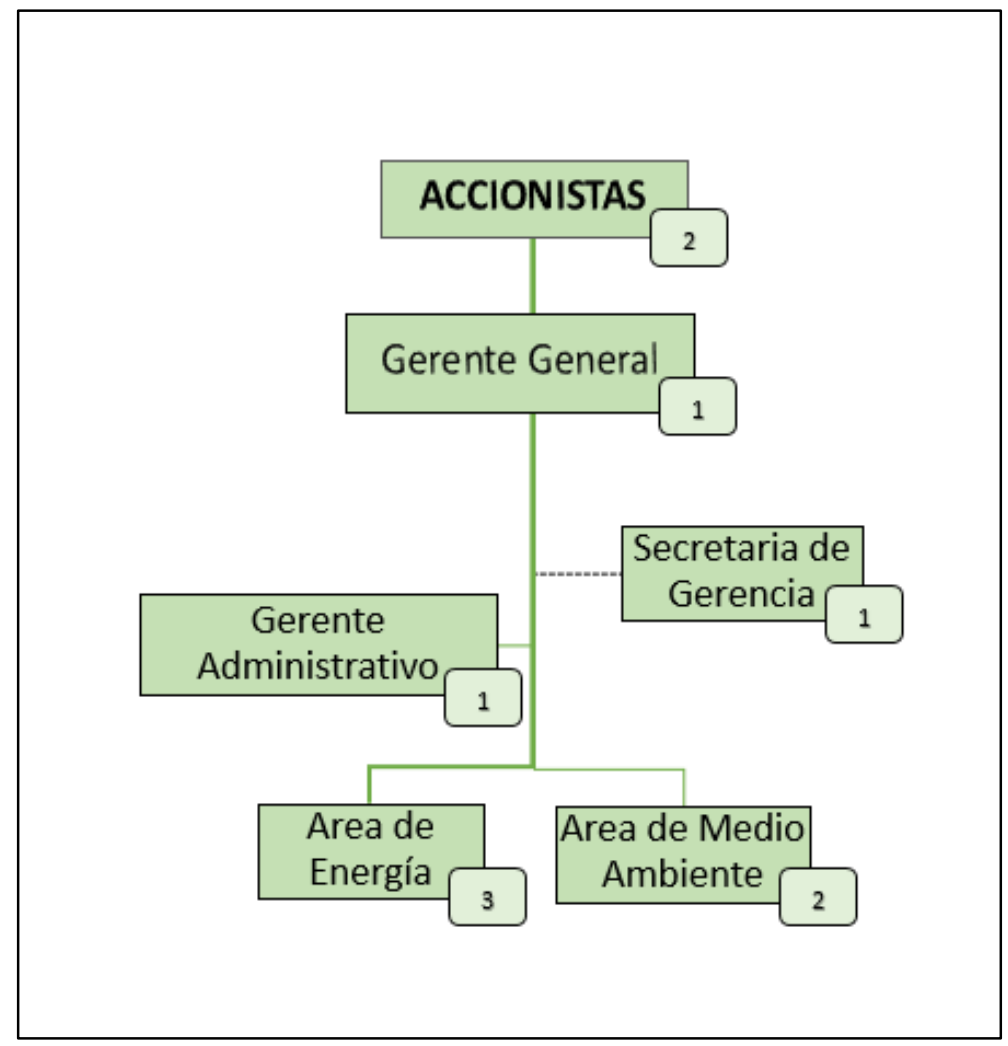

Figura 6. Organigrama de la empresa. Elaboración propia.

A continuación, se describe brevemente las funciones de los diferentes cargos de acuerdo al organigrama oficial:

\section{Gerencia General.}

En el asiento A0001 de la partida registral № 12477232 del registro de Personas jurídicas de la oficina Registral de Lima, consta registrado y vigente el acta de Junta General de accionistas del 04 de diciembre del 2011 donde se acordó el nombramiento como GERENTE GENERAL a favor de AMADEO CARRILLO VILLENA, quien en adelante representará a la empresa con la ejecución de facultades tales como: Actos y Contratos Ordinarios, Representación Procesal, celebrar contratos, representar a la sociedad en la constitución de otras sociedades, firmas en Constancias y Certificados, y otras facultades que reforzarán la imagen e integridad de la empresa.

La siguiente información ha sido obtenida del Manual de Funciones de Hamek Ingenieros Asociados S.A.C

Funciones principales y funciones básicas:

- Planificar los objetivos generales y específicos de la empresa a largo y corto plazo. 
- Dirigir la empresa, tomar decisiones, supervisar y ser un líder de esta.

- Decidir respecto de contratar persona.

- Celebrar y firmar los contratos y obligaciones de la sociedad dentro de los criterios autorizados por el Estatuto y el directorio de Hamek Ingenieros Asociados S.A.C.

- Diseñar y ejecutar los planes de desarrollo, los planes de acción anual, los programas de inversión, mantenimiento y gastos.

- Crear climas organizacionales adecuados que permitan el desarrollo de la creatividad, la motivación y el desarrollo de las personas en la empresa.

- Abrir y cerrar y administrar las cuentas bancarias, sean corriente, de ahorro, crédito o cualquier otra naturaleza, con o sin garantía. Girar cheques sobre los saldos acreedores, deudores o sobregiros.

- Negociar, celebrar, modificar, rescindir y resolver contratos, convenios y compromisos.

- Analizar los problemas de la empresa en el aspecto financiero, administrativo, personal, contable entre otros.

\section{Gerencia Administrativo.}

EL gerente administrativo forma parte de los accionistas de la empresa y tiene como función:

- Formular y proponer a la Gerencia general Normas, políticas y procedimientos para el mejor funcionamiento de las actividades relacionada con la administración y contabilidad de la organización.

- Supervisar la formulación, ejecución y evaluación del presupuesto anual, de conformidad con las disposiciones legales aplicables.

- Elaborar y control de presupuesto.

- Aprobar y firmar el reporte de honorarios profesionales.

- Aprobar y firmar emisión de cheques, pago a proveedores, entre otros.

- Apoyar a la organización en todas las gestiones legales y reglamentarias. (asesoría externa fiscales, contables y/o laborales, etc.).

- Controlar de cuentas por cobrar y cuentas por pagar.

- Controlar de ingresos y egresos con el fin de administrar el capital a la gerencia.

- Controlar de contratos en ejecución en cuanto al inicio, finalización y términos de referencia, pagar garantizar la conformidad y cumplimiento con nuestros compromisos de contratos. 


\section{3. Área Medio Ambiente}

El área ambiental está representada por dos personas sus funciones son las siguientes:

- Gestionar el área de Medio Ambiente de acuerdo a las normativas internas.

- Implementado, desarrollar y mantener actualizado los diferentes, procedimientos, registros y formatos de control

- Establecer las relaciones con las diferentes áreas operativas y mantener comunicación fluida con cada una de ellas respecto de temas ambientales.

- Planificar y ejecutar los servicios del área medio ambiental

- Supervisar el cumplimiento efectivo y seguro de las tareas asignadas a los Ingenieros de Medio Ambiente y especialista externos.

- Asistir a las entidades para sustentar y presentar informes finales Atender fiscalizaciones, visitas, informes, reuniones, comités, etc.)

- Monitorear y hacer seguimientos a los plazos y términos de referencia de los contratos vigentes.

- Realizar actividades de capacitación ambiental.

\section{4. Área de Energía.}

EL área de energía está representada por tres personas sus funciones son las siguientes:

- Dirigir y planificar las reuniones semanales del área.

- Controlar y delegar funciones para cada servicio.

- Preparar cronogramas de actividades

- Supervisa al personal asignado en campo.

- Participar de las reuniones con los clientes.

- Implementación y mejora de procesos de los servicios.

- Elaboración de propuestas.

- Visitas a plantas para cotizaciones de los servicios.

- Solicitar implementación de quipos e implementos de seguridad.

- Monitorear y hacer seguimientos a los plazos y términos de referencia de los contratos vigentes.

- Realizar actividades de capacitación en el manejo de equipos de energía. 
Contador.

Funciones:

- Operar la información financiera de la empresa, basada en las normas y reglamento aplicable.

- Revisar, clasificar los documentos contables y financieros de la empresa.

- Responsable ante las auditorias por parte de la SUNAT.

- Elaborar las boletas de pago mensual de todo el personal.

Sistemas.

Funciones:

- Mantenimiento de las computadoras, impresoras y fotocopiadoras

- Actualización de los antivirus.

- Responsable del servidor.

\section{Análisis funcional}

Para realizar el presente análisis hemos tomado en cuenta las entrevistas a colaboradores de la empresa. Este análisis los realizaremos para las dos gerencias desde el punto de vista de cinco aristas: motivación, liderazgo, trabajo en equipo, clima organizacional y poder.

\section{Gerencia General}

\section{Motivación:}

La motivación del gerente general es alta, ya que como cabeza de la institución es quien está al pendiente de nuevos proyectos, trabaja de la mano con todas las áreas, sobre todo con el área administrativa, ya que es con la administración que analiza y toma las decisiones en la empresa.

Un colaborador del área de energía quien trabaja directamente con el gerente general comentó: "Yo conozco al ingeniero desde estudiante hace 10 años, comencé haciendo practicas pre profesionales y siempre el ingeniero se ha caracterizado por tener un buen trato, así como las oportunidades de crecimiento que he tenido ha sido porque siempre ha confiado en nosotros, es una persona que le gusta compartir sus conocimientos y gracias a ello he aprendido mucho, actualmente manejo el área de energía y por ello tengo un trato directo con el ingeniero. (Conversación informal, 2018) 


\section{Colaborador del área de ambiental:}

"Vengo trabajando en Hamek Ingenieros Asociados S.A.C hace 3 años, trabajar con el ingeniero es una gran experiencia, el trato que tiene con nosotros es un trato familiar, el respeto y confianza que tiene con nosotros a sido fundamental para que me sienta confortable trabajar en Hamek Ingenieros Asociados S.A.C"

\section{Liderazgo:}

Bajo lo antes mencionado, el gerente general de la empresa, es apreciado por los colaboradores de la empresa, rescatando que lidera la empresa con respeto y confianza a sus colaboradores, valores que destacan.

\section{Trabajo en equipo:}

La gerencia general está conformada por una persona que es a la vez accionista de la empresa.

\section{Clima organizacional:}

No se puede hacer un análisis ya que esta área está conformada por una persona.

\section{Poder:}

El gerente general toma decisiones técnicas en conjunto con los jefes de cada área, para las decisiones como empresa, estas son discutidas en conjunto con la gerencia administrativa.

\section{Gerencia de administración}

\section{Motivación:}

La motivación es alta en el área de administración, esto básicamente porque el cargo lo tiene una de las accionistas de la empresa, la confianza que tienen entre la gerencia general y administrativa es el principal motor para tener motivado al área.

El contador de la compañía le reporta directamente a la gerencia administrativa, quien comentó: "Yo vengo trabajando con Hamek Ingenieros Asociados S.A.C de manera externa desde hace cinco años, en todo este tiempo que vengo trabajando con ellos nunca he tenido ningún malestar, trabajo directamente con la gerente administrativa y siempre hemos tenido una buena comunicación, me siento bien trabajar para Hamek Ingenieros Asociados S.A.C. (Conversación informal, 2018). 


\section{Colaborador del área de energía:}

"Vengo trabajando con Erika constantemente ya que es quien lidera las entregas de las propuestas de trabajo, organiza las reuniones semanales, y está al pendiente de cualquier necesidad de todos en la empresa, pienso que es clave para el crecimiento de la empresa pues con el trabajo en conjunto con su padre han sabido lograr el crecimiento de la empresa".

\section{Colaborador del área ambiental:}

Pienso que el trabajo de la ingeniera es primordial para que Hamek Ingenieros Asociados S.A.C continúe en crecimiento, pues es ella quien está al pendiente de toda acción en la empresa, lo que más me agrada de sus funciones es que dentro de todas sus actividades se da tiempo para atender a todo tipo de necesidad que tuviésemos nosotros como colaboradores.

\section{Liderazgo:}

Bajo lo antes mencionado, el gerente administrativo de la empresa, es muy bien visto por todos los trabajadores de la empresa, rescatando que está siempre al pendiente de las necesidades de la empresa y sus colaboradores. Se percibe que tiene preparación académica suficiente para llevar adelante la organización.

\section{Trabajo en equipo:}

El área administrativa está conformada por una persona que es a la vez accionista de la empresa.

\section{Clima organizacional:}

No se puede hacer un análisis ya que esta área está conformada por una persona.

\section{Poder:}

La gerente administrativa cumple y realiza sus labores a tiempo, en la mayoría de las veces las decisiones se consultan al gerente general, de manera verbal.

Después de realizar el análisis funcional, podemos determinar que los colaboradores de Hamek Ingenieros Asociados S.A.C se sienten motivados trabajar para la empresa, destacan el buen clima laboral que tienen la empresa. 
A continuación, presentamos uno de los procesos de los servicios más representativos de Hamek Ingenieros Asociados S.A.C 


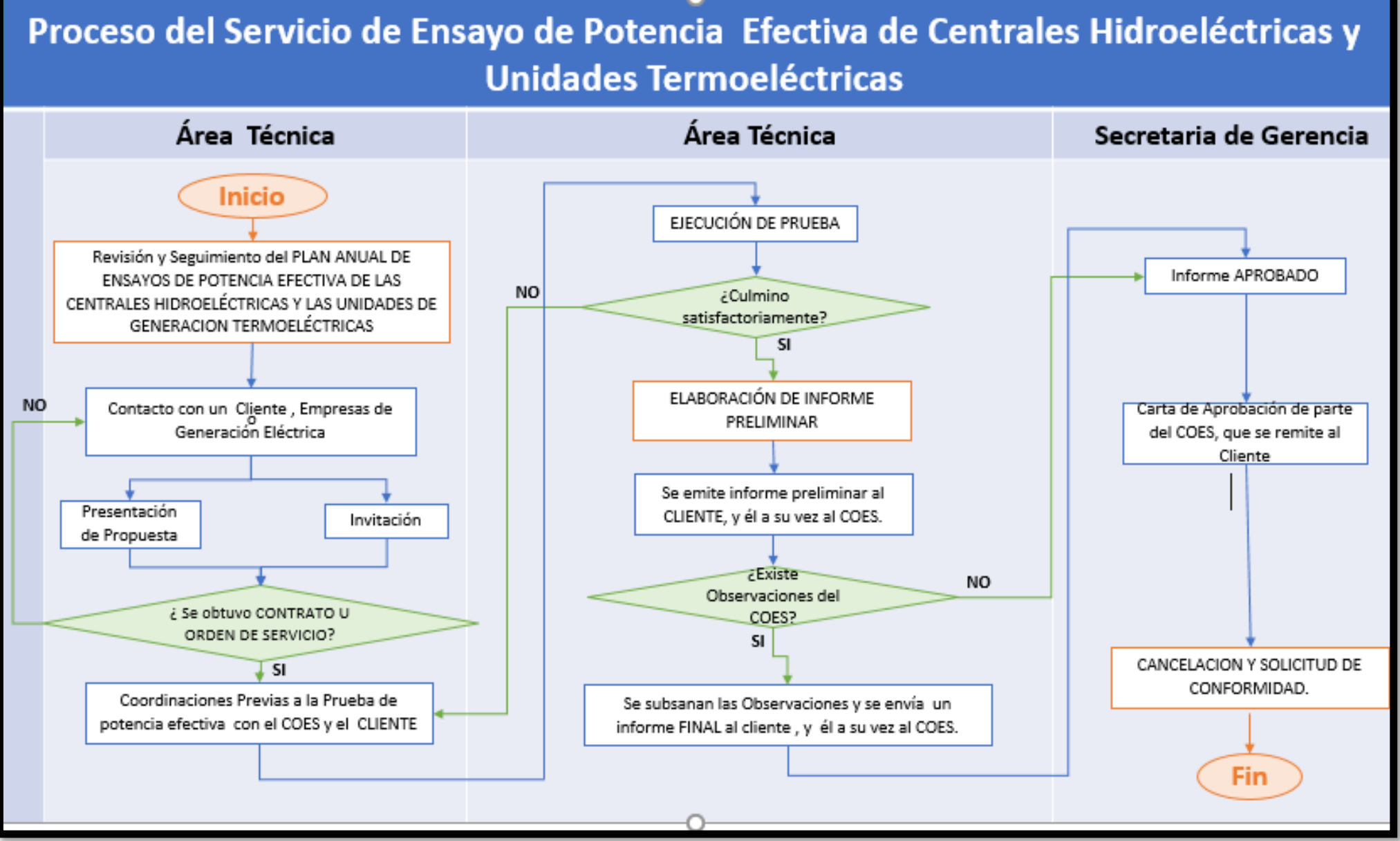

Figura 7. Diagrama de flujo del proceso del Servicio de Ensayo de Potencia efectiva de Centrales Hidroeléctricas y Unidades Termoeléctricas. 


\subsection{Situación de Mercado y Financiera actual de la Industria}

Se considera importante analizar la situación de los sectores de Minería y Energía en el Perú a efecto de determinar la situación del mercado como parte del análisis del entorno en el que se desenvuelve Hamek Ingenieros y Asociados S.A.C.

Según se detalla en la actualización del Plan Estratégico Sectorial Multianual (PESEM) 2016 - 2021 del MINEM referido a dichos sectores (2016):

El Perú es actualmente un país seguro para las inversiones y ofrece grandes oportunidades en el Sector Minero Energético. El marco legal que brinda el Estado al inversionista, dentro del respeto al medio ambiente y la inclusión social proporciona una nueva política y relación con las actividades extractivas. Es en este contexto que el Sector Minero Energético es uno de los motores para el desarrollo de la economía nacional, participando con aproximadamente el $10 \%$ del Producto Bruto Interno (PBI) y con el $62 \%$ de las exportaciones. (p. 3).

Sólo el sector Minería constituye uno de los principales sectores económicos del país y engloba el $49 \%$ de valor de las exportaciones y el $10 \%$ del PBI, asimismo, absorbe el $12 \%$ de la inversión privada (ver Figura 8).

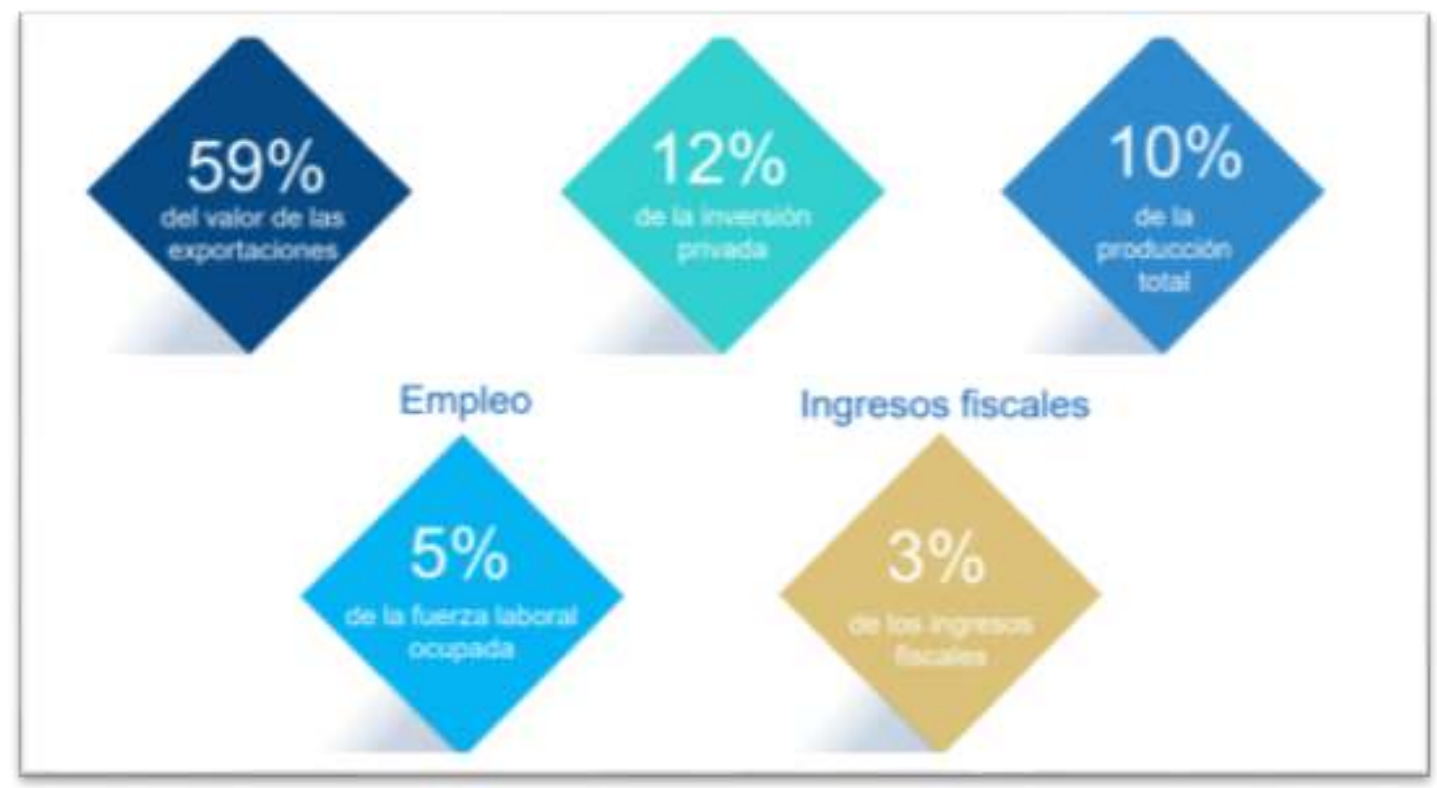

Figura 8. Importancia de la minería metálica, 2016. Adaptado de "Perú. Sector Minero", 2016.

También se considera importante mencionar que el Perú es uno de los países con mayores reservas de metales como el Oro, Plata, Cobre y Zinc (Ver Figura 9). 


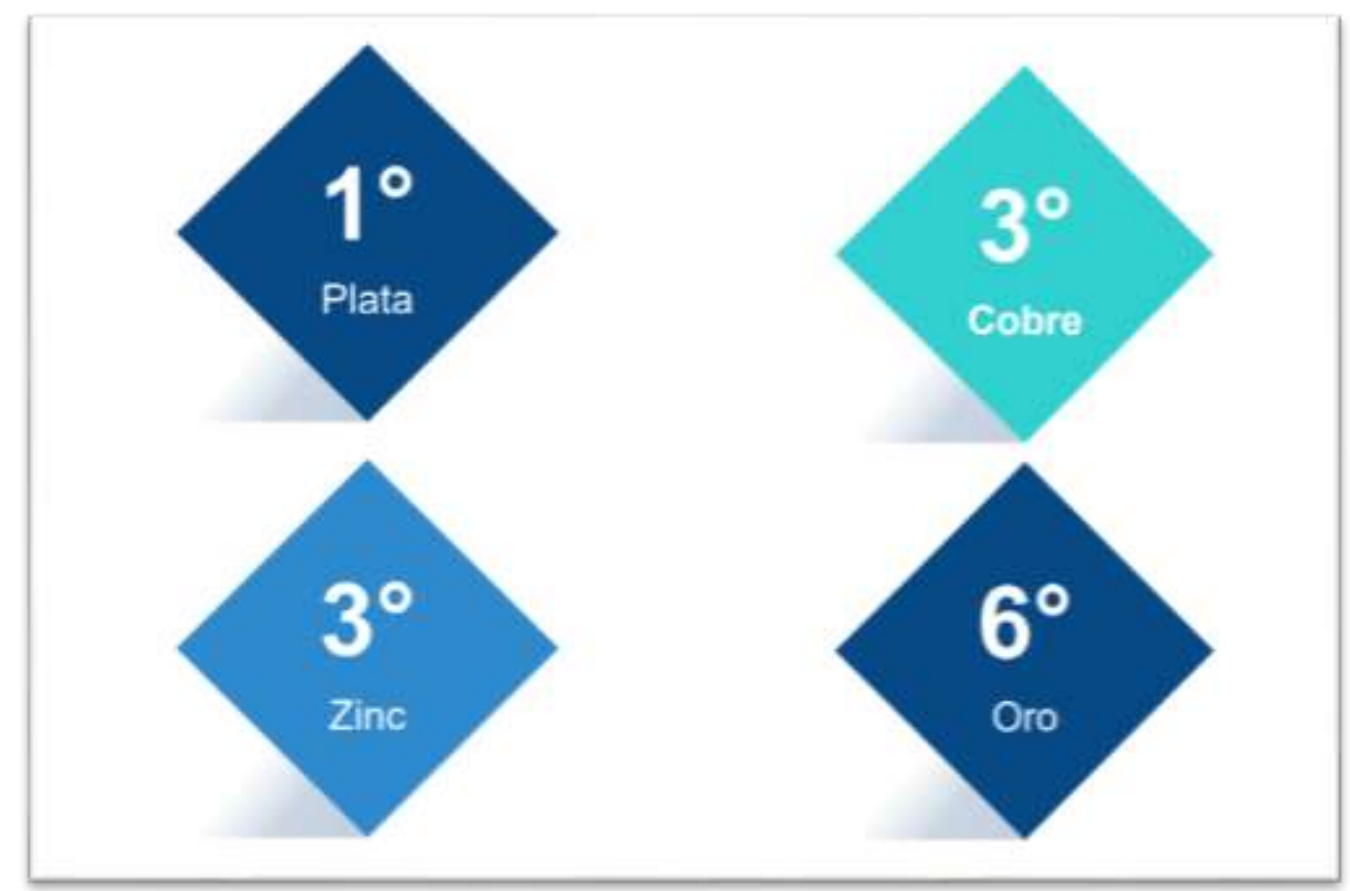

Figura 9. Importancia de la minería metálica, 2016. Adaptado de "Perú. Sector Minero", 2016.

Por otro lado, a nivel global se observa oportunidades favorables para el crecimiento del sector Minería, por:

- Incremento de tamaño de la industria mundial, considerando la demanda de minerales y el nivel de precio de los metales.

- Migración paulatina de las operaciones mineras hacia los países en vías de desarrollo.

- Concentración de la demanda minera en Asia.

- Incremento de costos en la actividad minera y la disminución de la disponibilidad del recurso humano competente.

- Preocupación por la preservación del medio ambiente y el desarrollo sostenible

- Mayores exigencias para compartir los beneficios de la industria, tanto de las comunidades como el estado.

- Énfasis en la innovación y el uso de nuevas tecnologías para mejorar la productividad.

- Mayor importancia de determinantes no mineros de la oferta, reciclaje.

Generan oportunidades de negocio en la medida que el sector se desarrolla cada vez más, dado que se requerirá contar con centrales de generación eléctrica para mantener el funcionamiento operativo y por ende la posibilidad de brindar los distintos servicios ofrecidos por Hamek Ingenieros Asociados S.A.C. 
Se considera importante mencionar los principales proyectos mineros que se culminarían en los siguientes años (ver Tabla 3) en el Perú y que consideran una inversión mayor de USD 1,000 millones. El valor total de la inversión supera los USD 41,200 millones y que evidencian el crecimiento de la inversión en el sector minería.

\section{Tabla 3}

Principales Proyectos Mineros en el Perú

\begin{tabular}{lccc}
\hline Proyecto & $\begin{array}{c}\text { Inversión } \\
\text { Proyectada }\end{array}$ & $\begin{array}{c}\text { Mineral } \\
\text { Principal }\end{array}$ & $\begin{array}{c}\text { Puesta } \\
\text { en marcha }\end{array}$ \\
\hline La granja & 4000 & Cobre & 2022 \\
Quellaveco & 4882 & Cobre & \\
Minas Conga & 4800 & Oro & \\
Galeno & 3400 & Cobre & \\
Hierro Apurímac & 2900 & Hierro & 2024 \\
Huaquira & 2824 & Cobre & 2022 \\
Los Chankas & 2800 & Cobre & 2022 \\
Panpa de Pongo & 2400 & Hierro & \\
Michiquillay & 2400 & Cobre & \\
Rio Blanco & 2400 & Cobre & \\
Cañariaco & 1600 & Cobre & \\
Cotabambas & 1486 & Cobre & \\
Tía María & 1400 & Cobre & \\
Mar cobre (Mina justa) & 1348 & Cobre & 2021 \\
Zafranal & 1160 & Cobre & \\
\hline Total & 41200 & & \\
\hline
\end{tabular}

Nota. Adaptado de Observatorio Energético Minero (p. 1) por el Organismo Supervisor de la Inversión en Energía y Minería (Osinergmin). 2016, Lima, Perú.

Por otro lado, a nivel global se observan una proyección de crecimiento del sector Minería, en la medida que este crecimiento se vaya dando, estas empresas privadas construirán sus propias centrales para generar energía y ello constituye una oportunidad de negocio para Hamek Ingenieros Asociados S.A.C.

Con el incremento del sector minero se presenta una enorme oportunidad para el sector energía que actualmente tiene una sobrecapacidad de oferta de lo se necesita, en consecuencia, puede hacer frente a los grandes proyectos mineros que demandarán más energía. 
En noviembre del año 2014, el MEM publicó el Plan Energético Nacional 20142024. En el mencionado documento se presentan proyecciones de la demanda de energía en el horizonte 2014-2024 (ver Figura 10) para dos escenarios de crecimiento económico: un escenario optimista (escenario base) y un escenario conservador (escenario alternativo).

Como menciona Ríos (2016), "En el escenario optimista se espera un crecimiento económico promedio anual de $6.4 \%$, mientras que en el escenario conservador se espera un crecimiento económico promedio anual de 4.4\%” (p.1).

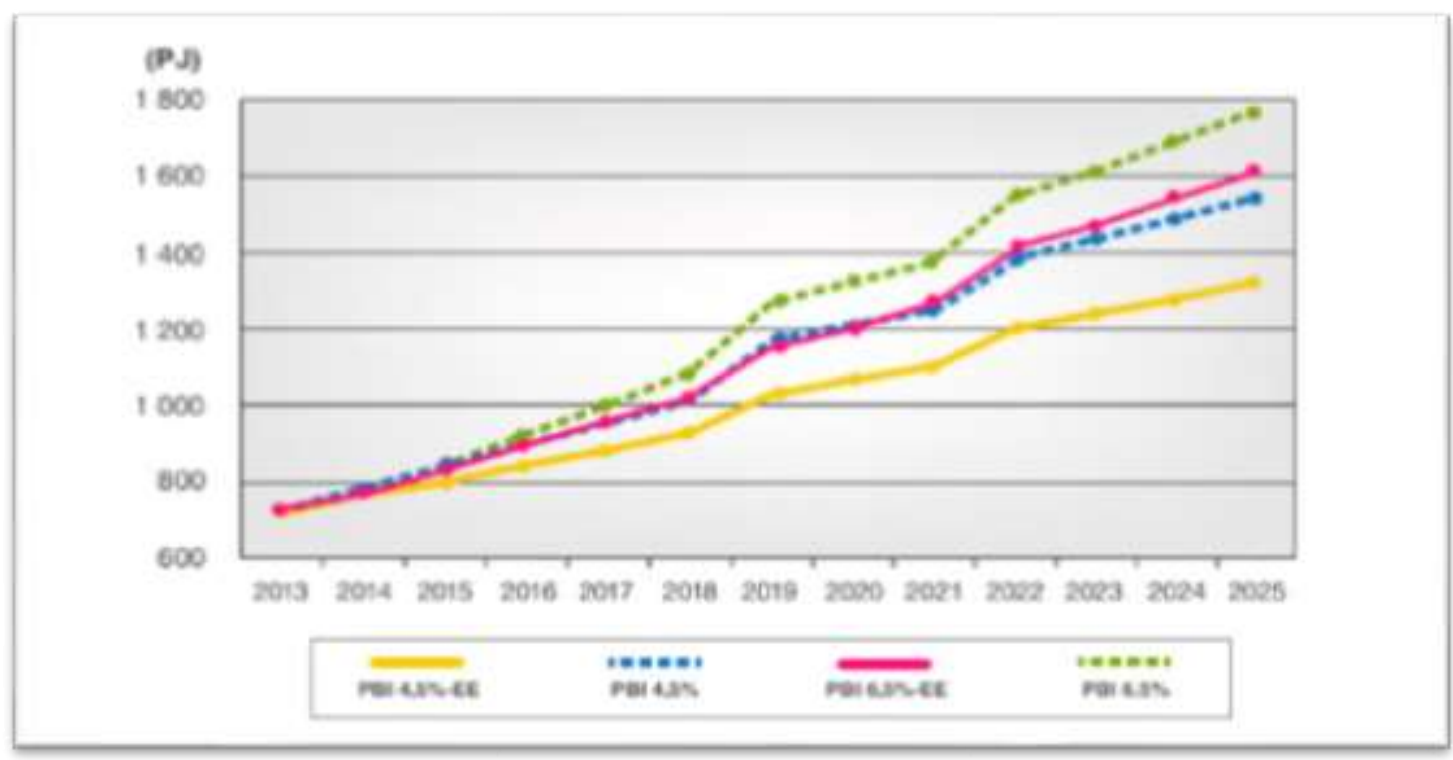

Figura 10. Proyecciones de demanda de energía entre el año 2014-2024. Adaptado de "Plan Energético Nacional 2014-2024" por el Ministerio de Energía y Minas (MINEM). 2014.

Se espera que el consumo final de energía eléctrica continúe creciendo en función al desarrollo de la economía interna del país, el crecimiento de la población urbana y la ampliación de la cobertura energética (ver Figura 11), a pesar de la aplicación de medidas de uso eficiente de la energía (EE) en los sectores residenciales, servicios, industrial y transporte. 


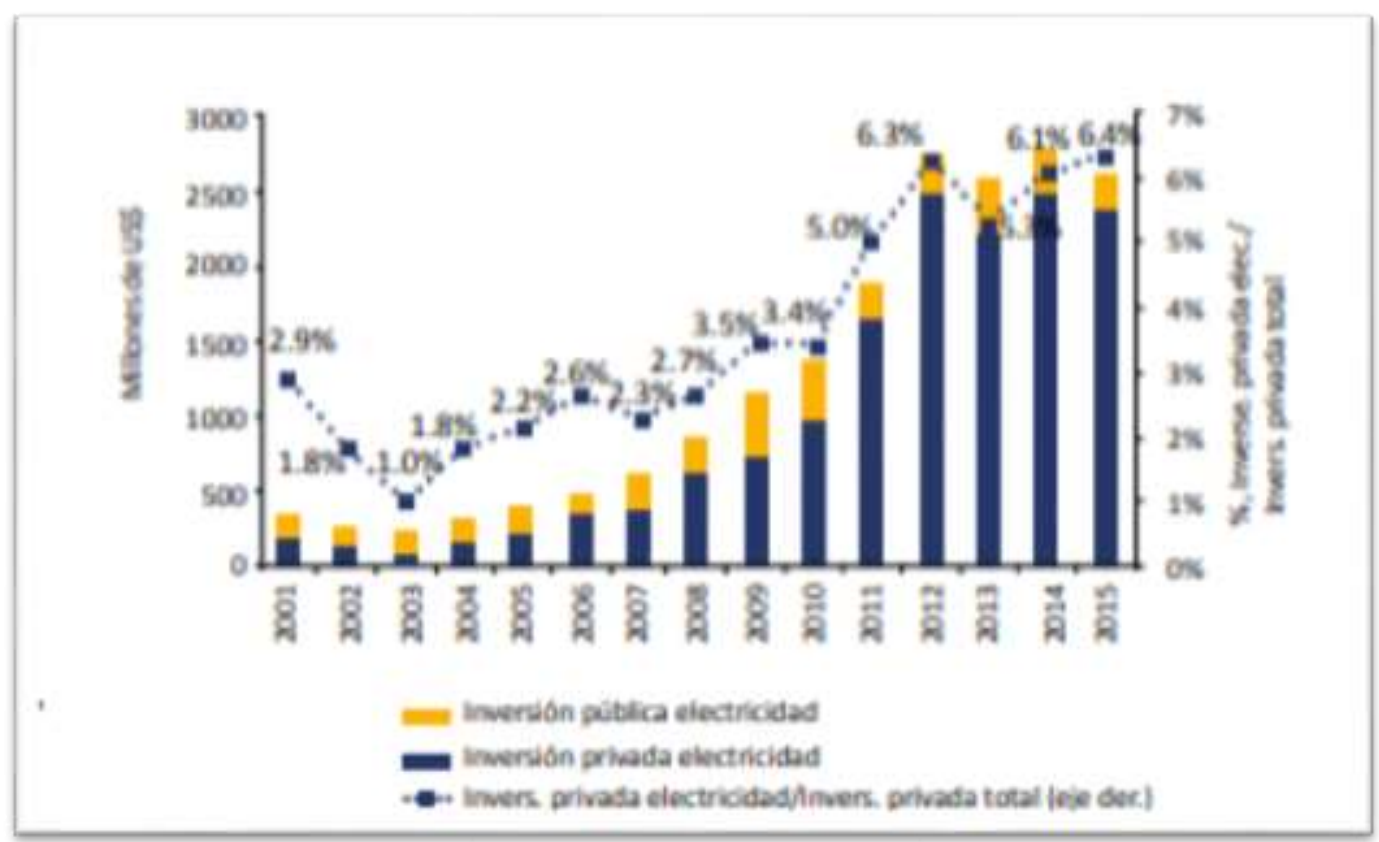

Figura 11. Inversiones en Electricidad. Adaptado de "la Inversión Pública en electricidad" por la Dirección General de Electricidad Rural del MINEM y BCRP, 2016.

La generación eléctrica del país es abastecida por empresas estatales y privadas, las cuales tienen importantes proyectos de expansión en marcha. El sector eléctrico peruano está compuesto por tres partes:

- Empresas Distribuidoras

Participación en tarifa final al cliente: $34 \%$

- $\quad$ Empresas Generadoras

Participación en tarifa final al cliente: $60 \%$

- Empresas Transmisoras

Participación en tarifa final al cliente: $4 \%$

El mercado del sistema eléctrico se distribuye entre las distintas empresas de Distribución Eléctrica (ver Tabla 4), debiendo anotar que en Lima se concentra cerca del $68 \%$ de la participación de mercado. 
Tabla 4

Participación de las Empresas Distribuidoras en el Mercado del Sistema Eléctrico Interconectado Nacional, 2014.

\begin{tabular}{|c|c|c|}
\hline $\mathrm{N}^{\circ}$ de Orden & Entidad Distribuidora & Participacion anual (\%) \\
\hline 1 & Luz del Sur S.A.A. & $29.00 \%$ \\
\hline 2 & Empresa de distribución Eléctrica de Lima Norte S.A.A. (EDELNOR) & $27.59 \%$ \\
\hline 3 & Empresa Regional de Servicio Publico Electricidad Electronortemedio S.A. (HIDRANDINA) & $8.99 \%$ \\
\hline 5 & ELECTROCENTRO S.A. & $4.93 \%$ \\
\hline 6 & Sociedad Eléctrica del Sur Oeste S.A. (seal) & $4.88 \%$ \\
\hline 9 & Electro Sur Este S.A.A. & $3.53 \%$ \\
\hline 10 & ELECTROSUR S.A. & $1.75 \%$ \\
\hline 11 & Electro Puno S.A.A & $1.74 \%$ \\
\hline 12 & Empresa concesionaria de Electricidad de Ucayali S.A. (ELECTRO UCAYALI) & $1.48 \%$ \\
\hline 13 & Consorcio Electrico Villacuri S.A.C. (COELVISAC) & $1.26 \%$ \\
\hline 14 & Empresa de Administración de Infraestructura Electrica S.A. (ADINELSA) & $0.25 \%$ \\
\hline 18 & Servicios eléctricos Rioja S.A. (SERSA) & $0.07 \%$ \\
\hline 19 & Empresa de servicios eléctricos municipales de Paramonga S.A. (EMSEMSA) & $0.06 \%$ \\
\hline 20 & ELECTROPANGOA S.A. (EPASA) & $0.02 \%$ \\
\hline 21 & EGEPSA & $0.01 \%$ \\
\hline 22 & Empresa de servicios electricos municipal de Pativilca S.A.C. (ESEMPAT) & $0.01 \%$ \\
\hline 23 & Empresa distribuidora de comercializadora de Electricidad San Ramon de Pangoa S.A. (EDELSA) & $0.01 \%$ \\
\hline & TOTAL DEL PERIODO & $100.00 \%$ \\
\hline
\end{tabular}

Nota. Adaptado de Participación de Empresas en el Mercado Eléctrico (p. 1) por el Organismo Supervisor de la Inversión en Energía y Minería (Osinergmin), 2016, Lima, Perú.

Las principales empresas de generación eléctrica en el Perú constituyen el mercado eléctrico (ver Figura 12), dicho mercado considera a empresas que abastecen del servicio al público y también a las empresas que generan energía eléctrica para su uso propio. 
Generación Hidráulica

$(21,710 \mathrm{GWh})$

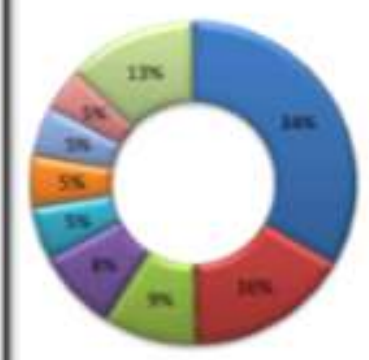

Generación Térmica

$(18,756 \mathrm{GWh})$

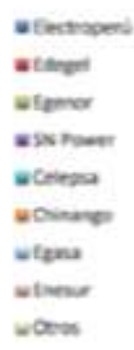

einer

exales

etitinet

etementas

vians

notios

Figura 12. El mercado eléctrico del Perú: una síntesis de la experiencia adquirida, 2014. Adaptado de "La industria de la electricidad en el Perú: 24 años de aportes al crecimiento económico del país" por el Organismo Supervisor de la Inversión en Energía y Minería (Osinergmin), 2016.

Existe una expectativa de crecimiento en el sector eléctrico, dado los proyectos de generación eléctrica que se tienen en agenda para los siguientes años (ver Tabla $5)$, siendo importante precisar que estas mejoras fueron posibles, gracias a la privatización posterior a las reformas iniciadas en 1992. 
Tabla 5

Principales Proyectos de Generación Eléctrica a Futuro

\begin{tabular}{llll}
\hline Nombre del Proyecto & Empresa & Ubicación & Potencia (MW) \\
\hline CI Ho4 & Enersur & Moquegua & 735 \\
C.H. Veracruz & Compañía energética Veracruz S.A.C & Amazonas y Cajamarca 730 \\
C.H. Vchadin II & AC energía S.A. & Amazonas y Cajamarca & 600 \\
C.H. San Gaban III & Hydro Global & Puno & 205.8 \\
C.S. Rubi & Enel Green Power S.A. & Moquegua & 144.5 \\
C.E. Parque Nazca & Enel Green Power S.A. & 126 \\
C.T. Chilca & Enersur S.A. & Ica & 112.8 \\
C.T. Santo Domingo de los Olleros & Termochilca & Chilca & 100 \\
C.S. Intipampa & Enersur S.A. & Lima & 40 \\
C.H. Centauro I y II & Corporación minera Perú & Moquegua & 25 \\
C.H. Angel I & Generadora energía S.A.C & Ancash & 19.9 \\
C.H. Angel II & Generadora energía S.A.C & Puno & Puno \\
C.H. Angel III & Generadora energía S.A.C & Puno & 19.9 \\
C.H. Huatoroki & Empresa de Generació Hidraulica Selva Junin & 19.9 \\
C.H. Santo Lorenzo I & Empresa de Generació electrica Santo L Huánuco & 19.2 \\
C.H. Marañon & Hidroelectrica Marañon S.R.L & Junin & 18.7 \\
C.H. Yarucaya & Huaura Power group S.A. & Lima & 18 \\
C.H. Raura II & Amazonas Generación S.A. & IIMA & 16.5 \\
C.H. Colca & Empresa de Genración Colca II & Junin & 13 \\
\hline & & 12.1 \\
\hline
\end{tabular}

Nota. Adaptado de Participación de Empresas en el Mercado Eléctrico (p. 1) por el Organismo Supervisor de la Inversión en Energía y Minería (Osinergmin), 2016, Lima, Perú.

También es importante mencionar el crecimiento de las líneas de trasmisión eléctrica (ver Figura 13) a lo largo de toda la geografía del Perú en los últimos veinte años como consecuencia de la construcción de una nueva infraestructura de transmisión lo cual permite brindar el servicio eléctrico a una mayor parte de la población. 


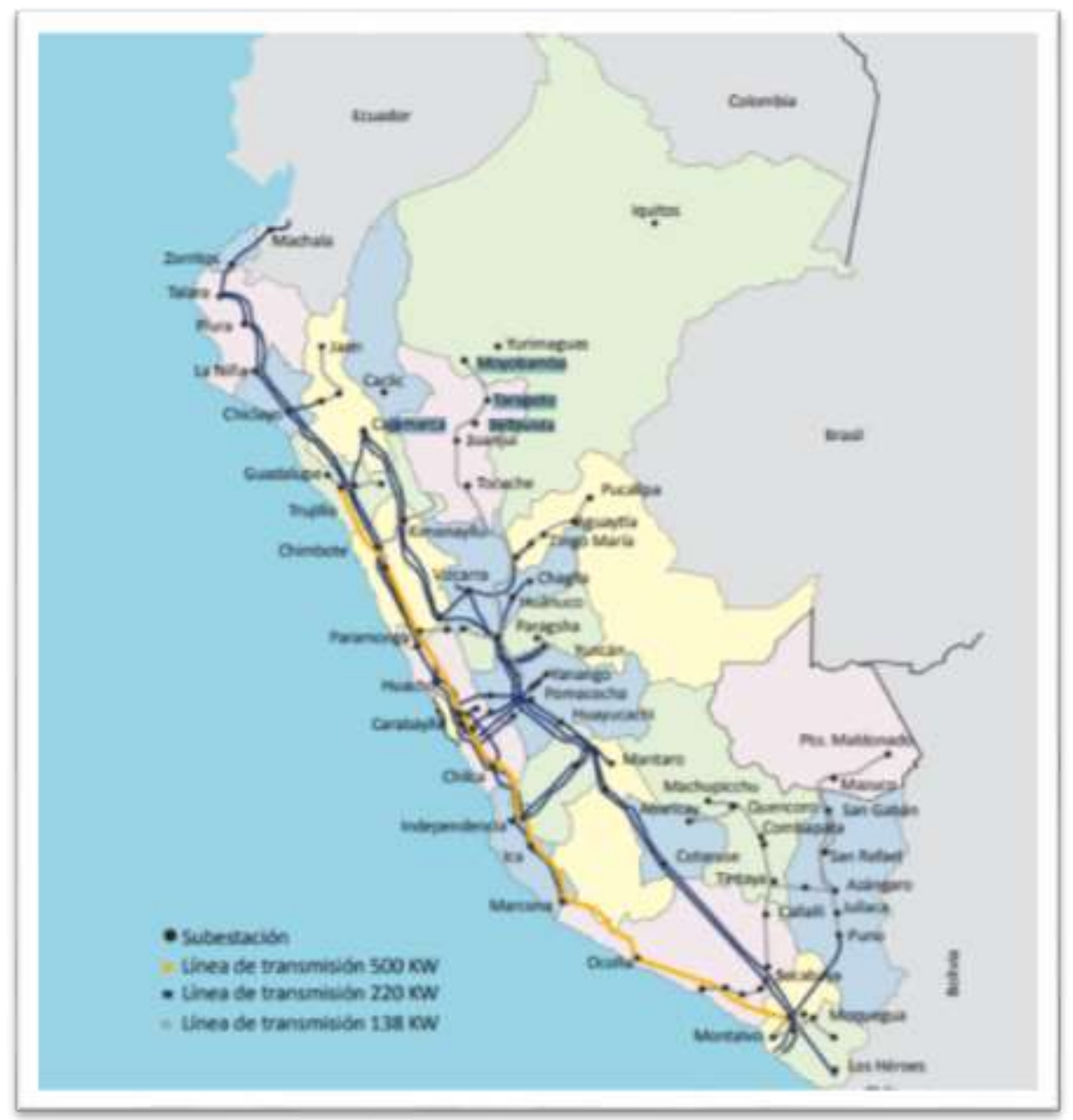

Figura 13. Principales líneas de transmisión eléctrica, 2014. Tomado de "La industria de la electricidad en el Perú: 24 años de aportes al crecimiento económico del país" por el Organismo Supervisor de la Inversión en Energía y Minería (Osinergmin), 2016.

Es por ello que ante el inminente crecimiento del sector eléctrico, se hace necesario a creación de una institución que supervise, garantice y fiscalice a todos los integrantes del Sistema Eléctrico Interconectado Nacional (SEIN), en consecuencia y para cubrir dicha necesidad nace el Comité de Operación Económica del Sistema Interconectado Nacional (COES), entidad privada conformada por todos los agentes del SEIN, que tiene como finalidad coordinar la operación de corto, mediano y largo plazo del SEIN, al mínimo costo, preservando la seguridad del sistema, el mejor aprovechamiento de los recursos energéticos, así como planificar el desarrollo de la transmisión y administrar el mercado de Corto Plazo.

Respecto a las tendencias actuales del sector energía se observa:

- $\quad$ Incremento del uso de energía renovable y generación limpia de energía.

- $\quad$ Creciente interés por la eficiencia energética. 
- $\quad$ Mayor preocupación por asuntos sociales y ambientales sostenibles.

- Desarrollo de la Aplicación de energía nuclear.

- $\quad$ Mayor exploración y explotación de gas natural en el planeta.

- $\quad$ Mayor exploración y explotación de gas natural en el planeta.

- $\quad$ Incremento en el uso de GNV para el transporte.

- Demanda creciente de la energía.

- $\quad$ Mayor preocupación por el acceso al uso de la energía.

Respecto a la posición del Gobierno Peruano se detallan los principales objetivos estratégicos sectoriales (Tabla 6), que benefician también a Hamek Ingenieros y Asociados S.A.C., en la medida que hay una marcada preocupación en la reducción del impacto ambiental de las actividades minero-energéticas. 
Tabla 6

Acciones Estratégicas Sectoriales

\begin{tabular}{|c|c|}
\hline Objetivos Estrategicos Sectoriales & Acciones Estratégicas Sectoriales \\
\hline $\begin{array}{l}\text { I. Incrementar el desarrollo económico } \\
\text { del país mediante al aumento de la } \\
\text { competitividad del Sector Minero-Energético }\end{array}$ & $\begin{array}{l}\text { I.1. Promover actividades mineras y energéticas } \\
\text { I.2. Garantizar el abastecimiento de la energía e impulsar } \\
\text { la diversificación de la matriz energética } \\
\text { I.3. Promover y consolidar la formación de la minería } \\
\text { I.4. Incrementar el conocimiento de los recursos minero- } \\
\text { energéticos y garantizar la seguridad juridica del rol concedente } \\
\text { I.5. Incrementar la utilización de las aplicaciones nucleares en } \\
\text { los sectores productivos, servicios e investigacion del pais. }\end{array}$ \\
\hline $\begin{array}{l}\text { II. Disminuir el impacto ambiental de las } \\
\text { operaciones minero-energéticas }\end{array}$ & $\begin{array}{l}\text { II.1. Fomentar que las operaciones mineras y energéticas se } \\
\text { realicen cumpliendo con los estandares ambientales } \\
\text { II.2. Promover la eficiencia energética y el uso de los recursos } \\
\text { energeticos renovables } \\
\text { II.3. Mejorar de la Gestión de la remediacion de pasivos } \\
\text { ambientales del sector } \\
\text { II.4. Impulsar las aplicaciones de energia nuclear para la } \\
\text { conservacion del medio ambiente. }\end{array}$ \\
\hline $\begin{array}{l}\text { III. Contribuir en el desarrollo humano y en las } \\
\text { relaciones armoniosasde los actores del sector } \\
\text { Minero-Energético }\end{array}$ & $\begin{array}{l}\text { III.1. Mejorar la gestión social en las areas de influencia de las } \\
\text { actividades mineras y energeticas } \\
\text { III.2. Incrementar el acceso a la energía } \\
\text { III.3. Desarrollar el estudio de los peligros geologicos y } \\
\text { estudios geoambientales que afecten la seguridad de la } \\
\text { poblacion } \\
\text { III.4. Desarrollar, promover y aplicar la ciencia y tecnología } \\
\text { nuclear en beneficio de la salud poblacional }\end{array}$ \\
\hline $\begin{array}{l}\text { IV. Fortalecer la gobernanza y la modernización } \\
\text { del sector Minero-Energético }\end{array}$ & $\begin{array}{l}\text { IV.1. Modernizar la gestion sectorial } \\
\text { IV.2. Mejorar el marco legal minero-energético } \\
\text { IV.3. Promover la coordinacion y articulacion entre las } \\
\text { diferentes entidades públicas y privadas vinculadas al sector } \\
\text { IV.4. Fortalecer la gestion desentralizada del sector } \\
\text { minero-energético }\end{array}$ \\
\hline
\end{tabular}

Nota. Adaptado de Análisis de tendencias y eventos futuros del sector minero (p. 31) por el Ministerio de Energía y Minas (MINEM), 2016, Lima, Perú. 


\section{Capítulo III. Formulación de Visión, Misión y Valores de la Empresa}

Para lograr desarrollar un plan estratégico eficiente, es necesario plantear estrategias con acciones organizativas basadas en la visión y misión, promoviendo que los colaboradores sean el grupo de interés, y participen activamente en cumplimiento de los objetivos de la empresa.

En el presente capítulo se aplicarán las herramientas necesarias para analizar y desarrollar la misión, visión y valores de la empresa en estudio, siguiendo el modelo de proceso Estratégico de Fred. R. David (2013).

Es un modelo o proceso que adopta un enfoque de tipo racional y representa algo así como un camino o guía sobre cómo elegir y poner en marcha una estrategia organizacional, el modelo de David consta de tres partes principales: Formulación, Ejecución, Evaluación de Estrategias.

En el año 2014, Hamek Ingenieros Asociados S.A.C., inicio una etapa de fortalecimiento comercial ingresando a El Salvador, comenzando así la captación de clientes internacionales, alienados a este crecimiento la empresa vio la necesidad de ofrecer nuevos servicios y capacitar a su personal en las normativas eléctricas internacionales, actualmente Hamek Ingenieros Asociados S.A.C., mantiene servicios con Chile y EI Salvador.

Dada la coyuntura interna y externa, la empresa en estudio decidido redefinir su visión y misión

En cuanto a sus valores de Hamek Ingenieros Asociados S.A.C., estas se encuentran definida de manera expresa y formal, sin embargo, estas no se encuentran enmarcados de manera organizacional que genere identidad corporativa hacia el grupo de interés.

Para el análisis de la Visión, Misión y Valores hemos utilizado el esquema teórico del autor Fred R. David (2013), y los criterios de evaluación del autor Fernando D’Alessio (2014).

\subsection{Visión}

De acuerdo a D’Alessio (2014):

" La visión de una empresa es la definición que desea para su futuro e implica una respuesta a la pregunta ‘¿Qué queremos llegar a ser?’. Así, puede decirse que la visión es una percepción o imagen clara de lo que una organización espera lograr en el mediano y largo plazo". 
Una visión bien definida se compone de dos partes: una ideología central y una visión de futuro, asimismo debe cumplir con características específicas.

1. La Ideología central: Fuente de inspiración que define el carácter duradero de una empresa.

Sobre la ideología central: La empresa enfatiza una orientación al desarrollo de sus servicios con alta orientación al cuidado del medio ambiente, basado en un eficiente uso energético.

2. Visión de futuro: Se debe enunciar la visión en tiempo verbal futuro.

La empresa sostiene que desea alcanzar el liderazgo en la consultoría nacional en los temas de energía y medio ambiente con presencia destacada en el ámbito internacional.

3. Características de la visión: a) simple, clara y comprensible; b) ambiciosa, convincente, y realista; c) definida en un horizonte de tiempo, que permite los cambios; d) proyectada a un alcance geográfico, e) conocida por todos, f) expresada de tal manera que permita crear un sentido de urgencia y g) una idea clara desarrollada sobre adonde desea ir la organización.

\subsubsection{Visión actual de la empresa.}

La Visión actual de Hamek Ingenieros Asociados S.A.C., declarada desde el 2014 se detalla a continuación:

“Alcanzar el liderazgo en la consultoría nacional en los temas de energía y medio ambiente con presencia destacada en el ámbito internacional."

\subsubsection{Análisis de la visión actual.}

Considerando la información descrita en los numerales anteriores y tomando como base los criterios propuestos por D’Alessio (2014) para la evaluación de una visión, se obtuvo las siguientes observaciones respecto a la visión de Hamek Ingenieros Asociados S.A.C.

1. Sobre la ideología central: La empresa remarca que desea alcanzar el liderazgo en consultoría nacional, esta precisión determinada por la empresa si se encuentra dentro del propósito que persigue la empresa.

2. Sobre el término "temas de energía y medio ambiente", los alcances en bastante amplio pues en ambos sectores existen múltiples servicios de los que Hamek Ingenieros Asociados S.A.C., no realiza y no es de su especialidad. 
3. Sobre la visión futuro: la empresa manifiesta proyectarse a un mercado internacional, pero no señala un alcance geográfico, ni horizonte de tiempo en que se lograra. De acuerdo, a los servicios mostrados en su página web los servicios de Hamek Ingenieros Asociados S.A.C., también hacen presencia en EI Salvador y Chile. Con ello podemos concluir que la empresa tiene como mercado objetivo los países en Latinoamérica.

4. Sobre las siete características de la visión: se han establecido ponderaciones y calificaciones para evaluar el nivel de cumplimiento de las características citadas por el autor. Del análisis realizado se concluye que la visión actual muestra un nivel de cumplimiento de 1.8 sobre un rango de $1 \mathrm{a}$ 4, lo que da como resultado $38 \%$. Las características que muestran la calificación más baja son (a) horizonte de tiempo, (b) alcance geográfico y (c) el sentido de urgencia: mientras que la muestra la calificación más alta es simple, clara y comprensible. Los resultados se detallan en la siguiente tabla.

Tabla 7

Criterios para Evaluar la Visión Actual

\begin{tabular}{lccc}
\hline Características & Ponderación & Calificación & $\begin{array}{c}\text { Calificación } \\
\text { ponderada }\end{array}$ \\
\hline Simple, Clara y comprensible & 0.2 & 2 & 0.4 \\
Ambiciosa, convincente y realista & 0.2 & 2 & 0.4 \\
Definida en un horizonte de tiempo que & 0.1 & 1 & 0.1 \\
permita los cambios & & 2 & 0.2 \\
Proyectada en un alcance geografico & 0.1 & 1 & 0.2 \\
Conocida por todos & 0.2 & 1 & 0.1 \\
Expresada de tal manera que permita & 0.1 & 2 & 0.4 \\
crear un sentido de urgencia & & & \\
Una idea clara desarrollada sobre a & & & \\
donde desea ir la organización & & & \\
\hline \multicolumn{1}{c}{ TOTAL } & & & \\
\hline
\end{tabular}

Nota. Elaboración propia 
3.1.3. Matriz de la visión para la empresa.

Para la elaboración de la matriz de la Visión para Hamek Ingenieros Asociados S.A.C. se tomó en cuenta los criterios de evaluación de la visión propuesta detallados a continuación (ver Tabla 8):

Tabla 8

Descripción de Criterios para la Evaluación de la Visión Propuesta

\begin{tabular}{|c|c|c|}
\hline Características & Descripción & Check List \\
\hline Simple, Clara y comprensible & $\begin{array}{l}\text { Concreta pero con mucho significado. Que sea } \\
\text { entendida por todos los grupos de interes. }\end{array}$ & \\
\hline \multirow[t]{3}{*}{ Ambiciosa, convincente y realista } & Que implusa a seguir adelante en el logro de objetivos. & \\
\hline & Que cuenta con argumentos que respaldan. Que se & \\
\hline & pueda visualizar y describir como existente, y sea alcanzable. & \\
\hline Definida en un horizonte de tiempo & Con plazosdeterminados que consideren los cambios & \\
\hline que permita los cambios & requeridos. & \\
\hline Proyectada en un alcance geográfico & Considerar el alcance geográfico de la empresa & \\
\hline Conocida por todos & Que sea replicable y difundida a todos los niveles & \\
\hline Expresada de tal manera que permita & Que llame a la toma de acción. & \\
\hline crear un sentido de urgencia & & \\
\hline Una idea clara desarrollada sobre a & Que marque el rumbo. & \\
\hline
\end{tabular}

Nota. Elaboración propia.

\subsubsection{Visión propuesta.}

Respecto a la visión propuesta, se elaboró teniendo en cuenta los criterios detallados en la Tabla 8 y que aplican a la definición siguiente:

Al 2021, mantener el liderazgo en el Perú como consultora especialista en energía y medio ambiente. Ampliar la presencia en el Salvador y Chile. 


\subsection{Misión}

David (2013) define la misión de la siguiente manera:

La declaración de la misión es la expresión perdurable del propósito que distingue a una organización de otras empresas similares; es la declaración de la razón de ser una organización y la respuesta a la pregunta ¿Cuál es nuestro negocio? Una declaración de misión es esencial para establecer los objetivos y formular estrategias de manera efectiva. (p.44)

Asimismo, D’Alessio (2014), define a una misión de una empresa como, "la forma en que aspira servir a la sociedad, tener las herramientas necesarias para hacer posible el crecimiento y diferenciar a la empresa de los demás".

Una buena declaración de misión debe poseer las siguientes características:

- Amplia en alcance para permitirla creatividad de sus gerentes.

- Clara en definir que es la organización y que aspira ser

- Generadora de la impresión que la organización goza de éxito, tiene rumbo y es merecedora de apoyo e inversión.

- Debe ser capaz de excluir iniciativas riesgosas, pero a la vez flexible para permitir un trabajo creativo.

- Contundente para distinguir a la organización del resto.

- Un marco para evaluar actividades actuales y futuras.

- Enunciada en términos suficientemente claros para que pueda ser atendida ampliamente en toda la organización.

- Proveedora de criterios para ayudar a la selección de estrategias.

- Reconciliación de los grupos de interés.

- Genere emociones y pensamientos positivos.

- Motivadora

- Relacionada con la gestión operativa de la organización

- Dinámica en orientación

- Transmisora de la responsabilidad social de la organización

\subsubsection{Misión actual de la empresa.}

A continuación, presentamos la Misión que plantea Hamek Ingenieros Asociados S.A.C, declarada desde el 2012. 
"Superar las expectativas de nuestros clientes en todos los servicios de consultoría que brindamos en los temas de energía y medio ambiente, aplicando una ingeniería y tecnología de punta, conservando en nuestro personal una mística de innovación, superación continua y compromiso con el desarrollo sustentable de nuestro país". (Hamek Ingenieros Asociados S.A.C., 2012)

\subsubsection{Análisis de la misión actual.}

Si bien la misión de la empresa posee parte de los elementos y características indicados por D‘Alessio (2014) y David (2013) como por ejemplo, detallar claramente los objetivos, y como llegar a ello, no termina por completar todos los aspectos mencionados por D‘Alessio para finalmente tener una misión integral. La misión es resumida, y no considera elementos trascendentales como la descripción del negocio.

En la tabla 9 se han establecido ponderaciones y calificaciones para evaluar el nivel de cumplimiento de las características indicadas por D’Alessio.

Del análisis realizado se concluye que la misión actual muestra un nivel de cumplimiento de 3.08 sobre un rango de 1 a 4 , lo que da como resultado $77 \%$. El aspecto que muestra la calificación más baja es: productos y servicios y la calificación más alta es: tecnología, filosofía de la organización, auto concepto de la organización y preocupación por la imagen pública.

Los resultados se detallan a continuación. 
Tabla 9

Criterios para Evaluar la Evaluación de la Visión Actual

\begin{tabular}{lccc}
\hline Características & Ponderación & Calificación & $\begin{array}{c}\text { Calificación } \\
\text { ponderada }\end{array}$ \\
\hline Clientes - consumidores & 0.12 & 3 & 0.36 \\
Productos o servicios & 0.12 & 2 & 0.24 \\
Tecnologías & & 4 & 0.40 \\
Objetivos de la organización: & 0.10 & 3 & 0.36 \\
Supervivencia, crecimiento y rentabilidad & 0.12 & 4 & 0.48 \\
Filosofía de la organización & & 4 & 0.40 \\
Auto concepto de la organización & 0.12 & 3 & 0.36 \\
Preocupación de la imagen pública & 0.10 & 4 & 0.48 \\
Preocupación de los empleados & 0.12 & & 3.08 \\
\hline TOTAL & 0.12 & 4 & \\
\hline
\end{tabular}

Adaptado de El proceso Estratégico Razonada. Un enfoque de Generación ( $p$ 63), por F, D'alessio 2014. Lima, Perú: Copyring 2014 Por Pearson Educación de Perú S.A. *Calificación 1 - 4, donde 4 es mayor fortaleza y 1 menor debilidad. Nota. Elaboración propia.

\subsubsection{Elementos de la misión para la empresa.}

A continuación, se describen los componentes según D'Alessio, y su desarrollo al analizarlos al interior de Hamek Ingenieros Asociados S.A.C. (ver Tabla 10). 
Tabla 10

Componentes para la Elaboración de la Misión

\begin{tabular}{|c|c|c|}
\hline Características & Pregunta Clave & Hamek \\
\hline Clientes - consumidores & ¿Quiénes son los clientes de la empresa? & $\begin{array}{l}\text { El Sector de energía, minas, vivienda, } \\
\text { turismo, petróleo, pesquero y producción. }\end{array}$ \\
\hline Productos o servicios & $\begin{array}{l}\text { ¿Cuáles son los principales productos o } \\
\text { servicios que ofrecen la empresa }\end{array}$ & $\begin{array}{l}\text { Área de Energía: Estudios y pruebas de Operatividad } \\
\text { de Centrales generadoras, estudios de costos de } \\
\text { mantenimiento. } \\
\text { Área Ambiental: Instrumentos de Gestión Ambiental, } \\
\text { Monitorios ambientales, Estudios de Riesgos y Planes } \\
\text { de Contingencia. }\end{array}$ \\
\hline Mercado & $\begin{array}{l}\text { Término geográficos ¿En donde } \\
\text { compite la empresa? }\end{array}$ & A nivel Nacional, e Internacional (El Salvador y Chile). \\
\hline Tecnologías & $\begin{array}{l}\text { ¿La empresa está al día desde el punto } \\
\text { de vista tecnológico }\end{array}$ & Tecnología de última generación \\
\hline $\begin{array}{l}\text { Preocupación por la } \\
\text { supervivencia el crecimiento } \\
\text { y rentabilidad. }\end{array}$ & $\begin{array}{l}\text { ¿La empresa está comprometida } \\
\text { con el crecimiento y la solidez financiera? }\end{array}$ & $\begin{array}{l}\text { Comprometidos con el objetivo de crecer generando } \\
\text { utilidades, basados con un trabajo en equipo, buscando } \\
\text { un crecimiento sostenibles. }\end{array}$ \\
\hline Filosofía de la organización & $\begin{array}{l}\text { ¿Cuáles son las creencias valores, aspiraci } \\
\text { prioridades éticas basadas en la empresa }\end{array}$ & $\begin{array}{l}\text { Espíritu de Servicio, responsabilidad, honestidad } \\
\text { y trabajo en equipo. }\end{array}$ \\
\hline Auto concepto de la organización & ¿Cuál es la ventaja competitiva? & Especialistas en Energía y Medio Ambiente. \\
\hline Preocupación por los empleados & $\begin{array}{l}\text { ¿Sus colaboradores son un activo } \\
\text { valioso para la empresa }\end{array}$ & $\begin{array}{l}\text { Reconoce a sus colaboradores como un valor } \\
\text { fundamental para lograr los objetivos. }\end{array}$ \\
\hline
\end{tabular}

Nota. Adaptado de Conceptos de Administración Estratégica (p.24), por F. D'Alessio 2014. Lima, Perú: Copyring 2014 por Pearson Educación.

\subsubsection{Misión propuesta.}

Tomando en consideración los criterios desarrollados en la tabla 11, conceptos tomados en cuenta por D’Alessio (2014), a continuación, presentamos la misión propuesta.

"Somos una empresa peruana privada tenemos como misión, contribuir al desarrollo del Perú y de los países donde Hamek Ingenieros Asociados S.A.C tiene presencia a través del uso eficiente de la energía, preservando el medio ambiente y al desarrollo sostenible del país basándose en la calidad de sus servicios".

\subsection{Valores}

D’Alessio (2014) indica que los valores de una organización son políticas y directrices que norman y encaminan el desempeño de sus funcionarios y establecen el 
patrón de actuación que guía el proceso de toma de decisiones. Los valores determinan la filosofía de la organización al representar claramente sus creencias actitudes, tradiciones y su personalidad, Así mismo los valores son indispensables para (a) moldear los objetivos y propósitos, (b) producir las políticas y (c) definir las intenciones estratégicas.

Para Chiavenato (2009), los valores se transmiten en todos los niveles de las relaciones humanas como el interpersonal, el organizacional, el cultural, el psicológico, el sociológico y el político económico. Asimismo, estos valores son comunicados en las organizaciones a través de diferentes acciones, como:

- Planes de Inducción

- Capacitaciones y desarrollo de personal

- Las recompensas

- Las sanciones

- Lo que se dice al no admitir la responsabilidad de los actos

- Lo que se calla cuando surgen problemas

- Lo que se hace cuando existe angustia por la criticas

- $\quad$ Lo que no se hace al evitar discutir problemas importantes

- Congruencias o hipocresía, cuando no se hace lo que se dice.

Cuando una organización no tiene valores definidos, puede ocasionar conflictos y inestabilidad dentro del ámbito laboral, por ello los valores de una empresa deben ser expuestas, explicados y reafirmarlo.

Las empresas poseen culturas organizacionales particulares, determinadas por el entorno socioeconómico, político, legal, los códigos de conducta, políticas de trabajo, entre otros. Estas culturas se caracterizan por compartir valores que determinan el comportamiento de la organización. (Chiavenato, 2009)

La matriz de las cuatro culturas corporativas de Mc Donald y Gandz (como se cita en Chiavenato, 2009) analiza cuatro variables tales como flexibilidad versus estabilidad y enfoque interno versus enfoque externo, donde cada cuadrante especifica un tipo de cultura corporativa y los valores dominantes que la caracterizan (ver Figura 14). 


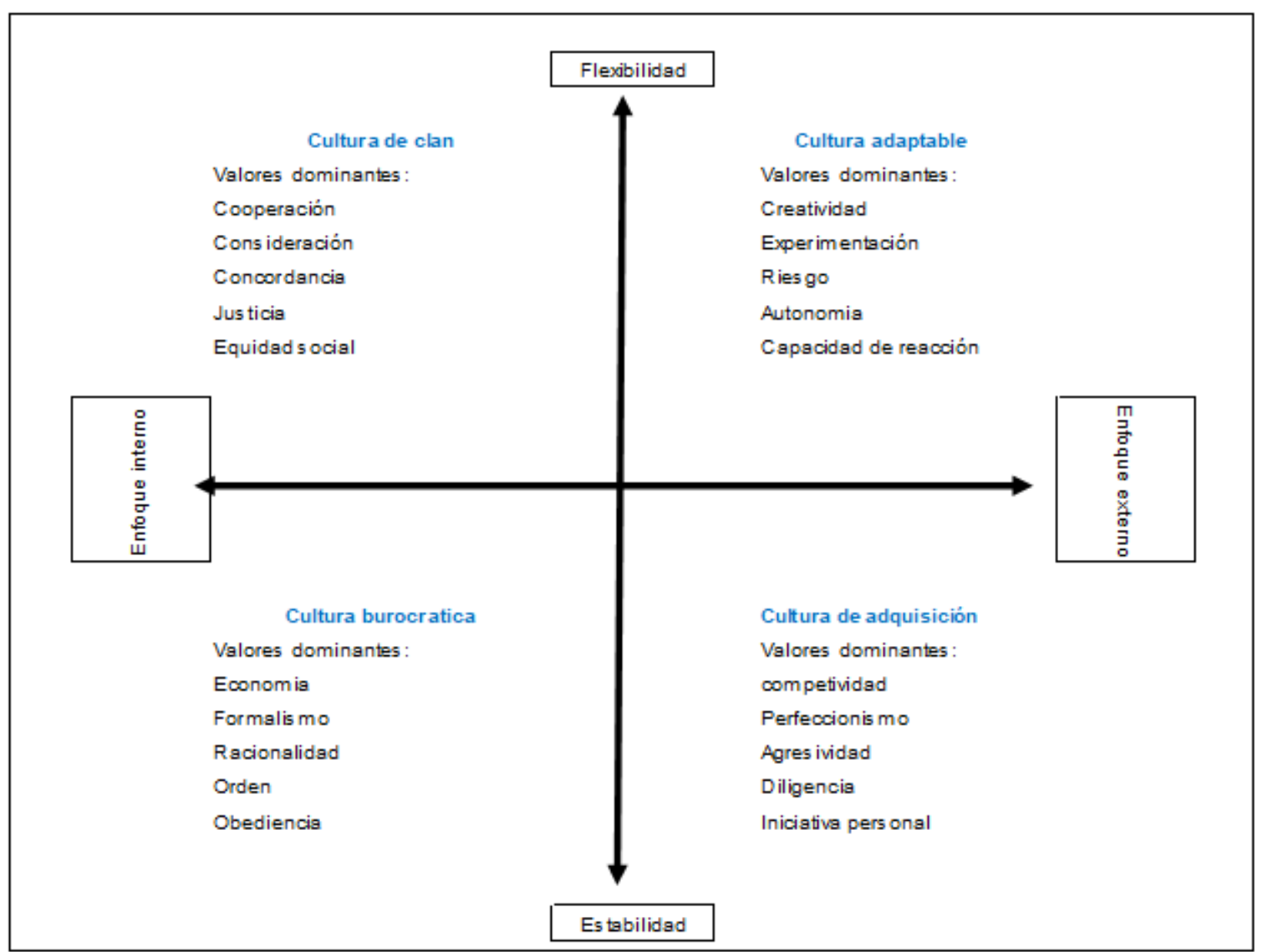

Figura 14. Las cuatro culturas corporativas. Tomado de "Comportamiento Organizacional” (p 136) por I. Chavenato, 2009. Copyright 2009 por Mc Graw Hill.

Otra forma de clasificar los valores corporativos es a través de la generación: en tal sentido Robbins y Judge (2013) muestran clasificación de valores dominantes según la generación de la fuerza laboral. 
Tabla 11

Valores Dominantes en la Fuerza Laboral Actual

\begin{tabular}{|c|c|c|c|}
\hline Genaración & $\begin{array}{l}\text { Época de ingreso a } \\
\text { fuerza laboral }\end{array}$ & $\begin{array}{l}\text { Edad actual } \\
\text { aproximada }\end{array}$ & $\begin{array}{l}\text { Valores laborales } \\
\text { dominantes }\end{array}$ \\
\hline \multirow[t]{2}{*}{ Baby boomers } & 1965 a 1985 & Entre 45 y 65 & Éxito, logro, ambición, disgusto \\
\hline & & 65 años & por la autoridad, lealtad a la carrera. \\
\hline Generación X & 1985 a 2000 & Entre 28 y 42 años & $\begin{array}{l}\text { Equilibrio entre el trabajo y su vida personal, } \\
\text { orientado a los equipo, no les gustan las reglas, } \\
\text { lealtad en las relaciones. }\end{array}$ \\
\hline Milenarios & De 2000 a las & Menos de 30 años & $\begin{array}{l}\text { Dignos de confianza, éxito financiero, confianza } \\
\text { y lealtad hacia ellos y el equipo. }\end{array}$ \\
\hline
\end{tabular}

Nota. Adaptado de Comportamiento Organizacional (p. 146) por Robbins y Judge (2013), copyringht 2016 por Pearson Educatión.

El modelo de las siete "s" de Pascal y Athos (como se cita en Chiavenato, 2009) muestra los elementos de la organización que tienen relación directa y bidirección con los valores empresariales, y la importancia de su alineamiento. Es así que la identificación de los valores compartidos es el punto inicial si la organización se plantea redefinir alguno de sus elementos, dado que deberá mantener la concordancia. 


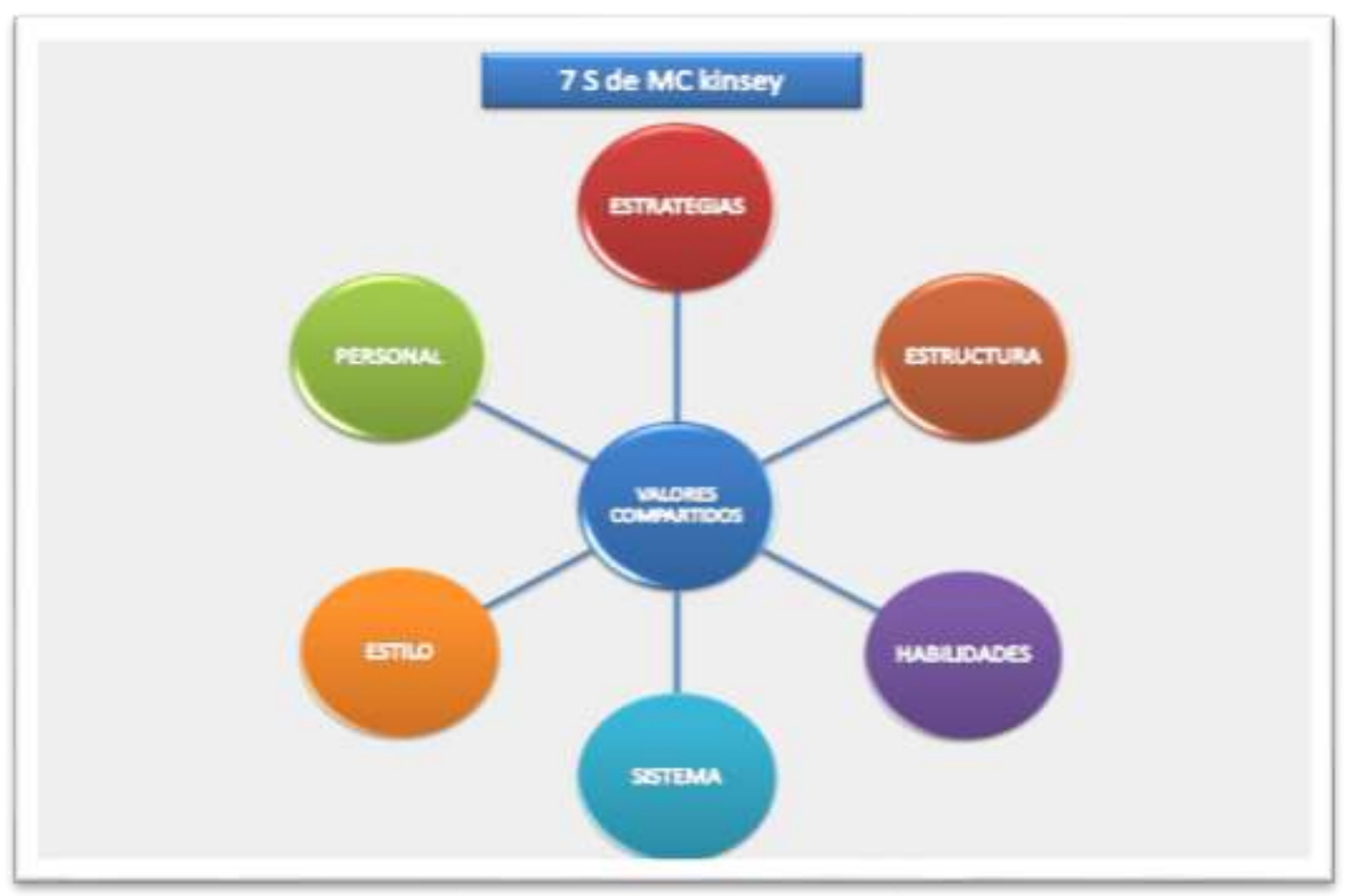

Figura 15. Valores básicos y modelo de la organización de las 7 "s" adaptado de "Comportamiento Organizacional" (p.134) por I. Chiavenato, 2009. Copyright 2009 por Mc Graw Hill.

\subsubsection{Valores actuales de la empresa.}

Actualmente, los valores que se promueven dentro de Hamek Ingenieros Asociados S.A.C. son: Espíritu de servicio, responsabilidad, honestidad y trabajo en equipo.

\subsubsection{Análisis de los valores actuales.}

Se realizará un análisis de los valores que actualmente tiene Hamek Ingenieros Asociados S.A.C, y en base a ello se presentará una nueva propuesta.

\subsubsection{Elementos de los valores propuestos para la empresa.}

A continuación (ver Tabla 12) se muestran los factores a considerar para conocer la importancia de los valores que es, dentro de una organización. 
Tabla 12

Factores para el Desarrollo de Valores

\begin{tabular}{ll}
\hline \multicolumn{1}{c}{ Factor } & \multicolumn{1}{l}{ Pregunta Clave } \\
\hline Significación & ¿Qué significado tienen los valores? ¿Qué los hace tan importantes? \\
Universalidad & ¿Qué podria ocurrir si nadie respeta los vaores? \\
Liderazgo & ¿Qué podria ocurrir si alguien se apega a determinados valores? \\
Reciprocidad & ¿Cómo se sentiria una persona si esta norma le fuese aplicada? \\
Publicidad & ¿Qué justificarian otras personas esa acción? \\
Defensa & ¿Si una persona asumiese la responsabilidad de un accion o falta \\
Responsabilidad & ¿Es posible intuir que una acción o la falta de ellas es correcta o incorrecta? \\
\hline Intuición & Las consecuencias de una acción o la falta de ella generaciones futuras. \\
\hline
\end{tabular}

Adaptado de Comportamiento Organizacional (p. 134) por I. Chiavenato, 2009.

Nota. Elaboración propia.

\subsubsection{Valores Propuestos.}

De los análisis de los factores indicados en la Tabla 12; alineados a la visión y misión propuesta se determinaron los valores que ajustan mejor a la cultura de la empresa, estos son los descritos a continuación:

- Responsabilidad

- Superación

- Innovación

- Compromiso con el cliente,

- Calidad

Para cada uno de los Valores propuestos hecho una descripción teniendo en cuentas las definiciones de Chiavenato (2009) (ver Tabla 13). 
Tabla 13

Descripción de Valores Propuestos

\begin{tabular}{|c|c|}
\hline Valores & Descripción \\
\hline Responsabilidad & $\begin{array}{l}\text { Obligación de desarcir las consecuencias desivas para los derechos o intereses } \\
\text { de otras personas derivadas de la actuacion propia o ajena, bien se deriven } \\
\text { aquellas del incumplimiento de contratos o biende daños producidos por simple } \\
\text { culpa o negligencia. (Diccionario Real Academia Española) }\end{array}$ \\
\hline Superación & $\begin{array}{l}\text { La superación personal es un interesante proceso } \\
\text { de crecimiento en todos los ámbitos o áreas de la } \\
\text { vida de una persona. } \\
\text { (Florelis Valenzuela Cordova. 2003) }\end{array}$ \\
\hline Innovación & $\begin{array}{l}\text { La innovación es como la introducción } \\
\text { de un nuevo o significativamente mejorado producto (bien o servicio), de un } \\
\text { proceso, de un nuevo método de comercialización, o de un nuevo método } \\
\text { organizativo en las prácticas internas de la empresa, la organización del lugar de } \\
\text { trabajo o de las relaciones exteriores. (Manuel de Oslo, 2005). }\end{array}$ \\
\hline $\begin{array}{l}\text { compromiso con el } \\
\text { cliente }\end{array}$ & $\begin{array}{l}\text { Es la capacidad de anticiparse para identificar cuales son las necesidades del } \\
\text { cliente y encontrar la forma de ofrecer un producto y/o servicio que no solo cubra } \\
\text { esas necesidades de forma efectiva sino que además, supere las expectativas. } \\
\text { (Empresariados, 2016). }\end{array}$ \\
\hline Calidad & $\begin{array}{l}\text { Propiedad o conjunto de propiedad inerente a algo que permiten juzgar su valor. } \\
\text { (Diccionaria Real Academia Española) }\end{array}$ \\
\hline
\end{tabular}

Nota. Elaboración propia.

\subsection{Alineamiento estratégico de la Visión, Misión y Valores de la empresa.}

Como resultado de la investigación cualitativa realizada a la empresa Hamek Ingenieros Asociados S.A.C. y en base a diferentes bibliografías, se ha evaluado la visión, misión y valores que actualmente tiene la empresa en estudio, y sea procedido a proponer formalmente los lineamientos estratégicos para que la cultura organizacional está basada en valores, para que la misión sea viva y la visión se haga realidad. 
Tabla 14

Relación de los Valores Organizacionales con la Misión y Visión

\begin{tabular}{|c|c|c|}
\hline Valores & Misión & Visión \\
\hline & $\begin{array}{l}\text { Ser reconocidos en el mercado nacional e internacional, se } \\
\text { consigue con un equipo humano que sepa tomar decisiones } \\
\text { responsables de manera consciente. }\end{array}$ & $\begin{array}{l}\text { El logro de los servicios de alta calidad, se consigue con un equipo } \\
\text { humano responsable y que tome decisiones coherentes. }\end{array}$ \\
\hline \multicolumn{3}{|l|}{ Responsabilidad } \\
\hline Superación & $\begin{array}{l}\text { En una cultura de organizacional basada en la confianza, } \\
\text { responsabilidad y conducta etica, motiva a los colaboradores } \\
\text { a trabajar con eficacia, eficiencia e innovación. }\end{array}$ & $\begin{array}{l}\text { El contar con una cultura organizacional, permitirá convertirnos en } \\
\text { lideres en consultoria en energía y medio ambiente. }\end{array}$ \\
\hline Innovación & $\begin{array}{l}\text { El personal debe estar en una busqueda constante de } \\
\text { impulsar nuevas lineas de servicios y mejora de los } \\
\text { procesos. aprendizaje y adaptacion ante escenarios } \\
\text { cambiantes, buscando innovar y mejorar procesos. }\end{array}$ & $\begin{array}{l}\text { La busqueda constante de las mejoras de los procesos y nuevas } \\
\text { lineas de servicios, se bsucara reconocimiento, dandole mayor valor } \\
\text { a la empresa y con ello liderar a nivel nacional e ingresar a otros } \\
\text { mercados buscando asi tambien ser lider a nivel internacional. }\end{array}$ \\
\hline $\begin{array}{l}\text { Compromiso con el } \\
\text { cliente }\end{array}$ & $\begin{array}{l}\text { Los colaboradores deben mostrar una amplia vocación de } \\
\text { servicio hacia sus clientes en cada acción que realizan; esto } \\
\text { involucra cubrir las expectativas de los clientes. }\end{array}$ & $\begin{array}{l}\text { Toda empresa líder se caracteriza por comprometerse con los } \\
\text { servicios ofrecidos, buscando siempre superar las expectativas de } \\
\text { los clientes. }\end{array}$ \\
\hline Calidad & $\begin{array}{l}\text { Tener servicios con altos estandares de calidad, se logra con } \\
\text { una cultura de superación constante. }\end{array}$ & $\begin{array}{l}\text { Toda organizacion líder se caracteriza por ofrecer alta calidad en los } \\
\text { servicios brindados; por tanto, el compromiso con el cliente es clave } \\
\text { para alcanzar el liderazgo. }\end{array}$ \\
\hline
\end{tabular}

Nota. Elaboración propia

En cuanto al alineamiento de la misión, visiones propuestas podemos precisar lo siguiente:

1. Al ser una empresa consultora especialista en energía y medio ambiente trabajando siempre por superar las expectativas del cliente (Misión), permitirá que la empresa para el 2022 pueda ser reconocida a nivel nacional e internacional. (Visión)

2. La cultura de innovación y trabajo con equipos en última generación (Misión), fortalecerá y brindará mayor garantía a nuestros clientes, permitiendo así ser reconocidas a nivel nacional e internacional (Visión)

3. Conservar la mística de innovación, superación continua y compromiso con el desarrollo sustentable de nuestro país (Visión), fortalece y afianza la imagen corporativa, buscando así el reconocimiento a nivel nacional e internacional (Visión). 


\section{Capítulo IV. Análisis Externo}

En el presente capitulo, se realizará un análisis de cómo afectan las variables externas, y comprender el entorno en que actúa la empresa, para poder identificar y evaluar las oportunidades y amenazas externas, que permita a la empresa Hamek Ingenieros Asociados S.A.C., elaborar un plan estratégico para tomar decisiones de inversión, lograr los objetivos a largo plazo y establecer políticas para lograr objeticos anuales.

El objetivo en el presente capítulo es identificar y analizaran las tendencias que puedan afectar o beneficiar a la empresa. Dentro de los factores de influencia se tiene a las variables Políticas, Económicas, Legales, Tecnológicas, Culturales y Ecológicas, habiéndose realizado, a partir de investigaciones y de las opiniones de los expertos consultados, buscando poder identificar todos los factores externos claves que afecten o podrían afectar para la propia empresa, determinando finalmente si se comportan como oportunidad o amenaza.

La empresa no puede ejercer ningún tipo de influencia ni control ante las variables externas.

Este análisis permite que la empresa Hamek Ingenieros Asociados S.A.C., se encuentre preparada y pueda aprovechar las oportunidades que se presenten y tratar de mitigar las amenazas.

Al final del capítulo se desarrolla la Matriz de Evaluación de Factores Externos EFE, siguiendo la metodología propuesta por Fred R. David (2013), la misma que permitirá identificar las oportunidades y amenazas, ya sea para aprovecharlas en beneficio de la empresa o, de lo contrario, para disminuir sus consecuencias y poder hacerle frente a cada una de estos factores externos.

\subsection{Tendencias de las variables del entorno}

De acuerdo con David (2013) "la matriz de evaluación de factores externos (EFE) permite que los estrategas resuman y evalúen información económica, social, cultural, demográfica, ambiental, política, gubernamental, legal, tecnológica y competitiva” (p. 80).

En este capítulo se analizarán las tendencias en las variables del entorno en los aspectos Político, Económicos, Legal, Social, Tecnológico y Ecológico, que podrían afectar a Hamek Ingenieros Asociados S.A.C., con el fin de considerar acciones y 
estrategias adecuadas para aprovechar oportunidades y afrontar las amenazas a las que se enfrenta.

Al final del capítulo se desarrolla la Matriz de Evaluación de Factores Externos EFE, la misma que le permita identificar la posición de la empresa, utilizando una estrategia que les permita hacerle frente a cada una de estos factores externos.

\subsubsection{Análisis Político-Gubernamental.}

Entre los años 2017 y 2018, el Perú experimento una inestabilidad política; destacando escándalos de corrupción de la empresa brasileña Odebrecht, el indulto a Alberto Fujimori y la renuncia de Pedro Pablo Kuczynski. (El Comercio, 2018). Finalmente asume la presidencia, Martin Vizcarra, anteriormente primer vicepresidente de la República, quien encuentra el país en una grave crisis institucional.

Como señala Mongilardi (2017) "la inestabilidad política tiene un impacto negativo en la imagen del país, en la actividad económica y en la inversión privada, dando lugar a un menor empleo y a una posible reducción de la calificación de riesgo país". Se concluye que la inestabilidad política reduce la inversión en los diferentes sectores del país, con un riesgo de paralización de proyectos de inversión.

Es importante precisar que el Estado es el accionista mayoritario de 34 empresas nacionales, 12 empresas del sector de energía, todas ellas agrupadas en el Fondo Nacional de Financiamiento de la Actividad Empresarial del Estado (FONAFE). El FONAFE está dirigido por cinco ministros, además dirige y norma la actividad empresarial del Estado y aprueba el presupuesto. (FONAFE, 2018).

Ejerce las representaciones de la titularidad de las acciones, de las que es propietario el Estado, ante la junta generales de accionistas, por lo tanto, cuando los gobiernos cambian, sus políticas económicas y decisiones, pueden llevar a limitaciones de financiamiento, ejecuciones e inversiones de proyectos.

Con la reforma de la industria eléctrica peruana se eliminó el monopolio que ejercía el Estado sobre la generación y venta de energía, lo que llevo a realizar tres actividades de forma independiente: Generación, Transmisión y Distribución.

-La Generación, se encargan de abastecer de energía y de la producción, utilizando las fuentes hibridas y térmicas. Es realizada por empresas privadas y del estado. 
-La Transmisión, tiene como misión trasferir la energía desde la generadora hasta el cliente. Es realizado por empresas privadas y estatales con menor participación.

-Distribución, son las encargadas de recibir energía eléctrica de las generadoras y de las transmisoras y entregarlas al usuario final. Son realizadas por empresas mayormente privadas.

Producto de esta reforma, el Gobierno se limitó a cumplir una función normativa, supervisora y de fijación de tarifas. Es a partir de este contexto que la, Ley de Concesiones Eléctricas define los roles que debe cumplir el Ministerio de Energía y Minas (MEM) como formulador de política energética, el Organismo Supervisor de la Inversión en Energía y Minería (OSINERGMIN) como ente regulador de tarifas, y el Comité de Operación Económica de Sistema (COES) como operador del despacho del sistema eléctrico. Adicionalmente, resalta la función que cumple la Agencia de Promoción de la Inversión Privada del Perú (PROINVERSIÓN), la cual promueve la inversión de las compañías privadas en el país. (Equilibrium Clasificadora de Riesgo S.A., 2018).

Existe inferencia en el sector eléctrico por el COES, debido que las empresas consultoras dependen de sus normas, las pruebas se realizan por el tiempo que el ente regulador lo decide, los cambio que realiza hace que las empresas se ajusten a sus normas. Tiene participación en la adjudicación de servicios, las empresas dependen de sus normativas, si decide ser menos exigente o cambiar sus normas, sería una amenaza para las empresas que se encuentran inscritas.

El ministro de Energía y Minas, Francisco Ismodes, aseguro que el Gobierno impulsara políticas para aumentar la participación de la energía renovable y las inversiones en el sector. En agosto del 2018, hubo una participación del $4.4 \%$ en las renovables en generación de energía dentro del Sistema Interconectado Nacional (SIN) y el Gobierno se ha fijado alcanzar para el 2030 un 14\%, el cual está estimulando la inversión en proyectos renovables, con el fin de mejorar la competitividad frente a otras tecnologías de generación convencional, lo cual entrara en discusión para que definan la nueva normativa.

Las Generadoras de RER aún no producen una cantidad significativa de la energía del mercado, por lo que el Gobierno se encuentra trabajando en un proyecto de reforma al marco regulatorio de los Recursos Energéticos Renovables, con el objetivo de permitir que las generadoras RER puedan participar libremente en el mercado local, Según lo manifestado por el MEM, el Gobierno espera instalar 260,000 paneles solares en zonas del país que requieren electricidad hacia el 2021. Las energías renovables son 
intensivas en mano de obra, sirven para estimular la economía del país, nos ayudan a ser competitivos y sostenibles, contribuyen a mitigar los efectos del cambio climático, contribuyen a diversificar la matriz energética del país.

Actualmente se necesita una política de Estado para el desarrollo de la energía, para promocionar la generación hidroeléctrica, eólica, a gas natural, geotérmico, solar y bioenergética, así como la eficiencia energética.

En la región Latinoamericana, la corrupción política ha estado en varios países de la región, en Bolivia con movilizaciones masivas, por la cuarta candidatura de Evo Morales, y en Chile comenzó en el 2018 un gobierno de coalición de centro derecha que llevo a Sebastián Piñera a la presidencia por segunda vez.

Países como Brasil, Chile, México, Perú y otros, miembros de la Alianza de Energía y Clima de las Américas ya han iniciado el cambio hacia una economía menos intensa energéticamente, aprovechando sus abundantes recursos renovables. Chile ha logrado eficiencia energética a través de reformas, sin embargo, aún existen retos estructurales, como los cambios en el sistema regulador.

La integración energética en América Latina es inadecuada, la región necesita agregar líneas de transmisión transfronterizas con unos 14.000 kilovatios de electricidad para aprovechar realmente su potencial, siendo el principal obstáculo que impide esta integración es político, los países latinoamericanos deberían aprovechar las ventajas que les ofrece la diversificación en el suministro eléctrico e interconectarse (Nytimes, 2019).

En los países de Centroamérica, Nicaragua y Guatemala enfrentan crisis políticas e institucionales de diferentes orígenes. El mercado eléctrico en Centroamérica busca comercializar la energía, por lo que es un tema político, de negociación entre los países. Centroamérica se beneficiaría si logra ampliar su red regional, pues en el istmo los precios de la electricidad son altos y su generación depende de petróleo importado. Para alentar las inversiones, el marco regulatorio del mercado eléctrico regional debe fortalecerse. Entre otras cosas, debe determinarse el costo de los derechos de transmisión y de las cuotas aplicables al envío de electricidad a través de las fronteras. (Viscidi, 2018).

Estas medidas son técnica y económicamente posibles, pero requieren que los gobiernos actúen en contra de algunos intereses y cedan cierto control sobre sus sistemas eléctricos nacionales. 


\subsubsection{Análisis Económico.}

A continuación, se analizarán los principales indicadores macroeconómicos del Perú.

\section{Producto Bruto Interno (PBI).}

La economía peruana ha presentado dos fases de crecimiento, entre el 2002 y 2013, el Perú se distinguió como uno de los países de más alto dinamismo en América Latina, con una tasa de crecimiento del PBI 6.1\% anual. Entre el 2014 y 2017, la economía se desaceleró, por la caída de comodities, como el cobre que es uno de los principales productos que exporta nuestro país. Para el 2018, se espera una aceleración del PIB basada en el aumento de la inversión privada, un impulso de la inversión pública, a través de la ejecución de las obras de reconstrucción de los daños causados por el Fenómeno del Niño y la vinculada a los Juegos Panamericanos que el Perú albergará en el 2019. (Banco Mundial, 2018).

EI PBI registro un crecimiento de $2.4 \%$ al cierre del 2017. Podemos observar (Ver Figura 16) que en el primer trimestre en el 2018 el comportamiento del PBI, que fue publicado por el Instituto Nacional de Estadística e Informática fue de 3.2\%, en comparación con el trimestre del 2017 que fue 2.3\%, el cual se debió al incremento en el consumo, la inversión y exportaciones.

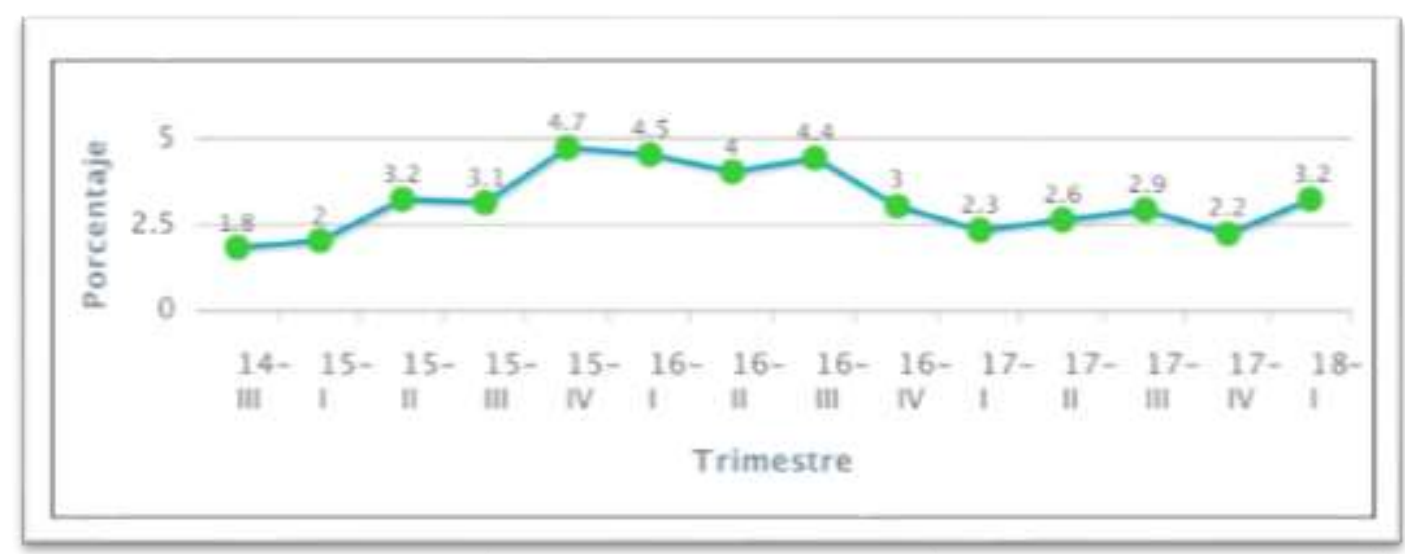

Figura 16. PBI Trimestral: Muestra la evolución del Producto Bruto Interno, por trimestres. Tomado de "Principales Indicadores" por Instituto Nacional de Estadística e Informática, 2018.

En el sector de energía, como lo señala la INEI (2018): 
En el primer trimestre de 2018, el valor agregado bruto de la actividad electricidad, gas y agua, registró un crecimiento de $1,4 \%$, respecto al mismo período del año anterior, explicado por el aumento de la producción del subsector agua $(4,4 \%)$ y el subsector electricidad y gas $(0,6 \%)$. (p.14).

Tabla 15

Electricidad, Gas y Agua: Valor Agregado Bruto

\begin{tabular}{lrrrrrr}
\hline & \multicolumn{3}{c}{$2017 / 2016$} & \multicolumn{2}{c}{$2018 / 2017$} \\
\hline Actividad & I Trim & II Trim & III Trim & IV Trim & Año & I Trim \\
\hline & & & & & & \\
Electricidad, gas y agua & 1 & 1.6 & 1.6 & 0.2 & 1.1 & 1.4 \\
Electricidad y gas & 1.9 & 2.2 & 1.8 & -0.2 & 1.4 & 0.6 \\
Agua & -3.2 & -1.2 & 0.3 & 2.1 & -0.5 & 5.4 \\
\hline
\end{tabular}

Nota. Adaptado de "PBI Trimestral-Informe-Técnico" por Instituto Nacional de Estadística Informática (INEI), 2018.

Además, la desaceleración del sector eléctrico se acentuó a lo largo del 2017, perdiendo eficiencia, porque se consume más electricidad, gas y agua para generar un sol de PBI, lo cual no favorece a la productividad, porque está orientado a que el gas y agua sea para el consumo púbico como la electricidad de hogares y solo una menor parte a la actividad productiva (Expreso, 2017). En conclusión, es que la sobre oferta en el mercado de electricidad excede a la demanda de la economía, generando problemas entre empresas generadoras y de distribución.

El crecimiento del consumo de energía en América Latina ha seguido la tendencia mundial, crecimiento constante, con excepciones en algunos años puntuales signados por las crisis económicas. La razón fundamental ha sido la caída en los precios de las materias primas exportadas, que ha traído consigo una disminución en los ingresos nacionales de los países, una reducción del PBI y consecuentemente una desaceleración o retracción de las economías.

El comportamiento del sector energético de América Latina en los últimos cinco años continúa su senda de crecimiento, este ha sido menos acelerado que en años anteriores. De 2014 a 2018 el consumo energético aumentó 1,4\%, un porcentaje bastante menor que el quinquenio anterior cuando creció $14 \%$. El menor crecimiento del consumo 
de energía está relacionado con el también menor crecimiento económico. El aumento del PBI regional que había sido en promedio de 14\% entre 2009 y 2013 cayó al 4\% en el período que va de 2014 a 2018, según los datos del Banco Mundial en valores constantes. En consecuencia, se puede afirmar que la menor actividad económica en Latinoamérica ha ido de la mano de un menor crecimiento en el consumo energético. (Honty, 2019)

En los países de Centroamérica, las inversiones en generación, transmisión y distribución de electricidad, representa en Honduras tiene mayor inversión con $2.47 \%$ del PIB, Costa Rica la mayor inversión en infraestructura eléctrica (1.13\% del PIB), Nicaragua, en cuarto lugar ( $0,8 \%$ del PIB), El Salvador por su parte, invirtió $(0.88 \%$ del PIB). Guatemala y Panamá mostraron los niveles más bajos. Lo que significa un 0,07\% del PIB en el caso de Guatemala y un 0,06\% del PIB panameño. (EI Nuevo Diario, 2017).

En Centroamérica se multiplican los proyectos de generación con fuentes renovables. El sector energía se mantiene como uno de los más codiciados por inversores nacionales y extranjeros. Generadores, distribuidores y comercializadores están inmersos en esta nueva revolución energética. Hoy en día, en la región Latinoamérica como Centroamérica, apuestan por la energía renovable, se espera un cambio en la matriz de generación, con la energía hídrica y el gas natural, pero con una creciente participación de las energías renovables no convencionales y una disminución en la participación del fuelóleo y el carbón. La capacidad eólica y solar de la región ha aumentado de manera significativa. (Jaramillo, 2018)

Brasil y Chile, tienen grandes posibilidades de elevar su producción de energía solar y eólica. Chile tiene más de la mitad de la capacidad solar de América Latina y en Brasil se concentra casi el 60 por ciento de la capacidad eólica de la región.

La guerra comercial entre las dos economías más grandes del mundo, se ha llevado a cabo a mediados del año 2018, Estados Unidos ha colocado aranceles a los productos chinos, los que se encuentran afectados en su mayoría son los tecnológicos, en tanto China es el mayor comprador de cobre en el Perú, este producto que se exporta tendría un aumento de impuesto. El Perú tiene una estructura comercial diversificada de sus exportaciones donde el $24 \%$ va Norteamérica, un 24\% a Europa, un 24\% Asia y 24\% a Latinoamérica, por lo cual se encontraría en una menor medida afectado con la guerra de aranceles entre Estados Unidos y China, pero si por la cotización de los metales y por la retracción de la economía de China y estadounidense, lo cual afectaría el PBI de 
nuestro país a mediano o largo plazo, además el Fondo Monetario Internacional (FMI) rebajó sus previsiones de crecimiento de la economía mundial para 2018 y 2019 debido al aumento de las tensiones comerciales, que podrían minar la confianza de las empresas y provocar volatilidad en los mercados financieros.

\section{Inversión Privada.}

El presidente del BCRP, Julio Velarde señalo que la inversión privada ha disminuido desde el 2014 al 2016 por la caída de confianza de los inversionistas, el cual estimo una proyección de $4.4 \%$ en el 2018 y $7.4 \%$ al 2019. (Perú 21, 2018).

En el 2018, la inversión privada alcanzo un crecimiento anual de 4\%, después de cinco años, volvió aportar crecimiento al país, la cual representa el $80 \%$ de la inversión total del país. (El Comercio, 2019).

EI BCP indico que, si se logra materializar los siguientes proyectos mineros, en los próximos trimestres, como Quellaveco (Anglo American), con 4,880 millones de dólares; Michiquillay (Southern), 2,400 millones; Ampliación de Toromocho (Chinalco), 1,300 millones; Mina Justa (Minsur), 1,270 millones; y Tía María (Southern), 1,400 millones, el Perú puede elevar su producción de cobre en más de 20\%. (El Peruano, 2018a). Industrias que son fundamentales para el crecimiento del país como la minería no podrían desarrollarse sin una adecuada generación de energía eléctrica. Un acceso eficiente a fuentes de energía permite la creación de trabajos relacionados y una mayor productividad.

De acuerdo con el último estudio de Osinergmin, en los últimos 20 años, la producción de electricidad ha aumentado hasta un $186 \%$, alcanzando los 48,3 miles de GWh en el 2014. Este sector representa el 1,4 \% del PBI y engloba a más de 6,6 millones de usuarios de electricidad. Hasta la fecha actual, en el país se ha mantenido un ritmo de crecimiento sostenido y existen proyecciones positivas para el futuro. 


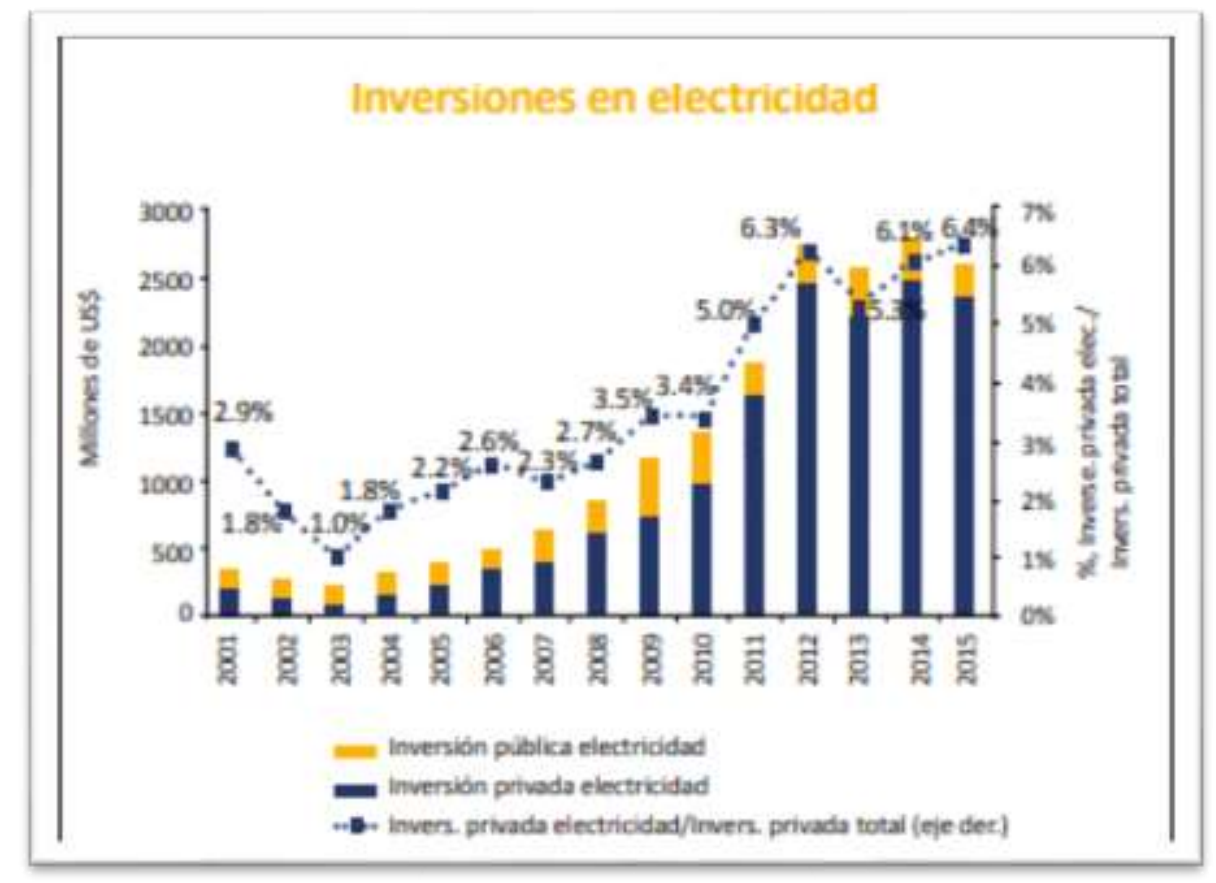

Figura 17. Inversiones. Adaptado de "La industria de la Electricidad en el Perú" por Organismo Supervisor de la Inversión en Energía y Minería (OSINERGMIN), 2016.

El Perú sigue atrayendo inversión privada, Prolnversión adjudicó el holding estatal colombiano Interconexión Eléctrica E.S.P., la buena pro de dos proyectos en enlaces eléctricos comprometiendo una inversión de 272 millones de dólares que beneficiará a seis departamentos del país. (El Peruano, 2017).

El Estado promueve la participación de la inversión privada mediante Asociaciones Público Privadas (APP) y Proyectos en Activos. El Estado faculta al sector privado para que se encargue de la ejecución, explotación y gestión de una obra o para la prestación de un determinado servicio público.

La inversión eléctrica (generación, transmisión y distribución) ha sido promovida por el Estado mediante la publicación de un marco normativo adecuado y transparente. El Ministerio de Energía y Minas en el 2014 señalo, que la inversión privada representó el $91 \%$ del total de la inversión ejecutada en el sector eléctrico y la pública solo el $9 \%$. (OSINERGMIN, 2016). Por lo tanto, el crecimiento genera un mejor clima de negocios y dinamismo en el sector, además de un círculo virtuoso de inversión, empleo y consumo en la economía.

La agencia clasificadora de riesgo crediticio Fitch Ratings (2018) ratificó lo siguiente: 
Mantuvo la calificación crediticia de nuestro país en BBB+ con perspectiva estable, debido a las sólidas cuentas fiscales y externas, además de la credibilidad y consistencia de las políticas macroeconómicas que han otorgado estabilidad macroeconómica y han generado espacio fiscal para realizar medidas que soporten el crecimiento del país sin deteriorar la sostenibilidad fiscal (p.1)

Hecha la observación anterior, esta acreditación atrae la inversión privada y hay una fuerte proyección en la inversión en el sector energético y medio ambiente, siendo considerado el Perú, uno de los países de Latinoamérica más atractivo para la inversión extranjera, el cual representa una oportunidad para Hamek Ingenieros y Asociados S.A.C., para seguir desarrollándose en el país y en el exterior.

Los países de América Latina tendrán que aumentar su capacidad de generación eléctrica en un $70 \%$ para el 2030 y para eso hace falta mucha energía e inversión. El aumento de la población, la mejora de las condiciones de vida de sus habitantes y el crecimiento de la actividad económica están multiplicando la demanda energética. Pero para ser capaces de alcanzar el nivel de inversión económica suficiente, el sector energético y los gobiernos de estos países, necesitarán colaborar con el sector privado.

La participación privada en inversiones en energías renovables a nivel mundial, superó el 90\% del total de las inversiones en el año 2017. Ello permite estimar que la participación del sector privado seguirá consolidándose en el futuro y que irá acompañada de regulaciones que aseguren la sostenibilidad jurídica y financiera de las inversiones.

América Latina ha invertido entre 2010 y 2014 más de 80.000 millones de dólares en energías renovables no convencionales. Estas inversiones reflejan la rápida evolución que ha sufrido América Latina en el sector energético hacia una gama más diversificada de fuentes de energías renovables. Muchos de países, como Perú y Chile, ya han iniciado el cambio hacia una economía menos nociva con el medio ambiente. (BBVA, 2018).

En el 2018 se triplicó la inversión en proyectos que ingresaron al Sistema Eléctrico Interconectado Nacional (SEIN), pero aún se tienen pocos incentivos para el uso o inversión en energías renovables. 
Inversión Pública.

El Ministerio de Economía y Finanzas (MEF) informó que la inversión pública sumó 2.681 millones de soles (US\$819 millones) en mayo de 2018, lo que significa un crecimiento de $36,3 \%$ en términos reales, la segunda tasa más alta del año y la tercera tasa más alta registrada desde julio 2013. La cual estuvo impulsada principalmente por obras de gobiernos locales y el gobierno nacional, consolidándose como uno de los principales motores de la economía peruana. (América Economía, 2018)

EI MEF prevé que la inversión pública crecerá 17.4\% en el 2018 en términos reales, $4 \%$ en el $2019,4 \%$ en el 2020 y $3.4 \%$ en el 2021. (El Peruano, 2018b).

Las empresas del sector electricidad contribuyen con el Tesoro Público mediante el pago de tributos. El Estado constituye el canon hidroenergético, este es la participación de que gozan los Gobiernos Regionales y Locales sobre los ingresos y rentas obtenidos por el Estado por la utilización del recurso hídrico en la generación de energía eléctrica, que representa el $40 \%$ del Impuesto a la Renta (IR) pagado por las empresas concesionarias que generan electricidad mediante recursos hídricos. Los recursos del canon son transferidos a los gobiernos regionales y municipalidades para el financiamiento de proyectos de inversión que beneficien a sus pobladores. (OSINERGMIN, 2016).

En la región Centroamérica, de enero a junio 2019 se presentaron 42 estudios de impacto ambiental para realizar obras en redes eléctricas y construir plantas generadoras de energía en diferentes zonas de los países. En la actualidad, una gran cantidad de naciones disponen de sistemas mixtos, donde la gestión pública se interrelaciona con la privada. (Central América, 2019)

\section{Inflación.}

La inflación en el Perú se ha mantenido en el rango 1\% a 3\%, que es el rango meta del Banco Central de Reserva (BCR), cerrando en el 2019 en 1.9\%, continuando ser una de las más bajas de la región (BCR, 2019).

Al 2017, el Perú tuvo 1.37\% de inflación, la más bajas desde el 2009, en los últimos diez años la tasa de inflación no ha superado el rango meta, a excepción de los años 2011 y 2014 que registro una tasa de $4.74 \%$ y 4.4\%(PUCP, 2018). 
La inflación en el Perú se mantiene como la segunda más baja entre los países latinoamericanos, después de Ecuador, lo que beneficia a las personas como a las empresas.

Otros países de la Región se mantienen estables como Chile, Colombia, Bolivia y Brasil con cifras que no superan el 4\%; Argentina cuenta con una inflación de 24,8\%; y Venezuela representa un caso particular que termino con una inflación de 2,616\%.

A continuación, detallamos la tasa de inflación de los últimos once años en el Perú en porcentaje anual.

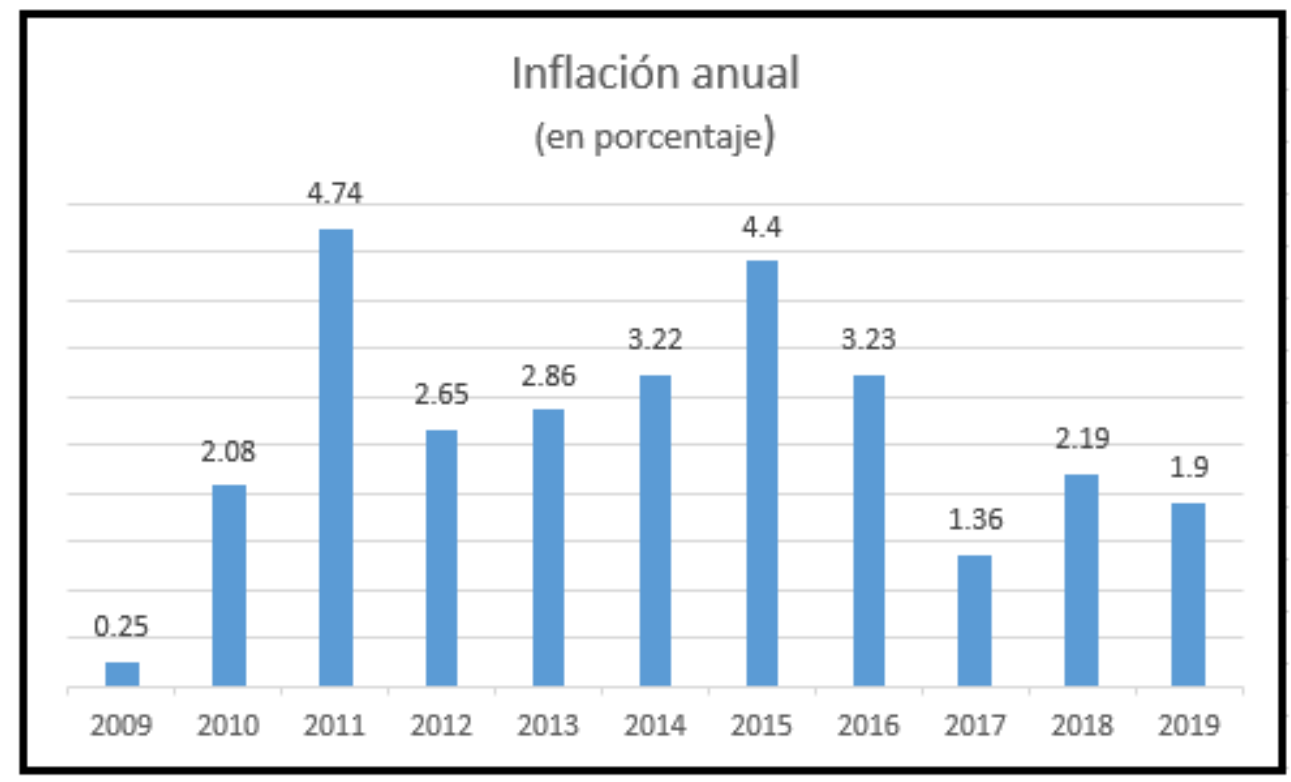

Figura 18. Inflación: Variación porcentual anual últimos once años. Elaboración propia.

Según se ha visto las expectativas de inflación en el Perú está cayendo, lo cual beneficia el uso eficiente del recurso productivo e incentivo de la inversión de las empresas de diferentes sectores.

En América Latina, los países con la inflación más baja son El Salvador (-0,4\%), Ecuador $(0,3 \%)$ y Panamá $(1,1 \%)$, tres economías cuya moneda oficial es el dólar. La alta inflación ha sido una preocupación mucho mayor para América Latina, erosiona los salarios reales, y golpea a los trabajadores informales, que tienen poca capacidad para renegociar sus salarios, ha estado creciendo desde un $4 \%$ a un $8,1 \%$ en los primeros cinco meses del año 2019 (excluyendo a Venezuela). 
En la región Centroamérica, Nicaragua se registró con la tasa de inflación más alta de $4.06 \%$, mientras que en el resto de países está por debajo de 4\%. La inflación acumulada paso de $0.92 \%$ de mediado 2018 a $0.49 \%$ a junio 2019 .

\section{Tipo de cambio.}

El tipo de cambio o precio del dólar en el Perú en los últimos años ha tenido fluctuaciones interviniendo el Banco Central de Reserva del Perú (BCR) para que no exista alteraciones bruscas, la cual se determina por el libre mercado, siendo uno de los factores claves el tipo de cambio de la tasa de interés de los Estados Unidos, determinado por el Banco Central o la FED, cada vez que sube la tasa de interés, los dólares que están en el Perú se van a Estados Unidos buscando una mayor rentabilidad, existiendo menos dólares lo que hace que aumente el tipo de cambio, las exportaciones de nuestro país al mundo hace que entren más dólares y con ello el tipo de cambio baje y las crisis externas hace que los inversionistas compren dólares, lo que suba el tipo de cambio(Gestión, 2018)

En diciembre del 2018 y 2019 el tipo de cambio en el mercado peruano bajo al pasar de S/3.37 a S/3.314 por dólar, asociado a un menor riesgo de la guerra comercial entre Estados Unidos y China y el precio de cobre ha ido disminuyendo, en el Perú la moneda sol se ha depreciado en $1.64 \%$, a pesar que el BCR estuvo intervenido muy poco en el mercado cambiario. (El Comercio, 2018).

Al cierre del diciembre 2017 llego a 3.24, siendo el año 2012 el peor año para el dólar; cerrando a su nivel más bajo de 2.46 en más de 16 años, por el crecimiento de China que demando una gran cantidad de metales produciendo una tremenda entrada de dólares.

Existen muchos factores que determinan que el tipo de cambio tenga variaciones, la situación económica internacional es determinante para analizar la evolución del precio del dólar.

A continuación, presentamos las fluctuaciones del tipo de cambio al cierre de los últimos diez años. 


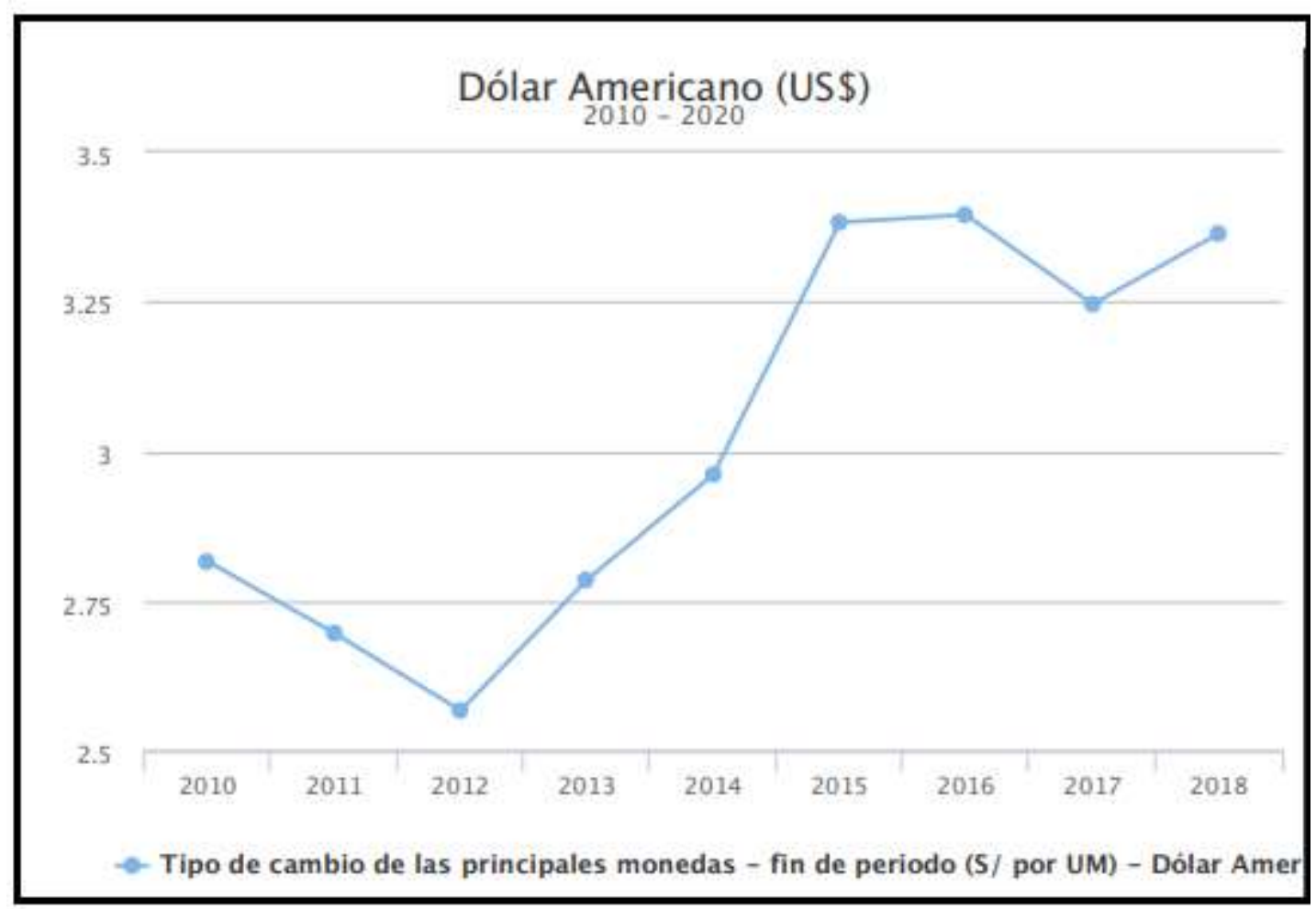

Figura 19. Tipo de cambio Nominal. Adaptado de "Nota Semanal Estadística/Gráficos Dinámicos” por Banco Central de Reserva del Perú (BCRP), 2018.

\section{Empleo.}

La principal fuente de ingresos de los ciudadanos en el Perú es el empleo. El mercado laboral tiene una demanda de empleo por las empresas y una oferta de empleo por las familias. La población económicamente activa (PEA) está compuesta por todas aquellas personas mayores de 14 años de edad, que están dispuestas a trabajar. Perú tiene 31 millones de habitantes. La mitad, es decir, 16 millones, pertenecen a la PEA.

De los 16 millones, el $42 \%$ se encuentra subempleado por ingresos, lo que significa que la persona tiene un empleo, pero obtiene al mes menos que un ingreso mínimo referencial, en enero de 2018 ascendió a 961 soles. 2\% son subempleados por horas; en esta categoría se encuentran aquellos que trabajan menos de 34 horas a la semana, desean trabajar más, pero no encuentran dónde. El desempleo se acerca a $4 \%$ de la PEA y está compuesto por aquellos que desean trabajar, pero no encuentran dónde. En 2017 y de acuerdo con cifras del INEI, el empleo formal disminuyó $2.8 \%$, lo que puede haber llevado a crecer el subempleo o el desempleo. El 74\% de los trabajadores en el Perú lo 
hace en el sector informal, sin acceso a beneficios sociales de ningún tipo. (Gestión, 2018a)

EI INEI informó que el año marzo 2017-febrero 2018, en el área urbana del país el empleo adecuado creció en $0.8 \%$, es decir, 64,400 personas mejoraron su nivel de empleo. Asimismo, el ingreso promedio de las mujeres disminuyó en 3.8\% y el ingreso de los hombres en $1.3 \%$. Las mujeres ganan en promedio el $66.7 \%$ del ingreso de los hombres. (INEI, 2018a).

En el sector de servicio, la INEI informo que en el segundo trimestre al 2018:

El empleo adecuado aumentó en la rama de Construcción en 8,1\% (21 mil 300 personas) y en Comercio en 3,4\% (16 mil 300 personas); mientras que disminuyó en Manufactura en 3,4\% (14 mil personas) y en Servicios en 1,0\% (19 mil 300 personas). El 60,1\% de la población adecuadamente empleada se encuentra en Servicios, el 14,9\% en Comercio, el 13,9\% en Manufactura y el 9,3\% en Construcción. (p.6).

Tabla 16

Lima Metropolitana: Población Adecuadamente Empleada, según Ramas de Actividad. Trimestre móvil: Febrero-marzo-abril 2017 y 2018 (Miles de personas).

\begin{tabular}{lcccc}
\hline & & & \multicolumn{2}{c}{ Variación } \\
\cline { 4 - 5 } Ramas de actividad & Feb-Mar-Abr 17 & Feb-Mar-Abr 18 & $\begin{array}{c}\text { Absoluta } \\
\text { Porcentual } \\
\text { (Miles) }\end{array}$ & \begin{tabular}{c} 
(\%) \\
\hline Total
\end{tabular} \\
Manufacturas & $3,064.00$ & 3057.1 & -6.9 & -6.2 \\
Construcción & 438.5 & 423.5 & -15 & -3.4 \\
Comercio & 261.6 & 282.9 & 21.3 & 8.1 \\
Servicios & 469.6 & 485.9 & 16.3 & 3.5 \\
\hline
\end{tabular}

Nota. Adaptado de "Situación del Mercado Laboral en Lima Metropolitana" por Instituto Nacional de Estadística Informática (INEI), 2018. 
De acuerdo a lo publicado por OSINERMING en el 2016 se encontró lo siguiente:

Según estadísticas del MEM el empleo directo del sector eléctrico acumuló un crecimiento de 66\% entre 2001 y 2014 (ver Figura 20) Si bien el nivel de empleo en electricidad es inferior al 1\% con respecto a la población económica activamente ocupada (p.264)

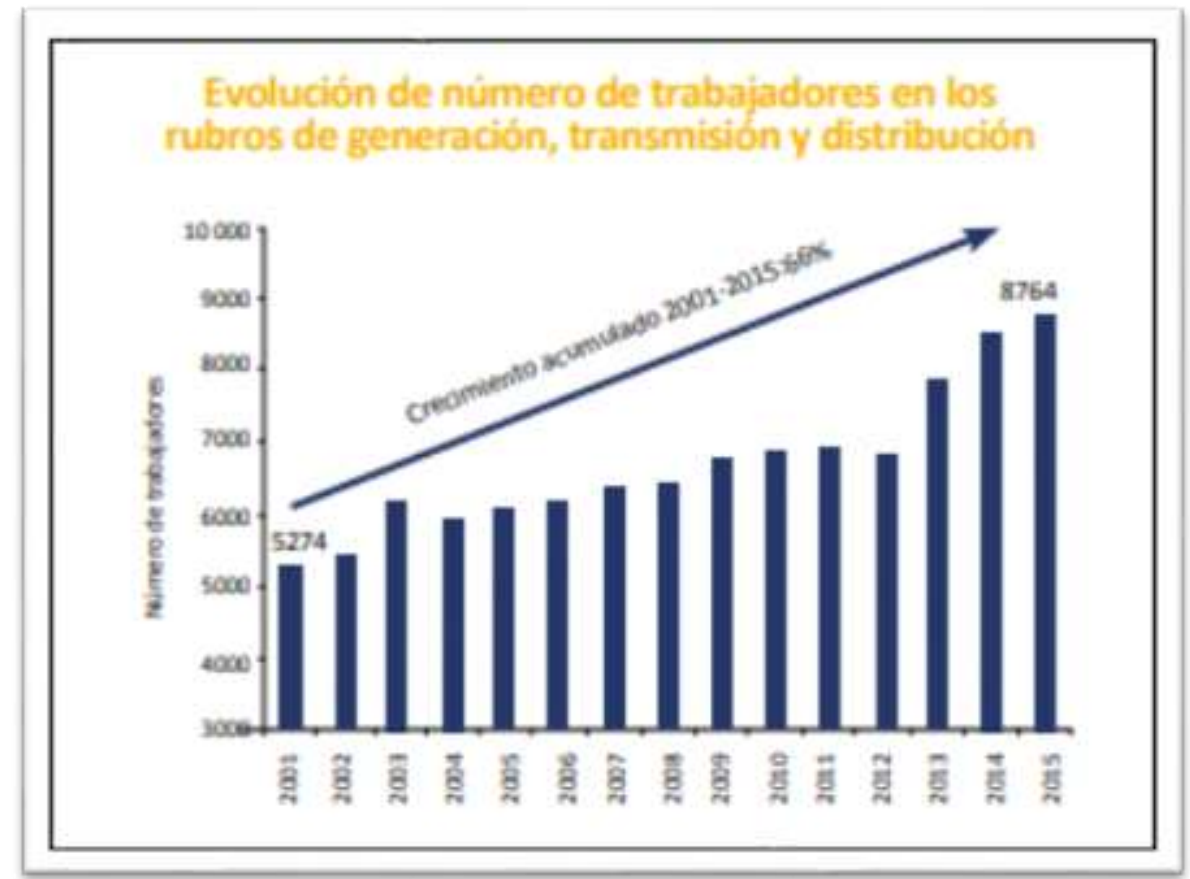

Figura 20. Empleo. Tomado de "La industria de la Electricidad en el Perú" por Organismo Supervisor de la Inversión en Energía y Minería (OSINERGMIN),2016.

\subsubsection{Análisis Legal.}

Los sectores de energía y medio ambiente desempeñan un papel importante en el funcionamiento económico en el país, en la que se encuentra la intervención del Estado.

Para el sector energético, las consultoras en cumplimiento con el procedimiento técnico y en base a las normas legales vigentes emitidas por OSINERGMIN, como organismo regulador independiente y autónomo del mercado eléctrico, tiene como actividad principal, el administrar un marco normativo y regulatorio estable y transparente.

Los procedimientos en el sector energético, donde participan son en cumplimiento de los Programas de Mantenimiento aprobados por el COES-SINAC, vigente desde el 01 
de enero 2012, dejando sin efecto el "Procedimiento para la Supervisión del Cumplimiento de los Programas de Mantenimiento aprobados por el COES-SINAC.

A la fecha, las normativas de los procedimientos no han tenido modificación por la que aún se encuentra vigente. La empresa Hamek Ingenieros Asociados S.A.C., atiende las necesidades de las empresas generadoras en el marco del cumplimiento de los procedimientos operativos del COES.

Para los servicios ambientales, se desarrollan en cumplimiento a las normativas emitidas por el Ministerio del Ambiente que garantiza el cumplimiento de las normas ambientales, basadas en un compendio de la Legislación Ambiental Peruana debidamente actualizado.

De acuerdo con la Ley General del Ambiente (Ley № 28611, 2004): Toda actividad humana que implique construcciones, obras, servicios y otras actividades, así como las políticas, planes y programas públicos susceptibles de causar impactos ambientales de carácter significativo, está sujeta, de acuerdo a ley, al Sistema Nacional de Evaluación de Impacto Ambiental (SEIA) el cual es administrado por la Autoridad Ambiental Nacional (ANA).

Esta normativa obliga es que todas las actividades relacionadas a los diferentes sectores productivos del país deben contar con un instrumento de gestión ambiental.

\subsubsection{Análisis Cultural.}

Como lo señala Gamio, P. (2017):

El desarrollo de energías "limpias", como la eólica o solar, no sólo contribuirá a la disminución de gases de efecto invernadero sino también ayudará a disminuir diversos conflictos sociales generados por actividades como la extracción de petróleo en la Amazonía. (p. 1).

Dado que Perú, es una de las principales naciones afectadas por el cambio climático y es por esta razón que sufrimos de desastres naturales como el fenómeno del niño que año a año, obliga a realizar obras de infraestructura para la reconstrucción de zonas afectadas, sobre todo en la parte norte del país.

Nuevamente Gamio, P. (2017) anota:

Las principales fuentes de emisión de gases de efecto invernadero, y que a la vez son las fuentes de energía nacional, son de naturaleza fósil como los 
hidrocarburos (el petróleo, por ejemplo). Al otro lado, están las energías renovables convencionales y las no convencionales.

Mientras que en las primeras encontramos a la energía producida por represas, hidroeléctricas y el gas natural, las energías renovables no convencionales reúnen a la energía solar, cuya versión más popular es generada por paneles solares (fotovoltaica); la eólica (por acción del viento); la geotérmica (que usa la energía subterránea); y la bioenergía (basada en el uso de la agricultura sostenible como la madera seca). Sin embargo, en Perú aún estamos muy lejos de desarrollar al $100 \%$ todo nuestro potencial energético de manera "limpia".

El impacto Cultural para los clientes van de la mano, por un lado vienen acompañados de conflictos socioculturales por la falta de previsión de los beneficios para las comunidades del desarrollo de proyectos de inversión sobre todo del sector privado y por otro lado el rechazo natural de las poblaciones a que se concreten estos proyectos porque entran en conflicto de convivencia de la naturaleza con el desarrollo, resulta trascendental que se involucre a las comunidades con una política comunicativa clara basada en los beneficios que se obtendrán con el desarrollo de los proyectos de inversión en armonía con el medio ambiente.

Las empresas, deben convivir con la incertidumbre que los proyectos no se paralicen por el rechazo de las comunidades y la población poco informada, por lo cual está expuesta a un mayor grado de riesgo por empresas de distribución eléctrica, al enfrentar riesgos asociados a la medición y calidad de servicio en zonas rurales de difícil acceso.

En la región Centroamérica, los biocombustibles, como cualquier otra energía, acarrean riesgos sociales y ambientales, por lo que se hace necesario controlar las condiciones en que se desarrollan. Este control es aún más preciso en los países centroamericanos, los cuales son reconocidos por su potencial para producir biocombustibles.

Chile viene trabajando en los últimos años para abordar los desafíos del sector, la competencia y la asequibilidad en el tema de energía. Sin embargo, aún existen retos estructurales, como los cambios en el sistema regulador, la intermitencia de las energías renovables y las consecuencias del cambio climático. Chile ha mostrado un gran compromiso en posibles intercambios bilaterales de electricidad con países como Perú y Argentina. Pero aún necesita hacer reformas importantes para poder aprovechar las 
oportunidades que brindan los cambios tecnológicos como las redes inteligentes y así mejorar su eficiencia energética. (Banco Mundial, 2017).

\subsubsection{Análisis Tecnológico.}

Según estudio del World Economic Forum [WEF] (2016) "Lo digital está afectando la oferta y la demanda del sector energético de diferentes maneras. Se observan cambio en los patrones de consumo, la optimización de activos, las asociaciones entre sectores, y el mayor uso de plataformas industriales", hoy estamos frente a un mundo cambiante donde se exige una mayor agilidad, más velocidad, y más competencia digital.

Como lo señala el WEF (2016):

Hay cuatro tendencias que juegan de forma coherente en todos los mercados: el cambio de patrones de consumo, nuevas formas de optimización de activos, las asociaciones entre sectores, y el mayor uso de plataformas industriales. (p. 1).

El mundo digital está cambiando los patrones de consumo, hoy se busca menos propiedad y más de pago por uso y cada vez las personas se encuentran más familiarizadas con el uso de la tecnología en sus quehaceres diarios, esto repercute en cambios de la demanda de energía.

La tecnología se ha desarrollado en los últimos años de manera exponencial, muchas empresas peruanas medianas y grandes, están invirtiendo en software e infraestructura tecnológica y existe una tendencia para las pequeñas empresas. Las compañías que utilizan las nuevas tecnologías como base para cualquier acción tienen más capacidad de innovar y de que esto les dé una posición aventajada en el futuro.

La tecnología ha permitido en innovar en equipos de mayor precisión y conectividad del sector energético, el cual está cambiando rápidamente, hoy en día los equipos son más sofisticados y están conectados a la red, lo cual ayuda a que las empresas puedan redefinir las relaciones con sus consumidores.

En los países de Latina América y Centroamérica, la incorporación masiva de nuevas tecnologías, impactara al panorama energético de la región. La energía se está descentralizando, y las nuevas tecnologías permiten digitalizar los datos, y tomar decisiones más rápidas, que satisfagan sus objetivos corporativos, no solo económicos, sino ambientales y de responsabilidad social. (Banco Mundial, 2017). 
Las innovaciones tecnológicas han aumentado la eficiencia y reducido los costos promoviendo así la competitividad de la red de energía renovable.

Muchas compañías están mirando estas megas tendencias para encontrar nuevas formas de ahorrar dinero y cumplir los objetivos de sostenibilidad.

\subsubsection{Análisis Ecológico.}

El medio ambiente y la ecología poseen mayor atención e incertidumbre por parte de las organizaciones, gobiernos y empresas. El mal uso de los recursos naturales ha puesto en peligro la ecología, el aire, el agua, los bosques se están reduciendo y agotando, muchas especies animales se están extinguiendo por la caza, pesca y la destrucción de sus hábitats naturales por los contaminantes y no es solo por las grandes empresas que explotan indiscriminadamente el suelo, el aire, sino de todos.

El vínculo entre la energía y el cambio climático es muy fuerte, por el altísimo consumo de energías fósiles lo que ha provocado el calentamiento del clima, que ya sufrimos y que seguiremos experimentando en las próximas décadas. El consumo de energía proveniente de los combustibles fósiles, carbón, petróleo y gas natural, ha ido en aumento. Pero la quema de los combustibles fósiles es la responsable de la producción de los gases de efecto invernadero, causantes del calentamiento global. Aumento del nivel del mar, sequías cada vez más severas, fenómenos meteorológicos extremos, son algunas de las consecuencias del cambio climático y que ya se han empezado a manifestar.

La única forma de detener el cambio climático pasa por cambiar nuestros patrones de consumo. Es imprescindible producir más con menos, aumentar la eficiencia energética de todos los procesos y sustituir el consumo de energías fósiles por renovables.

En el Perú se están llevando a cabo lograr el desarrollo sostenible, es decir, lograr el desarrollo de los pueblos sin poner en peligro el ecosistema. $Y$ todo empieza desde el gobierno poniendo énfasis a las resoluciones, decretos supremos, políticas nacionales; con estas exigencias gubernamentales, se está buscando mejorar la calidad de vida de los pobladores mediante el manejo de recursos naturales y actividades de desarrollo que sean compatible con el medio ambiente.

El Perú tiene un alto potencial para la generación de energía renovable convencional y la no convencional, siendo esta ultima la más amigable con el medio ambiente, ya que no genera contaminación, porque se deja de usar petróleo el cual produce efecto invernadero causando el aceleramiento del cambio climático. 
Las consultorías ambientales, que son demandados por empresas y entidades de todos los sectores profesionales, han derivado en la necesidad de contar con permisos, programas, procedimientos y estudios que deben ser desarrollados por los profesionales del sector. (MINAM, 2018).

La producción y distribución de energía eléctrica requiere de una serie de actividades que conllevan una serie de impactos en el ámbito local, como son la generación de residuos, los vertidos a cauces próximos, el ruido, los campos electromagnéticos, el impacto visual, etc., la que pasa por determinadas medidas preventivas. La elaboración de Evaluaciones de Impacto Ambiental (EIA), de acuerdo con la normativa existente, permite evaluar de forma previa el impacto de las infraestructuras de producción, transformación y distribución sobre el medio natural.

De esta manera, el país se está adecuando a las tendencias que existe en países desarrollados, el Estado está empleando nuevas reglas y avances en el sector ambiental, desarrollando capacidades que promuevan, de manera efectiva, la conservación de recursos naturales y ambiental, con un equilibrio con el crecimiento económico. Para las empresas consultoras del medio ambiente es una oportunidad, por sus servicios que ofrecen.

Existe un incremento en parques de energía eólica y solar en el Perú, donde existe una mayor presencia en el sector de energías renovables, contribuyendo a diversificar la matriz energética del país, reduciendo la emisión de gases de efecto invernadero, para satisfacer la necesidad del país de una generación eficiente y sostenible y a la generación de empleo en las zonas en que se implanta.

Para Hamek Ingenieros Asociados S.A.C, es una oportunidad porque antes de la implementación de los parques eólicos, se necesita estudios y cuando estén instalados se requiere una evaluación del desempeño de parques eólicos.

América Latina lidera cada vez más los esfuerzos globales para la transición a fuentes de energía renovables. Está preparada para tomar un papel protagónico en los campos del cambio climático y la energía renovable a nivel mundial. El enorme potencial y la rápida propagación de la energía renovable en la región, han alimentado la esperanza de una transición global a una economía baja en carbono. Centroamérica posee algunos de los recursos geotérmicos más prometedores del mundo, por lo que si se utiliza puede ayudar a la región a asegurar y proveer electricidad de bajo costo y bajo carbono. El Salvador, Costa Rica y Panamá apuntan a un futuro brillante para la adopción eólica y solar en la región. (SICA, 2017). 


\subsection{Impacto en clientes / proveedores de cada uno de las variables del entorno}

Como lo señala David (2013) "Los cambios en las fuerzas externas se traducen en cambios en la demanda del consumidor tanto de productos y servicios industriales como de consumo" (p. 83), por otro lado, también menciona que "Las fuerzas externas afectan directamente a los proveedores y distribuidores".

Este impacto de las fuerzas externas se detalla en la Tabla 17 a continuación: 
Tabla 17

Impacto de Variables Externas en Clientes y Proveedores

\begin{tabular}{|c|c|c|c|c|c|}
\hline Análisis & Elemento & Impacto en: & Oportunidad / Amenaza & Sustento & Impacto \\
\hline Político - Gubernamental & Inestabilidad Política & Clientes / Proveedores & Amenaza & Afecta Actividad Económica e Inversión Privada & Ingresos / Ventas \\
\hline Político - Gubernamental & Limitación Financiam. FONAFE & Clientes / Proveedores & Amenaza & Limitación Financiamiento Proyectos & Ingresos / Ventas \\
\hline Económico & Calificación Riesgo País /Crecimiento PBI & Clientes / Proveedores & Oportunidad & Crecimiento Sector Energía y Gas & Ingresos / Ventas \\
\hline Económico & Fomento Inversión Privada & Clientes / Proveedores & Oportunidad & Incentivo a la Inversión Privada & Ingresos / Ventas \\
\hline Económico & Acuerdo Energético Perú Brasil & Clientes / Proveedores & Oportunidad & Incentivo a la Inversión Pública y Privada & Ingresos / Ventas \\
\hline Económico & Hub Energético Latam & Clientes / Proveedores & Oportunidad & Incentivo a la Inversión Pública y Privada & Ingresos / Ventas \\
\hline Económico & Riesgo Guerra Comercial EEUU China & Clientes / Proveedores & Amenaza & Afecta crecimiento del pais & Ingresos / Ventas \\
\hline Legal & Normativas Legales & Clientes & Oportunidad & Favorece desarrollo Sector Energetico y Medioambiente & Ingresos / Ventas \\
\hline Tecnológico & Mejoras Tecnologia equipamientos & Clientes / Proveedores & Oportunidad & Tecnificación de equipos de medición & Rentabilidad \\
\hline Ecológico & Generacion Energia Limpia / Cuidado Medio Ambiente & Clientes & Oportunidad & Favorece desarrollo de estudios de impacto ambiental & Ingresos / Ventas \\
\hline Ecológico & Factores Climáticos & Clientes & Amenaza & Favorece desarrollo de estudios de impacto ambiental & Ingresos / Ventas \\
\hline Ecológico & Exigencias Calidad / Sector Público y Privado & Clientes & Oportunidad & Favorece desarrollo de estudios de impacto ambiental & Ingresos / Ventas \\
\hline
\end{tabular}

\section{Nota. Elaboración propia.}




\subsection{Efecto en la empresa de cada uno de las variables del entorno Impacto Político / Económico.}

Como lo señala Marthans (2017), referido a la crisis política que atraviesa el país "La crisis podría afectar entre uno y hasta dos puntos porcentuales en el PBI (de $4 \%$ de crecimiento a $2 \%$ para el 2018 )" y esto afectaría tanto las inversiones públicas como las privadas por las expectativas de confianza de los agentes de mercado, y podría traducirse en un deterioro de la calificación crediticia de Perú , lo cual resulta contrario dado que, como lo señala Marthans (2017) "El "Perú debiera estar buscando elevar el nivel de Mayor Grado de Inversión, esa debería ser una meta del Estado", se concluye que la inestabilidad político social desincentiva la inversión en el sector energético y genera incertidumbre y escepticismo lo cual constituye una amenaza para el sector y por ende para las intenciones de Hamek Ingenieros y Asociados S.A.C de desarrollarse.

Por otro lado, la solidez de las finanzas públicas según detalla la Fitch Ratings (2018) fomenta la inversión privada y dado el crecimiento del sector energía eléctrica, constituye también una oportunidad para Hamek Ingenieros y Asociados S.A.C:

La solidez de las finanzas públicas según Fitch Ratings (2018):

El continuo crecimiento económico y la credibilidad del marco fiscal han permitido que la deuda pública se ubique por debajo de la mediana de países con similar calificación, lo que refleja la prudencia en el manejo de las cuentas fiscales. (Ver Figura 21). 


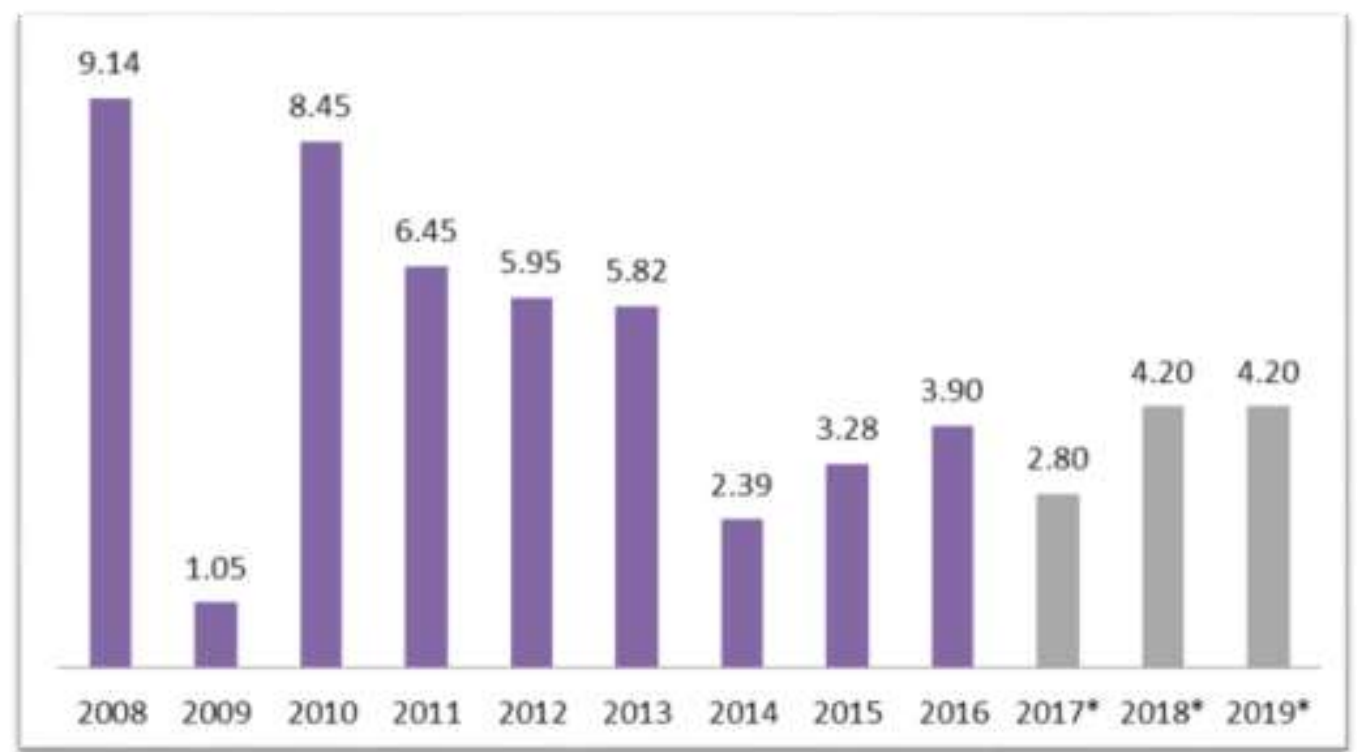

Figura 21. Producto Bruto Interno por Banco Central de Reserva del Perú (BCRP). Cifras estimadas, 2018.

Lo anterior permite que el Perú sea calificado como uno de los países de la región con menor tasa de riesgo país y ello se constituya como una importante oportunidad para el desarrollo del sector energía, a continuación, se muestra un comparativo del riesgo país con países de la región como Chile, Colombia y México (ver Figura 22). 
Riesgo-País-(EMBIG)-de-la-Alianza-del-Pacifico\|

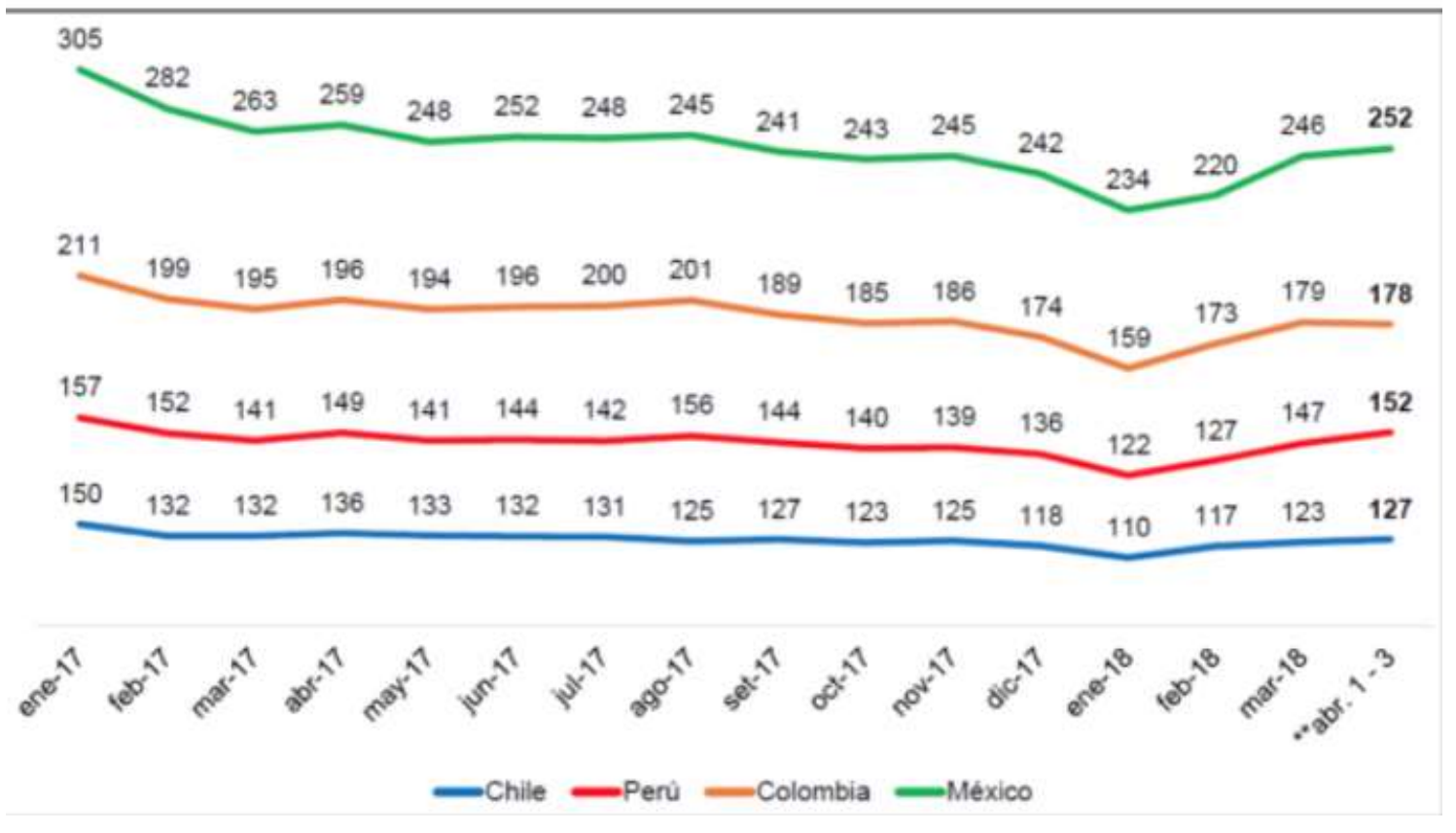

Figura 22. Riesgo País de la Alianza del Pacifico. JP Morgan. Elaborado por el Banco Central de Reserva del Perú (BCRP). 2018.

La política Monetaria, según Fitch Ratings (2018) "Se resalta la baja inflación y las expectativas de inflación ancladas al rango meta del Banco Central de Reserva (BCR). Así también, menciona que la continua caída de la dolarización financiera permite mayor flexibilidad cambiaria y menor exposición ante un descalce de monedas" y finalmente,

Los Balances Macroeconómicos Externos, para Fitch Ratings (2018) "El Perú mantiene una sólida posición de reservas internacionales y un bajo déficit en cuenta corriente. Estima que dicho déficit será financiado totalmente por inversión extranjera directa".

El hecho de que el Perú mantenga una calificación crediticia BBB+ con un gasto público controlado y políticas macroeconómicas coherentes aumentan el grado de confianza para la inversión privada en el sector energético y constituye una gran oportunidad para Hamek Ingenieros y Asociados S.A.C para desarrollarse en el mercado local con sus servicios de asesoría pero además buscar diversificarse en otros sectores de mucho interés (Diversificación concéntrica) teniendo en cuenta el crecimiento del sector energético a nivel local con el desarrollo de nuevos proyectos en las regiones del sur, como Tacna, Arequipa y Cuzco, donde opera la mayoría de las empresas mineras, 
en vista que existe un gran consumo de energía en mineras. Importante precisar además que el sector experimenta desaceleración en su crecimiento y ello afecta a Hamek Ingenieros Asociados S.A.C., dado que presta servicios a este sector.

A nivel regional se observa que para el año 2019 habría un crecimiento entre el $0.8 \%$ y el $1.4 \%$ el Producto Interno Bruto (PIB) de la región según el reporte "Panorama de América Latina 2019: una leve recuperación"

"La expansión estará encabezada por avances en Brasil, Colombia, Perú y Uruguay, y una normalización en Chile", explicó el área analítica de la calificadora del Moody's Analytics (dic. 2018).

Según esta misma fuente "Perú será el país con la mayor expansión en el 2019, con un 3,7\%; seguido de Colombia, con un 3,3\%; Chile con un 3,2\% y Uruguay con un $3,1 \%$.", además, "Brasil, la mayor economía de la región, podría encaminarse hacia un $2,0 \%$, mientras que México, en el segundo puesto, se desaceleraría a un $1,6 \%$."

Respecto a los países de Centroamérica, un informe elaborado por la Unidad de Desarrollo Económico de la sede subregional de la Comisión Económica para América Latina y el Caribe (CEPAL) en México, señala que las economías que experimentarán mayores crecimientos para el período 2019 serían Republica Dominicana con un 4,7\%, Panamá con un $4.6 \%$, Honduras con un 3,6\%, Guatemala con un 3,0\% y Costa Rica con un $2,9 \%$.

Respecto al consumo de energía eléctrica en la región de Latinoamérica y el Caribe, el informe The Energy Path of Latin America and the Caribbean, publicado en el 2019 por el Banco Interamericano de Desarrollo (BID), señala que la demanda en américa latina crecerá entre un 2,7\% y un 3,6\% anual hasta 2040 y la oferta aumentará al mismo nivel, lo que demandará una fuerte inversión, esto se traduce a un consumo entre 2.800 y 3.400 Twh (Teravatios/hora), cifra que representa el doble del consumo actual.

También se menciona que.

"La matriz eléctrica de los países de la región también cambiará en los próximos años. Las fuentes hidroeléctricas y el gas natural seguirán siendo dominantes, con cuotas del $44 \%$ y del $23 \%$ respectivamente sobre el total, aunque aumentará la participación de las fuentes de energías renovables no convencionales como la geotermal o los 
biocombustibles, en detrimento de los combustibles fósiles, cuyo peso en la matriz se reducirá desde el $10 \%$ hasta el $6 \%$ en $2040 . "$

Respecto a Centroamérica, cada país presenta una realidad distinta en toda la región , y según la CEPAL en un informe del 2016, existen en toda la región, son 323 el número de agentes participantes en los sistemas eléctricos de los seis países en todos los segmentos ( residencial e industrial), además, Las pérdidas de electricidad, técnicas y no técnicas, en la región fueron del 17,4\% lo que presenta una oportunidad para Hamek Ingenieros y Asociados S.A.C.para el desarrollo de estudios técnicos buscando minimizar la pérdida técnica.

El Perú tiene como objetivo convertirse en el Hub Energético, exportando electricidad a Ecuador, Chile y Bolivia. La interconexión con el Ecuador traerá seguridad hídrica al Perú y precios competitivos, con Chile se mantendrá la competitividad eléctrica en los siguientes años, con Bolivia se está identificando las potencialidades. No es solo exportar energía eléctrica barata, sino con un precio competitivo y el diferencial se quede en el Perú.

El acuerdo energético entre Perú y Brasil, favorecen a ambos países, porque Brasil suministra energía eléctrica al Perú y este último exporta de excedentes energéticos a la mayor económica de Latinoamérica, dando una interconexión eléctrica de ambos países, donde Brasil participa en proyectos hidroeléctricos en el Perú, un mayor comercio, la construcción de centrales hidroeléctricas en la Amazonía peruana y el establecimiento de las condiciones para la venta de electricidad al mercado peruano y al brasileño. Todo lo anteriormente mencionado, constituye oportunidades de crecimiento del sector energía eléctrica y por consiguiente para la prestación de servicios de Hamek Ingenieros y Asociados S.A.C.

\section{Impacto Legal.}

El marco normativo y regulatorio referido a la Ley $N^{\circ} 24844$, Ley de Concesiones Eléctricas (LCE) del año 2012, y el Reglamento de Protección Ambiental en las Actividades Eléctricas (RPAAA) sientan las bases para realzar la importancia de una certificación ambiental para actividades eléctricas, siendo OSINERGMIN, la entidad encargada de fiscalizar el cumplimiento de las normas ambientales en actividades del sector electricidad.

El proceso de privatización iniciado en los años 90, permitieron que el sector energético dejara de ser controlado, por el Estado y permitió la llegada de la inversión 
privada que ayudo mucho en el crecimiento del sector, luego se creó OSINERGMIN como ente fiscalizador del servicio pero además que exista en convivencia con el medio ambiente, este escenario le permitió a Hamek Ingenieros y Asociados S.A.C. desarrollarse, hoy en día el marco legal fiscalizador y normativo sólido e independiente del Estado, constituye una oportunidad muy atractiva para las empresas consultoras de sector energético.

El Ministerio de Energía Minas dictamina normas previamente revisada también con OSINERGMIN, este último se encarga que las normas se cumplan, como, por ejemplo; las normas de calidad, eficiencia y normas técnicas. La existencia de un marco regulatorio estable y claro, genera oportunidades a Hamek Ingenieros y Asociados S.A.C., para se consolide en el mercado local y con las expectativas de ingresar a otros países de la región.

\section{Impacto Cultural - Ecológico.}

El impacto Cultural y Ecológico para los clientes van de la mano, por un lado vienen acompañados de conflictos socioculturales por la falta de previsión de los beneficios para las comunidades del desarrollo de proyectos de inversión sobretodo del sector privado y por otro lado el rechazo natural de las poblaciones a que se concreten estos proyectos porque entran en conflicto de convivencia de la naturaleza con el desarrollo, resulta trascendental que se involucre a las comunidades con una política comunicativa clara basada en los beneficios que se obtendrán con el desarrollo de los proyectos de inversión en armonía con el medio ambiente.

Bien llevado el desarrollo de los proyectos de inversión en el sector energético que sea inclusivo y participativo con las comunidades y los pobladores cercanos al proyecto, respecto a los beneficios que se conseguirán y el cuidado del medio ambiente, permitirá que se sensibilicen y por lo tanto, evitaría se presenten los conflictos socioculturales, conseguido lo anterior, los proyectos no tendrían retrasos en su desarrollo que obedezcan a un rechazo de la población y sería muy favorable para que Hamek Ingenieros y Asociados S.A.C preste sus servicios en un entorno de competencia

Por otro lado, existe una mayor orientación al cuidado de la naturaleza y al uso de energías renovables que mantengan un equilibrio con el medio ambiente, esto conlleva a Hamek Ingenieros y Asociados S.A.C. a considerar diversificar los servicios ofrecidos a futuro, dado que las principales fuentes de generación de energía siguen siendo las hidroeléctricas y termoeléctricas, sin embargo con el transcurrir de los años, la matriz energética cambiará con la incorporación de energía eólica y solar en varios países de la 
región de Centroamérica y Latinoamérica ante la falta de fuentes de energía convencionales o el agotamiento de recursos como el agua. Finalmente, las exigencias van en aumento, tanto por los sectores gubernamentales como privados a nivel local y en países de la región dentro de un marco legal y regulatorio

\section{Impacto Tecnológico.}

El constante desarrollo tecnológico permite incorporar nuevas formas de generación de energía, y dado que la demanda energética se mantendrá en crecimiento, esto genera oportunidades para la realización de estudios para las certificaciones ambientales y asesoría técnica en el sector por parte de Hamek Ingenieros y Asociados S.A.C., además, la tecnología permite desarrollar equipos de medición de alta precisión, necesarios para poder realizar los estudios técnicos requeridos.

\subsection{Oportunidades y Amenazas}

Del análisis externo para Hamek Ingenieros Asociados S.A.C., se detallan las oportunidades y amenazas más relevantes:

Oportunidades:

- Calificación Riesgo País acompañado de proyección de crecimiento del PBI

- Fomento de la inversión privada por parte del Estado y para la generación eficiente.

- Marco Normativo y regulatorio estable y claro

- Acuerdo energético de Perú con Brasil que permita abastecer de energía desde Perú y que apertura un mercado de integración

- Perú como Hub energético que permitirá la exportación de excedentes de energía a Ecuador, Chile y Bolivia.

- Incorporación de Tecnología que permite la innovación constante en equipos de mayor precisión y conectividad que generan además una ventaja competitiva.

- Incremento e impulso de parques de generación de Energía Eólica y Solar como parte del desarrollo de nuevos fuentes de energía renovable.

- Incremento de las exigencias gubernamentales y empresariales a efectos de contar con certificaciones y estudios técnicos que respalden el desarrollo de proyectos e inversiones en energía

Amenazas:

- Inestabilidad política que frena Proyectos de Inversión.

- Interferencia o Injerencia política en el sector eléctrico COES 
- Limitaciones para el financiamiento de proyectos en las empresas que forman parte del FONAFE por disposiciones gubernamentales.

- Riesgo de una Guerra Comercial entre China y EEUU.

- Impacto negativo de factores climáticos en el desarrollo del sector

El impacto de estos factores será medido con la elaboración de una matriz EFE que evalúa el impacto de los factores externos.

\subsection{Matriz de evaluación de los Factores Externos EFE}

Como lo señala David (2013): "Una matriz de evaluación de factores externos (EFE) permite a los estrategas resumir y evaluar información económica, social, cultural, demográfica, ambiental, política, gubernamental, legal, tecnológica y competitiva “.

La Matriz de evaluación de los factores Externos EFE (ver Tabla 18) se elaboró habiéndose realizado previamente un análisis del sector energético para determinar las oportunidades y amenazas del sector, fundamentado en fuentes primarias basadas en entrevistas a profundidad realizada a expertos y profesionales del sector (Ver Apéndice № 8, pág. 334), adicionalmente para la construcción de las principales oportunidades y amenazas consolidadas en la matriz EFE se recurrió a fuentes secundarias referidas a bibliografías relacionadas al sector, artículos en revistas especializadas e informes técnicos y estadísticos del entorno, determinándose la valoración y el peso ponderado de cada una de las oportunidades y amenazas sobre el sector. (Ver Apéndice Nㅜ10, pág. 340), 
Tabla 18

Matriz de Evaluación de Factores Externos (EFE)

\begin{tabular}{|c|c|c|c|c|c|c|}
\hline Factor & Tipo Factor & Peso & Valor & Ponderado & Afecta En & Pag. \\
\hline \multirow{5}{*}{ Económico } & Oportunidades & & & & & \\
\hline & Fomento de la inversión privada por parte del Estado & 0.05 & 4 & 0.2 & Ventas & 78 \\
\hline & Calificación Riesgo País acompañado de proyección de crecimiento del PBI & 0.05 & 4 & 0.20 & Ventas & $78 / 98$ \\
\hline & Acuerdo Energético Perú Brasil & 0.06 & 4 & 0.25 & Ventas & 102 \\
\hline & Hub Energètico para los paises de Ecuador, Chile y Bolivia & 0.08 & 3 & 0.23 & Ventas & 102 \\
\hline Legal & Marco Normativo y Regulatorio estable y claro & 0.08 & 4 & 0.30 & Ventas & $88 / 103$ \\
\hline Tecnológico & Incorporación de tecnología para mejora de equipos de medición & 0.07 & 3 & 0.20 & Rentabilidad & 104 \\
\hline \multirow[t]{3}{*}{ Ecológico } & Incremento e Impulso Parques Energía Eólica / Solar - Energía Renovable & 0.04 & 3 & 0.11 & Ventas & 94 \\
\hline & Incremento exigencias gubernamentales y empresariales & 0.08 & 4 & 0.31 & Ventas & 93 \\
\hline & Amenazas & & & & & \\
\hline \multirow[t]{2}{*}{ Político Gubernamental } & Inestabilidad política que frena Proyectos de Inversión & 0.09 & 4 & 0.38 & Ventas & 68 \\
\hline & Interferencia /Injerencia política en el sector eléctrico COES & 0.09 & 3 & 0.28 & Ventas & $68 / 97$ \\
\hline \multirow[t]{2}{*}{ Económico } & Limitaciones de financiamiento por parte del FONAFE & 0.09 & 3 & 0.28 & Ventas & 69 \\
\hline & Riesgo de Guerra Comercial entre China y EEUU & 0.09 & 3 & 0.28 & Rentabilidad & 75 \\
\hline \multirow[t]{2}{*}{ Ecológico } & Impacto negativo de factores climáticos en desarrollo del sector & 0.13 & 3 & 0.38 & Rentabilidad & 92 \\
\hline & Total & 1.00 & & 3.41 & & \\
\hline
\end{tabular}

Calificar entre 1 y 4

4 Muy Importante

3 Importante

2 Poco Importante

1 Nada Importante

Nota. Elaboración propia 
Referida a la Matriz de Evaluación de Factores Externos (EFE), David (2013) señala:

Sin importar el número de oportunidades o amenazas clave que se incluyan en una matriz EFE, la puntuación ponderada total más alta posible para una organización es de 4.0 y la más baja de 1.0. La puntuación ponderada total promedio es de 2.4. Una puntuación ponderada total de 4.0 indica que una organización responde de manera extraordinaria a las oportunidades y amenazas existentes en su industria. En otras palabras, que las estrategias de la empresa aprovechan eficazmente las oportunidades existentes y minimizan los posibles efectos adversos de las amenazas externas. Una puntuación total de 1.0 indica que las estrategias de la empresa no están aprovechando las oportunidades ni evitando las amenazas externas.

De la evaluación de los factores externos (EFE) se obtiene un puntaje de 3.41, que está por encima del promedio de 2.4, por lo que la empresa Hamek Ingenieros y Asociados S.A.C., está teniendo éxito aprovechando las oportunidades externas y evitando las amenazas a la que se enfrentaría, es decir, tiene un enorme potencial de desarrollo dada las condiciones favorables del mercado local y fundamentadas en el crecimiento de la economía peruana, la existencia de un marco regulatorio que se mantiene en el tiempo y la tendencia al cuidado del medio ambiente lo que genera enormes oportunidades de brindar los servicios de asesoría en el sector energético y estudios técnicos referidos al uso eficiente de la energía y el cuidado del medio ambiente, dentro de las amenazas más representativas se tiene en cuenta la injerencia que podría influir en las decisiones del COES referidas al cambio de condiciones del servicio, $p$, el adecuado funcionamiento del fondo público de inversiones FONAFE y los efectos climáticos que podrían afectar proyectos de inversión en el sector energético, también es relevante mencionar el enorme potencial de crecimiento a nivel regional dado los niveles de exigencia por parte de los sectores gubernamentales, el crecimiento de la demanda en países vecinos lo que permite la celebración de acuerdos energéticos para generar y distribución energía desde Perú hacia países como Brasil, Ecuador, Chile y Bolivia, además de las exigencias empresariales para que las empresas cumplan con la normativa del cuidado del medio ambiente a nivel de países de Latinoamérica. 


\section{Capítulo V. Análisis de la Industria}

En el presente capitulo se analizará y evaluará el nivel de competencia de la empresa Hamek Ingenieros Asociados S.A.C., dentro de la industria en la que se encuentra, o se desea ingresar, utilizando las cinco fuerzas competitivas propuesta por Michael Porter: los nuevos competidores, proveedores, sustitutos, clientes y competencia en el mismo sector.

Se detallará aquellas variables sobre las cuales la empresa Hamek Ingenieros Asociados S.A.C., tiene influencia, con la finalidad de determinar qué tan atractiva es esta industria y cuál es el perfil competitivo de empresa dentro de su industria, para poder decidir si la industria es atractiva, en relación a oportunidades de inversión y rentabilidad.

Para este capítulo se realizaron entrevistas en profundidad a expertos en la industria de energía del Perú.

El análisis de la industria permitirá identificar a los principales actores, cuál es su actual poder de negociación dentro de la cadena, y, además, analizar su comportamiento en el mercado, todo ello servirá para que la empresa Hamek Ingenieros Asociados S.A.C., pueda establecer las estrategias necesarias que maximicen las relaciones con estos actores.

Se determinará la matriz de atractividad de las cinco fuerzas; asimismo se comparará a Hamek Ingenieros Asociados S.A.C., con los competidores de la industria del sector de energía en el Perú y en el extranjero donde ofrece sus servicios; seguidamente se determinarán la matriz de perfil competitivo (MPC).

\subsection{Descripción del Mercado (demanda) e Industria (oferta)}

Como indica Quintanilla (2016), es importante analizar el sector energético peruano a largo plazo, no solo de manera coyuntural. En los últimos trece años, la electricidad creció 132 \%; los hidrocarburos, 276 \%; el cobre, 179 \%, y el PBI, 101. 


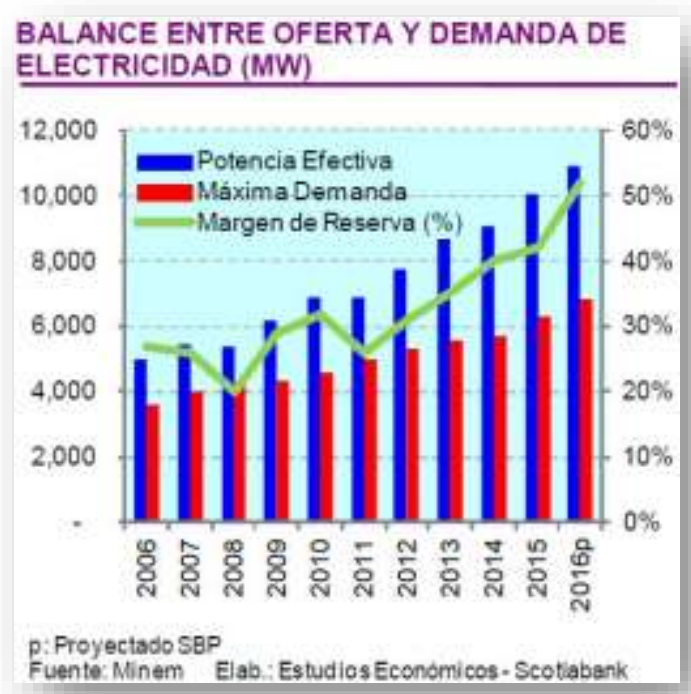

Figura 23. Balance entre Oferta y Demanda de Electricidad. Por Minem. Estudios Económicos-Scotiabank Banco.

El desafío para el Perú radica en contar con energía suficiente para garantizar el crecimiento industrial, minero y económico, en general. Eso implica crear las condiciones para la inversión.

\subsection{Descripción las cinco fuerzas competitivas de la industria.}

Las cinco fuerzas de Porter es un modelo de gestión empresarial, utilizado para desarrollar las estrategias de la organización. A continuación, se analizará las cinco fuerzas de competitividad en la industria: Desarrollo potencial de productos sustitutos, el ingreso potencial de nuevos competidores, rivalidad entre empresas competidoras y consumidores.

Durante el desarrollo de cada matriz, se asigna un factor de relevancia a cada elemento de análisis a cada uno de las fuerzas.

Uno significa bajo atractividad y cinco una alta atractividad.

Finalmente se saca el promedio de las matrices para hallar el grado de atractividad para cada elemento de análisis y se suman todos, dando como resultado el nivel de atractividad de dicha matriz (Porter, 2014).

\subsubsection{Amenaza de productos sustitutos.}

Según David (2013) establece como productos sustitutos al límite máximo al precio que se puede cobrar antes de que los consumidores migren a un producto que cubra la 
misma necesidad. Estos límites de precio establecen la ganancia máxima y generan un mayor nivel de competencia entre los rivales. La disponibilidad de productos sustitutos genera que el cliente realice una comparación de diversos aspectos tales como la calidad, las especificaciones técnicas, el nivel de desempeño, la practicidad de uso, el precio, entre otros. Es por ello, que las empresas se ven obligadas a intensificar esfuerzos para fidelizar a sus clientes y convencerlos que sus productos poseen atributos superiores a los productos sustitutos.

Esta industria muestra a la teoría de Porter un punto excepcional donde el estereotipo de "sustituto" no solo se enmarcaría con respecto al costo de la propuesta, sino a un beneficio mayor de sostenibilidad, quedando el factor "costo" relegado, sin dejar de ser menos importante para que, a lo largo, del tiempo pueda evolucionar y encontrar nuevas.

El criterio más importante que señala Porter es:

Disponibilidad de sustitutos, podemos determinar que Hamek Ingenieros Asociados S.A.C, se encuentra en un sector muy especializado donde las complejidades del uso de los equipos de medición en los sectores de energía y medio ambiente son muy altas.

El estado peruano ha establecido todo un marco legal para ambos sectores, para el sector ambiental lo establece con el objetivo de velar por el cuidado del medio ambiente, promover el uso sostenible de los recursos naturales, promover la conservación de la diversificación biológica y de las áreas naturales protegidos así como promover el desarrollo sostenible de la amazonia con una legislación adecuada, sobre esta base constitucional el estado crea la ley general del medio ambiente, además de las leyes que estructuran el sector medio ambiental.

El sector de energía provee de insumos esenciales para el desarrollo de las actividades económicas del país, debido a las características técnicas y económicas de algunas actividades que conforman la industria. Por estas razones existe la regulación de la industria energética.

Para ambos sectores, el marco legal está regido adicionalmente por las normas establecidas por cada ministerio en su sector. Es decir, los ministerios se encargan de normar, monitorear, fiscalizar y sancionar de acuerdo con el sector económico de su competencia. Además, se cuenta con órganos reguladores que poseen facultades específicas.

Por lo descrito se puede concluir que no existe la posibilidad que los servicios que ofrece Hamek Ingenieros Asociados S.A.C, puedan ser remplazados por servicios parecidos, ya todos ellos se encuentran bajo regulaciones ya establecidas por el estado 
peruano, para la empresa es importante competir en un mercado donde no hay sustitutos importantes, ya que sería un limitante para la rentabilidad y crecimiento.

\subsubsection{Amenaza de entrada de nuevos competidores.}

De acuerdo con Porter (2017), "es importante en todo plan estratégico conozcan el grado de amenaza que tiene la industria ante la llegada de nuevos competidores, y para ellos es necesario identificar de forma clara cada una de las barreras de entrada y sus implicaciones para la respectiva organización" (p.81).

Consideraremos los criterios más importantes, que señala Porter, para establecer la estrategia dentro del modelo de negocio de la empresa.

- Inversión necesaria o requisitos de capital, no es necesario tener un alto capital, su costo de entrada no es fuerte, por lo que las empresas se sentirán interesadas en participar.

- Barreras gubernamentales, impuesta por organismo, como el COES en el sector de energía y el SENACE para el sector de medio ambiente, en ambos casos una de los principales requisitos es poder estar inscrita como consultora calificada, para el desarrollo de estos servicios, por la altas exigencia basada en la experiencia de los profesionales y de la empresa, dependerá la inscripción y calificación para formar parte de consultoras autorizadas para la elaboración de estudios ambientales y de auditores energéticos.

En otros términos, para entrar al mercado de las consultoras en el sector de energía y media ambiente, en los servicios que ofrece Hamek Ingenieros Asociados S.A.C, estas tendrán que cumplir con una serie de requisitos exigidos por dichas entidades.

Represalias, no existe una reacción de las empresas ya establecidas en el sector. Entre las barreras de entrada, para ingresar a la industria es la falta de experiencia en el sector, pero es importante mencionar que la amenaza de nuevos competidores es latente, pues el servicio es muy especializado y asociado a expertos en el sector que actualmente forman parte del staff, de las empresas que actualmente prestan el servicio, pero que más adelante pueden buscar independizarse y volverse competidores de las actuales empresas en el mismo rubro.

\subsubsection{Poder de negociación de los clientes.}

De acuerdo a Bernal y Sierra (2013) "Las excelentes relaciones de las organizaciones con el cliente o los compradores son cada vez más un factor clave para la competitividad de las mismas" (p. 81) 
Bajo el panorama de la industria de energías y medio ambiente, se visualizan dos grupos principales dentro de los compradores, el Estado Peruano y Empresas privadas. Las principales variables que definen estos factores son:

- Concentración de clientes, en la actualidad, la demanda de energía del mercado peruano se ha ido incrementando, generando una necesidad de mayor producción en las tecnologías convencionales de producción de energía (MINEM, 2017).

De acuerdo al crecimiento del PBI en los sectores construcción, industrial, minero y manufacturero, las necesidades de estudio ambientales también está en aumento, por formar parte de muchos proyectos de inversión privada y pública.

- Diferenciación, los servicios no son diferenciados, son estándares con la competencias, el poder lo tiene la empresa. La competencia es limitada por ello los costos ya se encuentran dentro de parámetros ya establecidos.

Identificación de la marca, en el sector energía existen solo tres consultoras que se encuentran activos y acreditadas por el COES, para realizar los mismos servicios

que Hamek Ingenieros Asociados S.A.C ofrece, sin embargo es importante precisar que el COES tiene poder de decisión para la adjudicación y periodicidad de los distintos estudios de consultoría y de asesoría técnica.

El poder de negociación de los clientes es mayor, en esta industria los servicios que se ofrecen no son diferenciados, están estandarizados y las empresas que ofrecen el servicio son pocas para una demanda mayor.

\subsubsection{Poder de negociación de los proveedores.}

El poder de negociación de los proveedores afecta en gran medida en los costos de la empresa. Este impacto es alto, cuando en el mercado no se cuenta con un gran número de proveedores. Es por ello, que, dentro de las tácticas utilizadas por las empresas para hacer frente a esta problemática, una alternativa es aplicar la estrategia de integración hacia atrás, obteniéndose de esta manera el control del proveedor. (David, 2013).

Las variables más significativas de esta fuerza son las siguientes:

Concentración de proveedores, para el caso de la empresa Hamek Ingenieros y Asociados S.A.C, los proveedores que tiene, son empresas representantes de los equipos de medición energética y ambiental, en su gran mayoría son equipos importados, y por ser muy especializadas son pocas empresas que cuentan con la representación, esto dificulta a la empresa tener el poder de negociación. 
- Costos de cambio, para el caso de los laboratorios, los estándares ya se encuentran dentro de una escala de costos, o se incurre en costo al cambiar de proveedor.

La empresa no tiene poder de negociación con los proveedores, existen pocos proveedores, en el caso de laboratorios son menos, es por lo que la empresa no tiene la capacidad de mejorar plazos de entrega, ni mejores precios.

\subsubsection{Competencia en el mismo sector.}

De acuerdo con David 2013, señala lo siguiente:

La rivalidad entre empresas competidoras suele ser la más poderosa de las cinco fuerzas competitivas. Las estrategias de una empresa únicamente pueden tener éxito en la medida en que le proporcionen una ventaja competitiva sobre las estrategias de las empresas rivales. Los cambios de estrategia que pongan en práctica una empresa podrían dar lugar a represalias como la reducción de precios, las mejoras a la calidad, la introducción de nuevas características en los productos, el ofrecimiento de servicios, la extensión de garantías y el aumento de publicidad. (p. 76).

El Comité de Operaciones Económica del Sistema Interconectado Nacional (COES SINAC), indica que la empresa Hamek Ingenieros y Asociados S.A.C., tiene como competencia en consultoría en su sector de energía y medio ambiente a las siguientes empresas:

1. Centro de Conservación de Energía y del Ambiente (CENERGIA)

2. Alfa Plus SAC

A continuación, se describe a las empresas mencionadas, que ofrecen servicios similares y que representan una competencia directa:

\section{Centro de Conservación de Energía y del Ambiente (CENERGIA).}

Fue creado en 1984, como una asociación sin fines de lucro, integrando el esfuerzo de empresas e instituciones del sector público y privado, interesadas en promover la eficiencia energética en el país. En 1994, sus objetivos fueron ampliados para promover la conservación del ambiente y el desarrollo de las energías nuevas y renovables.

\section{Alfa Plus SA.}

Fue creado en 1988, no hay información sobre esta empresa en la web, sin embargo, se encuentra en la relación del COES como consultora calificada para desarrollar los servicios de Potencia Efectiva y Costos Variables, servicios similares a los servicios que Hamek Ingenieros y Asociados S.A.C., desarrolla en el sector de energía. 
Para considerar la intensidad de la competencia hay que considerar la influencia de los siguientes factores:

- Concentración, son pocas empresas las que dominan el mercado, las cuales han sido mencionadas anteriormente, solo son tres empresas.

Los competidores indirectos son numerosos o del mismo tamaño y fuerza competitiva. De acuerdo al brochure publicado en el 2010 los servicios que ofrece la consultora son múltiples dentro del sector de energía, se desarrollan en el sector eléctrico, hidrocarburo, minería, industrial y energía renovable.

- Diferenciación de producto, tienen una leve diferenciación basado en los plazos y del uso de equipos con más Tecnología y precisión. En realidad, el sector es muy estandarizado.

- $\quad$ Costo de cambio, la demanda de los proyectos crece, por la aparición de nuevas generadoras, ya que, según normas dictaminadas por el COES, las pruebas de Potencia y rendimiento se realizan cada dos años, y las de costos variables cuatro años.

Podemos concluir que el grado de rivalidad entre los competidores es baja, ya que no existe una gran cantidad de estos, lo que la empresa Hamek Ingenieros Asociados S.A.C. hace para diferenciarse de la competencia es dar un plus sobre sus tiempos de entrega, debido a que son servicios estandarizados.

\subsection{Matriz de atractividad de cada una de las cinco fuerzas}

La matriz de atractividad, según el estudio señalaron:

El modelo de matriz de General Electric / McKinsey (GE / Mckinsey) para el análisis de competitividad es una técnica para evaluar unidades de negocios estratégicas a la luz de la fortaleza de las unidades industriales individuales y el atractivo de la industria. Generalmente lo utilizan las empresas para elegir el posicionamiento estratégico del negocio (Han, J., Park, H., Ock, J., \& Jang, H., (2014), p. 468).

\section{Sustitutos.}

Se considera relevante analizar la matriz de atractividad de la industria frente a los productos sustitutos, según se detalla a continuación. 
Tabla 19

Matriz de Atractividad de Amenaza frente a Productos Sustitutos

\begin{tabular}{|c|c|c|c|c|c|}
\hline Conceptos & $\begin{array}{l}\text { No } \\
\text { Atractivo }\end{array}$ & $\begin{array}{c}\text { Poco } \\
\text { Atractivo }\end{array}$ & Neutral & Atractivo & $\begin{array}{c}\text { Muy } \\
\text { atractivo }\end{array}$ \\
\hline \multicolumn{6}{|c|}{ Poca disponibilidad de productos } \\
\hline sustitutos & & & & & 5.00 \\
\hline $\begin{array}{l}\text { Costo de cambio del } \\
\text { consumidor }\end{array}$ & & & & 4.00 & \\
\hline $\begin{array}{l}\text { Agresividad de los productos } \\
\text { sustitutos }\end{array}$ & & & & 4.00 & \\
\hline
\end{tabular}

Promedio

4.33 Atractivo

Calificación: Muy alto $=5$, Muy bajo $=1$.

Nota. Elaboración propia.

De la matriz, se puede concluir que existe poca disponibilidad de productos sustitutos, el costo de cambio del consumidor y la agresividad de los productos sustitutos son bastantes bajos, la cual resulta muy atractivo para Hamek Ingenieros y Asociados S.A.C, dando como resultando promedio 4.33 lo cual significa que es atractivo para la empresa, no hay amenaza para el sector.

\section{Potenciales.}

Se considera relevante analizar la matriz de atractividad de la industria frente a los potenciales, según se detalla a continuación.

Tabla 20

Matriz de Atractividad de Amenaza frente a Nuevos Participantes

\begin{tabular}{|c|c|c|c|c|c|}
\hline Conceptos & $\begin{array}{r}\text { No } \\
\text { Atractivo } \\
\end{array}$ & $\begin{array}{c}\text { Poco } \\
\text { Atractivo }\end{array}$ & Neutral & Atractivo & $\begin{array}{c}\text { Muy } \\
\text { atractivo }\end{array}$ \\
\hline Barreras de ingreso & & & & & 5.00 \\
\hline Requerimiento de capital & & 2.00 & & & \\
\hline Represalias esperadas & & 2.00 & & & \\
\hline
\end{tabular}

Promedio 3.00 Neutral

Calificación: Muy alto $=5$, Muy bajo $=1$.

Nota. Elaboración propia. 
El requerimiento del capital que se necesitan para ingresar al mercado, así como como las represalias que tomarían los competidores son poco atractivo, mientras que las barreras de ingreso son atractivas porque limitan el ingreso de nuevos competidores.

El resultado promedio frente a nuevos participantes es de 3.00, lo cual resulta neutral para la empresa, no existe entrada de nuevos competidores, por las barreras gubernamentales. Pero se debe considerar, que existe la amenaza del personal de la misma empresa o de la competencia, los cuales están aptos después de los años que establece el COES.

\section{Clientes.}

Se considera importante analizar la matriz de atractividad de la industria frente a los clientes, según se detalla a continuación.

Tabla 21

Matriz de Atractividad frente a los Clientes.

\begin{tabular}{|c|c|c|c|c|c|}
\hline Conceptos & $\begin{array}{r}\text { No } \\
\text { Atractivo }\end{array}$ & $\begin{array}{c}\text { Poco } \\
\text { Atractivo }\end{array}$ & Neutral & Atractivo & $\begin{array}{l}\text { Muy } \\
\text { atractivo }\end{array}$ \\
\hline Sensibilidad al precio & & & & 4.00 & \\
\hline Nivel de calidad de servicio & & & 3.00 & & \\
\hline Existencia de muchos clientes & & & & 4.00 & \\
\hline Pcos postores para satisfacer demanda & & & & & 5.00 \\
\hline
\end{tabular}

Calificación: Muy alto $=5$, Muy bajo $=1$.

Nota. Elaboración propia

El análisis de atractividad frente a los clientes arroja un puntaje de 4, el cual resulta atractivo para Hamek Ingenieros y Asociados S.A.C, fundamentado en la poca existencia de postores para satisfacer la demanda, además de la existencia de muchos clientes que demandan los servicios ofrecidos.

\section{Proveedores.}

A continuación, se describe una lista sobre el poder de negociación de proveedores de Hamek Ingenieros Asociados S.A.C. 
Tabla 22

Matriz de Atractividad frente a Proveedores.

\begin{tabular}{|c|c|c|c|c|c|}
\hline Conceptos & $\begin{array}{l}\text { No } \\
\text { Atractivo }\end{array}$ & $\begin{array}{c}\text { Poco } \\
\text { Atractivo }\end{array}$ & Neutral & Atractivo & $\begin{array}{l}\text { Muy } \\
\text { atractivo }\end{array}$ \\
\hline Número de proveedores & & 2.00 & & & \\
\hline $\begin{array}{l}\text { Los servicios de proveedores } \\
\text { son difereneciados }\end{array}$ & & 2.00 & & & \\
\hline Poco acceso a los suministros & & 2.00 & & & \\
\hline Baja frecuencia de renovación de equipo & & & & 4.00 & \\
\hline
\end{tabular}

Promedio

2.50 Neutral

Calificación: Muy alto $=5$, Muy bajo $=1$.

Nota. Elaboración propia

Del análisis de determina como promedio un puntaje de 2.4, lo cual significa que no influye ni positiva ni negativamente a la empresa. Pero debemos considerar que es la de menor promedio, es decir es más atractivo para la industria, ya que no tenemos poder de negociación con los proveedores, por ser pocos en el mercado y la empresa está expuesta a sus tiempos de entrega.

\section{Competencia en el mismo sector.}

A continuación, se analiza la competencia en el mismo sector con Hamek Ingenieros y Asociados S.A.C.

Tabla 23

Matriz de Atractividad frente a la Rivalidad de Competidores.

\begin{tabular}{|c|c|c|c|c|c|}
\hline Conceptos & $\begin{array}{r}\text { No } \\
\text { Atractivo }\end{array}$ & $\begin{array}{c}\text { Poco } \\
\text { Atractivo }\end{array}$ & Neutral & Atractivo & $\begin{array}{c}\text { Muy } \\
\text { atractivo }\end{array}$ \\
\hline Alta barrera de ingreso & & & & & 5.00 \\
\hline Poca presencia de competidores & & & & & 5.00 \\
\hline Alto nivel de estandarización de servicio & & & 2.00 & & \\
\hline Potencial de crecimiento de la demanda & & & & 4.00 & \\
\hline
\end{tabular}

Promedio

4.00 Atractivo

Calificación: Muy alto $=5$, Muy abajo $=1$.

Nota. Elaboración propia 
Del análisis se puede concluir que existen pocos competidores actuales, las barreras de ingreso son altas, el servicio es altamente calificada y estandarizada, lo cual resulta atractivo para Hamek Ingenieros y Asociados S.A.C, el potencial de crecimiento de la demanda es alta, dando como resultando promedio 4.00 lo cual significa que es Atractivo para Hamek Ingenieros y Asociados S.A.C.

\subsection{Análisis del Grado de atractividad de la industria}

De acuerdo a la elaboración de las matrices de atractividad en base a las cinco fuerzas de Michael Porter, a continuación, se presenta la calificación obtenida por cada una de las cinco fuerzas anteriormente analizadas, las cuales son: Amenaza de productos sustitutos, amenaza de competidores potenciales, poder de negociación de clientes, poder de negociación de proveedores y rivalidad entre competidores

La fuerza principal y secundaria atractivo para Hamek Ingenieros Asociados S.A.C., es la amenaza de productos sustitutos y poder negociación de los clientes, permitiendo elaborar estrategias destinadas a captar un número mayor de ellos y obtener fidelidad de ellos mismos. 
Tabla 24

Matriz del grado de Atractividad o Competitividad de la Industria

\begin{tabular}{|c|c|c|c|c|c|c|}
\hline \multirow[t]{2}{*}{ Fuerzas Competitivas } & \multirow[t]{2}{*}{ Puntaje } & \multicolumn{5}{|c|}{ Grado de Atractividad de la Industria } \\
\hline & & Muy Alto & Alto & Medio & Bajo & Muy Bajo \\
\hline Amenaza frente a Productos Sustitutos & 4.33 & & & & & \\
\hline Poder de Negociación de los Clientes & 4.00 & & & & & \\
\hline Poder de Negociación de los Proveedores & 2.50 & & & & & \\
\hline Total Global & 3.57 & & & & & \\
\hline
\end{tabular}

\section{Nota. Elaboración Propia.}


Se realiza un análisis de la atractividad de la industria teniendo en cuenta los resultados conseguidos en el análisis de cada una de las fuerzas de Porter de manera individual.

El puntaje general es de 3.47 que corresponde a un grado de atractivo alto, lo que se presenta como una oportunidad para Hamek Ingenieros Asociados S.A.C. pues le permite establecer estrategias y seguir desarrollando negocios sin una mayor preocupación respecto a la presencia de nuevos participantes, productos sustitutos o que tanto los proveedores como los clientes tengan un mayor poder de negociación.

\subsection{Matriz de perfil competitivo (MPC)}

Como lo anota David (2013):

La matriz de perfil competitivo (MPC) identifica los principales competidores de una compañía, así como sus fortalezas y debilidades principales en relación con la posición estratégica de una empresa que se toma como muestra. Los factores críticos de éxito en una MPC incluyen cuestiones tanto internas como externas; por consiguiente, las clasificaciones se refieren a las fortalezas y debilidades,

Donde, 4 = fortaleza principal, $3=$ fortaleza menor, $2=$ debilidad menor y $1=$ debilidad mayor. (p. 111)

Para la determinación de los factores críticos de éxito se recurrió a fuentes primarias basadas en entrevistas a profundidad realizada a expertos y profesionales del sector, determinándose la valoración y el peso ponderado de cada una de las oportunidades y amenazas sobre el sector, además para establecer las calificaciones se recurrió a la valoración de expertos del sector quienes evaluaron a cada una de las cuatro empresas en función del conocimiento profundo que tenía de estas empresas y su participación activa en las convocatorias técnicas realizadas para la prestación de los servicios técnicos.

Con la información disponible se confeccionó la Matriz de Perfil Competitivo (ver Tabla 25) para poder determinar la posición de Hamek Ingenieros y Asociados S.A.C., frente a sus competidores y obtiene un puntaje de 3.74 que es superior a los demás. 


\section{Tabla 25}

Matriz del Perfil Competitivo Hamek Ingenieros y Asociados SAC.

\begin{tabular}{|c|c|c|c|c|c|c|c|c|c|}
\hline & \multirow{2}{*}{ Factores Críticos de Éxito } & \multirow{2}{*}{ Pond. } & \multicolumn{3}{|c|}{ HAMEK } & \multicolumn{2}{|c|}{ CENERGIA } & \multicolumn{2}{|c|}{ ALFA PLUS } \\
\hline & & & Calif. & & Puntaje & Calif. & Puntaje & Calif. & Puntaje \\
\hline 1 & Trayectoria en Mercado Local & 0.15 & & 3 & 0.45 & 4 & 0.60 & 1 & 0.15 \\
\hline 2 & Conocimiento Sector / Esperiencia del Personal & 0.15 & & 4 & 0.60 & 3 & 0.45 & 2 & 0.30 \\
\hline 3 & Incursión Mercado Regional Chile / El Salvador & 0.20 & & 4 & 0.80 & 4 & 0.80 & 1 & 0.20 \\
\hline 4 & Equipos Tecnificados de Medición & 0.10 & & 3 & 0.30 & 4 & 0.40 & 1 & 0.10 \\
\hline 5 & Nivel del Servicio & 0.20 & & 4 & 0.80 & 4 & 0.80 & 1 & 0.20 \\
\hline \multirow[t]{2}{*}{6} & Participaciòn Relativa Mercado Local & 0.20 & & 4 & 0.80 & 3 & 0.60 & 1 & 0.20 \\
\hline & & 1.00 & & & 3.75 & & 3.65 & & 1.15 \\
\hline
\end{tabular}
4. Fortaleza mayor
3. Fortaleza menor
2. Debilidad menor
1. Debilidad mayor

Nota. Elaboración propia. 
Del análisis de la Matriz de Perfil Competitivo se obtuvo un puntaje de 3.74 versus el 3.64 obtenido por la empresa Cenergía. Las calificaciones dadas y los pesos que se le atribuyen a cada uno de los factores críticos se obtuvieron de realizar una entrevista en profundidad con un experto del sector que actualmente trabaja en un ente regulador, a quien previamente se le solicitó definir desde su perspectiva cuales eran los factores claves del sector para luego solicitarle pueda realizar una valoración teniendo en cuenta que se evaluaron a las tres empresas vigentes en el mercado participando de consultorías para el sector energético y medioambiente. Se excluye del análisis a la empresa Global Energy por no mantenerse activa en el mercado en los últimos años.

Importante precisar que la empresa Cenergia aventaja a Hamek Ingenieros Asociados S.A.C., cuenta con más trayectoria en el mercado y ha tecnificado más sus equipos para brindar sus servicios, respecto a lo precios ofertados son similares y regulados además están asociados a un nivel de servicio similar, de allí que no hay diferenciación y no se han incluido en la matriz de perfil competitivo. Respecto a Hamek Ingenieros Asociados S.A.C., cuenta con un mayor conocimiento técnico de la mano de su fundador y ello ha permitido tener una mayor participación en los distintos servicios donde Hamek Ingenieros Asociados S.A.C., participa de manera activa obteniendo para el año 2018 una participación del 42\% de los servicios prestados a nivel local superando en participación a su retador principal Cenergía.

Además, se considera valioso el capital humano conformado por especialistas en el sector dado el conocimiento que tienen que es valorado por el evaluador.

Respecto al mercado regional, tanto Cenergia como Hamek Ingenieros Asociados S.A.C., prestan servicios en varios países de la región, en el caso de Hamek Ingenieros Asociados S.A.C., presta servicios en El Salvador desde el 2014 y Chile desde el 2016 lo que finalmente le ha permitido incrementar sus ingresos totales del 2014 al 2018 en más de un $140 \%$.

Respecto a los competidores en el mercado de EI Salvador, Hamek Ingenieros Asociados S.A.C. compite con diez consultoras según Tabla 26 elaborada con la información proporcionada por la UT (2018) según se detalla a continuación: 
Tabla 26.

Relación de Empresas Competidoras en El Salvador.

\begin{tabular}{cccc}
\hline & Item & \multicolumn{1}{c}{ Empresas } & Procedencia \\
\hline & 1 & Mercados de Energía Consultoría (MdE) & Brasil \\
& 2 & Ergon Plus & Mexico \\
Servicios de & 3 & Thermogen Power Services Inc. & Canada \\
Consultoria & 4 & Centro de Conservacion de Energia y del Ambiente & Perú \\
& 5 & Sustanability \& Reserch S.A. de C.V & El Salvador \\
& 6 & Ingenieros Consultores Lee e Infante Ltda. & Colombia \\
& 7 & Universidad del Salvador & El Salvador \\
& 8 & Tecpro S.A. de C.V & El Salvador \\
& 9 & Estudios Electricos Soluciones de Vanguardia & Argentina \\
& 10 & Ingeniero Francisco Abel Martínez & El Salvador \\
\hline
\end{tabular}

Nota. Elaboración propia.

En el mercado de Chile, Hamek Ingenieros Asociados S.A.C. compite con ocho empresas que brindan servicios similares según se detalla en la Tabla 27 elaborada con la información proporcionada por el CEN (2018) según se detalla a continuación:

Tabla 27

Relación de Empresas Competidoras en Chile.

\begin{tabular}{lclc}
\hline & Item & & Empresas \\
\hline & & & Procedencia \\
Servicios & 1 & Thermogen power Services Inc. & Canada \\
Concultoria & 2 & Tecnatom S.A. (Tecnatom) & Madrid \\
& 3 & Certa Veritas B.V (Certa) & N.D \\
& 4 & InTractebel Engineering S.A. & Bélgica \\
& 5 & McHale and Associates, Inc. & Estados Unidos \\
& 6 & Tecpro S.A. de C.V & El Salvador \\
& 7 & Estudios Electricos Soluciones de Vanguardia & Argentina \\
\hline
\end{tabular}

Nota. Elaboración propia.

Finalmente, mencionamos que el experto del sector a la cual se le realizó una entrevista a profundidad anota que la empresa Alfa Plus tiene una participación inferior al 4\% para el año 2018. 


\section{Capítulo VI. Análisis Interno}

En el presente capítulo, se describe y analizan las actividades que conforman la cadena de valor, de la empresa Hamek Ingenieros Asociados S.A.C, identificando competencias, sus indicadores, comparación frente a la competencia y ventajas competitivas.

El objetivo es identificar sus factores estratégicos que se encuentran al interior de la empresa; es decir, aquellas fortalezas y debilidades relevantes, que permiten determinar si una la organización está en condiciones de aprovechar al máximo sus oportunidades y mitigar exitosamente las amenazas de su entorno.

Para la realización del presente capítulo, se han efectuado entrevistas de profundidad a la empresa, realizadas al gerente general, a los jefes de las dos áreas y al personal interno, con la finalidad de dar a conocer toda la información relevante, para evaluar internamente la empresa.

Se desarrollará el benchmarking de la empresa Hamek Ingenieros y Asociados S.A.C., para analizar la competencia, con el objetivo de tener una mejora continua, en cuanto a la calidad de sus servicios; con el fin de diferenciarse de sus competidores y lograr sus metas.

Es importante resaltar que la mayor dificultad del benchmarking es tener acceso información de otras empresas, debido a que las fuentes de la competencia en el sector de consultoría; de energía y medio ambiente son limitadas.

Finalmente, se implementa la Matriz de evaluación de factores internos conocida como la Matriz EFI.

\subsection{Descripción de las actividades de la cadena de valor de la empresa Hamek Ingenieros Asociados S.A.C: Logística interna, Operaciones, Logística externa, Mercadotecnia, Servicios, Adquisiciones, Recursos Humanos, Tecnología, Infraestructura}

Según Michael E. Porter, "El margen es la diferencia entre el valor total y los costes totales incluidos por la empresa para desempeñar las actividades generándonos al valor"

Como se muestra en la Figura 24, la cadena de valor clasifica las actividades generadoras de valor en dos actividades, Primarias y de Apoyo. 
Reciben las entradas o materias primas hasta que sufren el proceso de transformación, pasando a ser salidas o productos terminados.

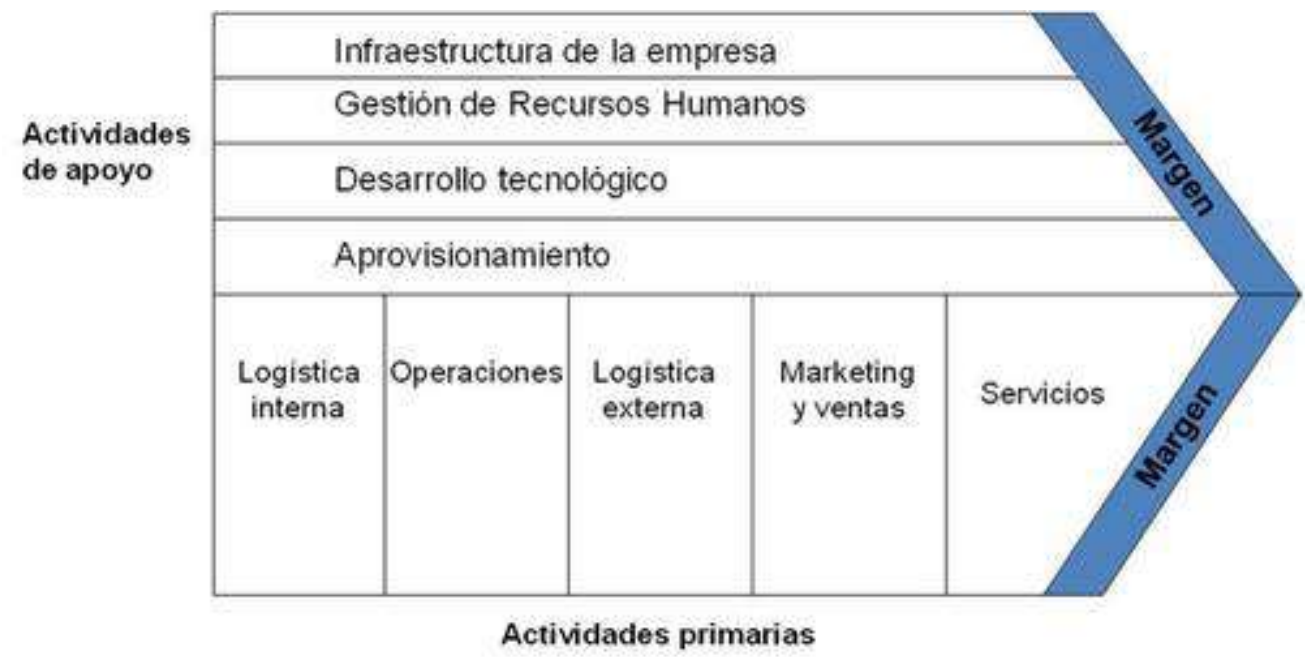

Figura 24. La cadena de Valor Tomado de "Administración” por Revista de la Empresa (2016).

A continuación, se describen las actividades de la cadena de valor de la empresa Hamek Ingenieros y Asociados S.A.C

\section{Actividades Primarias.}

\section{Logística (Interna).}

Hamek Ingenieros y Asociados S.A.C. cuenta con un proceso centralizado de documentación; es así que todas las facturas, contratos de personal, informes y otros documentos se almacenan en la sede principal en La Molina. Cada documentación se almacena con su respectiva orden de servicio, la cual debe estar autorizado por el jefe inmediato de cada área.

De la misma manera Hamek Ingenieros y Asociados S.A.C. cuenta con un proceso de recepción de documentos, proceso de cierre contable, proceso para realizar las órdenes de compra y un proceso administrativo.

En cuanto al transporte del personal a las zonas de trabajo, son realizados por empresas especializadas en el rubro, o en su defecto el personal es transportado con recursos propios. 
El área operativa, está a cargo de dos personas, que son los responsables de cada área.

El flujo de trabajo en Hamek Ingenieros y Asociados S.A.C. empieza con el envió de una carta de presentación con los servicios ofrecidos o en su defecto, se realiza una visita y se hace la presentación de los servicios. Seguidamente si existe interés se procede a realizar una visita técnica a las instalaciones de los posibles clientes, todo ello para elaborar la mejor propuesta económica, si la propuesta es aceptada por los clientes se realiza las coordinaciones para la programación del inicio de los servicios.

Para mayor detalle, se adjunta el diagrama de flujo general de los servicios de Hamek Ingenieros y Asociados S.A.C. 


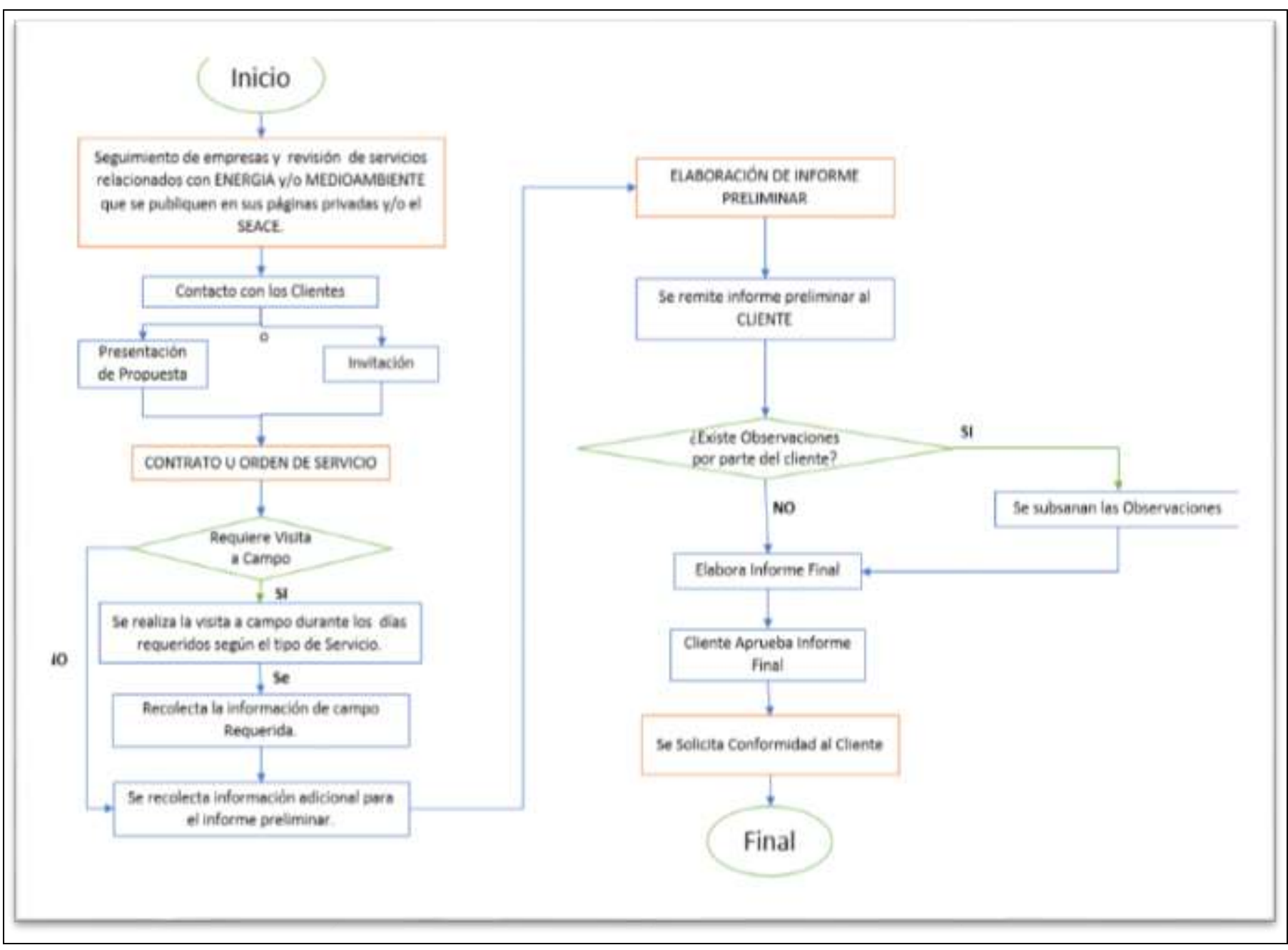

Figura 25. Diagrama de flujo de los servicios de la empresa 


\section{Almacén (Logística Interna).}

Una vez culminado los servicios de campo de Hamek Ingenieros y Asociados S.A.C., los equipos de medición en energía y medio ambiente son llevados al almacén ubicado dentro de la oficina de la empresa, del mismo modo los equipos de protección personal, son resguardados en el almacén. Ambiente acondicionado con las medidas necesarias para proteger y mantener en óptimas condiciones los equipos.

\section{Marketing y Ventas.}

Respecto al proceso de marketing, la empresa lo gestiona periódicamente a través de empresas especializadas. Cuenta con página web, cuyo contenido es revisado y actualizado permanentemente, tiene presencia en redes sociales, correo corporativo, y material publicitario y merchandising, así mismo una fuente importante para dar a conocer la empresa es a través de las recomendaciones obtenidas de sus clientes, lo que ayuda a incrementar la reputación de Hamek Ingenieros Asociados S.A.C.

\section{Post Venta.}

Hamek Ingenieros Asociados S.A.C no cuenta con un área exclusiva de Post venta, pero a través de las reuniones periódicas con los clientes a cargo del gerente general y de los jefes de cada área, se afianza una relación comercial duradera basada en una plena satisfacción de los servicios brindados.

\section{Actividades de Apoyo.}

\section{Abastecimiento.}

El proceso de compra y negociación de los materiales de oficina, inmobiliario y equipos de medición es realizado por la gerencia administrativa previa aprobación de la gerencia general.

\section{Recursos Humanos.}

La empresa no cuenta con un área de recursos humanos, el reclutamiento de personal es realizado directamente por la gerencia administrativa.

Todo personal nuevo pasa por una inducción en la cual se le entrega el reglamento interno, además se le brinda los alcances de la misión, visión, política y valores de la empresa.

Así mismo reciben capacitación en uso y mantenimiento de los equipos de medición de energía y medio ambiente. 
Infraestructura.

La dirección de la empresa está a cargo de la Gerencia General y la Gerencia Administrativa, quienes forman parte de la sociedad de la empresa.

Hamek Ingenieros y Asociados S.A.C. actualmente cuenta con una sola oficina principal, ubicada en la calle Santa Cruz de Tenerife MZ "C" Lote 6 Urb. La Capilla, La Molina.

\section{Desarrollo Tecnológico.}

La empresa cuenta con equipos de medición y equipos para el monitoreo ambiental, todos ellos de procedencia americana y alemana. Todos de última generación para el desarrollo de los procesos productivos, asimismo, Hamek Ingenieros Asociados S.A.C. no cuenta con un sistema ERP que le permita integrar la información administrativa, contable, y logística para la toma de decisiones.

La compañía no realiza investigación técnica ni desarrollo de productos nuevos, tampoco realiza estudios de mercado, en la Figura 26 se muestra la cadena de valor de la empresa Hamek Ingenieros Asociados S.A.C. 


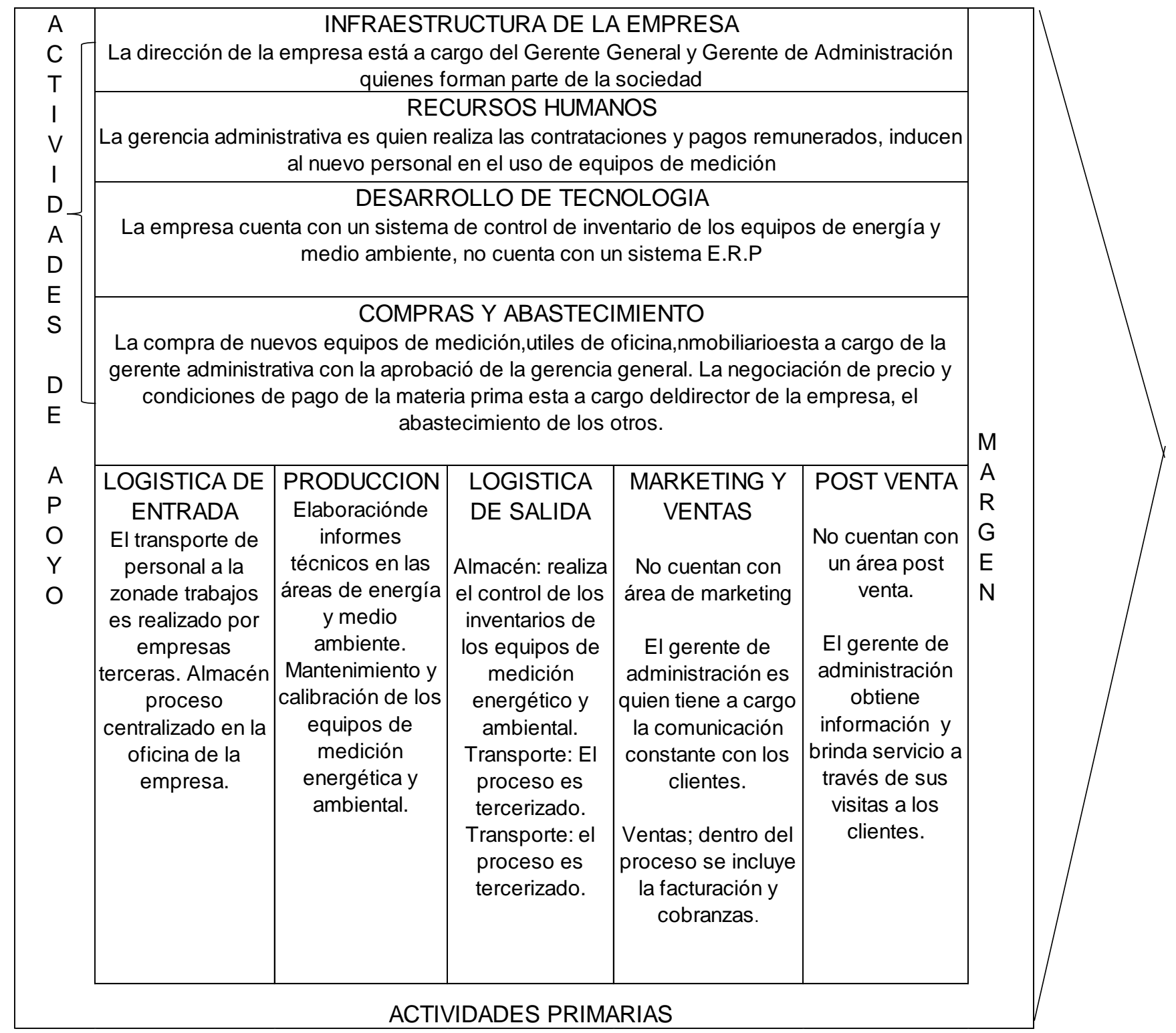

Figura 26. La cadena de valor de la empresa. Adaptado de Porter, M. (2014). Ventaja competitiva, creación y sustentabilidad de un rendimiento superior.

\subsection{Indicadores de cada una de las actividades de la cadena de valor}

Después de haber realizado un análisis de cada una de las actividades de la cadena de valor de la empresa, resulta fundamental hacer el seguimiento respectivo.

De acuerdo al análisis realizado se determinaron cuáles son los indicadores necesarios para cada una de las actividades, tanto primarias como de apoyo. En las siguientes tablas se muestran los indicadores señalando cuales están implementados y cuales aún no. 
En la tabla 28, se presenta los indicadores del proceso de la logística interna, se analizó ocho indicadores, de las cuales el indicador del costo de transporte se encuentra implementado, la implementación se elabora como parte de la determinación de los presupuestos de cada servicio, para el caso del nivel de desempeño de proveedores también es un indicador implementado en la empresa, pues es determinante para continuar solicitando los servicios a los mismos proveedores.

\section{Tabla 28}

Indicadores de Actividades Primarias: Logística Interna

\begin{tabular}{|c|c|c|c|c|}
\hline Proceso & Indicador & Objetivo & Valor / Unidad de medida & $\begin{array}{c}\text { Implementado } \\
\text { / No implementado }\end{array}$ \\
\hline & $\begin{array}{l}\text { Cumplimiento de los } \\
\text { procesos de } \\
\text { almacenaje de toda la } \\
\text { documentación } \\
\text { ingresada. }\end{array}$ & $\begin{array}{l}\text { Medir el cumplimiento de los } \\
\text { procesos de busqueda de la } \\
\text { documentación almacenada. }\end{array}$ & $\%$ de cumplimiento & No Implementado \\
\hline & $\begin{array}{l}\text { Puntualidad de las } \\
\text { empresas } \\
\text { transportistas, en el } \\
\text { traslado de personal. }\end{array}$ & $\begin{array}{l}\text { Medir el cumplimiento, } \\
\text { puntualidad de las empresas de } \\
\text { transporte al personal }\end{array}$ & $\%$ de cumplimiento & No Implementado \\
\hline \multirow[t]{6}{*}{$\begin{array}{l}\text { Logística } \\
\text { Interna }\end{array}$} & Costo de transporte & $\begin{array}{l}\text { Medir si los costos de transporte } \\
\text { estan alineados los costos } \\
\text { proyectados }\end{array}$ & $\begin{array}{l}\$ 90 \text { diarios por alquiler de } \\
\text { camioneta }\end{array}$ & Implementado \\
\hline & $\begin{array}{l}\text { Nivel de desempeño } \\
\text { de proveedores de los } \\
\text { proveedores de los } \\
\text { laboratorios, } \\
\text { empresas de } \\
\text { calibración de } \\
\text { equipos. }\end{array}$ & $\begin{array}{l}\text { Medir el desempeño del } \\
\text { proveedor (Calidad de servicio y } \\
\text { producto) }\end{array}$ & $\%$ de Cumplimiento & Implementado \\
\hline & $\begin{array}{l}\text { Puntualidad en la } \\
\text { entrega de nuestro } \\
\text { proveedores }\end{array}$ & $\begin{array}{l}\text { Medir el cumplimiento de la } \\
\text { entregas en fecha y horaros } \\
\text { acordados }\end{array}$ & $\%$ de cumplimiento & No Implementado \\
\hline & Rotacion de inventario & $\begin{array}{l}\text { Medir el numero de veces que } \\
\text { han renovado, los equipos y } \\
\text { materiales de oficina. }\end{array}$ & $\begin{array}{l}\text { Costo de venta / Costo } \\
\text { promedio de existencias }\end{array}$ & No Implementado \\
\hline & Informes Observados & $\begin{array}{l}\text { Medir la cantidad de informes } \\
\text { observados }\end{array}$ & $\%$ de informes devueltos & No Implementado \\
\hline & Fill rate & $\begin{array}{l}\text { Medir el nivel de cumplimiento en } \\
\text { la atención al pedido de } \\
\text { cotización }\end{array}$ & \% de atención & No Implementado \\
\hline
\end{tabular}

Nota. Elaboración propia.

En la tabla 29 se analizan los indicadores de las actividades de Producción y Mantenimiento, para ambos casos se determinó que sus indicadores se encuentran 
implementados, las actividades derivadas de los indicadores forman parte del control permanente de los servicios en ejecución. Nota. Elaboración propia.

\section{Tabla 29}

Indicadores de Actividades Primarias: Producción y Mantenimiento.

\begin{tabular}{|c|c|c|c|c|}
\hline Proceso & Indicador & Objetivo & Valor / Unidad de Medida & $\begin{array}{l}\text { Implementado } \\
\text { /No implementado }\end{array}$ \\
\hline \multirow[b]{2}{*}{ Producción } & $\begin{array}{l}\text { Cumplimiento del plan } \\
\text { de producción }\end{array}$ & $\begin{array}{l}\text { Medir la relacion entre lo } \\
\text { planeado y lo ejecutado }\end{array}$ & $95 \%$ de cumplimiento & Implementado \\
\hline & Costo de servicios & $\begin{array}{l}\text { Medir si los costos del servicio } \\
\text { terminado, si estan alineados a } \\
\text { los costos proyectados }\end{array}$ & $\begin{array}{l}\$ 8000 \text { proyectado por } \\
\text { consultoria }\end{array}$ & Implementado \\
\hline Mantenimiento & $\begin{array}{l}\text { Programa de } \\
\text { mantenimientos } \\
\text { preventivo }\end{array}$ & $\begin{array}{l}\text { Medir el cumplimiento del } \\
\text { programa de mantebimiento }\end{array}$ & $\%$ de cumplimieto & Implementado \\
\hline
\end{tabular}

Nota. Elaboración propia.

En la tabla 30 se puede constatar con los indicadores presentados para el proceso de servicio Post Venta, que la empresa la tiene implementada, esto permite a Hamek Ingenieros Asociados S.A.C. mantener una buena relación con sus clientes, fortaleciendo los lazos comerciales.

Tabla 30

Indicadores de Actividades Primarias: Servicio de Post Venta

\begin{tabular}{|c|c|c|c|c|}
\hline Proceso & Indicador & Objetivo & Valor / Unidad de Medida & $\begin{array}{l}\text { Implementado } \\
\text { /No Implementado }\end{array}$ \\
\hline \multirow{3}{*}{$\begin{array}{l}\text { Servicio Post } \\
\text { Venta }\end{array}$} & Reclamos de clientes & $\begin{array}{l}\text { Medir la cantidad de reclamos } \\
\text { de clientes }\end{array}$ & $\mathrm{N}^{\circ}$ de quejas & Implementado \\
\hline & $\begin{array}{l}\text { Nivel de satisfacción del } \\
\text { cliente }\end{array}$ & $\begin{array}{l}\text { Medir el grado de satisfacción } \\
\text { de los clientes con respecto a } \\
\text { los productos y servicios }\end{array}$ & \% de satisfacción & Implementado \\
\hline & $\begin{array}{l}\text { Programa de visitas } \\
\text { tecnicas }\end{array}$ & $\begin{array}{l}\text { Medir el cumplimiento del } \\
\text { programa de visitas a clientes }\end{array}$ & $\%$ de cumplimiento & Implementado \\
\hline
\end{tabular}

Nota. Elaboración propia. 
El proceso de abastecimiento, es uno de los procesos que la empresa lo tiene implementado, pues con ello buscan medir el nivel de satisfacción de sus clientes una vez se culminen los trabajos, usando un documento que denominan Acta de Conformidad. Para que Hamek Ingenieros Asociados S.A.C., cuente con una calificación optima, es necesario que nuestros proveedores cumplan con el compromiso y se respeten la calidad y plazos de las entregas.

\section{Tabla 31}

Indicadores de Actividades de Apoyo: Abastecimiento.

\begin{tabular}{|c|c|c|c|c|}
\hline Proceso & Indicador & Objetivo & Unidad de Medida & $\begin{array}{l}\text { Implementado } \\
\text { / No implementado }\end{array}$ \\
\hline \multirow{2}{*}{$\begin{array}{l}\text { Logística } \\
\text { Interna }\end{array}$} & $\begin{array}{l}\text { Puntualidad de empresas } \\
\text { transportistas, en el } \\
\text { traslado de personal. }\end{array}$ & $\begin{array}{l}\text { Medir el cumplimiento de } \\
\text { puntualidad de las empresas } \\
\text { de transporte de personal. }\end{array}$ & $\%$ de cumplimiento & No Implementado \\
\hline & $\begin{array}{l}\text { Nivel de desempeño de } \\
\text { proveedores de los } \\
\text { laboratorios, empresas de } \\
\text { calibracion de equipos. }\end{array}$ & $\begin{array}{l}\text { Medir el desempeño del } \\
\text { proveedor (Calidad de } \\
\text { servicio y producto) }\end{array}$ & $\%$ de cumplimiento & No Implementado \\
\hline
\end{tabular}

Nota. Elaboración propia.

Uno de los procesos que Hamek Ingenieros Asociados S.A.C.se encuentra en proceso de renovación, es Marketing y Ventas, solo los indicadores de venta, la empresa lo tiene implementado pues con ello podemos medir nuestro crecimiento en los mercados nacionales e internacionales. 
Tabla 32

Indicadores de Actividades Primarias: Marketing y Ventas

\begin{tabular}{|c|c|c|c|c|}
\hline Proceso & Indicador & Objetivo & Valor / Unidad de Medida & $\begin{array}{l}\text { Implementado } \\
\text { / No Implementado }\end{array}$ \\
\hline \multirow{6}{*}{$\begin{array}{l}\text { Marketing y } \\
\text { Ventas }\end{array}$} & \multirow{2}{*}{ Venta } & $\begin{array}{l}\text { Medir cantidad de servicios } \\
\text { prestados área energía }\end{array}$ & \% de participación & Implementado \\
\hline & & $\begin{array}{l}\text { Medir cantidad de servicios } \\
\text { prestados área medio } \\
\text { ambiente }\end{array}$ & \% de participación & Implementado \\
\hline & $\begin{array}{l}\text { Cumplimiento programa de } \\
\text { ventas }\end{array}$ & $\begin{array}{l}\text { Medir cumplimiento del } \\
\text { programa de venta. }\end{array}$ & $\begin{array}{l}\% \text { de cumplimiento del } \\
\text { programa }\end{array}$ & No Implementado \\
\hline & Participación de mercado & $\begin{array}{l}\text { medir la participación en el } \\
\text { mercado con lo productos }\end{array}$ & $\%$ de participación en soles & Implementado \\
\hline & $\begin{array}{l}\text { Desarrollo de nuevos } \\
\text { servicios }\end{array}$ & $\begin{array}{l}\text { Cuantificar los lanzamientos de } \\
\text { nuevos servicios }\end{array}$ & № de nuevos servicios & No Implementado \\
\hline & Rentabilidad de productos & $\begin{array}{l}\text { Medir el magen que aporta } \\
\text { cada servicio }\end{array}$ & $\% \mathrm{MB}$ y $\% \mathrm{MN}$ & No Implementado \\
\hline
\end{tabular}

Nota. Elaboración propia.

Contar con estadísticas comparables sobre el uso de las tecnologías de la información y de la investigación es crucial para formular políticas y estrategias concernientes al crecimiento de la empresa, poder medir el cumplimiento y el grado de avances de los proyectos es de vital importancia para la culminación satisfactoria del servicio. En la tabla 33 se puede visualizar que este proceso la empresa lo tiene implementado.

Tabla 33

Indicadores de Actividades de Apoyo: Desarrollo de Tecnología

\begin{tabular}{|c|c|c|c|c|}
\hline Proceso & Indicador & Objetivo & Valor / Unidad de Medida & $\begin{array}{c}\text { Implementado } \\
\text { /No Implementado }\end{array}$ \\
\hline \multirow{4}{*}{$\begin{array}{l}\text { Desarrollo de } \\
\text { Tecnologia e } \\
\text { Investigacion } \\
\text { y Desarrollo }\end{array}$} & $\begin{array}{l}\text { Cumplimiento pared } \\
\text { de proyectos }\end{array}$ & $\begin{array}{l}\text { Medir cumplimiento del } \\
\text { portafolio de proyectos }\end{array}$ & $\%$ de cumplimiento de proyectos & Implementado \\
\hline & Avance del proyecto & $\begin{array}{l}\text { Medir el grado de } \\
\text { avance del proyecto }\end{array}$ & $\%$ de avance del proyecto & Implementado \\
\hline & $\begin{array}{l}\text { Desarrollo de nuevos } \\
\text { productos }\end{array}$ & $\begin{array}{l}\text { Cuantificar los } \\
\text { lanzamientos de nuevos } \\
\text { productos }\end{array}$ & $N^{\circ}$ de nuevos productos & Implementado \\
\hline & $\begin{array}{l}\text { Rentabilidad por } \\
\text { producto }\end{array}$ & $\begin{array}{l}\text { Medir el margen que } \\
\text { aporta cada producto }\end{array}$ & $\% \mathrm{MB}$ y \% MN & Implementado \\
\hline
\end{tabular}

Nota. Elaboración propia. 
Correspondiente a las actividades de apoyo en recursos humanos todas las actividades que Hamek Ingenieros Asociados S.A.C., involucran aspectos que van desde la contratación del personal, capacitación, cumplimiento al programa de capacitación, logro de objetivos laborales, cuantificar al personal incorporado, vinculo y desvinculación con la empresa del personal, y la forma como los trabajadores se desarrollan al interno de la empresa con la finalidad de construir un ambiente grato que permita el buen desarrollo de las actividades de los colaboradores y que por ende se refleje en la calidad de los servicios que ofrece la empresa.

Tabla 34

Indicadores de Actividades de Apoyo: Recursos Humanos.

\begin{tabular}{|c|c|c|c|c|}
\hline Proceso & Indicador & Objetivo & Valor / Unidad de Medida & $\begin{array}{c}\text { Implementado } \\
\text { /No Implementado }\end{array}$ \\
\hline \multirow{8}{*}{$\begin{array}{l}\text { Recursos } \\
\text { Humanos }\end{array}$} & Capacitación & $\begin{array}{l}\text { Cuantificar las horas de } \\
\text { capacitación recibidas }\end{array}$ & Horas-hombre de capacitación & Implementado \\
\hline & $\begin{array}{l}\text { Cumplimiento, programa } \\
\text { de capacitación }\end{array}$ & $\begin{array}{l}\text { Medir el cumplimiento } \\
\text { del programa }\end{array}$ & $\%$ de cumplimiento & Implementado \\
\hline & & Medir el logro de & & \\
\hline & Nivel de desempeño labor & $\begin{array}{l}\text { objetivos laborales y } \\
\text { competencias }\end{array}$ & $\%$ de logro de objetivos & Implementado \\
\hline & Clima laboral & $\begin{array}{l}\text { Medir la satisfacción } \\
\text { laboral }\end{array}$ & $\%$ de satisfacción laboral & Implementado \\
\hline & Contrataciones & $\begin{array}{l}\text { Cuantificar el personal } \\
\text { incorporado }\end{array}$ & $\mathrm{N}^{\circ}$ de contratados & Implementado \\
\hline & Ausentismo & $\begin{array}{l}\text { Medir el grado de } \\
\text { inasistencia del } \\
\text { personal }\end{array}$ & Indice de ausentismo laboral & Implementado \\
\hline & Rotación de personal & $\begin{array}{l}\text { Cuantificar el \% de } \\
\text { personas que se } \\
\text { vinculan y se } \\
\text { desvinculan en la } \\
\text { organización en un } \\
\text { periodo de tiempo }\end{array}$ & $\begin{array}{l}\text { \% de trabajadores vinculados } \\
\text { + desvinculados / total de } \\
\text { trabajadores }\end{array}$ & Implementado \\
\hline
\end{tabular}

Nota. Elaboración propia.

\subsection{Benchmarking y comparación con los líderes de la industria de cada una de las actividades de la cadena de valor}

De acuerdo con Spendolini (1994), "El Benchmarking es un proceso sistemático y continuo para evaluar los productos, servicios y procesos de trabajo de las 
organizaciones que son reconocidas como representantes de las mejores prácticas, con el propósito de realizar mejores organizacionales" (portada).

Existen tres tipos de benchmarking (Spendolini, 1994):

El interno, ¿me comparo con los otros dentro de mi organización?; el competitivo, ¿me comparo con los otros que compiten conmigo?; y el funcional, ¿me comparo con los otros que hacen los mejor en un proceso especifico, independientemente que estemos o no en el sector de la organización bajo análisis? (p.20).

Se desarrollará el benchmarking de la empresa Hamek Ingenieros y Asociados S.A.C., para conocer cómo se desempeña frente a otras empresas de la competencia, con el objetivo determinar las mejoras en cuanto a la calidad de sus servicios, y tener un amplio nivel de competitividad.

Es importante resaltar que la mayor dificultad del benchmarking es tener acceso a las actividades de la cadena de valor de otras empresas, las fuentes de la competencia en el sector de consultoría de energía y medio ambiente es limitada (ver Tabla 35) 
Tabla 35

Benchmarking Competidores de la empresa

\begin{tabular}{|c|c|c|c|}
\hline $\begin{array}{c}\text { item } \\
\text { comparativo }\end{array}$ & $\begin{array}{c}\text { Hamek } \\
\text { Ingenieros } \\
\text { y Asociados } \\
\text { S.A.C. }\end{array}$ & $\begin{array}{c}\text { Centro de } \\
\text { Conservación de } \\
\text { Energía } \\
\text { y del Ambiente } \\
\text { (CENERGIA) }\end{array}$ & Alfa Plus SAC \\
\hline \multicolumn{4}{|c|}{ Datos Generales } \\
\hline Inicio de actividad & 2010 & 1994 & N.D \\
\hline Ubicaciòn & La Molina & San Borja & Surco \\
\hline Cobertura Lima/Provincia & SI & SI & SI \\
\hline Pagina Web & SI & SI & NO \\
\hline Red Social & SI & SI & NO \\
\hline Correo Electronico & SI & SI & NO \\
\hline \multicolumn{4}{|c|}{ Logistica Interna } \\
\hline Infraestructura & Bueno & Bueno & N.D \\
\hline Gestion de proveedores & Bueno & Bueno & N.D \\
\hline Proceso Administrativo & Bueno & Bueno & N.D \\
\hline \multicolumn{4}{|c|}{ Operación } \\
\hline Productividad & Bueno & Bueno & N.D \\
\hline Calidad & Bueno & Bueno & N.D \\
\hline Precio del Producto & Bueno & Bueno & N.D \\
\hline \multicolumn{4}{|c|}{ Marketing } \\
\hline Servicios & Bueno & Bueno & N.D \\
\hline Imagen Coorporativa & Bueno & Muy Bueno & N.D \\
\hline Atenciòn a los clientes & Bueno & Bueno & N.D \\
\hline Nuevos Clientes & Bueno & Bueno & N.D \\
\hline N.D & Bueno & Bueno & N.D \\
\hline \multicolumn{4}{|c|}{ Recursos Humanos } \\
\hline Cantidad de personal & 10 & 13 & N.D \\
\hline $\begin{array}{l}\text { Capacitaciòn de personal } \\
\text { Capacitacion en software }\end{array}$ & Bueno & Bueno & N.D \\
\hline especializados & Regular & Bueno & N.D \\
\hline Personal Motivado & Bueno & Bueno & N.D \\
\hline \multicolumn{4}{|c|}{ Tecnologia } \\
\hline Maquinaria y equipos modernos & Bueno & Bueno & N.D \\
\hline \multicolumn{4}{|c|}{ Infraestructura } \\
\hline Buenas condiciones & Bueno & Bueno & N.D \\
\hline
\end{tabular}

Nota. Elaboración propia.

La escala cualitativa utilizada para evaluar y comparar las empresas fue: Muy Buena, Buena, Regular, No Determina (N.D), esto se ha podido identificar a través de 
entrevistas realizadas a Gerentes y especialistas que conocen las empresas de la competencia por haber trabajado con ellos.

Como se aprecia en la Tabla 35, la empresa Hamek Ingenieros Asociados S.A.C. en su calidad de servicios está mejor valorada en comparación de sus competidores directos, pero se percibe una desventaja en tecnología con la empresa CENERGIA, debido a que este, al ser una ONG, tiene beneficios de obtener mejores productos del extranjero con tecnología de punta; se observa una desventaja menor con la competencia en infraestructura por su espacio de sus instalaciones y en marketing en su imagen corporativa.

La empresa Hamek Ingenieros Asociados S.A.C, se encuentra en fase de expansión a nivel regional, teniendo presencia en países como El Salvador y Chile, tiene como uno de los retos más grandes mantenerse competitivo, ya que no solo se enfrenta a empresas locales, sino que la competencia se da entre empresas de todo el mundo. Es así como recurre al benchmarking que son herramientas, como bajar costos, aumentar su calidad de sus servicios, etc.

\subsection{Determinar las competencias de la empresa}

Las competencias que se han podido identificar dentro de la empresa Hamek Ingenieros Asociados S.A.C., se obtuvieron a través de entrevistas realizadas al gerente general, gerente administrativa, clientes, información comercial y contable; las cuales determinan las ventajas competitivas de la organización.

A continuación, se resume las competencias más resaltantes de la empresa Hamek Ingenieros Asociados S.A.C. (ver Tabla 36)

Tabla 36

Las Competencias

\begin{tabular}{ll}
\hline Competencia de HAMEK & \multicolumn{1}{c}{ Caracterizada } \\
\hline Experiencia & Trayectoria profesional del Gerente y Fundador \\
Trabajo en equipo & Compromiso, Responsabilidad y Armonía \\
Buena relación con los clientes & La honestidad, la transparencia y cumplimiento de los servicios a tiempo \\
Calidad en sus servicios & Seguridad, Credibilidad, Responsabilidad \\
Personal capacitado & Preparación del personal cuando empieza y para \\
& el uso de equipos de medición de energía y medio ambiente \\
\hline
\end{tabular}

Nota. Elaboración propia. 
Las competencias mencionadas son importantes, para Hamek Ingenieros Asociados S.A.C, porque se consolida aún más como empresa, diversificando sus servicios y captando nuevos mercados, dichas competencias contribuye a cumplir los objetivos y metas que la empresa se haya trazado.

De igual forma, su propósito es abrir nuevas líneas de servicio, seguir ofreciendo servicios de calidad, aprovechando la buena relación que tiene con sus clientes y por las ventajas de ser reconocidos en el servicio que ofrecen.

\subsection{Identificación y determinación de las ventajas competitivas de la empresa}

Como lo señala Porter (2014):

Las empresas logran ventaja competitiva mediante actos de innovación. Enfocan la innovación en un sentido más amplio, que comprende tanto nuevas tecnologías como nuevos modos de hacer las cosas. Encuentran una nueva forma de competir o mejores medios para competir al modo antiguo (p. 284).

También anota que la innovación puede manifestarse en el diseño de un nuevo producto, en un nuevo método comercial, en un nuevo modo de llevar a cabo la formación y capacitación del personal, puede interpretarse como hacer las cosas de una manera distinta o cuestionarse si existen nuevas formas de hacer las cosas en la búsqueda además de una mayor eficiencia, finalmente anota que "el único modo de mantener una ventaja competitiva es mejorarla: pasar a tipos más perfeccionados" ( $p$. 287).

Por otro lado D’Alessio, F. (2014), menciona que "Es de interés crear ventajas competitivas para vencer a los competidores y moverse a una situación futura" (p. 364) y menciona algunas recomendaciones de cómo manejar la gerencia de las organizaciones tomando en cuenta la influencia del entorno buscando adaptarse a los cambios que se presenten, tener la capacidad de utilizar los recursos de la organización eficientemente, o establecer marcas de referencia supremas (benchmarking), adecuar la organización a un modelo moderno de organización, concentrarse en los objetivos particulares del negocio, destruir paradigmas buscando siempre innovar agresivamente.

De lo anterior se observa que Hamek Ingenieros Asociados S.A.C. tiene como principales ventajas competitivas, la sólida imagen en el mercado fundamentada en su experiencia a pesar de tener menos años de trayectoria que su principal competidor Cenergia, lo que le ha permitido incrementar su participación en el mercado local y además destaca su alto estándar de servicio que les ha permitido ingresar a mercados de 
la región como el Salvador y Chile, finalmente el personal especializado con el que cuenta que es formado por la organización para desarrollar todo su potencial.

Respecto al posicionamiento de Hamek Ingenieros Asociados S.A.C. en el mercado local se anota que desde el 2014 presenta un crecimiento notable restando participación a sus competidores, al cierre del año 2018 Hamek Ingenieros Asociados S.A.C. ha desplazado a su principal retador, Cenergia, a un segundo lugar, también se observa que el competidor más débil, Global Energy Environmental and Economic Consulting S.A, ha perdido presencia en el sector desde el año 2017. Ver Tabla 37.

Tabla 37

Participación Ingresos de la empresa en Mercado Local

\begin{tabular}{lcccc}
\hline & \multicolumn{4}{c}{ Participación \% Ingresos Locales-Hamek } \\
\cline { 2 - 5 } Empresa & 2015 & 2016 & 2017 & 2018 \\
\hline Cenergia & $51 \%$ & $53 \%$ & $56 \%$ & $45 \%$ \\
Hamek & $30 \%$ & $35 \%$ & $38 \%$ & $52 \%$ \\
Alfa Plus & $11 \%$ & $7 \%$ & $6 \%$ & $3 \%$ \\
Global Energy & $10 \%$ & $5 \%$ & $0 \%$ & $0 \%$ \\
\hline
\end{tabular}

Nota. Elaboracion propia.

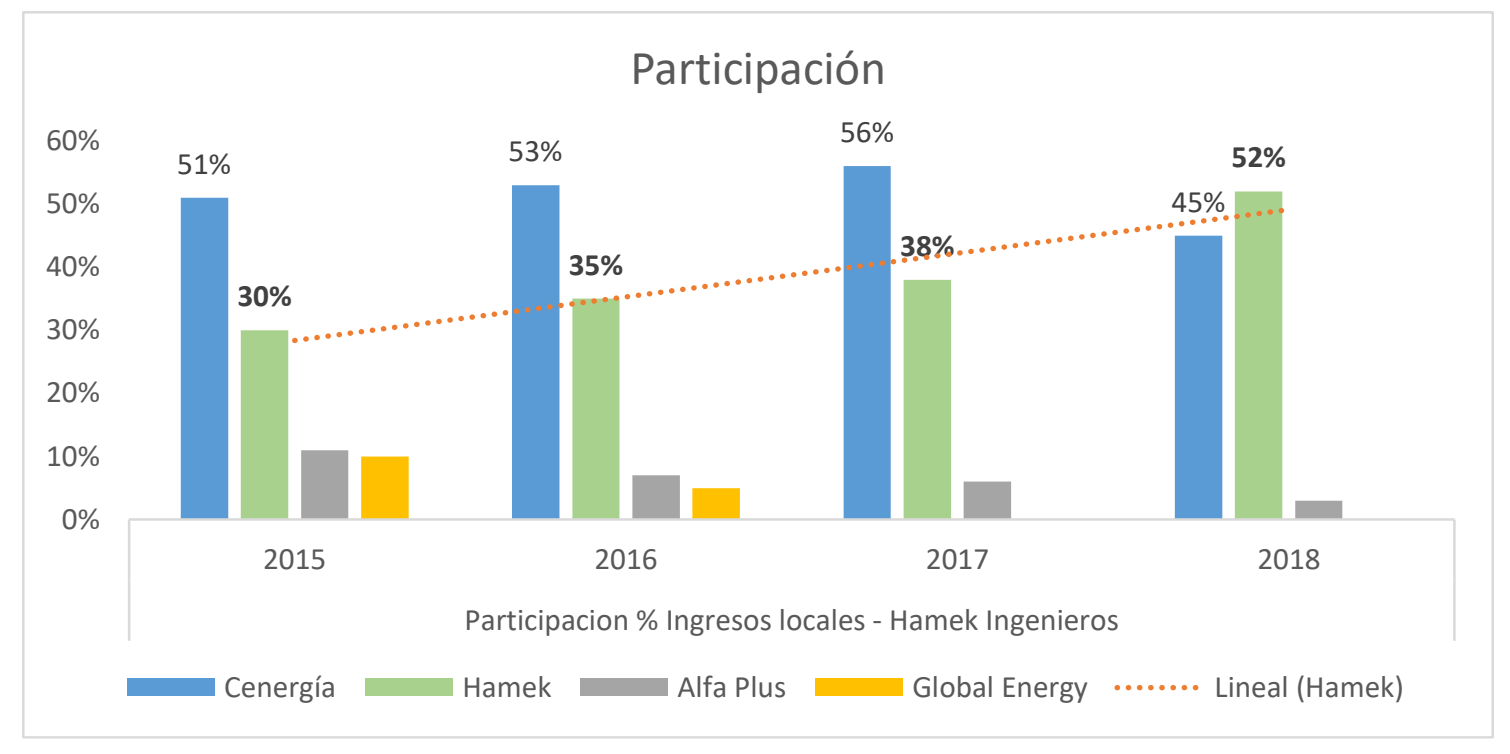

Figura 27. Participación Ingresos en mercado local

Hamek Ingenieros Asociados S.A.C. gracias a la trayectoria y crecimiento continuo que ha tenido desde su fundación logra posicionarse en el mercado local y en el 2014 la empresa decide ingresar al mercado internacional, teniendo como primer país de 
expansión al líder a nivel centroamericano en materia de mercado mayorista de energía El Salvador, para ello Hamek Ingenieros Asociados S.A.C. logra acreditarse con la Unidad de Transacciones (UT), quien es el administrador del mercado eléctrico y del sistema de transmisión en el Salvador, como empresa consultora experta en auditorías en Curvas de consumo de calor y parámetros técnicos y costo variable no combustible y costos de arranque y detención de unidades de generación. A la fecha ha participado en los dos tipos de auditorías en siete centrales térmicas.

En la actualidad, Hamek Ingenieros Asociados S.A.C. compite con ocho empresas consultoras, debidamente inscritas en la UT, como Ergon Plus S.A. con presencia en el sector desde el 2010 y Sustainability Research S.A., con presencia en el sector desde el 2011, ambas con trayectoria en la ejecución de diagnósticos energéticos, así como en el desarrollo de proyectos de ahorro de energía.

Continuando con su expansión en el 2016 Hamek Ingenieros Asociados S.A.C. ingresa a Chile, primer país en Sudamérica, teniendo como principal cliente al Coordinador Eléctrico Nacional (CEN) quien es el organismo encargado de la coordinación de la operación del conjunto de instalaciones del Sistema Eléctrico Nacional que operen interconectadas entre sí dentro del país.

Respecto a Chile, Hamek Ingenieros Asociados S.A.C. compite desde el 2016 con siete empresas consultoras como McHale \& Associates Inc, multinacional con sede matriz en Estados Unidos y Tractebel Chile, filial de la transnacional belga Tractebel Engineering, ambas con presencia a nivel mundial como consultoras especializadas en energía e infraestructura, lo que evidencia que Hamek Ingenieros Asociados S.A.C. está en capacidad de competir con empresas reconocidas a nivel mundial.

Respecto a la participación en los ingresos totales se evidencia un crecimiento significativo por parte de los servicios ofrecidos a nivel regional, de no tener participación en el año 2014 se tiene una participación para el cierre del año 2018 del orden del 28\% (Ver Tabla 38), lo que a la vez, ha significado que los ingresos totales de Hamek Ingenieros Asociados S.A.C. se incremente en más de un 140\% entre el año 2014 y el año 2018, es pertinente señalar que no se toma en cuenta la participación de los ingresos en el año 2016 en vista que no se registraron ingresos en El Salvador. 
Tabla 38

Participación Ingresos Servicios Consultoría

\begin{tabular}{lrrrrrr}
\hline & \multicolumn{7}{c}{ Participación } \\
& 2014 & 2015 & 2016 & 2017 & 2018 Promedio \\
\hline Internacional & $0 \%$ & $24 \%$ & $10 \%$ & $22 \%$ & $28 \%$ & $25 \%$ \\
Local & $100 \%$ & $76 \%$ & $90 \%$ & $78 \%$ & $72 \%$ & $75 \%$ \\
\hline Ventas Totales & $100 \%$ & $100 \%$ & $100 \%$ & $100 \%$ & $100 \%$ & \\
\hline
\end{tabular}

Nota. Elaboracion propia.

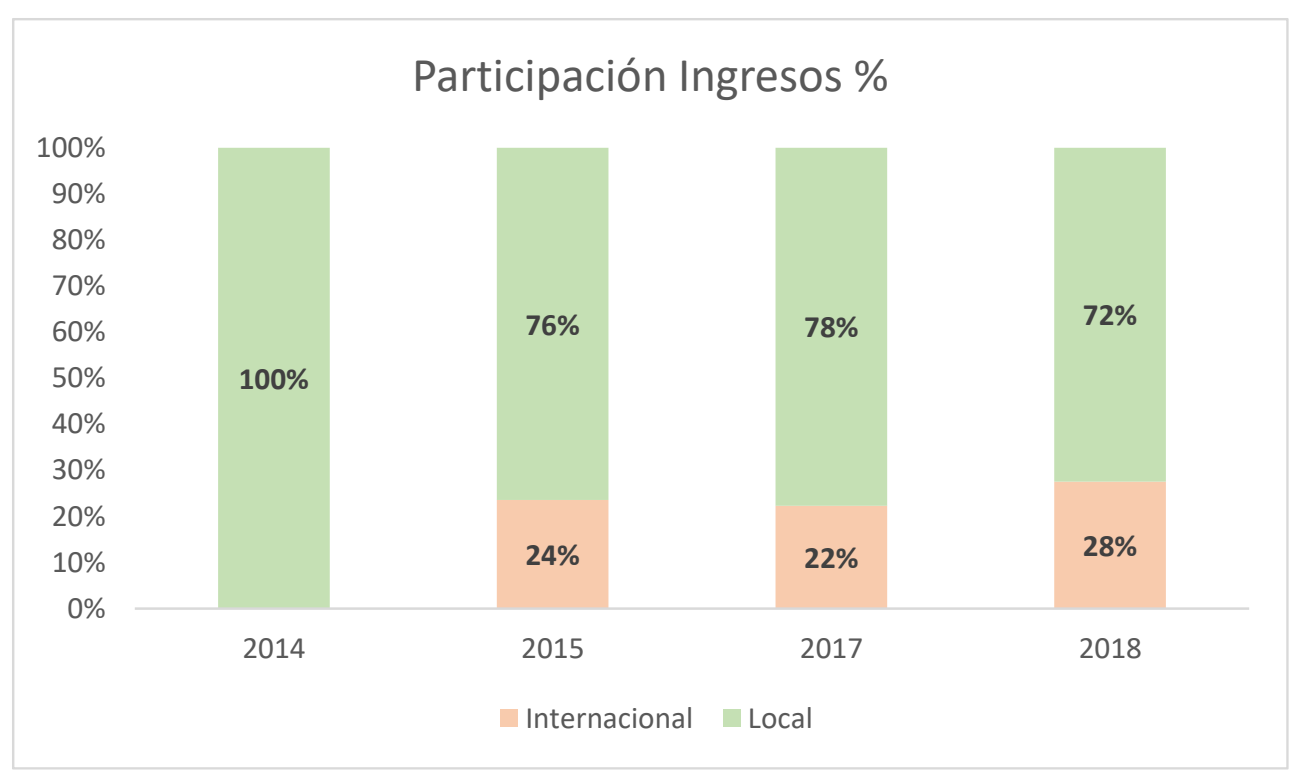

Figura 28. Evolución participación ingresos

Prosiguiendo con su proyección de crecimiento internacional, Hamek Ingenieros Asociados S.A.C. apunta a incursionar en servicios de consultoría especializada en los mercados eléctricos.

\subsubsection{Modelo VRIO.}

La modelo VRIO fue propuesta en el año 1991 por Jay Barney, está referida a las cuatro características de los recursos que nos hacen ser competitivos o visto desde otra perspectiva, son los recursos o capacidades que posibilitan una ventaja competitiva que sea sostenible por parte de Organización, como consecuencia de este análisis, identificaremos cuáles debemos considerar como vitales y aquéllos que son más prescindibles para Hamek Ingenieros y Asociados S.A.C. 
Este modelo analiza el grado en que los recursos o capacidades son (a) valiosos, (b) raros, (c) inimitables y (d) organizados, también es importante precisar que estos recursos internos pueden ser financieros, humanos, materiales y no materiales (de conocimiento, información, cultura, etc.).

Concluido el análisis Hamek Ingenieros y Asociados S.A.C. identificará los recursos que cumplan las cuatro condiciones VRIO mencionadas en el párrafo anterior por lo que han de ser protegidos y explotados al máximo para poder seguir manteniendo esa característica especial que les permita diferenciarse frente a los competidores.

Tabla 39

Matriz VRIO de la empresa

\begin{tabular}{lccccc} 
& Valioso & Raro & Inimitable & Organizado & Implicacion Efectiva \\
\hline Recurso Tangible & & & & & \\
Personal Experto en Sector & $\mathrm{SI}$ & $\mathrm{SI}$ & $\mathrm{NO}$ & $\mathrm{SI}$ & Ventaja Competitiva temporal \\
Acreditación Internacional & $\mathrm{NO}$ & $\mathrm{SI}$ & $\mathrm{NO}$ & $\mathrm{NO}$ & Desventaja Competitiva \\
Equipamiento Tecnológico & $\mathrm{SI}$ & $\mathrm{NO}$ & $\mathrm{NO}$ & $\mathrm{SI}$ & Paridad Competitiva \\
\hline
\end{tabular}

\begin{tabular}{lccccc}
\hline Recurso Intangible & & & & & \\
Experiencia en la Región & SI & SI & NO & SI & Ventaja Competitiva temporal \\
Solidez Financiera & SI & SI & NO & SI & Ventaja Competitiva temporal \\
Reputación Mercado Local & SI & SI & SI & SI & Ventaja Competitiva permanente \\
Gobierno Corporativo Emergente & NO & SI & NO & NO & Desventaja Competitiva \\
Politica Retencion Cuadros & NO & SI & NO & NO & Desventaja Competitiva \\
Poitica de Sucesión & NO & SI & NO & NO & Desventaja Competitiva \\
\hline
\end{tabular}

Nota. Elaboración propia.

Del análisis del Modelo VRIO se logra detectar que la principal ventaja competitiva permanente de Hamek Ingenieros Asociados S.A.C. es su reputación y reconocimiento a nivel local, además destacan como ventajas competitivas temporales, el personal experto y muy calificado con el que cuenta, su experiencia en la región brindando sus servicios y su solidez financiera.

También resulta relevante mencionar que dentro de las mayores desventajas competitivas destacan la falta de acreditación internacional en algunos países de la región Latinoamérica que podría permitirles ingresar a nuevos mercados con los servicios que actualmente brinda, la falta de una sólida política de retención de los mejores 
profesionales y especialistas, que quizás terminen trabajando a futuro, en un competidor directo, la falta de una política de sucesión familiar dada la orientación a formar un gobierno corporativo al interior de la empresa.

\subsection{Fortaleza y Debilidades}

Basados en la evaluación interna realizada por los líderes de la Organización a través de las entrevistas de profundidad se identifican las fortalezas y debilidades de Hamek Ingenieros Asociados S.A.C. según se detalla:

\section{Fortaleza.}

- Experiencia Internacional en países como El Salvador y Chile lo que les permite incrementar su competitividad y su margen de rentabilidad.

- La decisión de Inversión de Hamek Ingenieros y Asociados S.A.C, para sostener su crecimiento e internacionalización en países de la región.

- La gran trayectoria en el sector lo que permite contar con una reputación elevada para enfrentar nuevos desafíos en el mercado local y regional.

- La solidez financiera de la empresa, hasta el momento Hamek Ingenieros y Asociados S.A.C, no requiere apalancamiento financiero y tiene la suficiente generación de caja para cubrir cualquier flujo futuro, aunque insuficiente para hacer adquisiciones de equipos de última generación.

- El sentido de pertenencia de sus colaboradores, el personal se siente parte de la familia Hamek Ingenieros y Asociados S.A.C, existe un elevado grado de compromiso e identificación con la empresa que crea un ambiente adecuado para el cambio, la innovación y la orientación hacia un modelo moderno de organización.

- Personal Experto / Especialización, Hamek Ingenieros y Asociados S.A.C cuenta con personal altamente calificado y competente (expertos).

\section{Debilidades.}

- Falta de un plan estratégico dado el crecimiento experimentado por Hamek Ingenieros y Asociados S.A.C. desde su fundación en el año 2010.

- Bajo nivel de Gobierno Corporativo que le permita a Hamek Ingenieros y Asociados S.A.C., una respuesta rápida ante un crecimiento de la demanda. Actualmente el núcleo de la organización es familiar, existen dos (02) jefaturas 
que reportan al Gerente General y debajo de ellos, el personal especializado (expertos) para atender los servicios requeridos. El crecimiento que tiene Hamek Ingenieros y Asociados S.A.C., es por demanda, es decir, generada una necesidad de servicio se activa el reclutamiento del personal especializado y su formación.

- La marca Hamek Ingenieros y Asociados S.A.C., es reconocida en el mercado sin embargo no se invierte mucho en publicidad y las relaciones públicas son llevadas directamente por la Gerencia General, quien busca dar a conocer sus servicios participando en diversos eventos de los sectores relacionados donde existe un potencial de negocios y donde aún no se tiene mayor presencia.

- La modernización del equipamiento tecnológico, se presenta como una de las debilidades detectadas luego de realizadas las entrevistas de profundidad a los expertos del sector y donde la competencia lleva ligera ventaja en la medida que renueva sus equipos tecnológicos para realizar sus estudios favorecida porque funcionan como una organización sin fines de lucro y por ende recibe aportes del sector privado.

- Falta de una política de retención de recursos claves para reducir el riesgo de contar más adelante con futuros retadores dada la experiencia adquirida y el enorme potencial de desarrollo del sector.

- Falta de una política de sucesión familiar en primera instancia dado que la empresa familiar experimenta un crecimiento organizacional expresado en un incremento de sus ingresos, un incremento de su participación en el mercado local y su incursión en el mercado regional.

- Su infraestructura, Hamek Ingenieros y Asociados S.A.C., existe un área limitada para un posible crecimiento futuro lo que obliga a ver la posibilidad de trasladarse a un lugar distinto dadas las circunstancias.

- La certificación en ISO se considera como una mejora futura cuando la organización sea más robusta, no se considera como una debilidad a considerar.

Del análisis anterior se presenta la información de las fortalezas y debilidades a continuación (ver Tabla 40): 
Tabla 40

Fortalezas y Debilidades Hamek Ingenieros y Asociados SAC.

\begin{tabular}{|c|c|c|c|}
\hline Tipo de factor & Factores & Fortaleza & Debilidad \\
\hline \multirow{2}{*}{ Finanzas / Contabilidad } & Decisión de Inversión para crecimiento & & $x$ \\
\hline & Solidez Financiera & $x$ & \\
\hline \multirow{4}{*}{ Recursos Humanos } & Política de Retención Cuadros & & $\mathrm{x}$ \\
\hline & Personal Experto & $x$ & \\
\hline & Sentido Pertencia Personal & $\mathrm{x}$ & \\
\hline & Política de Sucesión & & $x$ \\
\hline \multirow{4}{*}{ Organización } & Reputación Mercado Local & $x$ & \\
\hline & Falta de Plan Estratégico & & $\mathrm{x}$ \\
\hline & Emergente Gobierno Corporativo & & $x$ \\
\hline & Incursión Mercado Regional & $x$ & \\
\hline Marketing y Comunicación & Fortalecimiento de Marca/Empresa & & $\mathrm{x}$ \\
\hline Tecnología & Modernización Equipamiento Tecnológico & & $x$ \\
\hline Infraestructura & Geolocalización Oficinas / Disponibilidad de espacios & & $\mathrm{x}$ \\
\hline
\end{tabular}

Nota. Elaboración propia.

\subsection{Matriz de Evaluación de los Factores Internos EFI}

Como lo señala David (2013):

Esta herramienta para la formulación de la estrategia resume y evalúa las fortalezas y debilidades importantes en las áreas funcionales de una empresa y también constituye una base para identificar y evaluar las relaciones entre ellas. Al desarrollar una matriz EFI, se requiere tener juicios intuitivos para que su apariencia de enfoque científico no implique que se le interprete como una técnica todopoderosa. Es más importante comprender bien los factores incluidos que las cifras (p. 148).

Para el análisis de la matriz EFI hemos listado los factores claves que se detectó en el análisis interno de Hamek Ingenieros y Asociados S.A.C, tomando en consideración las entrevistas en profundidad realizadas al Gerente General y a funcionarios claves dentro 
de la organización, para cada uno de estos factores asignamos una ponderación que vaya del 0.0 al 1.0 en función de la importancia del factor, debiendo sumar en conjunto 1.0. Por otro lado, cada factor tiene una clasificación de 1 a 4 para indicar si representa una debilidad mayor (1), una debilidad menor (2), una fortaleza menor (3) o una fortaleza mayor (4), debiendo anotar que las clasificaciones están basadas en la compañía, y las ponderaciones se basan en la industria.

A continuación, se muestran los resultados obtenidos del análisis de la matriz EFI para la empresa Hamek Ingenieros y Asociados S.A.C (ver Tabla 41) 
Tabla 41

Matriz de Evaluación de los Factores Internos Hamek Ingenieros y Asociados SAC

\begin{tabular}{|c|c|c|c|}
\hline Factores & Peso & Calificación & Calificación Ponderada \\
\hline Debilidades & 0.50 & & \\
\hline 1. Ausencia de Gobierno Corporativo & 0.12 & 2 & 0.24 \\
\hline 2. Modernización Equipamiento Tecnológico & 0.05 & 2 & 0.10 \\
\hline 3. Ausencia Política de Retención del Talento & 0.08 & 2 & 0.16 \\
\hline 4. Geolocalización Oficinas / Disponibilidad de espacios & 0.05 & 2 & 0.10 \\
\hline 5. Ausencia de Política de Sucesión & 0.08 & 2 & 0.16 \\
\hline 6. Inexistencia de un plan estratégico & 0.12 & 1 & 0.12 \\
\hline Fortalezas & 0.50 & & \\
\hline 1. Solidez Financiera & 0.08 & 4 & 0.32 \\
\hline 2. Participación de Mercado & 0.09 & 4 & 0.36 \\
\hline 3. Posicionamiento de la Marca/Empresa & 0.08 & 4 & 0.32 \\
\hline 4. Incursión Mercado Regional & 0.09 & 4 & 0.36 \\
\hline 5. Alianza / Convenio Internacional de Cooperación e Ingeniería para proyectos & 0.03 & 3 & 0.09 \\
\hline 6. Sentido de pertenencia del personal / Especialización & 0.04 & 3 & 0.12 \\
\hline 7. Trayectoria en el sector / Reputación & 0.09 & 4 & 0.36 \\
\hline
\end{tabular}

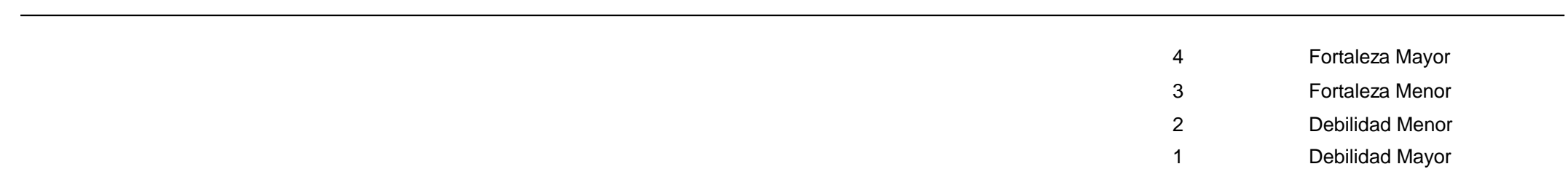

Nota. Elaboración propia. 
El puntaje obtenido es de 2,81, al ser superior al 2,40 se puede concluir que Hamek Ingenieros y Asociados S.A.C, cuenta con fortalezas que le permiten contrarrestar sus debilidades como la falta de política de sucesión y la falta de un plan estratégico y esto les ha permitido hasta el momento, tener un crecimiento sostenido en el mercado local además de permitirles expandirse mucho más a nivel regional.

También es destacable mencionar su trayectoria en el mercado local, la participación actual que tienen en los servicios donde participa en la actualidad, la reputación adquirida en el tiempo y la presencia de sus servicios en países del bloque andino lo que potencia más a la empresa para enfrentar próximos crecimientos.

Debemos precisar además que Hamek Ingenieros y Asociados S.A.C cuenta con una vasta trayectoria en el sector energético y medio ambiental lo que les ha permitido construir una imagen robusta además de incrementar su reputación en el mercado, esa es también una de las razones por la cual constantemente viene incorporando jóvenes profesionales dentro de su organización a los cuales forma en el sector siendo la retribución una mayor identificación del personal para con la empresa, importante trabajar en una política de retención de los mejores cuadros profesionales para aprovechar su capacidad profesional pero a la vez minimizar el riesgo de que en el futuro se vuelvan potencialmente competencia dado el grado de experiencia alcanzado.

Respecto a las debilidades destacan también es importante anotar que la existencia de un plan de sucesión familiar se constituye una debilidad para Hamek Ingenieros y Asociados S.A.C., la ausencia de un gobierno corporativo que les permita soportar un crecimiento ordenado, en la actualidad cuenta con una estructura gerencial reducida donde las funciones de administración, logística y personal se encuentran concentradas en la Gerencia de Administración, diferenciada de la Gerencia Técnica cuya estructura está conformada por dos Jefaturas Técnicas de las líneas energéticas y medio ambiente que le reportan directamente al Gerente General.

Finalmente mencionar que las otras dos debilidades detectadas son la falta de renovación de equipos tecnológicos para el desarrollo de nuevos negocios referidos al sector energía y medio ambiente que podría restarle cierta competitividad y las limitaciones de espacio de sus instalaciones y la ubicación de sus oficinas que no facilitaría una reacción inmediata ate un incremento de la demanda de sus servicios de asesoría o estudios técnicos, y finalmente la inexistencia de un plan estratégico que sirva de guía para el desenvolvimiento de la empresa en los siguientes años y que le permita 
mejorar su posicionamiento y mantener su vigencia como una empresa de asesoría en estudios técnicos e ingenieriles para el mercado local y regional. 


\section{Capítulo VII. Formulación de Objetivos y Diseño de las Estrategias}

En el presente capítulo, se definen los objetivos del plan estratégico que resultan fundamentales para escoger de una forma racional las estrategias que finalmente debe desarrollar Hamek Ingenieros Asociados S.A.C. para los siguientes tres años.

A lo largo del desarrollo del presente capítulo se definen hasta tres objetivos estratégicos que persiguen el crecimiento en el mercado regional y una mayor participación en el mercado local, y un aumento de la utilidad de cada periodo, por otro lado se determinan las estrategias a seguir para la consecución de estos objetivos concluido en análisis de la Matriz FODA, la Matriz PEYEA, la Matriz BCG Boston Consulting Group, la Matriz IE Interna Externa y finalmente la Matriz GE de la Gran Estrategia.

Al término del capítulo se estará en capacidad de formular las distintas estrategias posibles de desarrollarse y será el punto de partida para la Selección de la Estrategia a implementarse, en el siguiente Capítulo, en base a la mayor coincidencia de estrategias obtenida del análisis detallado de cada una de las matrices anteriores.

\subsection{Alcance y planteamiento de los objetivos estratégicos}

Como David del 2013 establece, los objetivos deben ser cuantitativos, medibles, realistas, comprensibles, desafiantes, jerárquicos, alcanzables y congruentes entre las diversas unidades organizacionales. Asimismo, cada objetivo debe contar con su propia línea de tiempo. Por lo general los objetivos se enuncian en términos de crecimiento de activos o ventas, rentabilidad, participación de mercado, grado y naturaleza de la diversificación, grado y naturaleza de la integración vertical, utilidades por acción y responsabilidad social (p. 133)

En este capítulo se explicará y detallará cuales son los objetivos estratégicos y los planes que se han trazado para el logro de los objetivos de la empresa para los siguiente cinco años.

\subsubsection{Objetivos y Estrategias.}

Se ha considerado que dos deben ser los objetivos estratégicos trazados a desarrollarse:

1. Mantener el liderazgo a nivel nacional y tener mayor presencia en Chile y el El Salvador.

2. Incrementar la rentabilidad de la empresa. 
Basado en la misión propuesta: "Somos una empresa peruana privada tenemos como misión, contribuir al desarrollo del Perú y de los países donde Hamek Ingenieros Asociados S.A.C tiene presencia a través del uso eficiente de la energía, preservando el medio ambiente y al desarrollo sostenible del país basándose en la calidad de sus servicios.

3. Asegurar el cumplimiento de los objetivos y la misión de la empresa a través del desarrollo de un plan de sucesión que garantice la permanencia, el crecimiento y la continuidad de la empresa.

\subsubsection{Análisis de los objetivos estratégicos.}

1. Diseñar y elaborar un planeamiento adecuado de las operaciones que puedan mejorar u optimizar los rendimientos económicos y financieros de Hamek Ingenieros Asociados S.A.C.

2. Encaminar las potencialidades y las fortalezas de la compañía para superar los actuales resultados y asegurar la sostenibilidad de crecimiento en los próximos años.

3. Identificar las debilidades y las amenazas que tiene la compañía tanto de manera interna como externa con la finalidad de minimizar sus impactos dentro de Hamek Ingenieros Asociados S.A.C., de esta manera conducir la compañía de una manera adecuada que asegure un crecimiento sostenible.

4. Aumentar las utilidades netas, esencialmente orientado al incremento de las utilidades a través de mayor presencia de Hamek en El Salvador y Chile.

5. Incrementar la participación en los mercados de El Salvador y Chile, a través de la homologación como proveedor en las más importantes empresas de generación de energía y contar con un representante comercial en ambas naciones.

6. Mantener la participación en el mercado local, considerando que la mayor fortaleza de Hamek Ingenieros Asociados S.A.C es la experiencia y competitividad de los servicios especializados que cuentan con la acreditación del COES (Ver Anexo 4), la empresa buscará mantener su liderazgo en el mercado local.

7. Realizar un proceso de Plan de Sucesión, con ello garantizar la permanencia, el crecimiento y la continuidad de la empresa a través del tiempo, previniendo alterar el equilibrio y la marcha habitual del negocio. 


\subsection{Diseño y formulación de estrategias}

Para finalizar con lo propuesto, se presentarán modelos y matrices donde se analizarán y desarrollarán las estrategias que se utilizarán para el logro de los objetivos planteados para la empresa Hamek Ingenieros Asociados S.A.C. durante los próximos tres años.

Para la formulación de estrategias se desarrolla el análisis de las matrices de Océano Azul, FODA, PEYEA, la Matriz Interna Externa, Matriz Boston Consulting Group y la Matriz de la Gran estrategia.

\subsubsection{Modelo Océano Azul.}

El Modelo Océano Azul acuñado por W. Chan Kim y Renée Mauborgne en su libro "La estrategia del Océano Azul" publicado en el 2004, es un método para evaluar la propuesta de valor y los modelos de negocios, así como explorar nuevos segmentos de mercados.

La estrategia del océano azul consiste en crear industrias nuevas a través de la diferenciación fundamental, en vez de competir en sectores existentes, modificando los mercados desatendidos, el objetivo es aumentar el valor que obtienen los clientes.

El modelo de océanos comprende dos conceptos:

- Océano rojo, están representados por las industrias existentes en el mercado, existen varios competidores y todos ellos conocen las reglas del juego para sobrevivir en la industria, de tal manera puedan obtener resultados esperados favorables, de lo contrario, las perspectivas de rentabilidad y crecimiento se ven reducidas.

- Océanos azules, son las industrias que no existen actualmente, es el espacio desconocido del mercado, no aprovechado aún. En el océano azul la competencia pierde validez porque las reglas del juego aún no existen.

Para innovar en valor Kim y Mauborgne, proponen una herramienta analítica que la denominan esquema de las cuatro acciones, la cual plantean las siguientes cuatro preguntas:

1. De las variables que el sector da por sentadas ¿Cuáles se deben eliminar?

2. ¿Qué variables se deben reducir muy por debajo de la norma del sector?

3. ¿Qué variables se deben aumentar muy por encima de la norma del sector?

4. ¿Qué variables, que el sector no haya ofrecido nunca, se deben crear?

En el libro de W. Chan Kim y René Mauborgne (2004): "La Estrategia del Océano Azul" se expone: "La necesidad de dejar a un lado la competencia destructiva entre las 
empresas (Océano rojo) si se quiere ser un ganador en el futuro, ampliando los horizontes del mercado y generando valor a través de la innovación (Océano azul)", en otras palabras, plantean la posibilidad de crear una estrategia basada en la no competencia, y esto solo será posible en nuevos mercados en donde no exista competencia.

Para el caso de Hamek Ingenieros Asociados S.A.C., la estrategia estará basada en penetrar los mercados ya existentes para obtener una mayor participación a nivel local y regional, fundamentado en la existencia de un entorno externo, favorable para seguir creciendo y por la posición de dominio que tiene Hamek Ingenieros Asociados S.A.C., en los servicios que actualmente brinda, lo que le permite tener una participación superior al $40 \%$ en los servicios brindados en el mercado local, además de haber ingresado al mercado regional desde el año 2014 ofreciendo estos servicios.

De lo anterior se concluye que Hamek Ingenieros Asociados S.A.C. se encuentra en el océano rojo por lo que no tiene aplicación en el océano azul.

\subsubsection{Lienzo de la estrategia actual de la empresa.}

La estrategia actual de Hamek Ingenieros Asociados S.A.C. está basada en los factores críticos de éxito de la Matriz del perfil Competitivo (MPC), en el análisis del MPC se compara a la empresa con sus competidores, Hamek Ingenieros Asociados S.A.C. desde sus inicios, ha fundamentado su crecimiento en el mercado local en base a al know how, adquirido lo que le ha permitido no solo tener la mayor participación en el mercado local para los servicios ofrecidos, sino que le ha permitido ingresar al mercado regional con su incursión en países como El Salvador y Chile.

Hamek Ingenieros Asociados S.A.C. en los últimos tres años, ha invertido en lograr posicionares en el mercado local, buscando liderar como consultora especialista en los servicios que ofrece, todo ello gracias al conocimiento del sector y a sus estándares de servicios.

Gracias a estas acciones, ha podido incorporar clientes líderes del sector de energía, por otro lado, actualmente son pocas las empresas constituidas como consultoras calificadas por el COES, todas ellas son bastante similares en tamaño, productos y precios. Es por ello que Hamek Ingenieros Asociados S.A.C., debe desarrollar un plan estratégico que le permita no solamente mantener su participación en el mercado local, sino además conseguir una mayor participación en los países en donde actualmente brinda sus servicios, considerando la reputación conseguida al haberse internacionalizado. 
Hamek Ingenieros Asociados S.A.C. es uno de los principales líderes a nivel nacional, su reputación en ampliamente conocida y valorada por los clientes, sin embargo, no es determinante cuando los precios de la competencia son menores. Estas características del sector ubican a la empresa en un océano rojo, pues existe rivalidad entre competidores y acciones orientadas a debilitarse entre ellos. Para la elaboración del lienzo, se han establecido seis variables que resumen las características más relevantes del sector y de la empresa; las cuales se describen a continuación: Trayectoria en el mercado, conocimiento de Know How, experiencia internacional, equipos tecnificados, calidad de servicio y participación de mercado.

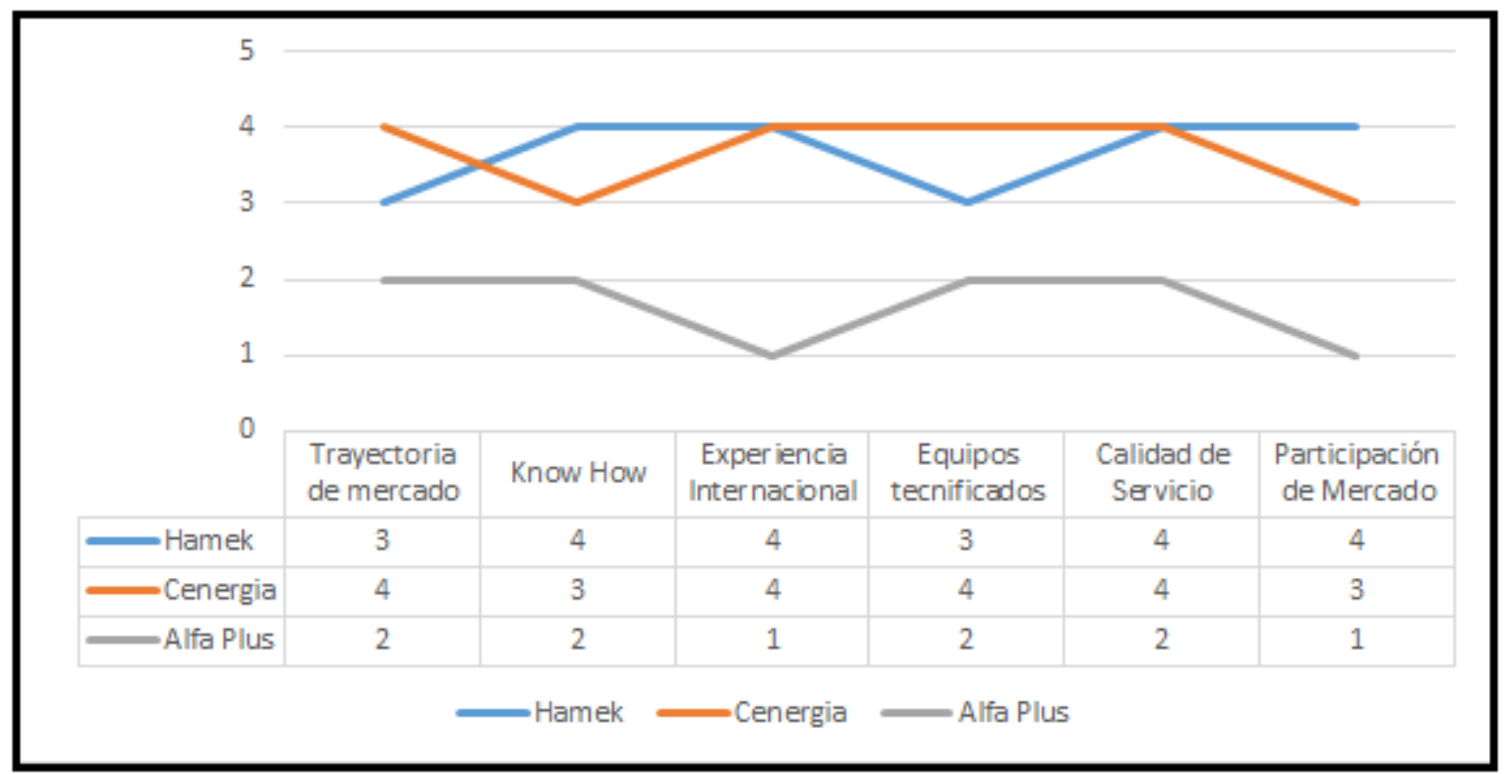

Figura 29. Lienzo de los atributos de la empresa y sus principales competidores

\subsubsection{Lienzo de la estrategia de la industria.}

Para obtener el lienzo de la industria se ha considerado las entrevistas a profundidad con un experto del sector, considerando a los competidores tales como Cenergía y Alpha Plus, como se observó en capítulos anteriores en la matriz de perfil competitivo (MPC).

Se identifica las variables para la industria, tomando en consideración el análisis de Matriz de Perfil Competitivo (Ver Tabla 25). Para establecer un resultado del sector, la metodología seguida será promediar las calificaciones obtenidas por cada una de las 
empresas en factores críticos de éxito considerados en dicha matriz. Importante precisar que se observa poca valoración por parte de dos empresas del sector lo que arroja una valoración industria menor para cada uno de estos factores.

A continuación, se presenta la gráfica del lienzo de la estrategia actual de la Industria, el cual se compara con el lienzo que aplica la empresa Hamek Ingenieros Asociados S.A.C.

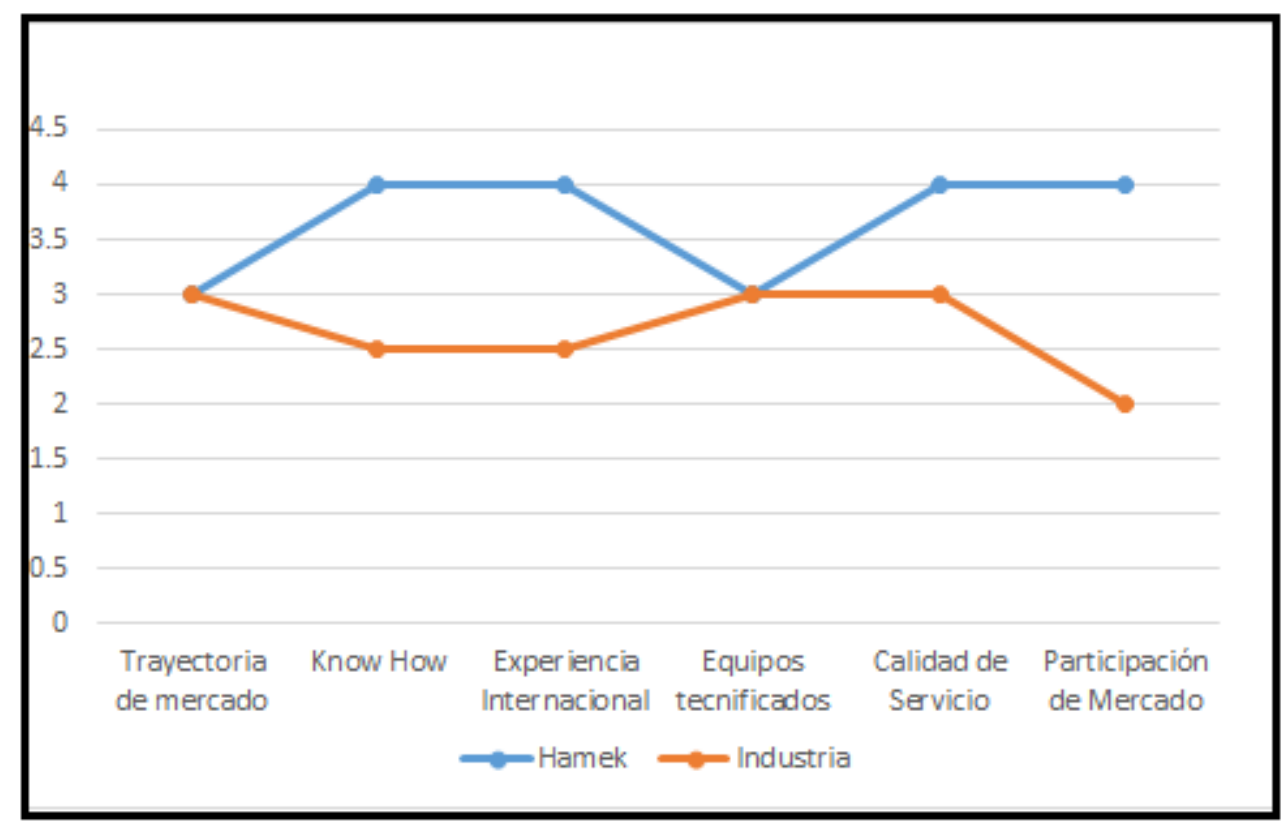

Figura 30. Lienzo de la estrategia de la Industria

\subsubsection{Matriz (eliminar, reducir, incrementar, crear).}

Como se menciona anteriormente, Hamek Ingenieros Asociados S.A.C. se desenvuelve en un océano rojo, donde existe una rivalidad entre los actuales competidores, con acciones orientadas a debilitarse entre ellos, como consecuencia de ello, Cenergía ha perdido participación siendo en el 2018, el primer retador de Hamek Ingenieros y Asociados S.A.C., que cuenta con una participación que supera el 40\%, y que Alfa Plus no tenga presencia desde el 2017 en los servicios de Consultoría y Auditoría en los que Hamek Ingenieros Asociados S.A.C. participa.

Es importante anotar que la guerra de precios para adjudicarse un servicio local, también influye en Hamek Ingenieros Asociados S.A.C. en su decisión de incursionar en el mercado regional dado que los precios son mayores y los costos en los que se incurre similares a los incurridos a nivel local, lo que le permite a Hamek Ingenieros Asociados S.A.C. no solo incrementar sus ingresos sino además obtener una mayor rentabilidad. 
En la siguiente tabla observamos que necesitamos eliminar, aumentar, reducir o crear, la que nos permitirá generar una nueva curva de valor en la cual se pueda trabajar un modelo del océano azul.

Tabla 42

Matriz (eliminar, reducir, incrementar, crear)

\begin{tabular}{ll}
\hline Eliminar & Reducir \\
\hline & Costos \\
& \\
\hline Aumentar & Crear \\
\hline Trayectoria en el mercado & Plan para las ventas \\
Conocimiento de Know How & Capturar nueva demanda \\
Experiencia internacional & \\
Calidad de servicio & \\
Participación de mercado. & \\
\hline
\end{tabular}

Nota. Elaboración propia.

\subsubsection{Lienzo de la nueva estrategia considerada.}

Para construir el lienzo de la nueva estrategia, se ha tomado como base el análisis de la estrategia actual de la empresa Hamek Ingenieros Asociados S.A.C., así como el análisis de la estrategia de los principales competidores en la industria.

Los servicios locales en comparación con los internacionales, según lo señalado por los accionistas de la empresa, tienen una margen de utilidad que supera el $100 \%$, siendo los costos similares.

Se considera, para desarrollar la nueva estrategia:

- Incrementar la participación en el mercado regional, a nivel Latinoamérica.

- Aumentar o reforzar la presencia de la empresa, en el sector energía en países como Chile y El Salvador.

En el siguiente gráfico se presenta el lienzo propuesto para Hamek Ingenieros Asociados S.A.C., resaltando aquella variable que representaría la estrategia de Océano Azul, marcando así la diferencia en la industria y alejándose de la competencia.

Se presenta la comparación entre las diferentes estrategias. Asimismo, se muestra la nueva posición competitiva sugerida para la empresa. 


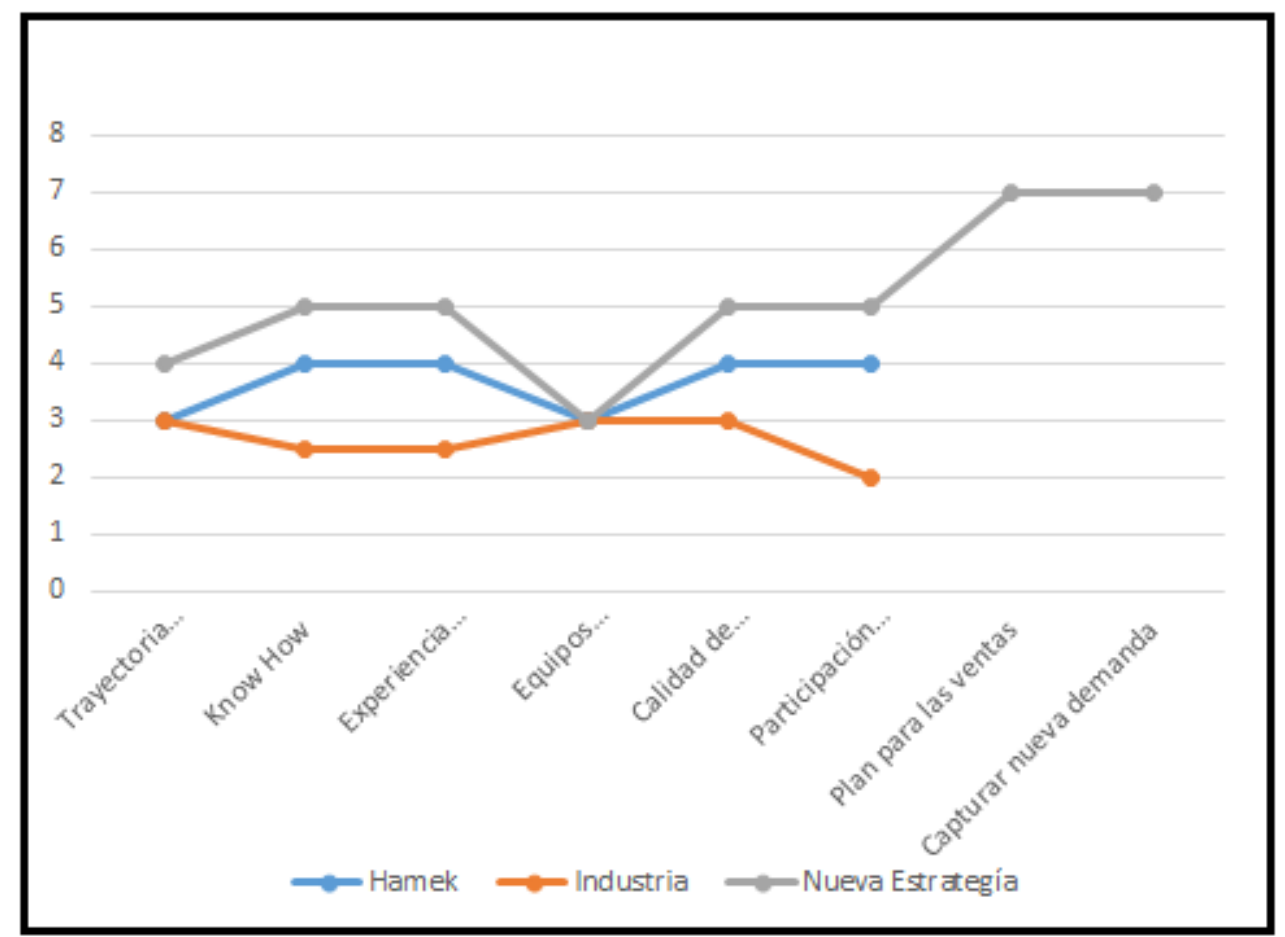

Figura 31. Lienzo de la nueva estrategia considerada

Las estrategias resultantes del Océano Azul son:

- Penetración de mercado

- Desarrollo de producto

- Desarrollo de mercado

\subsubsection{Matrices de formulación de estrategias.}

Para la determinación de las estrategias que debiera implementar Hamek Ingenieros Asociados S.A.C, se realizará el análisis respectivo de las variables internas y el entorno basados en el marco teórico vigente.

\subsubsection{Matriz FODA.}

La matriz de FODA resulta ser una de las matrices más relevantes y reconocidas al momento de realizar la formulación de estrategias dado lo intuitivo de su análisis.

Como lo señala D’Alessio (2008), esta matriz fue creada por Weihrich en el año 1982 como una herramienta de análisis situacional, su vigencia se mantiene y actualmente el desarrollo de las estrategias que se plantean en la matriz FODA consideran la identidad de la organización a través de su misión, visión y valores, pero además toma en cuenta el entorno y a la competencia, las estrategias se definen para 
cada uno de los cuatro cuadrantes de la matriz: fortalezas y oportunidades (FO), debilidades y oportunidades (DO), fortalezas y amenazas (FA) y debilidades y amenazas (DA).

Para el desarrollo de la matriz FODA traemos los factores determinantes de éxito o fracaso de las matrices EFI y EFE y las emparejamos determinando cuatro tipos de estrategias según se detalla, estrategias FO - Explotar, estrategias DO - Buscar, estrategias FA - Confrontar, y finalmente estrategias DA - Evitar.

La Matriz FODA se presenta a continuación (Ver Tabla 43) 


\section{Tabla 43}

\section{Matriz FODA Hamek Ingenieros y Asociados SAC}

ANALISIS EXTERNO

\begin{tabular}{|c|c|c|}
\hline \multirow[t]{2}{*}{ ANALISIS EXTERNO } & \multicolumn{2}{|c|}{ ANALISIS INTERNO } \\
\hline & FORTALEZAS & DEBILIDADES \\
\hline & F1 Participación de Mercado & D1 Ausencia de Gobierno Corporativo \\
\hline & F2 Posicionamiento de la Marca/Empresa & D2 Modernización Equipamiento Tecnológico \\
\hline & F3 Trayectoria en el sector / Reputación & D3 Falta de Certificaciones Internacionales Calidad \\
\hline OPORTUNIDADES & FO - EXPLORAR & DO - BUSCAR \\
\hline O1 Calificación Riesgo País / Crecimiento del PBI & $\begin{array}{l}\text { F2 - O1 Desarrollo de Producto - Sector Energía / Medio } \\
\text { Ambiente }\end{array}$ & D1 - O1 Reordenamiento Organizacional para enfrentar desafios \\
\hline O2 Marco Normativo y Regulatorio estable y claro & F2 - O2 Penetración de Mercado Interno & D3 - O3 Alianza / Consorcio Internacional de Cooperación Técnica \\
\hline O3 Acuerdo Energético Perú Brasil & F3 - O3 Penetración de Mercado LATAM & D3 - O4 Alianza / Consorcio Internacional de Cooperación Técnica \\
\hline O4 Hub Energético para los países LATAM & F3 - O4 Penetración de Mercado LATAM & D2 - O6 Diferenciación / Ventaja Competitiva \\
\hline O5 Incremento e Impulso Parques Energía Eólica / Solar & F3 - 05 Desarrollo de Producto - Sector Energía Renovable & D1 - O3 Reordenamiento Organizacional para enfrentar desafios \\
\hline $\begin{array}{l}\text { O6 Incremento exigencias gubernamentales y } \\
\text { empresariales }\end{array}$ & F3 - O6 Penetración de Mercado Interno \& Mercado LATAM & D2 - O7 Diferenciación / Ventaja Competitiva \\
\hline O7 Incorporación tecnología para mejora equipamiento & F3 - O7 Penetración de Mercado Interno \& Mercado LATAM & D3 - O5 Reordenamiento Organizacional para enfrentar desafios \\
\hline AMENAZAS & FA - CONFRONTAR & DA - EVITAR \\
\hline $\begin{array}{l}\text { A1 Inestabilidad política que frena Proyectos de } \\
\text { Inversión }\end{array}$ & F3 - A1 Penetración de Mercado LATAM & D3 A1 Diversificación Concéntrica \\
\hline A2 Limitaciones de financiamiento por parte del FONAFE & F3 - A2 Penetración de Mercado LATAM & D1 - A2 Alianza / Consorcio Internacional de Cooperacion Tecnica \\
\hline A3 Interferencia /Injerencia política en el sector eléctrico & F2 - A3 Desarrollo de Producto . Sector Medio Ambiente & D2 - A4 Diversificación Concéntrica \\
\hline A4 Riesgo de Guerra Comercial entre China y EEUU & F2 - A4 Diversificación Concéntrica & D2 - A3 Desarrollo de Producto \\
\hline
\end{tabular}

Nota. Elaboración propia. 
Del Análisis de la Matriz FODA establecemos como principal estrategia a implementar, la penetración del mercado latinoamericano aprovechando el posicionamiento que tiene Hamek Ingenieros Asociados S.A.C en la actualidad y su experiencia internacional previa, debidamente acreditada, en países como Chile y EI Salvador teniendo especial interés en aprovechar los acuerdos energéticos con Brasil y la posibilidad de que se constituya en un Hub energético para otros países de Latinoamérica como Ecuador, Chile y Bolivia, también se precisa que en la actualidad Hamek Ingenieros Asociados S.A.C está muy interesado en especializarse además en brindar el servicio de asesoría técnica referida al uso adecuado de la energía renovable que en el futuro próximo tendrá una mayor demanda, esto último implica que además se siga una estrategia que busque el desarrollo de nuevos productos en el sector energía y medio ambiente dada las experiencias observadas en otros países de la región siendo además una tendencia global el uso de energía en armonía con el medio ambiente y el equilibrio del ecosistema, también es importante que precisemos que la matriz energética en los países de Latinoamérica y Centroamérica viene cambiando, según la Organización Latinoamericana de Energía, OLADE (2010) son solamente tres países, donde se han hecho estudios recientes de potencial eólico, Brasil, México y Chile la Región cuenta con más de 244 GW disponibles para esta tecnología. 


\subsubsection{Matriz PEYEA.}

Como lo señala D’Alessio (2018), la matriz de la posición estratégica y la evaluación de la acción (PEYEA) de Dickel (1984) permite determinar cuál será la postura estratégica adecuada que debe tomar Hamek Ingenieros Asociados S.A.C., dicha matriz cuenta con dos ejes que combinan factores relativos al sector, referidos a la Fortaleza de la Industria (FI) y la Estabilidad del Entorno (EE) versus factores de la Organización referidos a su Fortaleza Financiera (FF) y a su Ventaja Competitiva (VC). Las posturas estratégicas posibles de adoptar están asociadas a la ubicación de Hamek Ingenieros Asociados S.A.C dentro de alguno de los cuatro cuadrantes y podrían ser, una postura agresiva, una postura conservadora, una postura defensiva o una postura competitiva.

Se identificaron los factores determinantes en la posición estratégica de Hamek Ingenieros Asociados S.A.C., y se establecieron para cada factor un valor según se detalla en la Tabla 44. 


\section{Tabla 44}

\section{Factores Determinantes Posición Estratégica}

Factores Determinantes de la Fortaleza Financiera (FF)

\begin{tabular}{|c|c|c|c|c|c|c|c|c|c|c|}
\hline Fortaleza Financiera [FF] & & & & & & & & & & Valor \\
\hline Crecimiento Ventas & Inferior & 0.0 & 1.0 & 2.0 & 3.0 & 4.0 & 5.0 & 6.0 & Superior & 4.00 \\
\hline Incremento Utilidad Bruta & Inferior & 0.0 & 1.0 & 2.0 & 3.0 & 4.0 & 5.0 & 6.0 & Superior & 4.00 \\
\hline Incremento Utilidad Operativa & Inferior & 0.0 & 1.0 & 2.0 & 3.0 & 4.0 & 5.0 & 6.0 & Superior & 4.00 \\
\hline Bajo nivel de apalancamiento / endeudamiento & Avanzado & 0.0 & 1.0 & 2.0 & 3.0 & 4.0 & 5.0 & 6.0 & Temprano & 3.00 \\
\hline \multicolumn{11}{|l|}{ Factores Determinantes de la Ventaja Competitiva [VC] } \\
\hline Ventaja Competitiva [VC] & & & & & & & & & & Valor \\
\hline Participación de mercado & Pequeña & 0.0 & 1.0 & 2.0 & 3.0 & 4.0 & 5.0 & 6.0 & Grande & 3.0 \\
\hline Lealtad / Clientes que vuelven a tomar servicios & Inferior & 0.0 & 1.0 & 2.0 & 3.0 & 4.0 & 5.0 & 6.0 & Superior & 4.0 \\
\hline Calidad del servicio / Tasa reclamos servicio & Avanzado & 0.0 & 1.0 & 2.0 & 3.0 & 4.0 & 5.0 & 6.0 & Temprano & 2.0 \\
\hline Ciclo de vida del producto & Baja & 0.0 & 1.0 & 2.0 & 3.0 & 4.0 & 5.0 & 6.0 & Alta & 2.0 \\
\hline \multicolumn{11}{|l|}{ Factores Determinantes de la la Fortaleza Industrial $[\mathrm{FI}]$} \\
\hline Fortaleza de la Industria [FI] & & & & & & & & & & Valor \\
\hline Potencial de Crecimiento & Bajo & 0.0 & 1.0 & 2.0 & 3.0 & 4.0 & 5.0 & 6.0 & Alto & 5.0 \\
\hline Potencial de Utilidades & Bajo & 0.0 & 1.0 & 2.0 & 3.0 & 4.0 & 5.0 & 6.0 & Alto & 5.0 \\
\hline Facilidad de entrada al mercado / Regulaciòn / Normativa & Fácil & 0.0 & 1.0 & 2.0 & 3.0 & 4.0 & 5.0 & 6.0 & Difícil & 4.0 \\
\hline Productividad / Utilización de la Capacidad & Baja & 0.0 & 1.0 & 2.0 & 3.0 & 4.0 & 5.0 & 6.0 & Alta & 4.0 \\
\hline
\end{tabular}

Factores Determinantes de la Estabilidad del Entorno [EE]

Estabilidad del Entorno [EE]

Modernización constante de equipamiento especializado / Medición

Muchos

$0.0 \quad 1.0$

Barrera de entradas al mercado

Pocas

$\begin{array}{lll}0.0 & 1.0 & 2.0 \\ 0.0 & 1.0 & 2.0\end{array}$

Rivalidad / Presión Competitiva

Alta

$\begin{array}{ll}0.0 & 1.0 \\ 0.0 & 1.0\end{array}$

2.0
2.0

$\begin{array}{ll}3.0 & 4.0 \\ 3.0 & 4.0 \\ 3.0 & 4.0 \\ 3.0 & 4.0\end{array}$

\begin{tabular}{ccclc} 
& & & & Valor \\
4.0 & 5.0 & 6.0 & Pocos & 2.0 \\
4.0 & 5.0 & 6.0 & Muchas & 5.0 \\
4.0 & 5.0 & 6.0 & Baja & 2.0 \\
4.0 & 5.0 & 6.0 & Baja & 2.0 \\
\hline
\end{tabular}

Nota. Elaboración propia. 
Se realiza el análisis de cada uno de los factores determinantes para determinar la posición estratégica de Hamek Ingenieros Asociados S.A.C., según se detalla en la Tabla 45. 


\section{Tabla 45}

Análisis Factores Determinantes Posición Estratégica

\begin{tabular}{|c|c|c|c|c|c|}
\hline \multicolumn{3}{|c|}{ Posición Estratégica Interna } & \multicolumn{3}{|l|}{ Posición Estratégica Externa } \\
\hline \multicolumn{3}{|c|}{ Ventaja competitiva (VC) } & \multicolumn{3}{|l|}{ Fortaleza de la industria $(\mathrm{Fl})$} \\
\hline Participación de mercado & & -3.00 & Potencial de Crecimiento & & 5.00 \\
\hline Lealtad / Clientes que vuelven a tomar servicios & & -1.00 & Potencial de Utilidades & & 5.00 \\
\hline Calidad del servicio / Tasa reclamos servicio & & -6.00 & Facilidad de entrada al mercado / Regulaciòn / Normativa & & 4.00 \\
\hline \multirow[t]{2}{*}{ Bajo nivel de apalancamiento / endeudamiento } & & -3.00 & Productividad / Utilización de la Capacidad & \multirow{3}{*}{ Promedio } & 4.00 \\
\hline & Promedio & -3.25 & & & 4.50 \\
\hline Total de la coordenada $X$ : & & 1.25 & $(V C+F I)$ & & \\
\hline \multicolumn{3}{|c|}{ Fortaleza Financiera (FF) } & \multicolumn{3}{|l|}{ Estabilidad del Entorno (EE) } \\
\hline Crecimiento Ventas & & 4.00 & Modernización constante de equipamiento especializado / Medición & & -2.00 \\
\hline Incremento Utilidad Bruta & & 4.00 & Barrera de entradas al mercado & & -5.00 \\
\hline Incremento Utilidad Operativa & & 4.00 & Rivalidad / Presión Competitiva & & -2.00 \\
\hline \multirow[t]{2}{*}{ Ciclo de vida del producto } & & 3.00 & Incremento exigencias gubernamentales y empresariales & & -2.00 \\
\hline & Promedio & 3.75 & & Promedio & -2.75 \\
\hline Total de la coordenada Y: & & 1.00 & $(F F+E E)$ & & \\
\hline
\end{tabular}

Nota. Elaboración propia. 
Con la valorización para cada uno de los factores determinantes en cada uno de los cuadrantes, construimos la Matriz PEYEA según se detalla en la figura 32 :

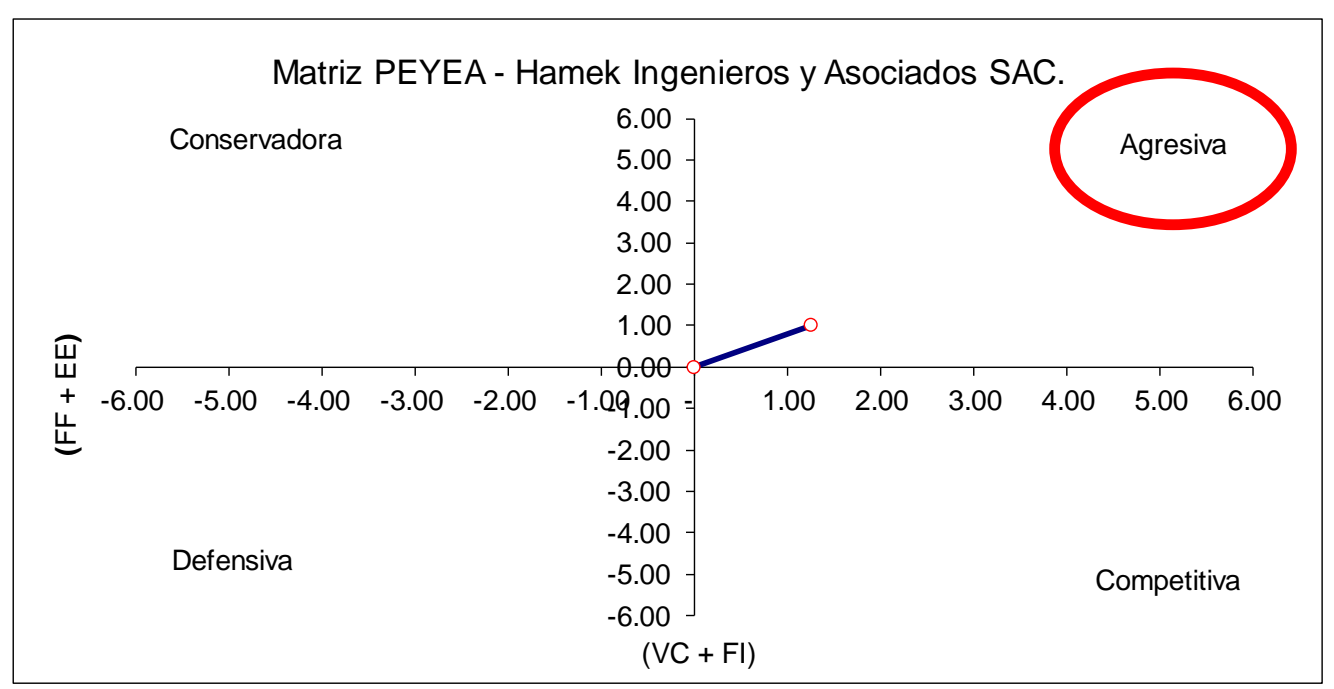

Figura 32. Matriz PEYEA. Elaboración Propia.

Del análisis de la Matriz PEYEA se concluye que Hamek Ingenieros Asociados S.A.C debe asumir una postura agresiva dado que la industria resulta muy atractiva y hay poca turbulencia en el entorno, lo cual favorece el implantar una estrategia de penetración del mercado en Latinoamérica dado que en el mercado local ya cuenta con una participación importante, también es destacable mencionar que Hamek Ingenieros Asociados S.A.C cuenta con una solidez financiera y un posicionamiento en el sector que le permite ser competitivo, vista la posición de dominio en el mercado lo recomendable es tomar ventaja de las oportunidades existentes, aumentar su participación del mercado latinoamericano, desarrollar nuevos productos o concentrar sus recursos en aquellos servicios diferenciados para generar una mayor ventaja competitiva, teniendo en cuenta que la demanda de energía eléctrica se mantiene en aumento en la región, la reputación de la empresa y la existencia de un potencial cambio en la matriz energética dentro de la región, lo que genera una mayor oportunidad de desarrollar los servicios de Hamek Ingenieros Asociados S.A.C. 


\subsubsection{Matriz Interna Externa.}

El concepto sobre la matriz interna y externa es:

La MIE también es una matriz de portafolio, porque en ella se grafica cada una de las divisiones o cada uno de los productos de la organización, ubicándolos en una de las nueve celdas que tiene. Estas celdas han sido formadas sobre la base de dos dimensione: los puntajes totales ponderados de las matrices EFE y EFI. (D'Alessio, 2016, p. 293).

La matriz interna y externa nos permitirá de acuerdo a los resultados que se obtuvo en la matriz de los factores interno (EFI) y factores externos (EFE), tomar las mejores decisiones para las estrategias que necesita Hamek Ingenieros Asociados S.A.C.

Los valores del EFI fue de 2.81 y el EFE fue de 3.41, analizado en capítulos anteriores, la empresa se encuentra en el cuadrante II, como se muestra en la figura 33 en la posición de crecer y construir por lo cual se recomienda utilizar estrategias intensivas y/o de integración:

- Penetración de mercado

- Desarrollo de mercado

- Desarrollo de producto

- Hacia adelante, hacia atrás, horizontal.

De lo anterior se concluye que Hamek Ingenieros Asociados S.A.C tiene las condiciones adecuadas en el mercado y las fortalezas para aumentar su posición de dominio y crecer. 


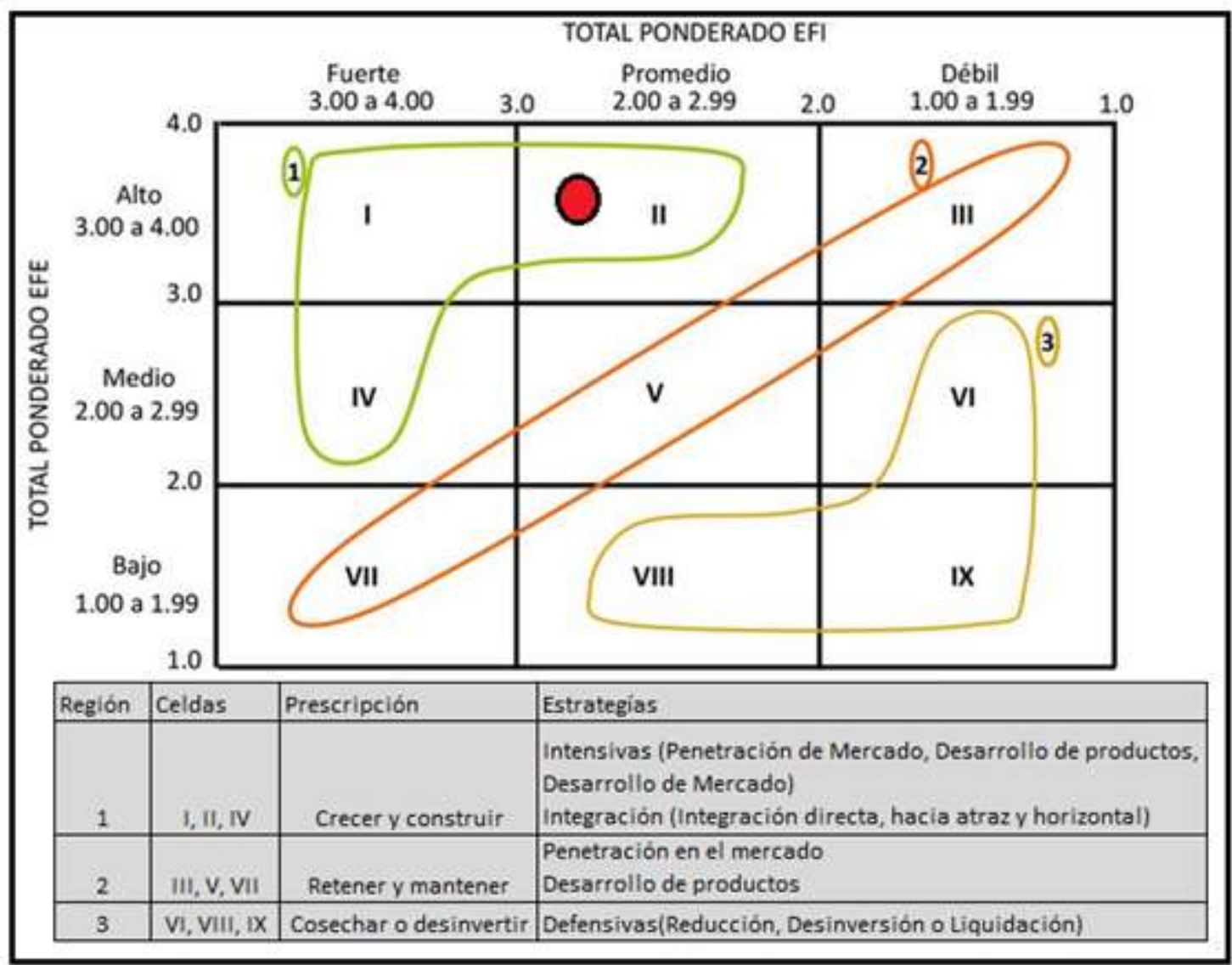

Figura 33. Matriz Interna y Externa

\subsubsection{Matriz Boston Consulting Group.}

La matriz Boston Consulting Group(BCG), "conocida como matriz de crecimiento de participación, representa gráficamente las diferencias entre divisiones, en términos de su participación relativa en el mercado y la tasa de crecimiento de la industria." (David, 2013, p.182)

Esta matriz permite graficar la cartera de negocios de la empresa en función a participación relativa en el mercado (eje $\mathrm{X}$ ) y la tasa de crecimiento de la industria (eje $\mathrm{Y}$ ). La matriz consta de cuatro cuadrantes, las cuales se definen como: interrogante, estrella, vaca y perro.

La empresa Hamek Ingenieros y Asociados S.A.C., tiene dos unidades de negocio, en el sector de energía y sector de medio ambiente, que conforman la organización, representado sus ventas anuales, sus porcentajes de utilidades, obteniendo la participación de mercado y tasa de crecimiento de la empresa. 
Tabla 46

Participación de mercado y tasa de crecimiento de la empresa

\begin{tabular}{|c|c|c|c|c|c|c|c|c|}
\hline $\begin{array}{l}\text { Unidad } \\
\text { de Negocio }\end{array}$ & $\begin{array}{c}\text { A. Ventas } \\
\text { año actual } \\
\text { del mercado } \\
\text { (soles) }\end{array}$ & $\begin{array}{c}\text { B. Ventas } \\
\text { año pasado } \\
\text { de la } \\
\text { organización } \\
\text { (soles) }\end{array}$ & $\begin{array}{c}\text { C. Ventas } \\
\text { año actual } \\
\text { de la } \\
\text { organización } \\
\text { (soles) }\end{array}$ & $\begin{array}{c}\text { D. Ventas } \\
\text { año actual } \\
\text { de la } \\
\text { organización } \\
\text { (\%) }\end{array}$ & $\begin{array}{l}\text { E. Utilidad } \\
\text { año actual } \\
\text { de la } \\
\text { organización } \\
\text { (soles) }\end{array}$ & $\begin{array}{c}\text { F. Utilidad } \\
\text { año actual } \\
\text { de la } \\
\text { organización } \\
\text { (\%) }\end{array}$ & $\begin{array}{c}\text { Participción } \\
\text { del mercado } \\
\text { (C/A) }\end{array}$ & $\begin{array}{c}\text { Tasa de } \\
\text { Crecimiento } \\
((\mathrm{C}-\mathrm{B}) / \mathrm{B})\end{array}$ \\
\hline $\begin{array}{l}\text { Servicio } \\
\text { del Área } \\
\text { Energética }\end{array}$ & $5,582,379.85$ & $2,567,286.00$ & $3,003,454.00$ & $91 \%$ & $828,106.00$ & $84 \%$ & $54 \%$ & $17 \%$ \\
\hline $\begin{array}{l}\text { Servicio } \\
\text { del Área } \\
\text { Medio Ambiente }\end{array}$ & $761,233.62$ & $282,431.00$ & $295,225.00$ & $9 \%$ & $156,528.00$ & $16 \%$ & $39 \%$ & $5 \%$ \\
\hline Total de Ventas & $6,343,613.46$ & $2,849,717.00$ & $3,298,679.00$ & $100 \%$ & $984,634.00$ & $100 \%$ & & \\
\hline
\end{tabular}

Nota: Adaptado de "el proceso estratégico un enfoque de gerencia" por D'Alessio, F., 2013, p.329.

Con los datos armamos la matriz BCG, se ha representado en el gráfico, el tamaño de círculo en \% de utilidades, la participación relativa en el mercado en la línea horizontal, la tasa de crecimiento con la línea vertical.

La participación relativa en el mercado, es la comparación de la participación de mercado de la empresa Hamek Ingenieros Asociado S.A.C de $0.44 \%$.con la del líder, que son ellos mismos, por lo que el sector de energía se encontrara posicionado en el eje vertical.

En el sector de medio ambiente, se compara con el líder que es la empresa Cenergia, el cual tiene una participación de mercado 0.79\% que duplica a la de Hamek Ingenieros Asociados S.A.C., obteniendo una participación relativa de 0.49\%.

Construyendo la matriz BCG, la empresa Hamek Ingenieros Asociados S.A.C., en el sector de energía se encuentra en el segundo cuadrante (estrella) y en el sector de medio ambiente se ubica en el primer cuadrante (interrogante). 


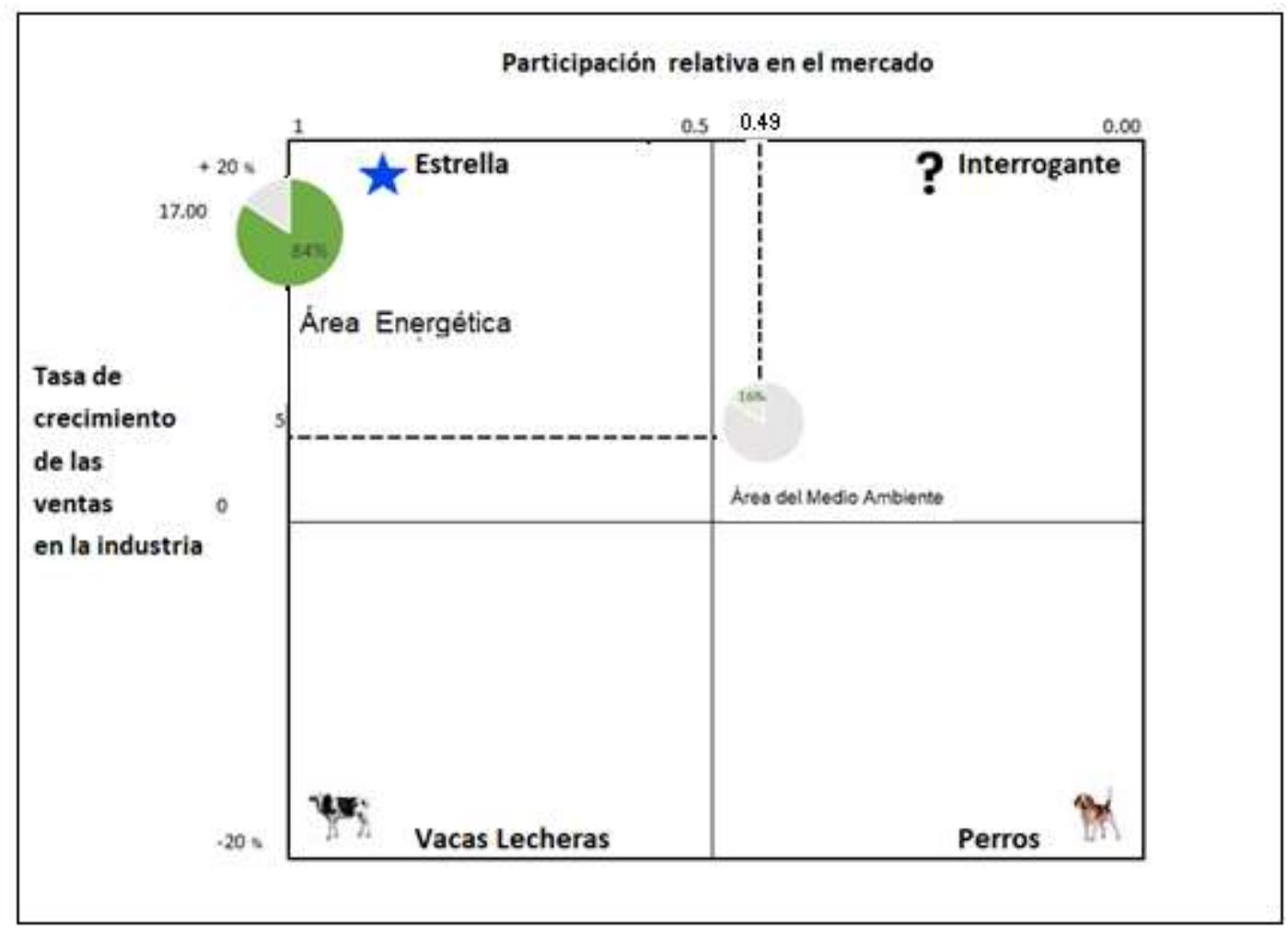

Figura 34. Matriz Consulting Boston Group

En el sector de energía ubicado en el segundo cuadrante (estrella), representa una alta participación relativa en el mercado y compiten en una industria con tasa de crecimiento elevada, la cual representa para la empresa las mejores oportunidades y crecimiento de rentabilidad a largo plazo.

Las estrategias son:

- Integración hacia atrás, hacia adelante u horizontal

- Penetración de mercado

- Desarrollo de mercado

- Desarrollo de producto

En el sector de medio ambiente la empresa se ubica en el primer cuadrante (interrogante) representa una baja participación relativa en el mercado, pero compite en una industria de alto crecimiento, generando menores ingresos

Las estrategias son:

- Penetración de mercado

- Desarrollos de mercado

- Desarrollo de producto

- Desinversión 


\subsubsection{Matriz de la Gran Estrategia.}

La Matriz de la Gran Estrategia se basa en:

La MGE de la gran estrategia es otra herramienta útil que ayuda a evaluar y

afinar la elección apropiada de estrategias para la organización. El fundamento de esta matriz se soporta en que la situación de un negocio es definida en términos de: (a) el crecimiento del mercado, rápido o lento; y (b) la posición competitiva de la empresa en dicho mercado, fuerte o débil. (D'Alessio, 2016, p. 296).

De acuerdo al enfoque teórico detrás de esta matriz, la situación de un negocio se define en función de dos variables: (a) crecimiento rápido o lento del mercado y (b) la posición competitiva fuerte o débil de la empresa en el mercado. Cuando se evalúa ambas variables en forma conjunta, es posible categorizar un negocio y ubicarlo en uno de cuatro cuadrantes posibles: cuadrante I, si la organización tiene una posición competitiva fuerte y el mercado donde opera tiene un crecimiento rápido; cuadrante II, si la empresa se encuentra en un mercado con crecimiento rápido y su posición competitiva es débil; cuadrante III, si el mercado crece lentamente y la organización tiene una posición competitiva débil y; cuadrante IV, si la empresa tiene una posición competitiva fuerte y el mercado donde opera tiene crecimiento lento.

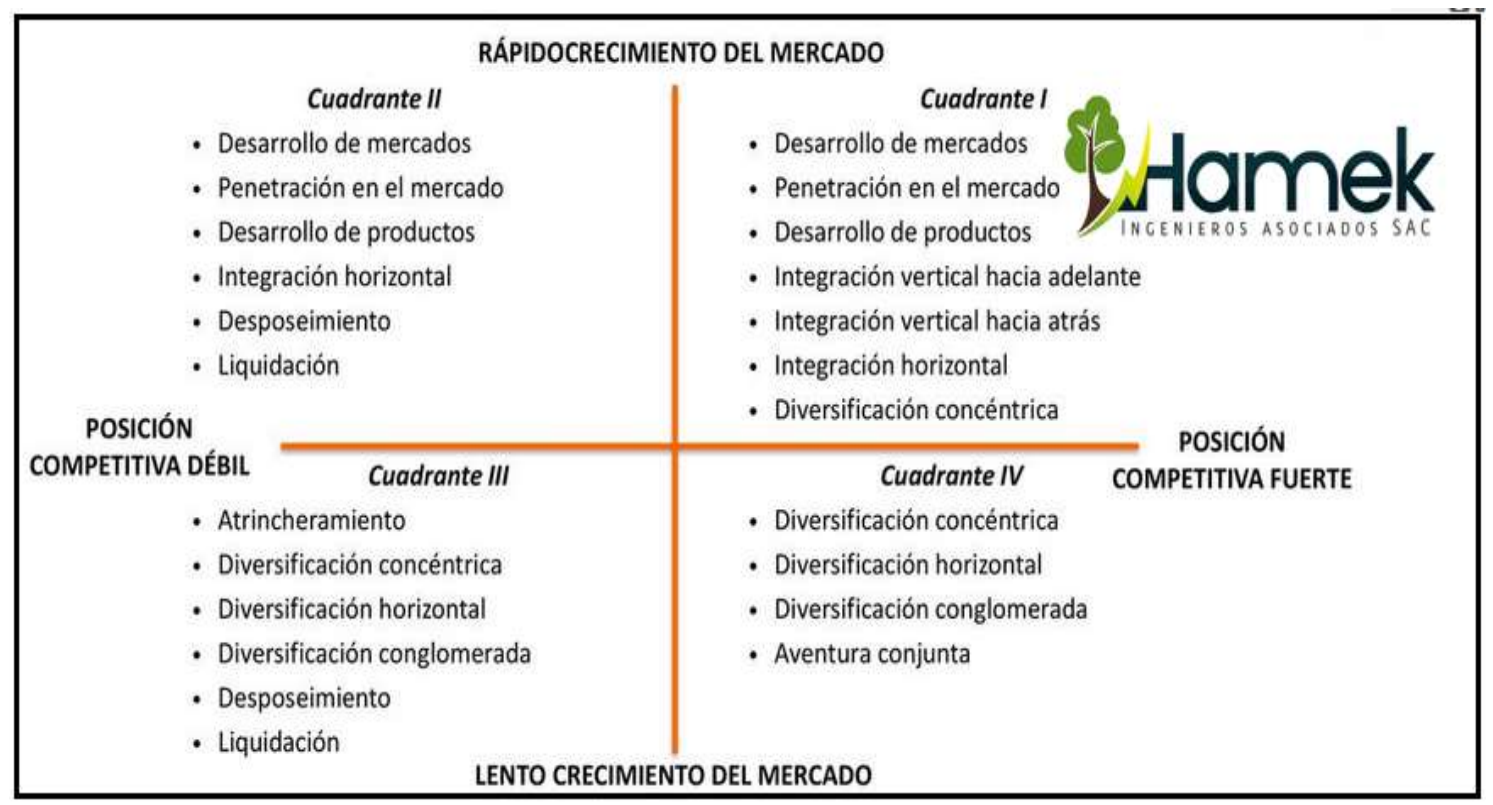

Figura 35. Matriz de la Gran Estrategia

El resultado obtenido de la matriz de la Gran Estrategia para la empresa Hamek Ingenieros Asociados S.A.C. se ubica en el cuadrante I, lo cual significa que se encuentra 
en posición competitiva fuerte y en rápido crecimiento del mercado (ver Figura 35), sus estrategias son:

- Penetración de mercado

- Desarrollos de mercado

- Desarrollo de producto

- Integración Vertical hacia adelante

- Integración Vertical hacia atrás

- Integración horizontal

- Diversificación Concéntrica

El sector energético peruano a largo plazo, no solo de manera coyuntural ha crecido en los últimos 13 años, la electricidad creció $132 \%$.

El desafío para nuestro país radica en contar con energía suficiente para garantizar el crecimiento industrial, minero y económico, en general. Eso implica crear las condiciones para la inversión. Las condiciones favorables permitirán atender el rápido crecimiento del mercado dado el crecimiento económico sostenido del país, así como las expectativas de crecimiento económico para los próximos 4 años.

\subsection{Resumen de las Estrategias Formuladas}

Los resultados las matrices están relacionadas entre sí, de esa forma podemos referir que las matrices EFE y EFI ayudaron a diseñar el FODA, en donde se realizó la primera selección de estrategias.

Después de haber elaborado las matrices FODA, PEYEA, BCG, IE, OCEANO AZUL y MGE, se generaron estrategias para cada una de ellas.

Se ha concluido diversas estrategias resultantes para proponer a Hamek Ingenieros Asociados S.A.C., para tener un panorama más claro, se presenta una tabla con la relación entre las estrategias obtenidas y las matrices. 
Tabla 47

Resumen de Estrategias

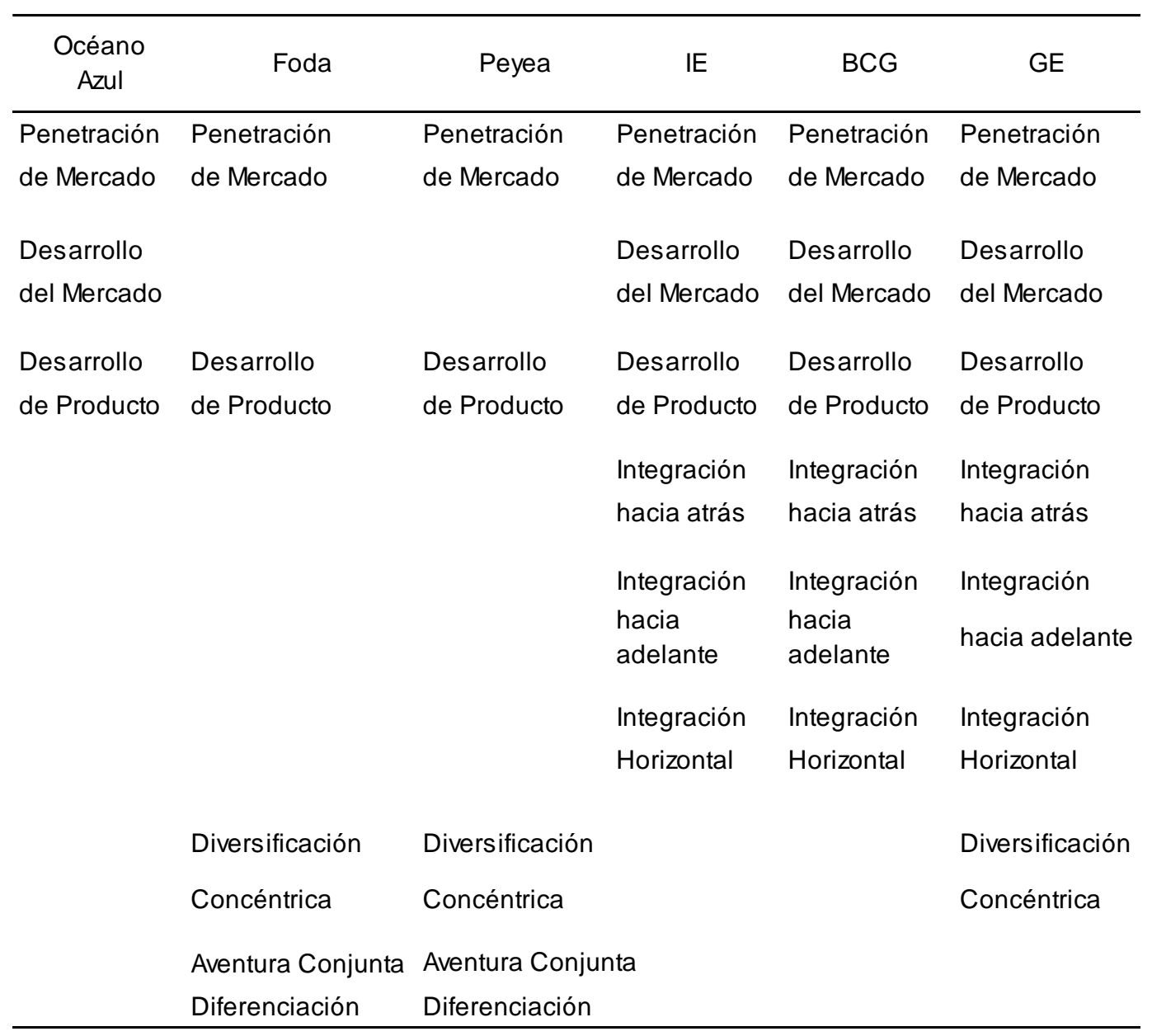

Nota. Elaboración propia. 


\section{Capítulo VIII. Selección de la Estrategia}

En el presente capítulo se analizarán los resultados obtenidos del análisis de la Matriz FODA, la Matriz PEYEA, la Matriz BCG Boston Consulting Group, la Matriz IE Interna Externa y finalmente la Matriz GE de la Gran Estrategia, para la Selección de la Estrategia a implementarse,

Para tal fin, se desarrolla la metodología de la Matriz de Decisión Estratégica para Hamek Ingenieros Asociados S.A.C., en base a la mayor coincidencia de estrategias obtenida del análisis detallado de cada una de las matrices detalladas anteriormente. Como consecuencia de este análisis se determinan las estrategias a implementarse referidas a la penetración del mercado regional y el desarrollo de producto.

Durante el desarrollo del capítulo se desarrolla el Método de Escenarios para sensibilizar el modelo a un cuadro de incertidumbre definiéndose alternativamente escenarios optimista y pesimista teniendo en cuenta las variables externas consideradas en el desarrollo del Capitulo V.

También se desarrolla el Método de Planeación Estratégica Cuantitativa MPEC buscando determinar el atractivo relativo entre las estrategias seleccionadas y poder determinar finalmente la estrategia principal a desarrollar y además la estrategia alternativa a implementar en caso no se consiga cubrir a cabalidad los objetivos estratégicos definidos.

\subsection{Método Factores Estratégicos Claves}

Se consideran las propuestas estratégicas desarrollado en el capítulo anterior a través de las cinco matrices (FODA, PEYEA, BCG, IE y MGE), para proceder a evaluar las estrategias y poder elegir aquella que se identifique con la funcionalidad, operatividad y aquella que ayude con el liderazgo estratégico.

En este método se identificarán los factores estratégicos clave, con los que cuenta Hamek Ingenieros y Asociados S.A.C., este método otorga una visión más concreta y real, otorgándole a la empresa, mayores conocimientos, técnicas y herramientas para competir en la industria, elaborar estrategias y conquistar la mayor cantidad posible de clientes. 


\subsubsection{Criterios de selección.}

La selección de la estrategia ideal para la empresa Hamek Ingenieros y Asociados S.A.C., tiene diversos enfoques, todos ellos deben buscar potenciar la mayor generación de valor para la organización, traducido en mayores ingresos y mayor rentabilidad.

A continuación, se listarán todas las estrategias obtenidas en las matrices previas con el fin de determinar cuáles son las estrategias que más se repiten. Luego, se seleccionarán y, de esta manera, quedarán determinadas las estrategias que la empresa debe aplicar.

\subsubsection{Matriz de selección.}

De acuerdo con Alessio (2016) "En esta matriz se suman las repeticiones y se retienen las estrategias con mayor repetición, e incluso otras que por algún motivo se consideren pertinentes para el proceso".

En base a las estrategias identificadas (ver Tabla 48), la Matriz de decisión estratégica.

Tabla 48

Matriz de Decisión Estratégica

\begin{tabular}{|c|c|c|c|c|c|c|c|}
\hline & $\begin{array}{c}\text { Océano } \\
\text { Azul }\end{array}$ & Foda & Peyea & IE & $B C G$ & GE & TOTAL \\
\hline Penetración de Mercado & $x$ & $x$ & $x$ & $x$ & $x$ & $x$ & 6 \\
\hline Desarrollo del Mercado & $x$ & & & $x$ & $x$ & $x$ & 4 \\
\hline Desarrollo de Producto & $x$ & $x$ & $x$ & $x$ & $x$ & $x$ & 6 \\
\hline Integración hacia atrás & & & & $x$ & $x$ & $x$ & 3 \\
\hline Integración hacia adelante & & & & $x$ & $x$ & $x$ & 3 \\
\hline Integración Horizontal & & & & $x$ & $x$ & $x$ & 3 \\
\hline Diversificación Concéntrica & & $x$ & $x$ & & & $x$ & 3 \\
\hline Aventura Conjunta & & $x$ & $x$ & & & & 2 \\
\hline Diferenciación & & $x$ & $x$ & & & & 2 \\
\hline
\end{tabular}

Nota. Elaboración propia.

En la tabla 48 se representa la matriz de decisión donde se compara las seis matrices desarrolladas frente a estrategias; con lo que se evalúa la estrategia con la que trabaja cada matriz; a partir de lo cual se elegirá la estrategia que más se encuentra 
presente y con mayor calificación, como resultado de las matrices desarrolladas, se observa que las estrategias que cuentan con igual calificación son las estrategias:

-Penetración de Mercado

-Desarrollo de Producto

La estrategia elegida como primera opción se decidirá en función a cumplir los objetivos trazados en el más corto plazo, conseguir mayor rentabilidad en menor tiempo, y con una menor inversión. A continuación, presentamos un cuadro comparativo de las inversiones proyectadas para ambas estrategias con igual puntaje.

Tabla 49

Inversión Proyectada por Estrategia

\begin{tabular}{lrrr}
\hline Estrategía & \multicolumn{3}{c}{ Inversión Total Por Año S/ } \\
\cline { 2 - 4 } & 2019 & 2020 & 2021 \\
Penetración de Mercado & 152,900 & 206,800 & 224,100 \\
Desarrollo de Producto & 253,000 & 263,000 & 294,000 \\
\hline
\end{tabular}

Nota. Elaboración propia

En la tabla 49 se puede observar que la Estrategia Penetración de Mercado tiene menos inversión que la estrategia desarrollo de producto, dado que el servicio ya se encuentra desarrollado y Hamek Ingenieros Asociados S.A.C., cuenta con los recursos necesarios para brindar dicho servicios, respecto a la estrategia de Desarrollo de Productos, se requiere una mayor inversión referida a la adquisición de equipos especializados de medición, contratación de nuevo personal calificado para el desarrollo de estos servicios, además, este último servicio requerirá trabajar en sociedad para adquirir el conocimiento y ser competitivos, importante precisar que estas alianzas se mantendrán hasta cuando Hamek Ingenieros Asociados S.A.C., logre adquirir la experiencia necesaria que lo vuelva competitivo.

Asimismo, otro de los factores analizados es el margen de utilidades que generan los servicios locales en comparación con los internacionales, según lo señalado por los accionistas los servicios ofrecidos en el extranjero, tienen una margen de utilidad que supera el $100 \%$ respecto al resultados conseguido a nivel local, reiterando que costos incurridos son similares.

Finalmente se considera importante tener en cuenta los valores conseguidos de un Valor Actual Neto (VAN) y la Tasa Interna de Retorno (TIR). 
Con los puntos analizados anteriormente se concluye que la estrategia que más se ajusta a los objetivos trazados es la estrategia en Penetración de Mercado, que será elegida como la estrategia principal y como segunda estrategia será el Desarrollo de producto.

\subsection{Método de Escenarios.}

El planteamiento de escenarios es una herramienta que en situaciones de rápido cambio del entorno busca reducir el nivel de incertidumbre y margen de error en el proceso de toma de decisiones. Su construcción permite describir las varias alternativas de futuro existentes para una situación en particular, permitiendo el análisis de problemas conjuntos e interrelacionados, facilitando un mejor conocimiento del grupo decisor acerca de los asuntos estratégicos (M. Godet, 2000).

De acuerdo a la bibliografía planteada como fuente de información, los escenarios son los métodos más populares de los estudios del futuro, permite simular consecuencias de escenarios posibles en las actividades claves de una empresa, todo ello permitirá a la organización predecir, comparar y optimizar el comportamiento de sus procesos simulados en un tiempo muy breve sin el coste ni el riesgo de llevarlos a cabo, haciendo posible la representación de los procesos, recursos, productos y servicios en un modelo dinámico.

La selección de la estrategia ideal para la empresa Hamek Ingenieros y Asociados S.A.C., tiene diversos enfoques, todos ellos deben buscar tomar la estrategia que potencie la mayor generación de valor de la organización.

Con la teoría basada en Godet, se procede a plantear dos escenarios alternativos del entorno para los próximos tres años, y confrontar las estrategias determinadas.

\subsubsection{Descripción de Escenarios considerados.}

En la tabla 50 se describirán tres situaciones considerando el periodo planteado en el presente estudio, la información descrita en la tabla está desarrollada basada en el análisis del entorno externo estudiado en el Capítulo IV. Una vez determinado los contextos, se procederá a elaborar la tabla 51, definición de escenarios, formando dos escenarios de estudio: El más probable y el menos probable. 


\section{Tabla 50}

\section{Definición de Contextos}

\begin{tabular}{|c|c|c|c|}
\hline Analis is Politico-Economico & 1 (Sin variacion) & 2 (Optimista) & 3 (Pesimista) \\
\hline Cercimiento del PBI & Estable & Alto $>4 \%$ & Bajo < 3\% \\
\hline Inversion privada & Sin cambios & Crece ilnversion & Cierre de empresa privada \\
\hline Inversion pública & Se mantiene & Crece inversion & Cierre de empresas públicas \\
\hline Inflación & Se mantiene & Menos inflacion & Mayor Inflación \\
\hline Tendencia del tipo de cambio & Estable $3.2-3.4$ & Alza $>3.4$ & A la Baja $<3.2$ \\
\hline Entorno politico-economico & Sin cambios & Mayor es tabilidad & Incremento de incertidumbre \\
\hline \multicolumn{4}{|l|}{ Análisis legal } \\
\hline $\begin{array}{l}\text { Exigencia en el cumplimiento de la normativa } \\
\text { (energetico-Ambiental) }\end{array}$ & Sin variación & politicas laxas & Políticas restrictivas \\
\hline $\begin{array}{l}\text { Nuevas poiticas regulatoria en el sector de } \\
\text { enegia y medio ambiente }\end{array}$ & Sin nuevas políticas & $\begin{array}{l}\text { Politicas que respalden el } \\
\text { crecimiento del sector }\end{array}$ & $\begin{array}{l}\text { Politicas que restrinjan el } \\
\text { crecimiento del sector }\end{array}$ \\
\hline \multicolumn{4}{|l|}{ Anális is cultural } \\
\hline Mayor consciencia ambiental & Se mantiene & Aumenta & Disminuye \\
\hline \multicolumn{4}{|l|}{ Análisis tecnologico } \\
\hline Desarrollo de tecnologia para el sector & Estandar se mantiene & Tecnologia de Punta al alcance & Tecnología inaccesible \\
\hline $\begin{array}{l}\text { Análisis ecológico } \\
\text { Conciencia ecológica /Medio ambiental } \\
\text { empresarial }\end{array}$ & $\begin{array}{l}\text { Incipiente conciencia } \\
\text { ambiental }\end{array}$ & Alta conciencia Ambiental & Baja conciencia ambiental \\
\hline
\end{tabular}

Nota. Elaboración propia. 
Tabla 51

Definición de Escenarios

\begin{tabular}{|c|c|c|}
\hline Analisis Politico-Economico & Escenario I (mas probable) & Escenario II (menos Probable) \\
\hline Cercimiento del PBI & Alto $>4 \%$ & Bajo $<3 \%$ \\
\hline Inversion privada & Crece Inversion & Cierres de Empresas Privadas \\
\hline Inversion publica & Crece Inversion & Cierres de Empresas Publicas \\
\hline Inflacion & Menos Inflacion & Mayor Inflacion \\
\hline Tendencia del Tipo de Cambio & Alza $>3.4$ & A la Baja $<3.2$ \\
\hline Entorno politico-economico & Mayor estabilidad & Incremento de incertidumbre \\
\hline \multicolumn{3}{|l|}{ Analisis legal } \\
\hline $\begin{array}{l}\text { Exigencia en el cumplimiento de la normativa } \\
\text { (energetico-Ambiental) }\end{array}$ & politicas laxas & Politicas restrictivas \\
\hline $\begin{array}{l}\text { Nuevas poiticas regulatoria en el sector de } \\
\text { enegia y medio ambiente }\end{array}$ & $\begin{array}{l}\text { Politicas que respalden el } \\
\text { crecimiento del sector }\end{array}$ & $\begin{array}{l}\text { Politicas que restrinjan el } \\
\text { crecimiento del sector }\end{array}$ \\
\hline \multicolumn{3}{|l|}{ Analisis cultural } \\
\hline Maror Consciencia Ambiental & Aumenta & Disminuye \\
\hline \multicolumn{3}{|l|}{ Analisis tecnólogico } \\
\hline Desarrollo de tecnología para el sector & $\begin{array}{l}\text { Tecnologia de punta al } \\
\text { alcance }\end{array}$ & Tecnologia inaccesible \\
\hline \multicolumn{3}{|l|}{ Análisis ecológico } \\
\hline $\begin{array}{l}\text { Conciencia ecologica /medio ambiental } \\
\text { empresarial }\end{array}$ & Alta conciencia ambiental & Baja conciencia ambiental \\
\hline
\end{tabular}

Nota. Elaboración propia. 
Tomando en consideración los análisis de lo anterior, se procede a seleccionar dos escenarios con mayor grado de probabilidad de ocurrencia del otro: (a) Escenario más probable y (b) Escenario menos probable, para luego ser contrastados con las estrategias seleccionadas, y finalmente determinar cuál es la que brindará los mejores resultados respectos a los criterios de selección determinados.

1. Escenario I (Más probable): Crecimiento económico, el PBI sea superior a $4 \%$ una coyuntura política económica con mayor estabilidad. El escenario presenta una mayor inversión pública como privada en nuestro país y por ende una mayor inversión en obras y proyectos de infraestructura, como consecuencia un crecimiento de empleo. Un crecimiento en el sector energético, así como mayor inversión en equipos y tecnología de punta para el sector.

2. Escenario II (Menos probable): Entorno político económico con incertidumbre, en donde aumenta el desempleo. Desaceleración del crecimiento energético, menos proyectos de inversión pública y privada, el gobierno aplicara normativas ambientales más exigentes sin medir las consecuencias, podría generar el cierre de varias empresas del sector.

\subsubsection{Comparación de estrategias con escenarios.}

En la siguiente tabla, se ha determinado los impactos que generarían los dos escenarios planteados sobre las principales variables de las estrategias alternativas resultantes. 
Tabla 52

Impactos en Principales Variables

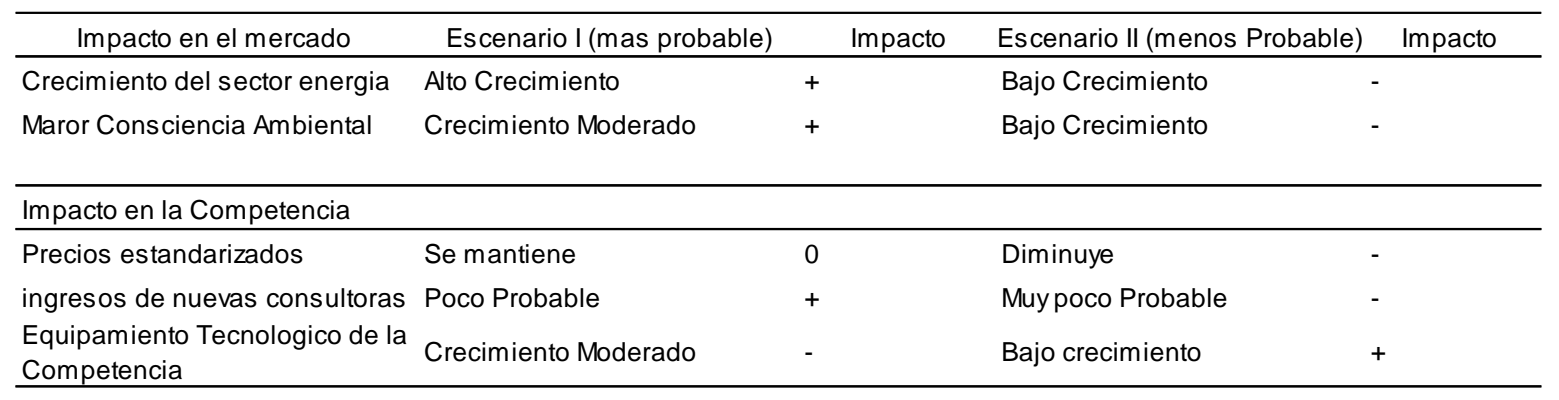

Nota. Elaboración propia.

\section{Tabla 53}

Impactos en las Estrategias

\begin{tabular}{lll}
\hline Estrategias & Escenario I (mas probable) & Escenario II (menos Probable) \\
\hline Penetración de Mercado & Altamentre Favorable & Poco Favorable \\
Desarrollo de Mercado & Favorable & Poco Favorable \\
\hline
\end{tabular}

Nota. Elaboración propia.

\subsection{Matriz de Planeación Estratégica Cuantitativa MPEC}

Además de clasificar las estrategias para obtener una lista de prioridades, sólo existe una técnica analítica en la literatura diseñada para determinar el atractivo relativo de las acciones alternativas viables. Esta técnica es la matriz cuantitativa de la planificación estratégica (MCPE) mencionada D’Alessio en el 2013.

Esta técnica indica, en forma objetiva, cuáles son las mejores estrategias alternativas. La MCPE usa la información obtenida de la matriz EFE, la matriz EFI, la matriz del perfil competitivo MPC sumadas al análisis PEYEA, la matriz del BCG, la matriz IE y la matriz de la gran estrategia.

La información se muestra en la Tabla 54 a continuación. 


\section{Tabla 54}

\section{Matriz Cuantitativa de la Planificación Estratégica (MCPE)}

\begin{tabular}{|c|c|c|c|c|c|}
\hline \multirow{2}{*}{\multicolumn{2}{|c|}{ Factores críticos para el éxito }} & \multicolumn{4}{|c|}{ Estrategias alternativas } \\
\hline & & \multicolumn{2}{|c|}{ Penetraciòn de Mercado } & \multicolumn{2}{|c|}{ Desarrollo de Producto } \\
\hline Oportunidades & Peso & CA & TCA & CA & TCA \\
\hline 1. Fomento de la inversión privada por parte del Estado & 0.059 & 3 & 0.176 & 2 & 0.118 \\
\hline 2. Calificación Riesgo País acompañado de proyección de crecimiento del PBI & 0.059 & 3 & 0.176 & 2 & 0.118 \\
\hline 3. Hub Energètico para los paises de Brasil, Ecuador, Chile y Bolivia & 0.059 & 2 & 0.118 & 4 & 0.235 \\
\hline 4. Marco Normativo y Regulatorio estable y claro & 0.074 & 4 & 0.294 & 4 & 0.294 \\
\hline 5. Incorporación de tecnología para aprovechamiento de energía & 0.074 & 4 & 0.294 & 4 & 0.294 \\
\hline 6. Tecnología permite innovación en equipos de mayor precisión y conectividad & 0.059 & 3 & 0.176 & 3 & 0.176 \\
\hline 7. Incremento e Impulso Parques Energía Eólica / Solar - Energía Renovable & 0.044 & 4 & 0.176 & 4 & 0.176 \\
\hline 8. Incremento exigencias gubernamentales y empresariales & 0.074 & 4 & 0.294 & 4 & 0.294 \\
\hline Amenazas & & & - & & \\
\hline 1. Inestabilidad política que frena Proyectos de Inversión & 0.125 & 2 & 0.250 & 1 & 0.125 \\
\hline 2. Interferencia /Injerencia política en el sector eléctrico & 0.125 & 2 & 0.250 & 1 & 0.125 \\
\hline 3. Limitaciones de financiamiento por parte del FONAFE & 0.075 & 2 & 0.150 & 1 & 0.075 \\
\hline 4. Riesgo de Guerra Comercial entre China y EEUU & 0.075 & 2 & 0.150 & 1 & 0.075 \\
\hline 5. Impacto negativo de factores climáticos en desarrollo del sector & 0.100 & 2 & 0.200 & 1 & 0.100 \\
\hline Fortalezas & & & - & & \\
\hline 1. Participación de Mercado & 0.150 & 3 & 0.450 & 3 & 0.450 \\
\hline 2. Experiencia Internacional en paises como El Salvador y Chile & 0.150 & 3 & 0.450 & 2 & 0.300 \\
\hline 3. Trayectoria en el sector / Reputación & 0.200 & 4 & 0.800 & 4 & 0.800 \\
\hline Debilidades & & & - & & \\
\hline 1. Ausencia de Gobierno Corporativo & 0.160 & 2 & 0.320 & 1 & 0.320 \\
\hline 2. Falta de Certificaciones Internacionales de Calidad Servicio & 0.100 & 2 & 0.200 & 2 & 0.400 \\
\hline 3. Modernización Equipamiento Tecnológico & 0.080 & 2 & 0.160 & 1 & 0.160 \\
\hline 4. Ausencia Política de Retención del Talento & 0.060 & 2 & 0.120 & 1 & 0.120 \\
\hline 5. Geolocalización Oficinas / Disponibilidad de espacios & 0.050 & 1 & 0.050 & 1 & 0.050 \\
\hline 6. Inadecuada gestión de la Inversión & 0.050 & 2 & 0.100 & 2 & 0.200 \\
\hline Total & & & 5.36 & & 5.01 \\
\hline
\end{tabular}

AS - Calificación del atractivo; TCA - Total de calificaciones del atractivo

Calificación del atractivo: 1 - no aceptable; 2 - posiblemente aceptable; 3 - probablemente aceptable; 4 la más aceptable

Nota. Elaboración propia. 
Del cuadro anterior se señala que la estrategia más atractiva a implementar es la Penetración del Mercado de ampliar los servicios a otros países de la región como parte del crecimiento de Hamek Ingenieros Asociados SAC., sin embargo se precisa que la estrategia de Desarrollo de Productos, orientada a estudios sobre gestión de energía en servicios como eficiencia energética, calidad de energía y estudios tarifarios, tiene un alto grado de atractividad por lo cual la recomendación es tener en cuenta como estrategia contingente.

\subsection{Descripción de la Estrategia Seleccionada}

La estrategia seleccionada será la penetración de mercado en la búsqueda de ampliar la participación de Hamek Ingenieros y Asociados S.A.C., en los mercados de Chile y El Salvador teniendo en cuenta las condiciones favorables del entorno externo referido a un mercado sin turbulencias y en crecimiento apoyado en los indicadores macroeconómicos locales, como el crecimiento del sector.

El objetivo de la estrategia principal es incrementar la participación en los mercados de Chile y El Salvador, para ello buscará penetrar con mayor fuerza en ambas naciones a través de un representante local que contribuya al crecimiento de Hamek.

Asimismo, otro de los factores que sustentan la selección de esta estrategia es el margen de utilidades que generan los servicios locales en comparación con los internacionales, según lo señalado por los accionistas los servicios ofrecidos en el extranjero, tienen una margen de utilidad que supera el $100 \%$ respecto al resultados conseguido a nivel local, reiterando que los costos incurridos son similares.

\subsection{Descripción de la Estrategia Contingente}

Respecto a la estrategia contingente que está referida al Desarrollo de Productos, debemos destacar la intención de Hamek Ingenieros y Asociados S.A.C., por ofrecer nuevos servicios referidos a estudios sobre gestión de energía, eficiencia energética referida a la producción y utilización de la energía; calidad de energía, referida a identificar y reducir las distorsiones y perturbaciones en las redes energéticas y estudios tarifarios para fijación de precios referido a la asesoría en contratos tarifarios para clientes libre y regulados sobre las opciones tarifarias más económicas a través de la evaluación de sus contratos, perfiles de carga y facturas de energía.

Esta decisión se fundamenta en que Hamek Ingenieros y Asociados S.A.C., también posee fortalezas como son el prestigio que tiene la empresa en el rubro, la especialización del personal técnico y profesional y la existencia de pocos rivales en el 
mercado además de las barreras altas de ingresos para potenciales retadores dado que deben pasar por un proceso de acreditación para poder brindar el servicio.

Hamek Ingenieros Asociados S.A.C., cuenta con clientes importantes del sector a los cuales se les podría ofrecer estos nuevos servicios tomando en cuenta que Hamek supera sus expectativas en el desarrollo de sus servicios y está técnicamente preparado para brindar estos nuevos servicios.

Importante precisar que el desarrollo de nuevos productos significa una mayor inversión en equipamiento de alta precisión para dichos estudios y toma un tiempo de maduración razón por la cual Hamek Ingenieros Asociados S.A.C., se vería obligado a trabajar en Consorcio con una empresa posicionada en el sector. 


\section{Capítulo IX. Implantación de la Estrategia}

En el presente capítulo se desarrolla la implementación de la estrategia seleccionada referida a la penetración de mercado con la ampliación de la presencia de Hamek Ingenieros Asociados S.A.C. a nivel regional pero además se tiene presente el desarrollo de la estrategia de contingencia, referida al desarrollo del producto con una mayor presencia de Hamek Ingenieros Asociados S.A.C. en la realización de estudios ambientales.

Para el desarrollo de la estrategia se toma en cuenta la definición de los objetivos específicos desde cuatro perspectivas, la financiera, la comercial, la interna y la de aprendizaje o innovación apoyados el Mapa de Estrategia descrito por Kaplan y Norton en el año 2013.

Además en el presente capítulo se definen las metas tangibles para cada uno de los objetivos específicos, las iniciativas y/o acciones asociados a estas metas, el presupuesto asociado a estas iniciativas, y finalmente al término del capítulo se define además el cronograma de implementación de las iniciativas a desarrollarse entre el año 2019 y el 2021, como punto de partida para el desarrollo del siguiente capítulo referido a la evaluación de la estrategia a implementarse que implica un análisis financiero profundo.

\subsection{Mapa de la Estrategia}

El concepto de los mapas estratégicos fue desarrollado por Robert Kaplan y David P. Norton, y plasmado en el libro de ambos Strategic Maps (2013) donde agrupan y describen los objetivos de una empresa desde cuatro perspectivas de una organización:

Una perspectiva financiera o de resultado: En organizaciones con fines de lucro, esto implica a accionistas, mientras que, en organizaciones sin fines de lucro, esto implica a las organizaciones financieras o subsidiarias.

Una perspectiva del cliente o mercado referida a la propuesta de valor que genere lealtad y convicción por el servicio ofrecido.

Una perspectiva del proceso (de negocio) interno, que implica, el proceso de gestión de las operaciones, el proceso de gestión de clientes, el proceso de innovación y el proceso social y regulatorio. Una perspectiva del aprendizaje, crecimiento o tecnológico, implica el desarrollo de los capitales humano, de la información y organizacional. En función a lo anterior hemos confeccionado la Tabla 55. 
Tabla 55

Prioridad de Estrategias Formulada

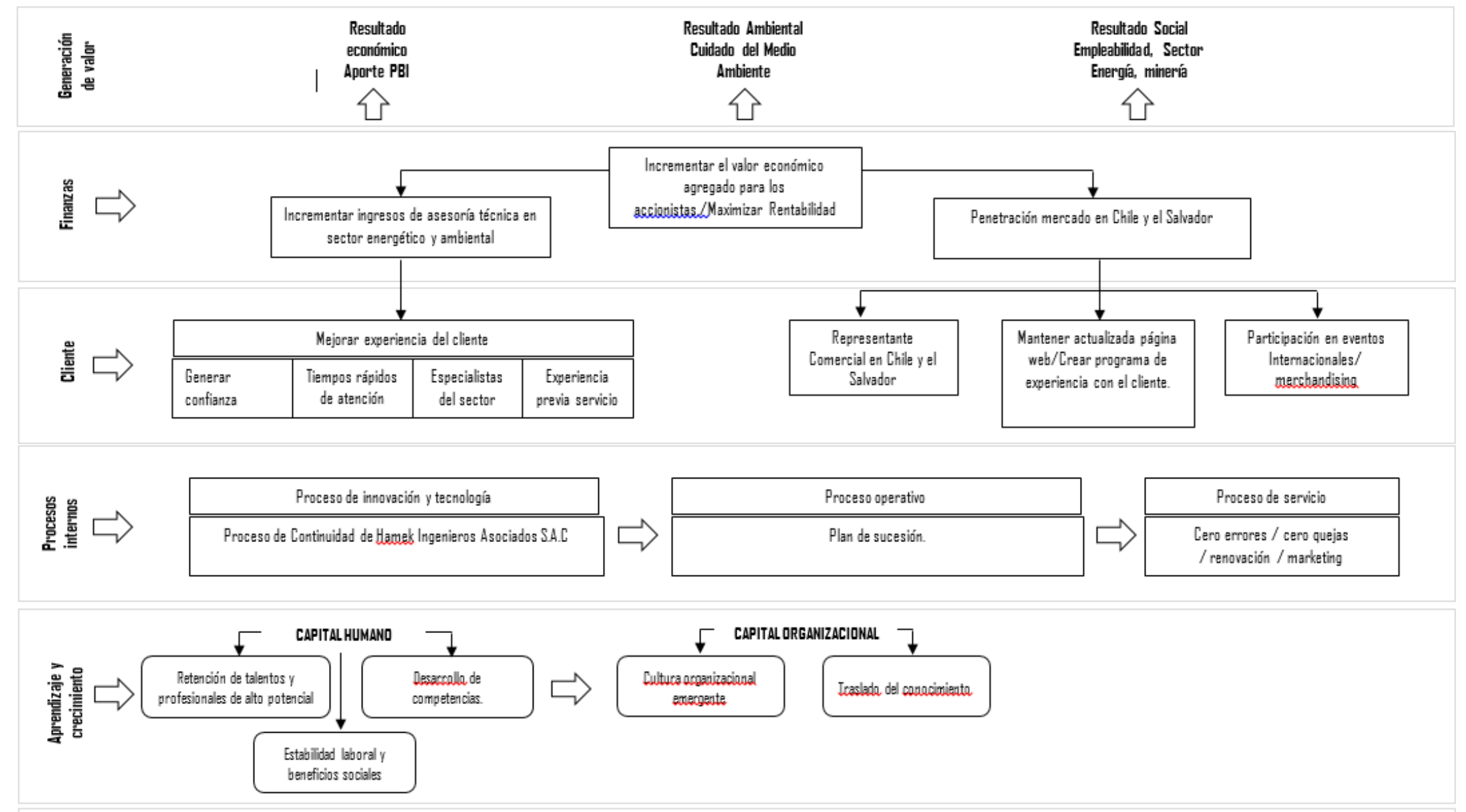

Nota. Elaboración propia 


\subsection{Objetivos específicos según el mapa de la estrategia}

En función a la Tabla 55 procedemos a elaborar los objetivos específicos para cada una de las perspectivas vistas con anterioridad según se detalla en la Tabla 56. 


\section{Tabla 56}

Objetivos Específicos Hamek Ingenieros y Asociados SAC.

\begin{tabular}{|c|c|c|}
\hline$\frac{9}{8}$ & Estrategia & Objetivo especifico \\
\hline 量 & $\begin{array}{l}\text { Buscar socios comerciales en los } \\
\text { países donde Hamek ya tiene } \\
\text { presencla. }\end{array}$ & Incrementar la rentabilidad. \\
\hline 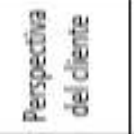 & $\begin{array}{l}\text { Lograr mantener resultados de } \\
\text { acreditación de calidad por encima } \\
\text { del } 98 \% \text { en cada uno de los serviolos } \\
\text { ofrecidos. }\end{array}$ & $\begin{array}{l}\text { Mejorar experiencia del cliente, generar } \\
\text { conflanza. }\end{array}$ \\
\hline 疍 & Elaboración de un Plan de sucesión. & $\begin{array}{l}\text { Mantener la continuidad de Hamek } \\
\text { Ingenieros Asociados } 5 . \text { A.C en el } \\
\text { tiempo. }\end{array}$ \\
\hline 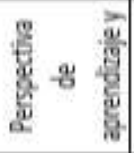 & $\begin{array}{l}\text { Potenciar ol capital humano y } \\
\text { tecnologico para poder cumplir } \\
\text { satisfactoriamente con los } \\
\text { requerimientos de los clientes e } \\
\text { incrementar reputación. }\end{array}$ & $\begin{array}{l}\text { Desarrollar lineas de carrera } \\
\text { Retener cuadros claves } \\
\text { Fortalecer formación del personal } \\
\text { Mejorar clima laboral. }\end{array}$ \\
\hline
\end{tabular}

Nota: Elaboración propia

\subsection{Indicadores para cada uno de los objetivos específicos}

En la tabla 57, se muestran los indicadores y la unidad de medida respectiva para cada uno de los objetivos específicos que se formularon para cada una de las estrategias detalladas en el punto anterior. 
Tabla 57

Indicadores para los Objetivos Específicos de las Estrategias Seleccionadas

\begin{tabular}{|c|c|c|c|c|}
\hline$\frac{8}{8}$ & Estrategia & Objetivo especifico & Indicadores & Unitlad de medida \\
\hline$\frac{g}{2}$ & $\begin{array}{l}\text { Buscar socios comerciales en los } \\
\text { paises donde tlamek va tiene } \\
\text { presencia. }\end{array}$ & incrementar la rentabilidad. & $\begin{array}{l}\text { gof (Utilidad Neta/Capital } \\
\text { Total) }\end{array}$ & Porcentaje \\
\hline$\frac{8}{2} \frac{8}{8}$ & $\begin{array}{l}\text { Loevar mantener resultados de } \\
\text { acreditación de calidad por encima } \\
\text { del } 94 \$ \text { en cada uno de los tervicios } \\
\text { ofrecidos. }\end{array}$ & $\begin{array}{l}\text { Mejorar experiencia del cliente, gunerar } \\
\text { confianza. }\end{array}$ & $\begin{array}{l}\text { Net Promstet Score (NPS) } \\
\text { (Prometores menos } \\
\text { detractores) }\end{array}$ & Porcentaje \\
\hline$\frac{\mathrm{E}}{\mathrm{g}}$ & Elaboración de un Plan de sucesión. & $\begin{array}{l}\text { Mantener ta continuidad de Hameik } \\
\text { Ingenieros Asociados } 5 . \text { A.C en el } \\
\text { tiempo. }\end{array}$ & $\begin{array}{l}\text { Participacide (Ingresos } \\
\text { Hamek/Ingrasos Sector) }\end{array}$ & Porcentaje \\
\hline$\frac{8}{8} \div \frac{\frac{y}{4}}{\frac{1}{2}}$ & $\begin{array}{l}\text { Potenclar el capital humano y } \\
\text { tecnológico para poder cumplir } \\
\text { satisfactoriamente con los } \\
\text { requerimientos de las clientes e } \\
\text { incrementar reputación. }\end{array}$ & $\begin{array}{l}\text { Desartollar lineas de carrera } \\
\text { lietener cuadros claves } \\
\text { Fortalecer formacion del personal } \\
\text { Mejorar clima Laboral. }\end{array}$ & Encuesta Clima Laboral & Porcentaje \\
\hline
\end{tabular}

Nota: Elaboración propia

\subsection{Metas para cada uno de los objetivos específicos}

Se presentan las metas establecidas por cada objetivo relacionado con la perspectiva financiera, clientes, internos, aprendizaje y crecimiento relacionando cada uno de ellos a sus indicadores. Las metas involucran compromisos individuales y de áreas específicas de la empresa, la elección de las metas debe ser realista, desafiante y alcanzable.

A continuación, se presenta las metas para cada objetivo específico propuestos para Hamek Ingenieros y Asociados S.A.C., para los próximos tres años, en la Tabla 58. 
Tabla 58

Meta para los Objetivos Específicos de las Estrategias Seleccionadas

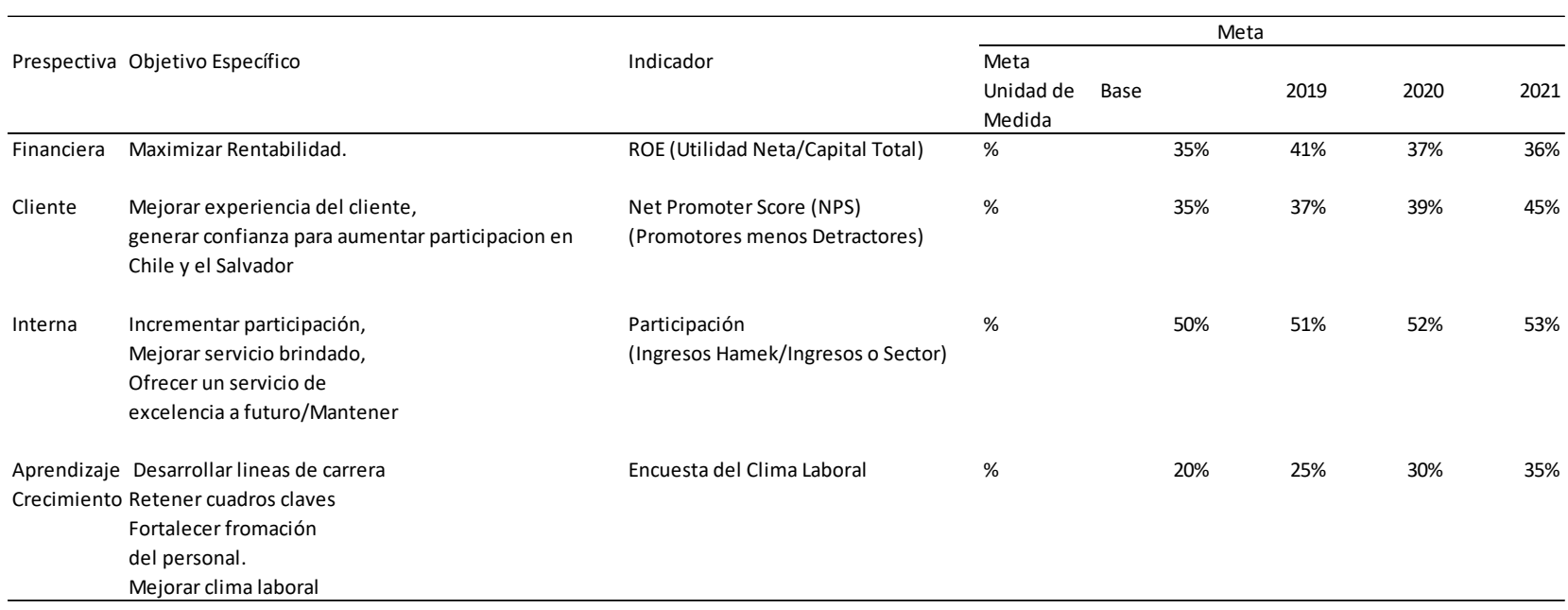

Nota. Elaboración propia.

\subsection{Iniciativas (acciones a llevar a cabo para cada uno de los objetivos específicos)} Estrategias, programas, políticas, reglas, procedimientos.

Las iniciativas son el conjunto de acciones que la empresa tiene que implementar para cumplir las metas. Se proponen las siguientes iniciativas para alcanzar los objetivos específicos, como se muestra en la tabla 59. 


\section{Tabla 59}

Iniciativas para cada uno de los Objetivos

\begin{tabular}{|c|c|c|}
\hline Prespectiva & Objetivo Específico & Iniciativa \\
\hline Financiera & Maximizar Rentabilidad. & $\begin{array}{l}\text { Implementar un sistema de gestiópresupuestal } \\
\text { y financiero. } \\
\text { Adquision de nuevos equipos de medición. }\end{array}$ \\
\hline Cliente & $\begin{array}{l}\text { Mejorar experiencia del cliente, } \\
\text { generar confianza para aumentar participacion en } \\
\text { Chile y el Salvador }\end{array}$ & $\begin{array}{l}\text { Mantener actualizado página web. } \\
\text { Crear un programa de experiencia del cliente. } \\
\text { Nivel de satisfacción. } \\
\text { Participacion de eventos Internacionales. } \\
\text { Merchadising }\end{array}$ \\
\hline Interna & $\begin{array}{l}\text { Incrementar participación, } \\
\text { Mejorar servicio brindado, } \\
\text { Ofrecer un servicio de } \\
\text { excelencia a futuro/Mantener }\end{array}$ & $\begin{array}{l}\text { Desarrollar un plan de marketing para la empresa } \\
\text { Desarrollar un plan de retención } \\
\text { Elaborar un plan de sucesión }\end{array}$ \\
\hline $\begin{array}{l}\text { Aprendizaje } \\
\text { Crecimiento }\end{array}$ & $\begin{array}{l}\text { Desarrollar lineas de carrera } \\
\text { Retener cuadros claves } \\
\text { Fortalecer fromación } \\
\text { del personal. } \\
\text { Mejorar clima laboral }\end{array}$ & $\begin{array}{l}\text { Invertir en el desarrollo del personal. } \\
\text { Desarrollar un plan de bienestar y salud en el trabajo } \\
\text { Programa de camaraderia y full day } \\
\text { Encuestas clima laboral }\end{array}$ \\
\hline
\end{tabular}

Nota. Elaboración propia

\subsection{Responsable de cada una de las iniciativas}

Los responsables de la empresa Hamek Ingenieros y Asociados S.A.C, es el Gerente General, Gerente Administrativo y el Jefe de Energía, son quienes se les encargarán del cumplimiento de los objetivos. 
Tabla 60

Responsable por Iniciativa Propuesta

\begin{tabular}{lll}
\hline I & Iniciativas & Responsable \\
\hline I1 & Capacitación de personal & Gerente Administrativo \\
I2 & Retencion de personal & Gerente Administrativo \\
I3 & Desarrollo de un plan de sucesión & Gerente General \\
14 & Desarrollo y ejecucion del plan de clima laboral & Gerente Administrativo \\
I5 & Adquision de equipos en energia y medio ambiente & Gerente Administrativo \\
16 & Contratacion de un representante comercial & Gerente General \\
I7 & Merchadising & Gerente Administrativo \\
I8 & Renovacion y actualizacion de la pagina web & Gerente Administrativo \\
19 & Participacion en eventos internacionales & Gerente General \\
I10 & Nivel de Satisfacción & Gerente Administrativo \\
\hline
\end{tabular}

Nota. Elaboración propia

\subsection{Presupuesto de cada una de las Iniciativas}

En función a las iniciativas planteadas en la tabla 60 se han estimado los presupuestos a invertir, de acuerdo a las iniciativas, así tenemos, una perspectiva financiera, perspectiva del cliente, perspectiva interna, y perspectiva de aprendizaje y crecimiento.

Los presupuestos estimados se han realizado partiendo de los costos de mercado a noviembre del 2018.

\subsubsection{Presupuesto en el plan de recursos humano.}

Este presupuesto contempla cinco factores a implementar, un sistema de gestión de talento humano, capacitación y retención de personal, mejora de clima laboral y feedback que estará a cargo de la gerencia general.

La implementación un sistema de gestión de talento humano hará posible mejorar la planificación de los programas de desarrollo de habilidades específicos, con ello se buscará mejorar el desempeño individual y organizacional de Hamek Ingenieros Asociados S.A.C., la aplicación se dará inicio en la etapa de reclutamiento y continuará empleándose en las distintas etapas de la gestión de personas. No habrá un presupuesto destinado para esta actividad, ya que esta se recurrirá los propios recursos de la empresa.

Para el caso de capacitación de personal, se elaborará un programa de entrenamiento parta el uso de los equipos de medición y de formación técnica. Se determinará un 
presupuesto anual de S/2000 en el primer año proyectado y un incremento de S/1000 en los años subsiguientes.

La retención del personal, consideramos fundamental para Hamek Ingenieros Asociados S.A.C., ya que actualmente el capital humano conforma la primera potencia o herramienta que la organización cuenta para lograr sus objetivos, para ello se está considerando un presupuesto para el primer año de S/2400, monto que será destinado para ofrecer un seguro privado de salud.

Otra iniciativa en recursos humanos es la mejora del clima laboral, si bien Hamek Ingenieros Asociados S.A.C., se caracteriza por tener un ambiente y clima grato para los trabajadores, se hace necesario potenciar esta actividad con la finalidad de mejorar la productividad de la organización, con ello se buscara una máxima eficiencia de los recursos humanos, mediante una buena gestión de los mismos, y el fomento de las relaciones laborales cada vez más estrechas y coordinadas, para ellos se pondrá dentro del programa anual, reuniones individuales entre los managers y los colaboradores, para el desarrollo de esta estrategia se tomaran los recursos propios de la empresa.

Como un penúltimo recurso de mejora al sistema del plan de recursos humanos se está considerando un feedback a cargo de la gerencia general.

Dentro del plan de captación y capacitación como última iniciativa se desarrollará el feedback de los servicios culminados, que será llevado por el gerente general.

La retroalimentación a través de una comunicación interna es necesario para evaluar y determinar puntos de mejora en cada actividad.

Finalmente, se está considerando una inversión de $\mathrm{S} / 4400$, monto para cubrir los gastos de la elaboración de un plan de sucesión, como parte de mejora al programa organización buscando con ello garantizar la continuidad de Hamek a través del tiempo. 
Tabla 61

Presupuesto en el Plan de Recursos Humanos

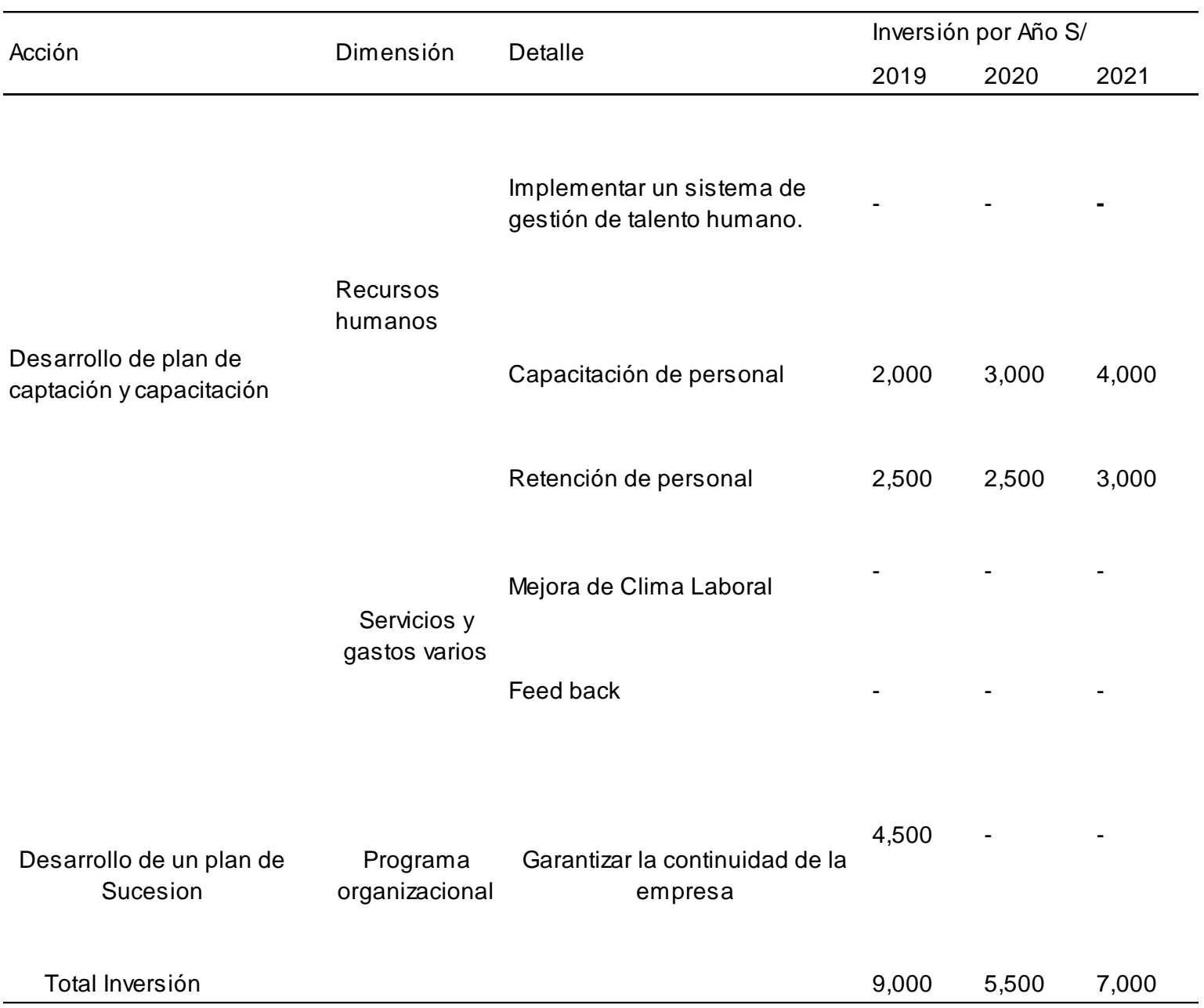

Nota. Elaboración propia.

\subsubsection{Presupuesto en plan de aprendizaje y crecimiento.}

Con el fin de despertar el deseo de la necesidad del personal de Hamek Ingenieros Asociados S.A.C., comprometerse con lo que son, y así se tenga mayor compromiso con sus emociones y objetivos trazados, se desarrollara actividades de integración, para la cual se dispondrá de algunos minutos al inicio de las labores diarios, los incentivos irán desde vales de consumo, artículos personal, pagos de viáticos de transporte de la semana y vales intangibles como mayor tiempo en horario de comida, medio día libre, o salidas más temprano. 
Para ello se destinará un presupuesto inicial de S/2000 por el primer año de implementación. Que se irán incrementado por los siguientes dos años.

Para poder medir la satisfacción del personal, se contratará a una empresa para realizar la evaluación del clima laboral, a través de una encuesta, podremos conocer la satisfacción y motivación del personal, todo ello con el fin de mejorar y conseguir que Hamek Ingenieros Asociados S.A.C., sea más eficiente y con mejores resultados. EI presupuesto destinado para esta mejora será de S/700.

Como plan de inversión será considera el desarrollo de plan de bienestar y salud en el trabajo, esta estrategia está orientada a la búsqueda del mejoramiento del ambiente laboral, con el fin de elevar la percepción favorable, la motivación, la productividad y el bienestar del componente humano.

El plan está dirigido a todo el personal de Hamek Ingenieros Asociados S.A.C., y se desarrollara a través de dinámicas laborales, se creará programas de salud, para ello se convocará durante el año a expertos o se buscara dentro de la organización a colaboradores que quieran compartir sus experiencias relacionadas en salud y nutrición, todo ello con la finalidad de crear una conciencia de salud y generar un cambio positivo, el presupuesto destinado para esta actividad es de $\mathrm{S} / 400$.

Se programará en el transcurso del año salidas de camaradería, actividad que ayudará a reforzar en vínculo de confianza entre todos los colaboradores de Hamek Ingenieros y Asociados S.A.C., con ello se busca fortalecer la amistad y la unión de todos los integrantes de la organización. El programa prevé dos eventos anuales, en el mes de junio mes de aniversario se plantea realizar un full day deportivo. 
Tabla 62

Presupuesto en plan de aprendizaje y crecimiento

\begin{tabular}{|c|c|c|c|c|c|}
\hline \multirow{2}{*}{ Acción } & \multirow{2}{*}{ Dimensión } & \multirow{2}{*}{ Detalle } & \multicolumn{3}{|c|}{ Inversión por Año S/ } \\
\hline & & & 2019 & 2020 & 2021 \\
\hline \multirow{4}{*}{$\begin{array}{l}\text { Desarrollo y ejecución } \\
\text { del plan de clima laboral }\end{array}$} & $\begin{array}{l}\text { Recursos } \\
\text { Humanos }\end{array}$ & Actividades de integración & 2,000 & 2,000 & 2,500 \\
\hline & & Evaluación de clima laboral & 700 & 800 & 800 \\
\hline & Servicios y & $\begin{array}{l}\text { Plan de Bienestar y salud en el } \\
\text { trabajo }\end{array}$ & 500 & 700 & 800 \\
\hline & Mastuss valius & $\begin{array}{l}\text { Programación de plan de } \\
\text { camaderia y full day }\end{array}$ & 2,000 & 2,500 & 2,500 \\
\hline Total Inversión & & & 5,200 & 6,000 & 6,300 \\
\hline
\end{tabular}

Nota. Elaboración propia

\subsubsection{Presupuesto en plan de implementación de equipos de medición.}

El presupuesto también contempla inversión en la adquisición de equipos de medio ambiental y para el área de energía, las mismas que serán adquiridas a empresas con tecnologías verdes o Green IT. Las mismas se refieren al uso eficiente de los recursos tecnológicos con ello se busca minimizar el impacto ambiental, maximizando su viabilidad económica y asegurando deberes sociales. Con ello estaremos posicionándonos con herramientas de mayor tecnología. 
Tabla 63

Presupuesto en plan de implementación de equipos de medición

\begin{tabular}{|c|c|c|c|c|c|c|}
\hline \multirow{2}{*}{ Descipción } & \multirow{2}{*}{ Cantidad } & \multirow{2}{*}{ Unidad } & \multirow{2}{*}{$\begin{array}{c}\text { Precio Unitario } \\
\mathrm{S} / .\end{array}$} & \multicolumn{3}{|c|}{ Inversión por Año S/ } \\
\hline & & & & 2019 & 2020 & 2021 \\
\hline Testo 350 new & 1 & Unid & 100,000 & 100,000 & 100,000 & \\
\hline Sonometro Clase 1 & 1 & Unid & 30,200 & 30,200 & & \\
\hline Hi vol PM 10 & 1 & Unid & 60,000 & & & 60,000 \\
\hline Micro vol 1100 & 1 & Unid & 43,100 & & & 43,100 \\
\hline Fluke 438 II & 1 & Unid & 80,000 & & 75,100 & \\
\hline PQ BOX 300 & 1 & Unid & 86,000 & & & 86,000 \\
\hline Total & & & & 130,200 & 175,100 & 189,100 \\
\hline
\end{tabular}

Nota. Elaboración propia.

\subsubsection{Presupuesto en plan comercial.}

Este presupuesto contempla las iniciativas comerciales que permitirá atraer nuevos clientes en los mercados internacionales donde Hamek ya tiene presencia. Para el desarrollo de estas actividades se hace necesario contar con representante comercial, quien tendrá como principal tarea abrir el mercado para Hamek Ingenieros Asociados S.A.C., buscar reuniones estratégicas con posibles clientes. El presupuesto destinado es de S/42000 para el primer año, monto que subirá progresivamente.

Con el propósito de agradecer la preferencia de nuestros clientes, se está considerando la entrega de unos Merchadising y presentes. Para ello se está destinando un presupuesto de S/3400 para el primer año, S/4000 para el 2020 y S/6000 para el 2021.

Así mismo con el propósito de garantizar la difusión de nuestros servicios a través de la web, se está programando la una actualización permanente para el 2019 y una renovación de diseño con mayores herramientas para el año 2020, y renovación para el 2021. 
Como tercera actividad programada se tiene conocer el nivel de satisfacción de nuestros clientes, para ello se elaborará una pequeña encuesta la cual se enviará una vez finalizada el servicio, la implementación de la encuesta ayudará a encontrar relacionar los resultados entre la satisfacción del cliente, la lealtad de estos y los resultados financieros.

Otra iniciativa comercial, considerada es la participación en eventos nacionales e internacionales, con la finalidad de difundir nuestros servicios y metodología de trabajo, mostrando el software y los equipos renovados con la que cuenta Hamek Ingenieros Asociados S.A.C. para el desarrollo de sus actividades. Los presupuestos determinados para estas iniciativas se encuentran en la tabla 64.

\section{Tabla 64}

Presupuesto en Plan Comercial

\begin{tabular}{|c|c|c|c|c|c|}
\hline \multirow{2}{*}{ Acción } & \multirow{2}{*}{ Dimensión } & \multirow{2}{*}{ Detalle } & \multicolumn{3}{|c|}{ Inversión por Año S/ } \\
\hline & & & 2019 & 2020 & 2021 \\
\hline & & $\begin{array}{l}\text { Research } \\
\text { (Investigación de } \\
\text { mercados externos) }\end{array}$ & - & - & - \\
\hline & & $\begin{array}{l}\text { Representante } \\
\text { Comercial }\end{array}$ & 42,000 & 48,000 & 54,000 \\
\hline & Marketing & & & & \\
\hline & & Merchadising & 3,500 & 4,000 & 6,000 \\
\hline \multicolumn{6}{|l|}{ Iniciativas } \\
\hline \multirow[t]{4}{*}{ Comerciales } & & Renovación y & & & \\
\hline & & $\begin{array}{l}\text { Actalización de la } \\
\text { pagina web }\end{array}$ & 700 & 3,000 & 1,500 \\
\hline & & Nivel de Satisfacción & 1,000 & 1,000 & 1,500 \\
\hline & $\begin{array}{l}\text { Viajes de } \\
\text { representación }\end{array}$ & $\begin{array}{l}\text { Participación a } \\
\text { eventos nacionales }\end{array}$ & 6,500 & 8,500 & 8,500 \\
\hline Total Inversión & & & 53,700 & 64,500 & 71,500 \\
\hline
\end{tabular}

Nota. Elaboración propia.

Después del análisis de cada iniciativa se procede a calcular los montos totales de inversión para los próximos tres años (Ver Tabla 64) para la estrategia principal referido a la Penetración del Mercado. 
Al respecto se ha considerado importante establecer la inversión requerida para implementar la estrategia contingente referida al Desarrollo de Productos según se detalla en la Tabla 65 para los siguientes tres años.

Tabla 65

Presupuesto Total de Inversión para los años 2019-2021 - Estrategia Principal

\begin{tabular}{|c|c|c|c|}
\hline \multirow{2}{*}{ Iniciativas } & \multicolumn{3}{|c|}{ Inversión por Año S/ } \\
\hline & 2019 & 2020 & 2021 \\
\hline $\begin{array}{l}\text { Presupuesto en el Plan } \\
\text { de Recursos Humanos }\end{array}$ & 9,000 & 5,500 & 7,000 \\
\hline $\begin{array}{l}\text { Presupuesto en plan de } \\
\text { aprendizaje y crecimiento }\end{array}$ & 5,200 & 6,000 & 6,300 \\
\hline $\begin{array}{l}\text { Presupuesto en plan de } \\
\text { implementación equipos } \\
\text { de medición }\end{array}$ & 130,000 & 175,000 & 189,100 \\
\hline $\begin{array}{l}\text { Presupuesto en plan } \\
\text { comercial }\end{array}$ & 53,700 & 64,500 & 71,500 \\
\hline Total Inversión & 197,900 & 251,000 & 273,900 \\
\hline
\end{tabular}

Nota. Elaboración propia. 
Tabla 66

Presupuesto Total de Inversión para los años 2019-2021 - Estrategia Contingente

\begin{tabular}{|c|c|c|c|}
\hline \multirow{2}{*}{ Iniciativas } & \multicolumn{3}{|c|}{ Inversión por Año S/ } \\
\hline & 2019 & 2020 & 2021 \\
\hline $\begin{array}{l}\text { Presupuesto en el plan de } \\
\text { recursos humanos }\end{array}$ & 25,800 & 31,700 & 32,000 \\
\hline $\begin{array}{l}\text { Presupuesto en plan de } \\
\text { aprendizaje y crecimiento }\end{array}$ & 4,700 & 7,500 & 8,200 \\
\hline $\begin{array}{l}\text { Presupuesto en plan de } \\
\text { implementación equipos de } \\
\text { medición }\end{array}$ & 210,300 & 205,300 & 232,300 \\
\hline $\begin{array}{l}\text { Presupuesto en plan } \\
\text { comercial }\end{array}$ & 12,200 & 18,500 & 21,500 \\
\hline Total Inversión & 253,000 & 263,000 & 294,000 \\
\hline
\end{tabular}

Nota. Elaboración propia. 


\subsection{Cronograma de cada una de las iniciativas}

Tabla 67

Cronograma de cada de las Iniciativas

ACTIVIDAD

$\begin{array}{lllllllllllll}\text { Trimestre } & 1 & 2 & 3 & 4 & 1 & 2 & 3 & 4 & 1 & 2 & 3 & 4\end{array}$

Plan de recursos humanos

Implementar un sistema de gestiòn de talento humano

Capacitación de personal

Retención de personal

Mejora de clima laboral

Feed back

Plan de aprendizaje y crecimiento

Actividades de Integración

Evaluación de clima laboral

Plan de bienestar y salud en el trabajo

Programación de plan de camaraderia y full day

Plan de implementación de equipos

Testo $350 \mathrm{New}$

Sonometro Clase 1

Hi vol PM 10

Micro vol 1100

Fluke 438 II

$P Q B O X 300$

\section{Plan Comercial}

Research (investigación de mercados externos)

Representantes Comercial

Merchadising

Renovación y actualización de la página web

Nivel de satisfacción

Participación a eventos nacionales e internacionales
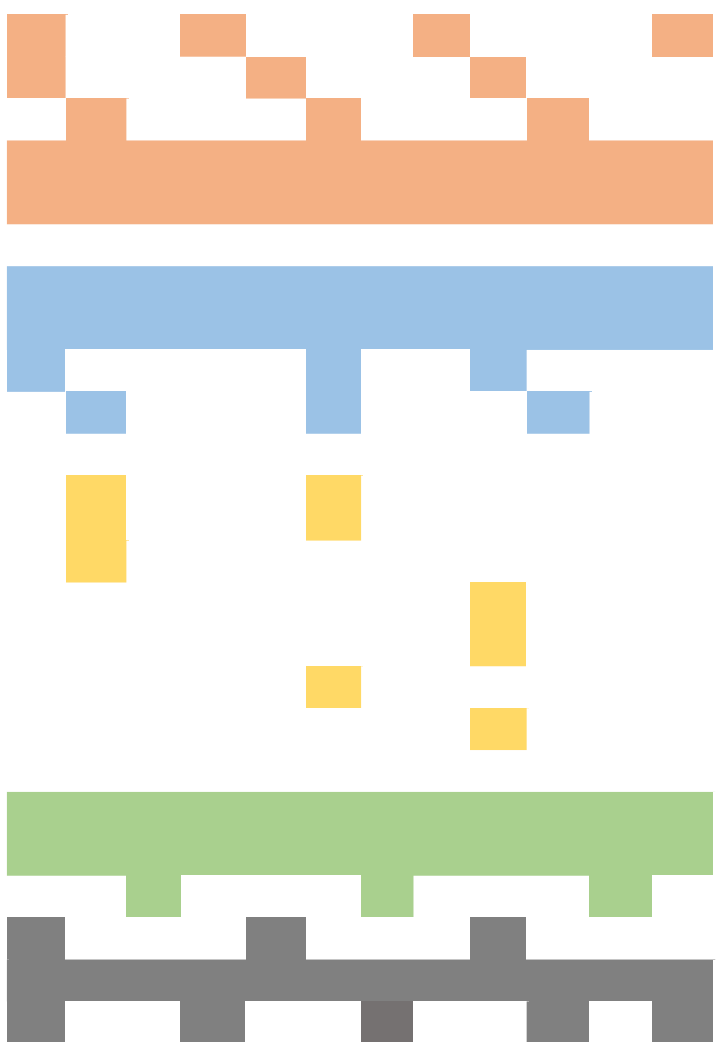


\section{Capítulo X. Evaluación}

En este capítulo se realizará en análisis financiero, cualitativo y cuantitativo de la estrategia de la empresa Hamek Ingenieros y Asociados S.A.C., tomando en cuenta las proyecciones de los estados financieros, el flujo de efectivo entre otros.

Se realizará la evaluación financiera de las dos estrategias seleccionadas, para ello primero se hará una evaluación cualitativa entre las dos estrategias con mayor puntaje en la matriz MPCE, analizada en el capítulo ocho. Luego se proyectarán los flujos de caja y estados financieros, tomando en cuenta los escenarios que se han contemplado para poder establecer, qué estrategia se debe llevar a cabo, bajo que escenarios y expectativas, para asegurar si dicha estrategia es viable en términos de rentabilidad y financieros.

Los datos financieros (balance general, estado de resultados, y flujos de efectivo) de los años 2014, 2016, 2017 y 2018, de la empresa Hamek Ingenieros Asociados S.A.C., fueron otorgados por el gerente administrativo. Los estados financieros se proyectarán de acuerdo al horizonte de tiempo planteado en el plan estratégico del año 2019 al 2021.

El objetivo es evaluar el impacto de las estrategias seleccionadas y determinar la conveniencia de implementar la mejor estrategia, para que el accionista tenga la mayor rentabilidad.

Finalmente, se determinará el valor del VAN, la TIR, ratios financieras, el COK y el Punto muerto de la empresa.

\subsection{Evaluación Cualitativa}

Tomando de cuenta lo descrito en los capítulos anteriores y analizando la información financiera de Hamek Ingenieros y Asociados S.A.C., (estado de resultados, balance general y flujos de efectivo) así como las ratios resultantes de esta información, se realizará una evaluación cualitativa para determinar qué tan conveniente resulta la estrategia principal, penetración del mercado regional versus la situación de no realizar mejora alguna y continuar trabajando de una forma habitual.

\subsubsection{Criterios de Evaluación.}

Para evaluar las estrategias de negocios de Hamek Ingenieros Asociados S.A.C., se han tomado en cuenta los criterios de evaluación establecidos por Richard Rumelt (David, 2008) las cuales son descritas a continuación: 
Congruencia: las estrategias no debieran presentar metas ni políticas inconsistentes, esto significa que la estrategia planteadas para Hamek Ingenieros Asociados S.A.C., debe ser consecuente con las políticas de la empresa y reflejar las expectativas de la dirección.

Consonancia: la estrategia seleccionada debe representar una respuesta adaptativa a los cambios del entorno, está referida a la necesidad que tienen los especialistas de evaluar series de tendencias, las estrategias planteadas deben considerar respuestas oportunas frente a los factores internos y externos.

Viabilidad: la estrategia seleccionada no debiera alterar en exceso los recursos de la organización ni generar problemas imposibles de solucionar, esto nos quiere decir que las estrategias propuestas deben ser objetiva y de acorde a la realidad de la empresa, debe ser realizable.

Ventaja: la estrategia seleccionada debe permitir la creación y mantenimiento de las ventajas competitivas. Esto significa que la estrategia debe impulsar y sostener las ventajas competitivas de la empresa.

\subsubsection{Comparación de la estrategia con los criterios.}

Tomando en cuenta las consideraciones planteadas en el capítulo anterior, realizamos la comparación con la estrategia propuesta.

1. Consistencia: la estrategia seleccionada "Penetración de Mercado" y la estrategia contingente "Desarrollo de Producto", se encuentran alineados con la visión y misión de la empresa, la primera estrategia busca que Hamek Ingenieros Asociados S.A.C., sea reconocida a nivel regional como una empresa competitiva en base a elevados estándares de servicio, mientras que la segunda estrategia está orientada a consolidar a Hamek Ingenieros Asociados S.A.C., en el mercado local. Asimismo, cada una de sus iniciativas están orientadas al fortalecimiento interno de la organización.

2. Consonancia: Referido a necesidad de considerar las tendencias de sector al momento de evaluar las estrategias, para el caso de Hamek Ingenieros Asociados S.A.C., ambas estrategias fueron seleccionadas después de un análisis de perspectivas de crecimiento que proyecta el sector energético a nivel regional y nacional.

3. Viabilidad: la estrategia plantea varias iniciativas que no necesitarán de financiamiento externo, pues a la fecha el crecimiento de Hamek Ingenieros 
Asociados S.A.C., se ha conseguido con recursos propios, con la implementación de la estrategia principal, desarrollo del mercado regional, se busca generar un incremento sustancial en las ventas, además el reconocimiento con la que cuenta Hamek Ingenieros Asociados S.A.C., en el mercado local será fundamental para desarrollar sus servicios en otros países de Latinoamérica.

4. Ventaja: la estrategia debe facilitar el desarrollo y mantenimiento de la ventaja competitiva. La estrategia seleccionada, penetración de mercado, permitirá a Hamek Ingenieros Asociados S.A.C., fortalecer las ventajas competitivas sostenibles, como, por ejemplo, un mayor prestigio en el sector.

En la Tabla 68 se muestra la comparación de la estrategia con los criterios definidos en el punto anterior.

Tabla 68

Cuadro Comparativo de Estrategia con Criterios Cualitativos

\begin{tabular}{|c|c|c|c|c|c|}
\hline Criterios cualitativos & Congruencia & Concordancia & Viabilidad & Ventaja & Se acepta \\
\hline $\begin{array}{l}\text { Implementar un sistema de gestión de } \\
\text { talento humano }\end{array}$ & $\mathrm{Si}$ & $\mathrm{Si}$ & $\mathrm{Si}$ & $\mathrm{Si}$ & Se acepta \\
\hline Capacitación de personal & $\mathrm{Si}$ & $\mathrm{Si}$ & $\mathrm{Si}$ & $\mathrm{Si}$ & Se acepta \\
\hline \multicolumn{6}{|l|}{ Retención de personal } \\
\hline Mejora de Clima Laboral & $\mathrm{Si}$ & $\mathrm{Si}$ & $\mathrm{Si}$ & $\mathrm{Si}$ & Se acepta \\
\hline Feed back & $\mathrm{Si}$ & $\mathrm{Si}$ & $\mathrm{Si}$ & $\mathrm{Si}$ & Se acepta \\
\hline Actividades de integración & $\mathrm{Si}$ & $\mathrm{Si}$ & $\mathrm{Si}$ & $\mathrm{Si}$ & Se acepta \\
\hline Evaluación de clima laboral & $\mathrm{Si}$ & $\mathrm{Si}$ & $\mathrm{Si}$ & $\mathrm{Si}$ & Se acepta \\
\hline Evaluación de clima laboral & $\mathrm{Si}$ & $\mathrm{Si}$ & $\mathrm{Si}$ & $\mathrm{Si}$ & Se acepta \\
\hline $\begin{array}{l}\text { Programación de plan de camaderia y full } \\
\text { day }\end{array}$ & $\mathrm{Si}$ & $\mathrm{Si}$ & $\mathrm{Si}$ & $\mathrm{Si}$ & Se acepta \\
\hline $\begin{array}{l}\text { Compra de equipos área ambiental y } \\
\text { energía }\end{array}$ & $\mathrm{Si}$ & $\mathrm{Si}$ & $\mathrm{Si}$ & $\mathrm{Si}$ & Se acepta \\
\hline $\begin{array}{l}\text { Research (Investigación de mercados } \\
\text { externos) }\end{array}$ & $\mathrm{Si}$ & $\mathrm{Si}$ & $\mathrm{Si}$ & $\mathrm{Si}$ & Se acepta \\
\hline Merchadising & $\mathrm{Si}$ & $\mathrm{Si}$ & $\mathrm{Si}$ & $\mathrm{Si}$ & Se acepta \\
\hline Renovación y Actalización de la pagina web & $\mathrm{Si}$ & $\mathrm{Si}$ & $\mathrm{Si}$ & $\mathrm{Si}$ & Se acepta \\
\hline $\begin{array}{l}\text { Participación a eventos nacionales e } \\
\text { internacionales }\end{array}$ & $\mathrm{Si}$ & $\mathrm{Si}$ & $\mathrm{Si}$ & $\mathrm{Si}$ & Se acepta \\
\hline
\end{tabular}

Nota. Elaboración propia

\subsection{Evaluación Financiera de la Estrategia}

Definida la estrategia principal de Hamek Ingenieros Asociados S.A.C. referida a ampliar su presencia en países andinos de Latinoamérica, lo que implica ampliar la 
participación en los países de la región donde ya cuenta con presencia, aprovechando la experiencia y reputación en el sector, se procede a realizar la respectiva evaluación financiera.

\subsubsection{Proyección de estados financieros (situación actual y con la nueva} estrategia).

Se determina los ingresos proyectadas para el periodo 2019 - 2021 tomando en cuenta un crecimiento de las ventas experimentado del año 2011 al año 2018 (Ver Tabla 69) utilizando para ello una regresión lineal que permita pronosticar un valor futuro a través de los valores existentes. (Figura 36). Importante precisar que este pronóstico no considera el incremento en las ventas como consecuencia de la implementación de estrategia alguna.

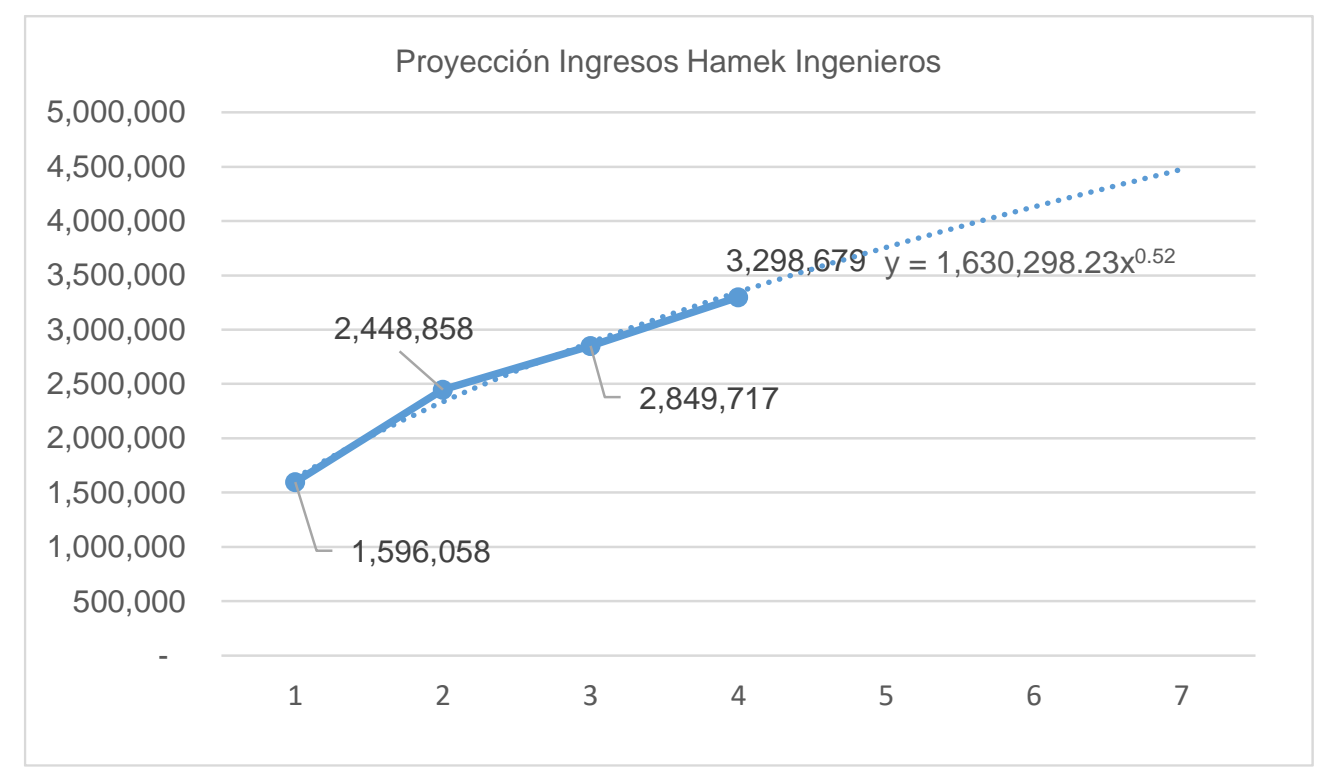

Figura 36. Pronóstico de Ingresos, utilizando el método de regresión lineal. 
Tabla 69

Ingresos Proyectados Hamek Ingenieros y Asociados SAC.

\begin{tabular}{rrrrrrrrrrr}
\hline $\mathbf{2 , 0 1 1}$ & $\mathbf{2 , 0 1 2}$ & $\mathbf{2 , 0 1 3}$ & $\mathbf{2 , 0 1 4}$ & $\mathbf{2 , 0 1 5}$ & $\mathbf{2 , 0 1 6}$ & $\mathbf{2 , 0 1 7}$ & $\mathbf{2 , 0 1 8}$ & $\mathbf{2 , 0 1 9}$ & $\mathbf{2 , 0 2 0}$ & $\mathbf{2 , 0 2 1}$ \\
\hline \hline 604,000 & 782,000 & 985,000 & $1,105,000$ & $1,596,058$ & $2,448,858$ & $2,849,717$ & $3,298,679$ & $3,764,709$ & $4,139,098$ & $4,484,541$
\end{tabular}

Nota. Elaboración propia

Siendo la estrategia principal de Hamek Ingenieros S.A.C. el ampliar su presencia en países andinos de la región de Latinoamérica, se ha considerado relevante analizar la participación de los ingresos segmentado por mercado local y mercado regional para estimar la proyección de crecimiento por mercado según se detalla a continuación.

Tabla 70

Crecimiento Proyectado por mercado

\begin{tabular}{|c|c|c|c|c|c|c|c|c|c|c|}
\hline & \multicolumn{6}{|c|}{ Participacion } & \multirow{2}{*}{$\begin{array}{c}\text { Crecimiento } \\
2018 \text { vs } 2017\end{array}$} & \multicolumn{3}{|c|}{ Proyeccion de Crecimiento } \\
\hline & 2014 & 2015 & 2016 & 2017 & 2018 & Promedio & & 2019 & 2020 & 2021 \\
\hline Internacional & $0 \%$ & $24 \%$ & $10 \%$ & $22 \%$ & $28 \%$ & $25 \%$ & $23 \%$ & $34 \%$ & $42 \%$ & $45 \%$ \\
\hline Local & $100 \%$ & $76 \%$ & $90 \%$ & $78 \%$ & $72 \%$ & $75 \%$ & $-7 \%$ & $10 \%$ & $10 \%$ & $10 \%$ \\
\hline Ventas Totales & $100 \%$ & $100 \%$ & $100 \%$ & $100 \%$ & $100 \%$ & & & & & \\
\hline
\end{tabular}

Nota. Elaboración propia.

Además, en caso, el crecimiento de ingresos no supere el $40 \%$ de la proyección durante su primer año o el $74 \%$ de la proyección al segundo año se considera importante implementar la estrategia de contingencia que incluye el Desarrollo de Productos o servicios en la Línea de Asesoría en el Sector Energía, para ello hemos considerado importante el analizar la composición de los ingresos segmentado por sectores, energía y ambiental según se detalla a continuación. 
Tabla 71

Crecimiento proyectado por Línea de Asesoría

\begin{tabular}{|c|c|c|c|c|c|c|c|c|c|c|}
\hline & \multicolumn{6}{|c|}{ Participacion } & \multirow{2}{*}{$\begin{array}{c}\text { Crecimiento } \\
2018 \text { vs } 2017\end{array}$} & \multicolumn{3}{|c|}{ Proyeccion de Crecimiento } \\
\hline & 2014 & 2015 & 2016 & 2017 & 2018 & Promedio & & 2019 & 2020 & 2021 \\
\hline Energía & $67 \%$ & $75 \%$ & $75 \%$ & $88 \%$ & & $88 \%$ & & $14 \%$ & $18 \%$ & $23 \%$ \\
\hline Ambiental & $33 \%$ & $25 \%$ & $25 \%$ & $12 \%$ & & $12 \%$ & & $30 \%$ & $30 \%$ & $30 \%$ \\
\hline Ventas Totales & $100 \%$ & $100 \%$ & $100 \%$ & $100 \%$ & & & & & & \\
\hline
\end{tabular}

Nota. Elaboración propia.

\subsubsection{Estado de Resultados (situación actual y con la nueva estrategia).}

Con la información histórica proporcionada para el periodo 2014 al 2018 se procede a analizar la composición de las partidas más representativas según se detalla en la Tabla 72, esta información será de mucha utilidad al momento de proyectar los estados de resultados en los periodos siguientes.

Además, considerando el crecimiento orgánico en las ventas sin implementar estrategia alguna se define un estado de resultados proyectados para el periodo 2019 2021 según se detalla en la Tabla 73. La proyección arroja como resultado una rentabilidad del $28 \%$ para el primer año y un $31 \%$ concluido al tercer año.

Implementando la estrategia principal que considera la Penetración de Mercado en el mercado andino se incrementan ingresos como consecuencia de tener una mayor participación en el mercado regional manteniéndose la proyección de rentabilidad en el primer año del 29\% pero mejorando en el segundo y tercer año proyectando conseguir una rentabilidad del $49 \%$ concluido el tercer año según se detalla en la Tabla 74

Finalmente se hizo un análisis adicional considerando que no se logre cubrir los objetivos de crecimiento en los ingresos, es decir, que no supere el $40 \%$ de la proyección durante su primer año o el $74 \%$ de la proyección al segundo año, en ese escenario se optaría por implementar la estrategia de contingencia que incluye el Desarrollo de Productos o servicios en la Línea de Asesoría en el Sector Energía, nuevamente la proyección de rentabilidad en el primer año inicia en un $27 \%$ pero para el tercer año se proyecta conseguir una rentabilidad del $40 \%$ según se detalla en la Tabla 75. 
Tabla 72

Estado de Pérdidas y Ganancias Actual

\begin{tabular}{lrrrr} 
en Soles & \multicolumn{3}{r}{} \\
\hline Cuenta & 2015 & 2016 & 2017 & 2018 \\
\hline Ingreso & $1,596,058$ & $2,448,858$ & $2,849,717$ & $3,298,679$ \\
Costo de Ventas & - & $-501,100$ & $-1,276,708$ & $-488,377$ \\
\hline Ganancia (Pérdida) Bruta & $1,596,058$ & $1,947,758$ & $1,573,010^{\prime}$ & $2,810,302$ \\
\hline Gastos de Ventas & $-200,310$ & $-422,193$ & 0 & $-504,965$ \\
Gastos Administrativos & $-801,250$ & $-892,523$ & $-366,343$ & $-937,792$ \\
\hline Ganancia (Pérdida) por actividades de operación & 594,498 & 633,043 & $1,206,667$ & $1,367,546$ \\
\hline Otros Ingresos y Egresos & - & 0 & 0 & 0 \\
Adiciones & - & 0 & 0 & 0 \\
Ingresos excepcionales & - & 0 & 0 & 0 \\
Ingresos Financieros & - & 0 & $-4,458$ & 0 \\
Gastos Financieros & - & 0 & 0 & 0 \\
Gastos excepcionales & - & 0 & 0 & 0 \\
\hline Resultado antes de Impuesto a las Ganancias & 594,498 & 633,043 & $1,202,210$ & $1,367,546$ \\
\hline Impuestos & $-178,350$ & $-177,252$ & $-336,620$ & $-382,912$ \\
\hline Utilidad Neta & 416,148 & 455,791 & 865,590 & 984,634 \\
\hline
\end{tabular}

\begin{tabular}{|c|c|c|c|c|}
\hline Part \% 2015 & Part \% 2016 & Part \% 2017 & Part \% 2018 & Promedio \\
\hline $100 \%$ & $100 \%$ & $100 \%$ & $100 \%$ & $100 \%$ \\
\hline $0 \%$ & $-20 \%$ & $-45 \%$ & $-15 \%$ & $-27 \%$ \\
\hline $100 \%$ & $80 \%$ & $55 \%$ & $85 \%$ & $82 \%$ \\
\hline$-13 \%$ & $-17 \%$ & $0 \%$ & $-15 \%$ & $-15 \%$ \\
\hline$-50 \%$ & $-36 \%$ & $-13 \%$ & $-28 \%$ & $-32 \%$ \\
\hline $37 \%$ & $26 \%$ & $42 \%$ & $41 \%$ & $40 \%$ \\
\hline $0 \%$ & $0 \%$ & $0 \%$ & $0 \%$ & $0 \%$ \\
\hline $0 \%$ & $0 \%$ & $0 \%$ & $0 \%$ & $0 \%$ \\
\hline $0 \%$ & $0 \%$ & $0 \%$ & $0 \%$ & $0 \%$ \\
\hline $0 \%$ & $0 \%$ & $0 \%$ & $0 \%$ & $0 \%$ \\
\hline $0 \%$ & $0 \%$ & $0 \%$ & $0 \%$ & $0 \%$ \\
\hline $0 \%$ & $0 \%$ & $0 \%$ & $0 \%$ & $0 \%$ \\
\hline $37 \%$ & $26 \%$ & $42 \%$ & $41 \%$ & $40 \%$ \\
\hline$-11 \%$ & $-7 \%$ & $-12 \%$ & $-12 \%$ & $-12 \%$ \\
\hline $26 \%$ & $19 \%$ & $30 \%$ & $30 \%$ & $29 \%$ \\
\hline
\end{tabular}

Nota. Elaboración Propia 
Tabla 73

Estado de Pérdidas y Ganancias Proyectado Sin Implementar Estrategia

\begin{tabular}{|c|c|c|c|c|c|c|c|}
\hline Cuenta & 2015 & 2016 & 2017 & 2018 & 2019 & 2010 & 2021 \\
\hline Ingreso & $1,596,058$ & $2,448,858$ & $2,849,717$ & $3,298,679$ & $3,764,709$ & $4,139,098$ & $4,484,541$ \\
\hline Costo de Ventas & 0 & $-501,100$ & $-1,276,708$ & $-488,377$ & $-663,866$ & $-729,885$ & $-790,800$ \\
\hline Ganancia (Pérdida) Bruta & $1,596,058$ & $1,947,758$ & $1,573,010$ & $2,810,302$ & $3,100,844$ & $3,409,213$ & $3,693,741$ \\
\hline Gastos de Ventas & $-200,310$ & $-422,193$ & 0 & $-504,965$ & $-565,946$ & $-622,227$ & $-674,158$ \\
\hline Gastos Administrativos & $-801,250$ & $-892,523$ & $-366,343$ & $-937,792$ & $-1,038,014$ & $-1,074,109$ & $-1,091,018$ \\
\hline Ganancia (Pérdida) por actividades de operación & 594,498 & 633,043 & $1,206,667$ & $1,367,546$ & $1,496,884$ & $1,712,876$ & $1,928,565$ \\
\hline \multicolumn{8}{|l|}{ Otros Ingresos y Egresos } \\
\hline Adiciones & 0 & 0 & 0 & 0 & - & - & - \\
\hline Ingresos excepcionales & 0 & 0 & 0 & 0 & - & - & - \\
\hline Ingresos Financieros & 0 & 0 & $-4,458$ & 0 & - & - & - \\
\hline Gastos Financieros & 0 & 0 & 0 & 0 & - & - & - \\
\hline Gastos excepcionales & 0 & 0 & 0 & 0 & - & - & - \\
\hline Resultado antes de Impuesto a las Ganancias & 594,498 & 633,043 & $1,211,125$ & $1,367,546$ & $1,496,884$ & $1,712,876$ & $1,928,565$ \\
\hline Impuestos & $-178,350$ & $-177,252$ & $-336,620$ & $-382,912$ & $-434,132$ & $-477,305$ & $-517,140$ \\
\hline \multirow[t]{2}{*}{ Utilidad Neta } & 416,148 & 455,791 & 874,505 & 984,634 & $1,062,752$ & $1,235,572$ & $1,411,425$ \\
\hline & $26 \%$ & $19 \%$ & $31 \%$ & $30 \%$ & $28 \%$ & $30 \%$ & $31 \%$ \\
\hline
\end{tabular}

Nota. Elaboración Propia 
Tabla 74

Estado de Pérdidas y Ganancias Proyectado con Estrategia de Penetración de Mercados

\begin{tabular}{|c|c|c|c|c|c|c|c|}
\hline Cuenta & 2015 & 2016 & 2017 & 2018 & 2019 & 2010 & 2021 \\
\hline Ingreso Ventas Actuales Clientes & $1,596,058$ & $2,448,858$ & $2,849,717$ & $3,298,679$ & $3,764,709$ & $4,139,098$ & $4,484,541$ \\
\hline Ingresos Nuevas Ventas Mercado Andino & & & & & 90,462 & 569,200 & $1,579,910$ \\
\hline Costo de Ventas & 0 & $-501,100$ & $-1,276,708$ & $-488,377$ & $-663,866$ & $-912,357$ & $-1,186,201$ \\
\hline Ganancia (Pérdida) Bruta & $1,596,058$ & $1,947,758$ & $1,573,010$ & $2,810,302$ & $3,191,306$ & $3,795,941$ & $4,878,250$ \\
\hline Gastos de Ventas & $-200,310$ & $-422,193$ & 0 & $-504,965$ & $-565,946$ & $-622,227$ & $-674,158$ \\
\hline Gastos Administrativos & $-801,250$ & $-892,523$ & $-366,343$ & $-937,792$ & $-1,112,093$ & $-1,238,903$ & $-1,504,131$ \\
\hline Ganancia (Pérdida) por actividades de operación & 594,498 & 633,043 & $1,206,667$ & $1,367,546$ & $1,513,267$ & $1,934,811$ & $2,699,962$ \\
\hline \multicolumn{8}{|l|}{ Otros Ingresos y Egresos } \\
\hline Adiciones & 0 & 0 & 0 & 0 & - & - & - \\
\hline Ingresos excepcionales & 0 & 0 & 0 & 0 & - & - & - \\
\hline Ingresos Financieros & 0 & 0 & $-4,458$ & 0 & - & - & - \\
\hline Gastos Financieros & 0 & 0 & 0 & 0 & - & - & - \\
\hline Gastos excepcionales & 0 & 0 & 0 & 0 & - & - & - \\
\hline Resultado antes de Impuesto a las Ganancias & 594,498 & 633,043 & $1,211,125$ & $1,367,546$ & $1,513,267$ & $1,934,811$ & $2,699,962$ \\
\hline Impuestos & $-178,350$ & $-177,252$ & $-336,620$ & $-382,912$ & $-434,132$ & $-477,305$ & $-517,140$ \\
\hline \multirow[t]{2}{*}{ Utilidad Neta } & 416,148 & 455,791 & 874,505 & 984,634 & $1,079,135$ & $1,457,506$ & $2,182,822$ \\
\hline & $26 \%$ & $19 \%$ & $31 \%$ & $30 \%$ & $29 \%$ & $35 \%$ & $49 \%$ \\
\hline
\end{tabular}

\section{Nota. Elaboración Propia}


Tabla 75

Estado de Pérdidas y Ganancias Proyectado con Estrategia de Desarrollo de Productos

\begin{tabular}{|c|c|c|c|c|c|c|c|}
\hline Cuenta & 2015 & 2016 & 2017 & 2018 & 2019 & 2010 & 2021 \\
\hline Ingreso Ventas Actuales Clientes & $1,596,058$ & $2,448,858$ & $2,849,717$ & $3,298,679$ & $3,764,709$ & $4,139,098$ & $4,484,541$ \\
\hline Ingresos Nuevos Productos Energía & & & & & 96,009 & 627,240 & $1,638,723$ \\
\hline Costo de Ventas & 0 & $-501,100$ & $-1,276,708$ & $-488,377$ & $-763,446$ & $-985,345$ & $-1,225,741$ \\
\hline Ganancia (Pérdida) Bruta & $1,596,058$ & $1,947,758$ & $1,573,010$ & $2,810,302$ & $3,097,273$ & $3,780,993$ & $4,897,523$ \\
\hline Gastos de Ventas & $-200,310$ & $-422,193$ & 0 & $-504,965$ & $-565,946$ & $-622,227$ & $-674,158$ \\
\hline Gastos Administrativos & $-801,250$ & $-892,523$ & $-366,343$ & $-937,792$ & $-1,099,073$ & $-1,208,373$ & $-1,454,691$ \\
\hline Ganancia (Pérdida) por actividades de operación & 594,498 & 633,043 & $1,206,667$ & $1,367,546$ & $1,432,254$ & $1,950,392$ & $2,768,675$ \\
\hline \multicolumn{8}{|l|}{ Otros Ingresos y Egresos } \\
\hline Adiciones & 0 & 0 & 0 & 0 & - & - & - \\
\hline Ingresos excepcionales & 0 & 0 & 0 & 0 & - & - & - \\
\hline Ingresos Financieros & 0 & 0 & $-4,458$ & 0 & - & - & - \\
\hline Gastos Financieros & 0 & 0 & 0 & 0 & - & - & - \\
\hline Gastos excepcionales & 0 & 0 & 0 & 0 & - & - & - \\
\hline Resultado antes de Impuesto a las Ganancias & 594,498 & 633,043 & $1,211,125$ & $1,367,546$ & $1,432,254$ & $1,950,392$ & $2,768,675$ \\
\hline Impuestos & $-178,350$ & $-177,252$ & $-336,620$ & $-382,912$ & $-434,132$ & $-477,305$ & $-517,140$ \\
\hline Utilidad Neta & 416,148 & 455,791 & 874,505 & 984,634 & 998,122 & $1,473,088$ & $2,251,535$ \\
\hline
\end{tabular}

\section{Nota. Elaboración Propia}




\subsubsection{Balance General (Situación actual y con nueva estrategia).}

El Balance General actual de la empresa Hamek Ingenieros Asociados S.A.C. se presenta en la Tabla 76, del período 2014 al 2018, tomado como base los cuatro años anteriores se proyectando tres escenarios: sin estrategia (ESE) y con las dos estrategias que fueron obtenidas; escenario con estrategia de Penetración de Mercado (ECE1) y escenario con estrategia de Desarrollo de Producto (ECE2) hasta el año 2021.

Podemos observar que los activos totales y patrimonio en el año 2021, en el ESE es menor al de ECE1 y ECE2.

A continuación, se presenta el Balance General sin estrategia en la tabla 77, el Balance General de la primera estrategia de Penetración de Mercado en la tabla 78 y el Balance General de la segunda estrategia de Desarrollo de Producto (ver Tabla 79). 
Tabla 76

Balance General Actual

Soles

\begin{tabular}{|c|c|c|c|c|}
\hline CUENTA & 2015 & 2016 & 2017 & 2018 \\
\hline \multicolumn{5}{|l|}{ Activos } \\
\hline \multicolumn{5}{|l|}{ Activos Corrientes } \\
\hline Caja y Bancos & 437,673 & 110,805 & 216,028 & 370,764 \\
\hline Cuentas por cobrar comerciales & 0 & 316,123 & 227,121 & 344,715 \\
\hline Cuentas por cobrar a terceros & 0 & 0 & 0 & 0 \\
\hline Existencias & 0 & 0 & 0 & 0 \\
\hline Existencias por Recibir & 0 & 0 & 0 & 0 \\
\hline Activos Diferidos & 167,080 & 63,390 & 74,794 & 63,390 \\
\hline Anticipos a Proveedores Exterior & 0 & 47,118 & 81,190 & 61,713 \\
\hline Total Activo Corriente & 604,753 & 537,435 & 599,133 & 840,581 \\
\hline Activo No Corriente & 0 & 0 & 0 & 0 \\
\hline Inmuebles, Maquinaria y Equipo & 411,333 & 849,613 & $1,295,024$ & $1,295,024$ \\
\hline Intangibles & 0 & 0 & 11,112 & 11,112 \\
\hline Depreciacion y Amortizacion Acumulada & $-217,728$ & $-314,123$ & $-424,871$ & $-424,871$ \\
\hline Total Activo No Corriente & 193,605 & 535,490 & 881,265 & 881,265 \\
\hline Total de Activos & 798,358 & $1,072,925$ & $1,480,398$ & $1,721,847$ \\
\hline Pasivo y Patrimonio & 0 & 0 & 0 & 0 \\
\hline Pasivos Corrientes & 0 & 0 & 0 & 0 \\
\hline Sobregiro y Prest. Bancarios & 0 & 0 & 0 & 0 \\
\hline Tributos por Pagar & 39,843 & 9,300 & 0 & 38,695 \\
\hline Remuneraciones Por Pagar & 0 & 0 & 0 & 0 \\
\hline Cuentas por Pagar Comerciales & 0 & 148,818 & 0 & 0 \\
\hline Obligaciones Financieras Corto Plazo & 0 & 0 & 0 & 0 \\
\hline Cuentas Por Pagar Diversos & 0 & 0 & 0 & 0 \\
\hline Total Pasivo Corriente & 39,843 & 158,118 & 0 & 38,695 \\
\hline Pasivo No corriente & 0 & 0 & 0 & 0 \\
\hline Obligaciones Financiera a Largo Plazo & 0 & 0 & 0 & 0 \\
\hline Total de Pasivo No Corriente & 0 & 0 & 0 & 0 \\
\hline Total de Pasivos & 39,843 & 158,118 & 0 & 38,695 \\
\hline Patrimonio & 0 & 0 & 0 & 0 \\
\hline Capital Social & 182,100 & 182,100 & 182,100 & 182,100 \\
\hline Reserva Legal & 0 & 0 & 0 & 0 \\
\hline Resultados Acumulados & 160,268 & 276,918 & 432,706 & 724,926 \\
\hline Resultado de Ejercicios & 416,148 & 455,790 & 865,592 & 776,126 \\
\hline Total de Patrimonio & 758,516 & 914,808 & $1,480,398$ & $1,683,152$ \\
\hline Total Pasivo y Patrimonio & 798,358 & $1,072,925$ & $1,480,398$ & $1,721,847$ \\
\hline
\end{tabular}

Nota. Adaptado de "Contabilidad de la Empresa 
Tabla 77

Balance General Proyectado sin estrategia

Soles

\begin{tabular}{|c|c|c|c|}
\hline CUENTA & 2019 & 2020 & 2021 \\
\hline \multicolumn{4}{|l|}{ Activos } \\
\hline \multicolumn{4}{|l|}{ Activos Corrientes } \\
\hline Caja y Bancos & $1,527,632$ & $2,887,128$ & $4,461,568$ \\
\hline Cuentas por cobrar comerciales & 176,183 & 251,354 & 339,328 \\
\hline \multicolumn{4}{|l|}{ Cuentas por cobrar a terceros } \\
\hline \multicolumn{4}{|l|}{ Existencias } \\
\hline \multicolumn{4}{|l|}{ Existencias por Recibir } \\
\hline Activos Diferidos & 425,000 & 216,538 & 108,762 \\
\hline \multicolumn{4}{|l|}{ Anticipos a Proveedores Exterior } \\
\hline Total Activo Corriente & $2,128,815$ & $3,355,019$ & $4,909,658$ \\
\hline \multicolumn{4}{|l|}{ Activo No Corriente } \\
\hline Inmuebles, Maquinaria y Equipo & $1,425,224$ & $1,600,324$ & $1,789,424$ \\
\hline Intangibles & 11,112 & 11,112 & 11,112 \\
\hline Depreciacion y Amortizacion Acumulada & $-555,915$ & $-740,871$ & $-996,115$ \\
\hline Total Activo No Corriente & 880,421 & 870,566 & 804,421 \\
\hline Total de Activos & $3,009,236$ & $4,225,584$ & $5,714,080$ \\
\hline \multicolumn{4}{|l|}{ Pasivo y Patrimonio } \\
\hline \multicolumn{4}{|l|}{ Pasivos Corrientes } \\
\hline \multicolumn{4}{|l|}{ Sobregiro y Prest. Bancarios } \\
\hline \multicolumn{4}{|l|}{ Tributos por Pagar } \\
\hline \multicolumn{4}{|l|}{ Remuneraciones Por Pagar } \\
\hline Cuentas por Pagar Comerciales & 280,000 & 245,000 & 212,500 \\
\hline \multicolumn{4}{|l|}{ Obligaciones Financieras Corto Plazo } \\
\hline \multicolumn{4}{|l|}{ Cuentas Por Pagar Diversos } \\
\hline Total Pasivo Corriente & 280,000 & 245,000 & 212,500 \\
\hline \multicolumn{4}{|l|}{ Pasivo No corriente } \\
\hline \multicolumn{4}{|l|}{ Obligaciones Financiera a Largo Plazo } \\
\hline Total de Pasivo No Corriente & 0 & 0 & 0 \\
\hline Total de Pasivos & 280,000 & 245,000 & 212,500 \\
\hline \multicolumn{4}{|l|}{ Patrimonio } \\
\hline Capital Social & 182,100 & 182,100 & 182,100 \\
\hline \multicolumn{4}{|l|}{ Reserva Legal } \\
\hline Resultados Acumulados & $1,501,052$ & $2,547,136$ & $3,798,484$ \\
\hline Resultado de Ejercicios & $1,046,085$ & $1,251,348$ & $1,520,995$ \\
\hline Total de Patrimonio & $2,729,236$ & $3,980,584$ & $5,501,580$ \\
\hline Total Pasivo y Patrimonio & $3,009,236$ & $4,225,584$ & $5,714,080$ \\
\hline
\end{tabular}

Nota. Elaboración propia. 
Tabla 78

Balance General con Estrategia de Penetración de Mercados

Soles

\begin{tabular}{|c|c|c|c|}
\hline CUENTA & 2019 & 2020 & 2021 \\
\hline \multicolumn{4}{|l|}{ Activos } \\
\hline \multicolumn{4}{|l|}{ Activos Corrientes } \\
\hline Caja y Bancos & $1,399,733$ & $2,760,028$ & $4,853,629$ \\
\hline Cuentas por cobrar comerciales & 225,122 & 321,174 & 433,585 \\
\hline \multicolumn{4}{|l|}{ Cuentas por cobrar a terceros } \\
\hline \multicolumn{4}{|l|}{ Existencias } \\
\hline \multicolumn{4}{|l|}{ Existencias por Recibir } \\
\hline Activos Diferidos & 425,000 & 216,538 & 108,762 \\
\hline \multicolumn{4}{|l|}{ Anticipos a Proveedores Exterior } \\
\hline Total Activo Corriente & $2,049,855$ & $3,297,740$ & $5,395,977$ \\
\hline \multicolumn{4}{|l|}{ Activo No Corriente } \\
\hline Inmuebles, Maquinaria y Equipo & $1,425,224$ & $1,600,324$ & $1,789,424$ \\
\hline Intangibles & 11,112 & 11,112 & 11,112 \\
\hline Depreciacion y Amortizacion Acumulada & $-555,915$ & $-740,871$ & $-996,115$ \\
\hline Total Activo No Corriente & 880,421 & 870,566 & 804,421 \\
\hline Total de Activos & $2,930,277$ & $4,168,306$ & $6,200,398$ \\
\hline \multicolumn{4}{|l|}{ Pasivo y Patrimonio } \\
\hline \multicolumn{4}{|l|}{ Pasivos Corrientes } \\
\hline \multicolumn{4}{|l|}{ Sobregiro y Prest. Bancarios } \\
\hline \multicolumn{4}{|l|}{ Tributos por Pagar } \\
\hline \multicolumn{4}{|l|}{ Remuneraciones Por Pagar } \\
\hline Cuentas por Pagar Comerciales & 280,000 & 245,000 & 212,500 \\
\hline \multicolumn{4}{|l|}{ Obligaciones Financieras Corto Plazo } \\
\hline \multicolumn{4}{|l|}{ Cuentas Por Pagar Diversos } \\
\hline Total Pasivo Corriente & 280,000 & 245,000 & 212,500 \\
\hline \multirow{2}{*}{\multicolumn{4}{|c|}{$\begin{array}{l}\text { Pasivo No corriente } \\
\text { Obligaciones Financiera a Larg }\end{array}$}} \\
\hline & & & \\
\hline Total de Pasivo No Corriente & 0 & 0 & 0 \\
\hline Total de Pasivos & 280,000 & 245,000 & 212,500 \\
\hline \multicolumn{4}{|l|}{ Patrimonio } \\
\hline Capital Social & 182,100 & 182,100 & 182,100 \\
\hline \multicolumn{4}{|l|}{ Reserva Legal } \\
\hline Resultados Acumulados & $1,501,052$ & $2,468,177$ & $3,741,206$ \\
\hline Resultado de Ejercicios & 967,125 & $1,273,029$ & $2,064,592$ \\
\hline Total de Patrimonio & $2,650,277$ & $3,923,306$ & $5,987,898$ \\
\hline Total Pasivo y Patrimonio & $2,930,277$ & $4,168,306$ & $6,200,398$ \\
\hline
\end{tabular}

Nota. Elaboración propia 
Tabla 79

Balance General con Estrategia de Desarrollo de Productos

Soles

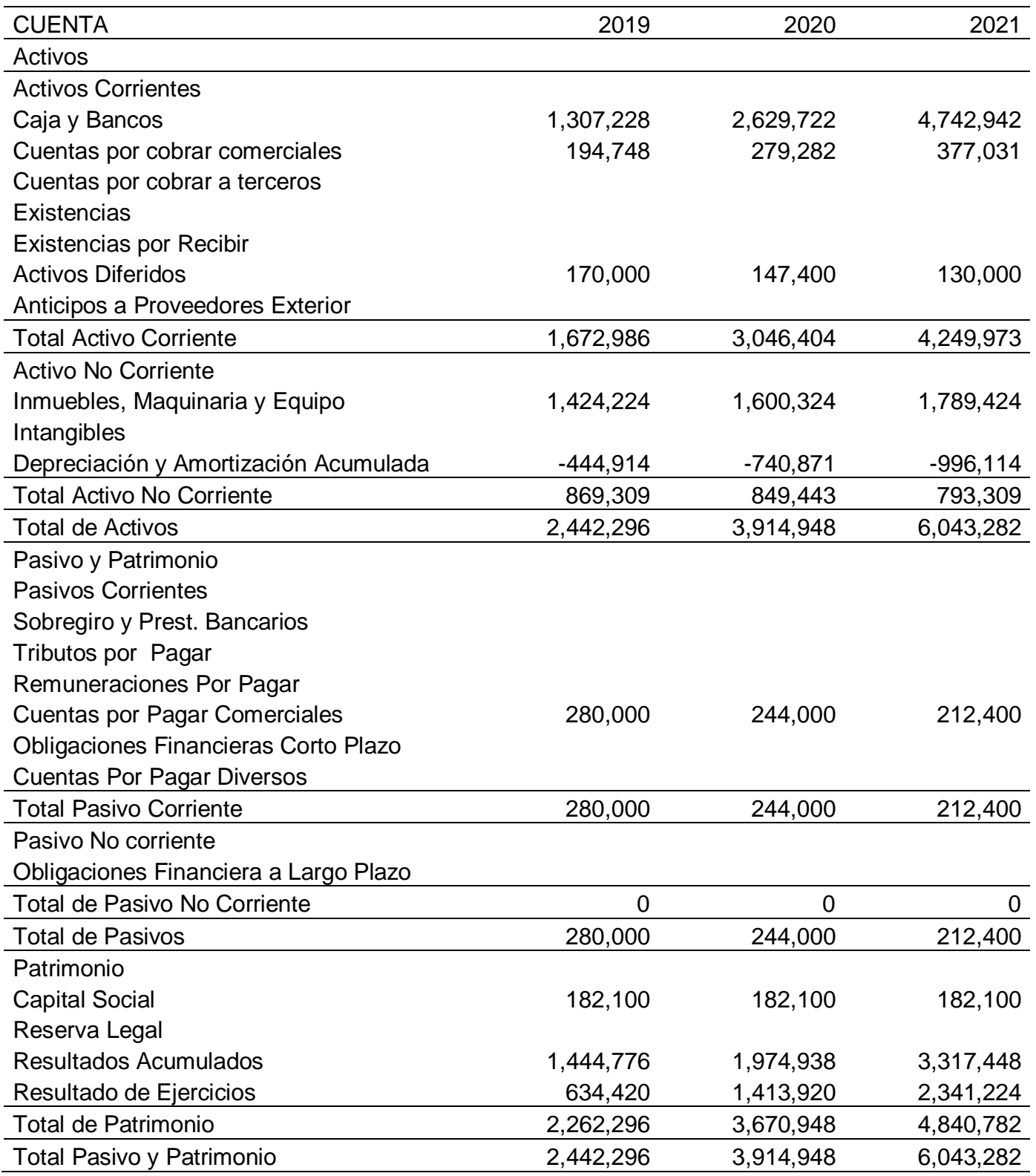

Nota. Elaboración propia 


\subsubsection{Flujo efectivo (Situación actual y con nueva estrategia).}

El flujo de efectivo de la situación actual de la empresa Hamek Ingenieros Asociados S.A.C., se observa en la tabla 80 y el flujo de efectivo sin estrategia y con las dos estrategias se detallará en la proyección de flujos.

Tabla 80

Flujo de Efectivo Actual

Soles

\begin{tabular}{lrrrr}
\hline CUENTA & 2015 & 2016 & 2017 & 2018 \\
\hline Ingreso & $1,596,058$ & $2,448,858$ & $2,849,717$ & $3,298,679$ \\
Costo de Ventas & 0 & $-501,100$ & $-1,276,708$ & $-488,377$ \\
\hline Ganancia (Pérdida) Bruta & $1,596,058$ & $1,947,758$ & $1,573,010$ & $2,810,302$ \\
\hline Gastos de Ventas & $-200,310$ & $-422,193$ & 0 & $-504,965$ \\
Gastos Administrativos & $-801,250$ & $-892,523$ & $-366,343$ & $-937,792$ \\
\hline Ganancia (Pérdida) por actividades de or & 594,498 & 633,043 & $1,206,667$ & $1,367,546$ \\
\hline OTROS INGRESOS Y EGRESOS & & & 0 & 0 \\
Adiciones & 0 & 0 & 0 & 0 \\
Ingresos excepcionales & 0 & 0 & $-4,458$ & 0 \\
Ingresos Financieros & 0 & 0 & 0 & 0 \\
Gastos Financieros & 0 & 0 & 0 & 0 \\
Gastos excepcionales & 0 & 0 & $1,367,546$ \\
\hline Resultado antes de Impuesto a las Ganc & 594,498 & 633,043 & $1,211,125$ & $-382,912$ \\
\hline Impuestos & $-178,350$ & $-177,252$ & $-336,620$ & 984,634 \\
\hline Utilidad Neta & 416,148 & 455,791 & 874,505 & $30 \%$ \\
\hline \multicolumn{1}{l}{ Ganancia (Pérdida) por actividades de or } & $26 \%$ & $19 \%$ & $31 \%$ & 0 \\
Depreciación (+) & 594,498 & 633,043 & $1,206,667$ & $1,367,546$ \\
Working Capital & 75,439 & 96,395 & 110,749 & 344,715 \\
\hline Utilidad O.N. & 0 & 167,305 & 227,121 & $1,022,831$ \\
Impuestos & 669,937 & 562,133 & $1,090,295$ & $-301,735$ \\
\hline Utilidad SI/O.N. & $-197,631$ & $-165,829$ & $-321,637$ & 721,096
\end{tabular}

Nota. Adaptado de "Contabilidad de la Empresa"

10.2.5. Proyección de Flujos (Situación actual y con nueva estrategia).

A continuación, se muestra los flujos proyectos de la empresa sin estrategia y con las dos estrategias ECE1 y ECE2, como se señaló la empresa Hamek Ingenieros Asociados S.A.C., cuenta con un fondo de caja necesario para mantener sus operaciones y para la compra de equipos en los próximos tres años, por lo cual no accederá a prestamos financiero ni de terceros, por lo cual no se determinará el Flujo Financiero, solo se hallará hasta el Flujo Económico. 
Podemos observar el Flujo Proyectado sin estrategia en la tabla 81.

\section{Tabla 81}

Proyección de Flujo sin estrategia

Soles

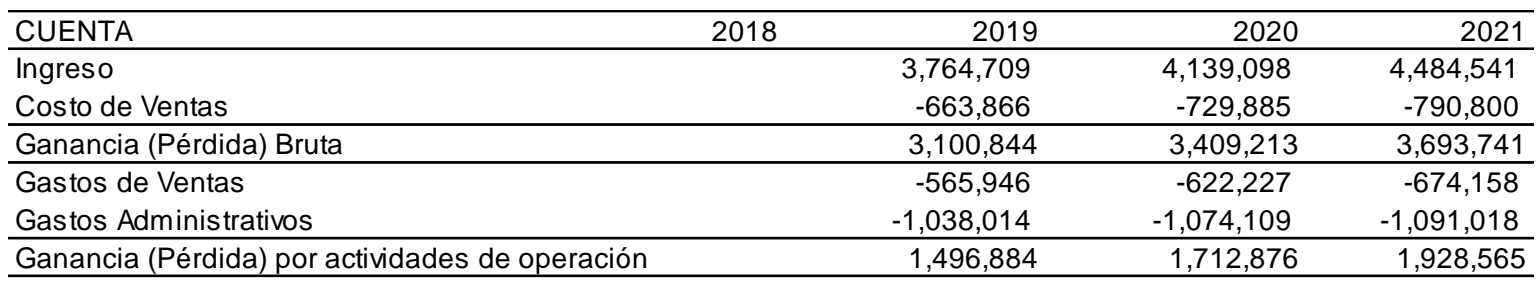

OTROS INGRESOS Y EGRESOS

\section{Adiciones}

Ingresos excepcionales

Ingresos Financieros

Gastos Financieros

Gastos excepcionales

\begin{tabular}{|c|c|c|c|}
\hline Resultado antes de Impuesto a las Ganancias & $1,496,884$ & $1,712,876$ & $1,928,565$ \\
\hline Impuestos & $-434,132$ & $-477,305$ & $-517,140$ \\
\hline Utilidad Neta & $1,062,752$ & $1,235,572$ & $1,411,425$ \\
\hline & $28 \%$ & $30 \%$ & $31 \%$ \\
\hline Ganancia (Pérdida) por actividades de operación & $1,496,884$ & $1,712,876$ & $1,928,565$ \\
\hline Depreciación (+) & 144,064 & 215,486 & 304,684 \\
\hline Working Capital & 0 & 0 & 0 \\
\hline Utilidad O.N. & $1,640,948$ & $1,928,362$ & $2,233,249$ \\
\hline Impuestos & $-484,080$ & $-568,867$ & $-658,809$ \\
\hline Utilidad SI/O.N. & $1,156,868$ & $1,359,495$ & $1,574,441$ \\
\hline
\end{tabular}

Nota. Elaboración propia

Para implementar las estrategias se obtiene la inversión en Capex, la cual se analizó en el capítulo anterior, la depreciación de las maquinas que se compraran, considerando las maquinas existentes que aún se encuentran depreciándose, con una vida útil de diez años y la inversión de working capital para los tres años.

Cuando el inversionista decide financiar una parte del proyecto, en tal situación se deben elaborar dos flujos de caja: el flujo de caja económico y el flujo de caja financiero, en nuestro plan estratégico solo se obtendrá hasta el primero, ya que la empresa Hamek Ingenieros y Asociados S.A.C. no cuenta con financiamientos 
Tabla 82

Inversión en Capex ECE1

\begin{tabular}{lrrrr}
\hline Año & 2018 & 2019 & 2020 & 2021 \\
\hline Presupuesto en el plan de recursos Hı & - & 9,000 & 5,500 & 7,000 \\
Presupuesto en el plan de aprendizaje & - & 5,200 & 6,000 & 6,300 \\
Presupuesto en el plan de implementa & 130,000 & 175,000 & 189,100 & \\
Presupuesto en plan comercial & - & 53,700 & 64,500 & 71,500 \\
\hline Total Inversión & 130,000 & 242,900 & 265,100 & 84,800 \\
\hline
\end{tabular}

Nota. Elaboración propia

Tabla 83

\section{Depreciación de Activos ECE1}

\begin{tabular}{llrr}
\hline Depreciación de Activos Fijos & Valor & Vida Útil & Depreciación \\
\hline Presupuesto en el plan de implementación de equipos de medición 2018 & 130,000 & 10 & 13,000 \\
Presupuesto en el plan de implementación de equipos de medición 2019 & 175,000 & 10 & 17,500 \\
Presupuesto en el plan de implementación de equipos de medición 2020 & 189,100 & 10 & 18,910 \\
\hline
\end{tabular}

Nota. Elaboración propia

Tabla 84

Depreciación de los Tres Años Proyectados ECE1

\begin{tabular}{lrrr}
\hline Años & 2018 & 2019 & 2020 \\
\hline Depreciación Anual & 13,000 & 30,500 & 49,410 \\
\hline
\end{tabular}

Nota. Elaboración propia

Tabla 85

Inversiones Working Capital ECE1

\begin{tabular}{lccc}
\hline Años & 2018 & 2019 & 2020 \\
\hline Cuentas por cobrar comerciales & 225,122 & 321,174 & 433,585 \\
Cuentas por pagar comerciales & 280,000 & 245,000 & 212,500 \\
Working Capital & $-54,878$ & 0 & 0 \\
\hline
\end{tabular}

Nota. Elaboración propia 


\section{Tabla 86}

\section{Proyección de Flujo con Estrategia de Penetración de Mercados}

Soles

\begin{tabular}{lrrrr}
\hline CUENTA & $\mathbf{2 0 1 8}$ & $\mathbf{2 0 1 9}$ & $\mathbf{2 0 2 0}$ & $\mathbf{2 0 2 1}$ \\
\hline \hline Ingreso Ventas Actuales Clientes & - & $3,764,709$ & $4,139,098$ & $4,484,541$ \\
Ingresos Nuevas Ventas Mercado Andino & - & 90,462 & 569,200 & $1,579,910$ \\
Costo de Ventas & - & $-663,866$ & $-912,357$ & $-1,186,201$ \\
\hline Ganancia (Pérdida) Bruta & $\mathbf{0}$ & $\mathbf{3 , 1 9 1 , 3 0 6}$ & $\mathbf{3 , 7 9 5 , 9 4 1}$ & $\mathbf{4 , 8 7 8 , 2 5 0}$ \\
\hline \hline Gastos de Ventas & - & $-565,946$ & $-622,227$ & $-674,158$ \\
Gastos Administrativos & - & $-1,112,073$ & $-1,238,873$ & $-1,504,101$ \\
\hline Ganancia (Pérdida) por actividades de operación & $\mathbf{0}$ & $\mathbf{1 , 5 1 3 , 2 8 7}$ & $\mathbf{1 , 9 3 4 , 8 4 1}$ & $\mathbf{2 , 6 9 9 , 9 9 2}$ \\
\hline \hline
\end{tabular}

OTROS INGRESOS YEGRESOS

Adiciones

Ingresos excepcionales

Ingresos Financieros

Gastos Financieros

Gastos excepcionales

\begin{tabular}{|c|c|c|c|c|}
\hline Resultado antes de Impuesto a las Ganancias & 0 & $1,513,287$ & $1,934,841$ & $2,699,992$ \\
\hline Impuestos & - & $-434,132$ & $-477,305$ & $-517,140$ \\
\hline \multirow[t]{2}{*}{ Utilidad Neta } & 0 & $1,079,155$ & $1,457,536$ & $2,182,852$ \\
\hline & $0 \%$ & $29 \%$ & $35 \%$ & $49 \%$ \\
\hline Depreciación (+) & - & 144,024 & 215,420 & 304,609 \\
\hline Capex & $-130,000$ & 242,900 & 265,100 & 84,800 \\
\hline Presupuesto en el plan de implementación de equipos de medición & $-130,000$ & 175,000 & 189,100 & - \\
\hline Presupuesto en plan comercial & - & 53,700 & 64,500 & 71,500 \\
\hline Working Capital & $-54,878$ & 0 & 0 & 0 \\
\hline Utilidad O.N. & $-184,877.75$ & "1,414,410.27 & 1,885,161.54 & $2,919,801$ \\
\hline Impuestos & & $-417,251$ & $-556,123$ & $-861,341$ \\
\hline
\end{tabular}

Nota. Elaboración propia

Respecto al flujo proyectado para la segunda estrategia existe una mayor compra de activos, y de su depreciación como podemos observar en las tablas a continuación.

\section{Tabla 87}

\section{Inversión en Capex ECE2}

\begin{tabular}{lrrr}
\hline Año & 2018 & 2019 & 2020 \\
\hline Presupuesto en el plan de recursos Humanos & - & 25,800 & 31,700 \\
Presupuesto en el plan de aprendizaje y crecimiento & - & 4,700 & 7,500 \\
Presupuesto en el plan de implementación de equipos de medición & 210,300 & 205,300 & 232,300 \\
Presupuesto en plan comercial & - & 12,200 & 18,500 \\
\hline Total Inversión & 210,300 & 248,000 & 290,000 \\
\hline
\end{tabular}

Nota. Elaboración propia 


\section{Tabla 88}

Depreciación de Activos ECE2

\begin{tabular}{llrr}
\hline Depreciación de Activos Fijos & Valor & Vida Útil & Depreciación \\
\hline Presupuesto en el plan de implementación de equipos de medición 2018 & 210,300 & 10 & 21,030 \\
Presupuesto en el plan de implementación de equipos de medición 2019 & 205,300 & 10 & 20,530 \\
Presupuesto en el plan de implementación de equipos de medición 2020 & 232,300 & 10 & 23,230 \\
\hline
\end{tabular}

Nota. Elaboración propia

\section{Tabla 89}

Depreciación de los Tres Años Proyectados ECE2

\begin{tabular}{crrr}
\hline Años & 2018 & 2019 & 2020 \\
\hline Depreciación Anual & 21,030 & 41,560 & 64,790 \\
\hline
\end{tabular}

Nota. Elaboración propia

\section{Tabla 90}

Inversiones Working Capital ECE2

\begin{tabular}{lccc}
\hline Años & Año 1 & Año 2 & Año 3 \\
\hline Cuentas por cobrar comerciales & 195,758 & 279,282 & 377,031 \\
Cuentas por pagar comerciales & 280,000 & 245,000 & 212,500 \\
Working Capital & $-84,242$ & 0 & 0 \\
\hline
\end{tabular}

Nota. Elaboración propia 


\section{Tabla 91}

Proyección de Flujo con Estrategia de Desarrollo de Productos

Soles

\begin{tabular}{|c|c|c|c|c|}
\hline CUENTA & 2018 & 2019 & 2020 & 2021 \\
\hline Ingreso Ventas Actuales Clientes & - & $3,764,709$ & $4,139,098$ & $4,484,541$ \\
\hline Ingresos Nuevos Productos Energía & - & 96,009 & 627,240 & $1,638,723$ \\
\hline Costo de Ventas & - & $-763,446$ & $-985,345$ & $-1,225,741$ \\
\hline Ganancia (Pérdida) Bruta & 0 & $3,097,273$ & $3,780,993$ & $4,897,523$ \\
\hline Gastos de Ventas & - & $-565,946$ & $-622,227$ & $-674,158$ \\
\hline Gastos Administrativos & - & $-1,099,073$ & $-1,208,373$ & $-1,454,691$ \\
\hline Ganancia (Pérdida) por actividades de operación & 0 & $1,432,254$ & $1,950,392$ & $2,768,675$ \\
\hline
\end{tabular}

OTROS INGRESOS YEGRESOS

Adiciones

Ingresos excepcionales

Ingresos Financieros

Gastos Financieros

Gastos excepcionales

\begin{tabular}{|c|c|c|c|c|}
\hline Resultado antes de Impuesto a las Ganancias & 0 & $1,432,254$ & $1,950,392$ & $2,768,675$ \\
\hline Impuestos & - & $-434,132$ & $-477,305$ & $-517,140$ \\
\hline \multirow[t]{2}{*}{ Utilidad Neta } & 0 & 998,122 & $1,473,088$ & $2,251,535$ \\
\hline & - & $27 \%$ & $36 \%$ & $50 \%$ \\
\hline Ganancia (Pérdida) por actividades de operación & 0 & $1,432,254$ & $1,950,392$ & $2,768,675$ \\
\hline Depreciación (+) & - & 144,024 & 215,420 & 304,609 \\
\hline Capex & $-210,300$ & 248,000 & 290,000 & 61,700 \\
\hline Presupuesto en el plan de implementación de equipos de medición & $-210,300$ & 205,300 & 232,300 & - \\
\hline Presupuesto en plan comercial & - & 12,200 & 18,500 & 21,500 \\
\hline Working Capital & $-84,242$ & 0 & 0 & 0 \\
\hline Utilidad O.N. & $-294,541.52$ & $1,328,277$ & $1,875,813$ & $3,011,583$ \\
\hline Impuestos & & $-391,842$ & $-553,365$ & $-888,417$ \\
\hline
\end{tabular}

Nota. Elaboración propia.

\subsubsection{Evaluación Financiera (VAN, TIR, Ratios Financieros).}

Para saber que tan viable es la primera estrategia y la segunda estrategia se determinara el VAN y el TIR.

\section{El Valor Actual Neto (VAN).}

A partir del flujo de caja económico podemos obtener el Valor Actual (VAN) para el ECE1 y ECE2. Del resultado del VAN podemos determinar que un proyecto de inversión es rentable si su VAN es positivo, no es rentable si es negativo.

Por lo tanto, debería descontarse el costo de oportunidad del inversionista (COK o $\mathrm{Ke}$ ), que representa la tasa mínima de rendimiento requerida para asignar recursos a un proyecto riesgoso, como la empresa no tiene deudas, no existe WACC. 


\section{Tasa interna de retorno (TIR).}

La TIR o Tasa Interna de Retorno, es la tasa de interés o rentabilidad que genera un proyecto. Y se encarga de medir la rentabilidad de una inversión. Se calculará el TIR, con el fin de saber si es viable invertir en las estrategias planteadas.

\section{El Punto Muerto.}

Como parte del análisis de plan estratégico es relevante considerar el punto muerto, que es el nivel de ventas que hace que el VAN sea cero, lo que significa que se está recuperando la inversión y obteniendo la rentabilidad deseada.

\section{El Costo de Oportunidad (COK)}

Es la tasa mínima de retorno de invertir en un proyecto que se exige como la mínima rentabilidad para su participación. EI COK fue elaborado para las economías desarrollada, fue diseñado para Estados Unidos, donde la base de riesgo es más segura, por lo que utilizamos los datos de Estados Unidos, porque en el Perú son sumamente complejo de estimar, como el proyecto es peruano hay que adaptar la formula, para contextualizarlo al nivel de riesgo peruano. La Tasa libre de riesgo se obtiene de los bonos sobrenado EEUU, el Rendimiento de mercado se obtuvo del S\&P400, la beta se obtuvo del sector Environmental \& Waste Services, es un sector similar a Hamek Ingenieros Asociados S.A.C. y se utiliza la beta apalancada.

Tabla 92
\begin{tabular}{lr} 
El Costo de Oportunidad (COK) \\
\hline Concepto & Tasa \% \\
\hline Tasa Libre de Riesgo E.E.U.U. & $2.92 \%$ \\
Rendimiento del Mercado E.E.U.U. & $12.25 \%$ \\
Beta desapalancada & 0.68 \\
Beta apalancada & 0.68 \\
Inflación de Perú & $2.97 \%$ \\
Inflación EE. UU. & $2.04 \%$ \\
Riesgo País Perú (en puntos básicos) & $1.90 \%$ \\
Riesgo Región & $4.36 \%$ \\
Tasa Impositiva Perú (IR) & $29.50 \%$ \\
\hline
\end{tabular}

Nota. Elaboración propia. 
Convertimos el COK nominal de Estados Unidos a COK real de Estados Unidos obteniendo COK Perú más el riesgo País y castigamos el proyecto y por ser una pequeña empresa y considerando el riesgo región se obtiene el COK real del proyecto.

Las proyecciones financieras se han hecho a precio constante, por lo que no se considera el efecto inflación, se trabaja con el COK real.

Tabla 93

COK del proyecto

\begin{tabular}{llr}
\hline COK del Proyecto & Calculo & Resultado \\
\hline COK Nominal USA & $2.92 \%+0.68(12.25 \%-2.92 \%)$ & $9.26 \%$ \\
COK Real USA & $((9.26 \%-2.04 \%) /(1+2.04 \%))$ & $7.08 \%$ \\
COK Real Perú & $7.08 \%+1.9 \%$ & $8.98 \%$ \\
Castigo de negocio & $8.98 \%+5 \%$ & $13.98 \%$ \\
COK Proyecto real & $13.98 \%$ & $13.98 \%$ \\
\hline
\end{tabular}

Nota. Elaboración propia.

Para la implementación de la primera estrategia, de penetración de mercado, se obtiene el VAN y el TIR en las tablas 94 como se observa.

Tabla 94

EI VAN y TIR con Estrategia de Penetración de Mercados

\begin{tabular}{lrrrr}
\hline Año & 2018 & 2019 & 2020 & 2021 \\
\hline FCE sin estrategia & $-103,817.37$ & $1,156,868.10$ & $1,359,495.30$ & $1,574,440.75$ \\
FCE ECE 1 & $-184,877.75$ & $997,159.24$ & $1,329,038.89$ & $2,058,459.39$ \\
Valor con Opción & $-81,060.38$ & $-159,708.86$ & $-30,456.42$ & $484,018.64$ \\
COK & $13.98 \%$ & & & \\
VAN & $82,246.89$ & & & \\
TIR & $30 \%$ & & & \\
\hline
\end{tabular}

Nota. Elaboración propia.

Se obtiene un Van mayor a cero, es rentable, crea valor para la empresa observamos que la TIR es mayor al COK, lo que significa que la inversión en el proyecto da una rentabilidad mayor que la rentabilidad mínima exigida por el inversionista, por lo cual, se acepta invertir en la estrategia de penetración de mercado. 
Para la implementación de la segunda estrategia, obtenemos el VAN y el TIR, en las siguientes tablas 95 .

Tabla 95

EI VAN y TIR con Estrategia de Desarrollo de Productos

\begin{tabular}{lrrrr}
\hline Año & 2018 & 2019 & 2020 & 2021 \\
\hline FCE sin estrategia & $-103,817.37$ & $1,156,868.10$ & $1,359,495.30$ & $1,574,440.75$ \\
FCE ECE2 & $-294,541.52$ & $936,463.82$ & $1,322,494.24$ & $2,123,219.52$ \\
Valor con Opción & $-190,724.15$ & $-220,404.29$ & $-37,001.06$ & $548,778.76$ \\
COK & $13.98 \%$ & & & \\
VAN & $-41,971.22$ & & & \\
TIR & $9 \%$ & & & \\
\hline
\end{tabular}

Nota. Elaboración propia.

Se observa un VAN negativo y un TIR menor a la tasa esperada por el inversionista, lo que nos lleva a no considerar la estrategia de desarrollo de producto.

A fin de tener con mayor precisión la situación de la empresa Hamek Ingenieros Asociados S.A.C, es necesario calcular sus indicadores, a continuación:

\section{Ratios Financieros.}

Los Ratios financieros nos permitirán medir el estado actual y pasado de la empresa. A continuación, se analizará las ratios financieras más representativos.

\section{Ratio de Liquidez.}

Esta ratio medirá la capacidad que tiene la empresa para pagar sus obligaciones corrientes (pasivos corrientes), con activos de corto plazo (activos corrientes).

\section{Liquidez General.}

La empresa puede afrontar sus obligaciones a corto plazo con sus activos de corto plazo, su indicador es mayor a primero, tiene una liquidez para los tres años. Posee una capacidad para cubrir sus deudas a corto plazo. Por cada sol de pasivos a corto plazo en el en el año primero hay S/7.32 de activos a corto plazo para operaciones 
inmediatas, este va aumentando año a año hasta ser S/25.39 debido al mejor uso de los activos y existe mayor liquidez.

\section{Prueba Acida.}

La empresa tiene la capacidad de afrontar sus obligaciones a corto plazo con sus activos muy corto plazo como la caja y banco, cuentas por cobrar, la cual va mejorando en el transcurro de los años, incrementándose. Es igual que liquidez general porque no hay existencias.

\section{Prueba Defensiva.}

La empresa afronta sus obligaciones a corto plazo con efectivo líquido y valores negociables con los que cuenta, la cual e incrementa cada año. Por cada sol de pasivos a corto plazo en el en el año primero hay $S / 5$ en caja y bancos, este va aumentando año a año hasta ser S/22.84 debido al mejor uso de los activos y existe mayor liquidez.

\section{Capital de Trabajo Neto.}

La empresa opera con fluidez, se nota un incremento conservador relacionado con el volumen de operaciones de la empresa. Por cada sol de ventas en el año primero hay S/ 0.53 de capital de trabajo para solventar las actividades de corto plazo, este va aumentando año a año hasta $\mathrm{S} / 0.89$ debido al mejor uso de los activos y existe mayor liquidez.

Tabla 96

Ratios de Liquidez

\begin{tabular}{lccc}
\hline Ratios de Liquidez & Año1 & Año 2 & Año 3 \\
\hline Liquidez General & 7.32 & 13.46 & 25.39 \\
Prueba Ácida & 7.32 & 13.46 & 25.39 \\
Prueba Defensiva & 5.00 & 11.27 & 22.84 \\
Razón Capital Trabajo Neto & 0.53 & 0.70 & 0.89 \\
\hline
\end{tabular}

Nota. Elaboración propia.

\section{Ratio de Solvencia.}

Permiten analizar la capacidad de la empresa para responder por las obligaciones a corto y largo plazo, miden la capacidad de endeudamiento y el respaldo con el que enfrentan sus deudas totales. Las ratios de Solvencias son: 
Apalancamiento.

Por cada sol de patrimonio en el en el año primero se tiene $S / 0.11$ veces la cantidad de deuda. Se aprecia que este indicador va disminuyendo año a año hasta llegar al año tres reflejándose que no existe deuda bancaria y que los pasivos comerciales se mantienen en un nivel bajo.

\section{Grado de Endeudamiento Total}

Nos permite observar si los terceros tienen mayor presencia que los capitales propios. La empresa Hamek Ingenieros y Asociados S.A.C., tiene una posición de solvencia que le permite cubrir adecuadamente sus obligaciones financieras. Por cada sol de activo en el en el año primero se tiene 0.10 veces la cantidad de deuda. Se aprecia que este indicador va disminuyendo año a año hasta el año tres reflejándose que no existe deuda bancaria y que los pasivos comerciales se mantienen en un nivel bajo.

\section{Multiplicador de Capital.}

Se observa que este valor año a año disminuye debido a la depreciación de los bienes. Por cada sol de patrimonio en el en el año primero se tiene $S / 1.11$ veces el valor de los activos de la empresa. Se ve que este valor año a año disminuye debido a la depreciación de los bienes.

Cobertura de Interés.

No se puede determinar porque no hay gastos financieros

Cobertura servicio deuda.

No se puede determinar porque no hay deuda bancaria

Tabla 97

Ratios de Solvencia

\begin{tabular}{lccc}
\hline Ratio de Solvencia & Año1 & Año 2 & Año 3 \\
\hline Apalancamiento & 0.11 & 0.06 & 0.04 \\
Endeudamiento Total & 0.10 & 0.06 & 0.03 \\
Multiplicador de Capital & 1.11 & 1.06 & 1.04 \\
Cobertura Intereses & 0 & 0 & 0 \\
Cobertura Servicio Deuda & 0 & 0 & 0 \\
\hline
\end{tabular}

Nota. Elaboración propia. 


\section{Ratio de Rentabilidad.}

Esta ratio nos permite evaluar los resultados de la gestión empresarial. Nos muestran el poder de generación de utilidades de la empresa y la capacidad de obtener un rendimiento sobre los recursos obtenidos. Es la ganancia o utilidad sobre la inversión, los cuales son:

\section{Margen bruto.}

Mide la rentabilidad de las ventas frente al costo de ventas. Por cada sol de ventas, se genera en el año primero se tiene $\mathrm{S} / 0.85$ de utilidad bruta. Año a año aumenta reflejando la tendencia positiva de las proyecciones hasta llegar En el año tres a S/ 1.09.

Margen operativo.

Mide la rentabilidad de las ventas frente a costos operativos. Por cada sol de ventas, se genera en el año primero el valor de $\mathrm{S} / 0.40$ soles de utilidad antes de participaciones. Año a año aumenta reflejando la tendencia positiva de las proyecciones. En el año tres este indicador aumenta hasta llegar a S/ 0.60

\section{Margen neto.}

Es el margen porcentual que representa la ganancia neta de la empresa en relación con sus ventas en un periodo determinado. Por cada sol de ventas, se genera en el año primero el valor $\mathrm{S} / 0.40$ de utilidad antes de participaciones. Año a año aumenta reflejando la tendencia positiva de las proyecciones. En el año tres este indicador aumenta hasta llegar a $S / 0.60$ en el año tres.

\section{Poder Adquisitivo Básico.}

Por cada sol de activo, se genera en el primer año el valor de $S / 0.74$ de utilidad operativa. Este indicador se mantiene año a año. En el año tres este indicador es menor debido a que el valor de los activos por el volumen de caja retenido es alto.

\section{Rentabilidad del Patrimonio (ROE).}

Muestra la rentabilidad del patrimonio neto, mide el rendimiento de los capitales aportados por los accionistas del negocio. Por cada sol de patrimonio, se genera en el año uno S/0.41 de utilidad neta. Este va disminuyendo año a año debido a que los pasivos son mínimos y los resultados se mantienen en la empresa.

\section{Rendimiento operativo del Activo Total (ROA).}

Muestra la rentabilidad de los activos totales. Mide la eficiencia de la empresa en el uso de los activos para producir utilidades netas. Por cada sol de activo, se genera en 
el año uno S/0.37 de utilidad neta. Este va disminuyendo año a año debido a que los pasivos son mínimos y los resultados se mantienen en la empresa.

\section{Tabla 98}

Ratios de Rentabilidad

\begin{tabular}{lccc}
\hline Ratios de Rentabilidad & Año1 & Año 2 & Año 3 \\
\hline Margen Bruto & 0.85 & 0.92 & 1.09 \\
Margen Operativo & 0.40 & 0.47 & 0.60 \\
Margen Neto & 0.40 & 0.47 & 0.60 \\
Poder Adquisitivo Básico & 0.74 & 0.59 & 0.50 \\
Rentabilidad Patrimonial (ROE) & 0.41 & 0.37 & 0.36 \\
Rentabilidad Activo Total (ROA) & 0.37 & 0.35 & 0.35 \\
\hline
\end{tabular}

Nota. Elaboración propia. 


\section{Conclusiones y Recomendaciones}

\section{Conclusiones}

El sector de energía en el Perú y en los mercados de Chile y el Salvador se encuentra en etapa de crecimiento siendo una oportunidad de crecimiento para Hamek Ingenieros Asociados S.A.C.

La empresa desea continuar formar parte de las empresas líder en los servicios especializados, y para ello es consiente que debe desarrollar un plan estratégico que le permita alcanzar un crecimiento sostenible.

Hamek Ingenieros Asociados S.A.C. presenta como ventaja competitiva la experiencia internacional, desde el 2014 su mercado es también centroamericano y sudamericana. Teniendo en su cartera de clientes a grandes representantes del rubro.

La solidez financiera de la empresa, hasta el momento Hamek Ingenieros y Asociados S.A.C, no requiere apalancamiento financiero y tiene la suficiente generación de caja para cubrir cualquier flujo futuro, aunque insuficiente para hacer adquisiciones grandes, como una nueva oficina.

El bajo nivel de gobierno corporativo que tiene Hamek Ingenieros y Asociados S.A.C., no permitirá una respuesta rápida ante un crecimiento de la demanda.

Hamek Ingenieros Asociados S.A.C., posee una débil organización interna, sin plan de sucesión que asegure la continuidad del negocio.

El plan Estratégico presentado plantea 10 iniciativas enfocadas en aumentar los ingresos, reducir costos y gastos, y fortalecimiento institucional. Las implementaciones de estas iniciativas buscan alcanzar el logro de los objetivos estratégicos de Hamek Ingenieros Asociados S.A.C.

El Perú tiene como objetivo convertirse en el Hub Energético, exportando electricidad a Ecuador, Chile y Bolivia. La interconexión con el Ecuador traerá seguridad hídrica al Perú y precios competitivos por ende mayor crecimiento en el sector, y en consecuencia mayor oportunidad de crecimiento para Hamek Ingenieros Asociados S.A.C.

De acuerdo con la tabla 94, tomando como base los cálculos de flujo de caja con implementación podemos concluir que la aplicación de las estrategias de penetración de mercado genera un VAN financiero de S/82,246.89 es rentable para la empresa. 


\section{Recomendaciones}

Se recomienda fortalecer el equipamiento tecnológico de los equipos, para entrar a competir a nivel internacional.

Expandir su participación en el mercado internacional a través de búsqueda de clientes y con el apoyo de representantes comerciales en los países en donde Hamek Ingenieros Asociados S.A.C. tiene presencia y en donde Hamek Ingenieros Asociados S.A.C. desea ingresar.

Cumplir con el cronograma establecido para la implementación de las iniciativas, a fin de asegurar que se cumplan con los objetivos en el tiempo establecido. Asimismo, realizar un seguimiento y control periódico, para detectar falencias y tomar acciones oportunas para asegurar el cumplimiento del Plan Estratégico 2019-2021 


\section{Referencias}

Aguado, L. \& Marín A. (2014). Formulación Plan Estratégico 2014-2018 de la empresa Potencia y Tecnologías Incorporadas S.A. (Tesis para optar el grado de magister en administración). Universidad de Valle, Santiago de Cali, Colombia. Recuperado de http://bibliotecadigital.univalle.edu.co/bitstream/10893/9714/1/CB-0424434-MAADM.pdf

América economía. (2018). Inversión pública del Perú crece 36\% en mayo, la tercera tasa más alta en cinco años. Recuperado de https://www.americaeconomia.com/economia-mercados/finanzas/inversionpublica-del-peru-crece-363-en-mayo-la-tercera-tasa-mas-alta-en

Andrade, G. (2016) Planificación estratégico para la empresa BDO Ecuador Cía. Ltda, (Tesis de grado para la obtención del título de ingeniería comercial desarrollo de la planificación estratégica para la empresa BDO Ecuador Cía. Ltda.) Universidad Internacional, Ecuador. Recuperado de http://repositorio.uide.edu.ec/bitstream/37000/997/1/T-UIDE-1048.pdf

Apaza, E. (2017). Plan Estratégico de la empresa consultora Jica Ingeniería y construcción S.A.C (Tesis para obtener el título de grado de economista). Universidad Nacional de Altiplano, Lima, Perú. Recuperado de http://repositorio.unap.edu.pe/handle/UNAP/4704

Banco Bilbao Vizcaya [BBVA]. (2018). América Latina, comprometida con las energías renovables. Recuperado de https://www.bbva.com/es/america-latinacomprometida-energias-renovables/

Banco Central de Reserva del Perú [BCRP]. (2017). Evolución Favorable de la Economía Peruana en 2017. Recuperado de http://www.bcrp.gob.pe/docs/Transparencia/Notas-Informativas/2017/notainformativa-2017-12-31.pdf

Banco Central de Reserva del Perú [BCRP]. (2018). Notas de estudios del BCRP. Recuperado de http://www.bcrp.gob.pe/docs/Publicaciones/NotasEstudios/2018/nota-de-estudios-32-2018.pdf

Banco Mundial. (2018). Perú panorama general. Recuperado de http://www.bancomundial.org/es/country/peru/overview

Banco Mundial. (2017). La energía que necesita la América Latina del futuro.

Recuperado de ttps://www.bancomundial.org/es/news/feature/2017/11/23/ energias-renovables-america-latina-futuro

Bernal, C. \& Sierra, H. (2008). Proceso Administrativo para las organizaciones del siglo XXI (13ra.ed). Naucalpan de México, México: Editorial Pearson Prentice. 
Central América (2019). Sistema eléctrico en Centroamérica. Recuperado de ttps://www.centralamericadata.com/es/search?q1=content_es_le:"sistema+eléctric O"

Comité de Operación Económica del Sistema Interconectado Nacional. [COES SINAC] (2018). Recuperado de http://www.coes.org.pe/Portal/

David, F. (2013). Conceptos de Administración Estratégica (14a.ed.). México D.F, México: Pearson Educación.

Diario Correo (2018). ¿Cómo afecta al Perú la guerra de aranceles entre Estados Unidos y China?. Recuperado de https://diariocorreo.pe/economia/como-afecta-al-peru-lapelea-de-aranceles-entre-estados-unidos-y-china-829410/

D’Alessio, F. (2014). El proceso estratégico Un enfoque de gerencia (3da. ed.). Lima., Perú: Editorial Pearson.

Duke Energy. (2016). Duke Energy en Perú: 17 años de historia. Recuperado de http://blog.orazul.pe/duke-energy-en-peru-17-anos-de-historia/

El Comercio (2017). Abugattás: "Hay gente que pone trabas a la transparencia". Recuperado de https://elcomercio.pe/cade/abugattas-hay-gente-pone-trabastransparencia-noticia-478401

El Comercio (2018). ¿Cuáles son los retos de Martin Vizcarra tras la renuncia de PPK?. Recuperado de https://elcomercio.pe/politica/son-retos-martin-vizcarra-renunciappk-noticia-406144

El Comercio (2018). BCR: El precio del dólar en Perú podría estar inflado. Recuperado de https://elcomercio.pe/economia/peru/bcr-cree-precio-dolar-peru-inflado-noticia433174

El Comercio (2018). Guerra comercial de Trump con China ya es una realidad: ¿Afecta al Perú?. Recuperado de https://elcomercio.pe/economia/mundo/guerra-comercialee-uu-china-afecta-peru-noticia-433343

El Nuevo Diario (2017). Centroamérica solo invierte 0,7\% de su PIB en energía. Recuperado de https://www.estrategiaynegocios.net/lasclavesdeldia/1088643330/centroam\%C3\%A9rica-solo-invierte-07-de-su-pib-en-energ\%C3\%ADa

EI Peruano (2017). Interconexión Eléctrica invertirá US\$ 272 millones. Recuperado de https://elperuano.pe/noticia-interconexion-electrica-invertira-272-millones60718.aspx

El Peruano (2018a). Se observará aceleración de la inversión privada en 4.4\%. Recuperado de https://elperuano.pe/noticia-se-observara-aceleracion-deinversion-privada-44-67496.aspx 
El Peruano (2018b). Inversión pública aumentó 13.4\%. Recuperado de https://elperuano.pe/noticia-inversion-publica-aumento-134-64302.aspx

Equilibrium Clasificadora de Riesgo S.A. Analisis del Sector Electrico Peruano. Recuperado de http://www.equilibrium.com.pe/sectorialelectrmar18.pdf.

Escuela de Administración de Negocios para Graduados [ESAN]. (2018). El Perú encaminado hacia el salto tecnológico. Recuperado de https://www.esan.edu.pe/conexion/bloggers/tecnologias-deinformacion/2017/08/el-peru-encaminado-hacia-el-salto-tecnologico/

Expreso (2017). El Sector Electricidad, Gas y Agua y el PBI. Recuperado de https://www.expreso.com.pe/opinion/jorge-f-campodonico/sector-electricidad-gasagua-pbi/

Fitch Raiting (2018, marzo 23). Fitch Ratings ratifica calificación del Perú pese a crisis. El Comercio, Redacción. Recuperado de https://elcomercio.pe/economia/peru/fitchratings-ratifica-calificacion-crediticia-peru-noticia-406112

Flores, V., González, V., \& Lara, E. (2017) plan estratégico de ventas para la empresa IPSOMARY S.A. (Tesis de Ingeniero Comercial). Universidad Laica Vicente Rocafuerte, Guayaquil. Recuperado de http://repositorio.ulvr.edu.ec/bitstream/44000/1747/1/T-ULVR-1463.pdf

Fondo Nacional de Financiamiento de la Actividad Empresarial del Estado [FONAFE]. (2018). FONAFE Empresa. Recuperado de http://www.fonafe.gob.pe/portal?accion $=c \& t=13 \& \mathrm{i}=108 \& \mathrm{n}=2 \& \mathrm{o}=103 \& \mathrm{~m}=2$

Gamio, P. (2017, octubre) Perú: ¿Por qué es necesario desarrollar energías "limpias" frente al cambio climático? Actualidad Ambiental. Recuperado de http://www.actualidadambiental.pe/?p=46918

Osterwalder, A., \& Pigneur, Y. (2014). Generación de modelos de negocio. (14a.ed.). España: Editorial Egedsa

Gestión (2018a). La realidad del empleo en el Perú. Recuperado de https://gestion.pe/blog/economiaparatodos/2018/03/la-realidad-del-empleo-en-elperu.html

Gestión (2018b). BCR mantuvo tasa de referencia en $2.74 \%$ por segundo mes consecutivo. Recuperado de https://gestion.pe/economia/bcr-mantuvo-tasareferencia-2-74-segundo-mes-consecutivo-233398

Gestión (2018c). BCR mantiene su tasa de referencia en 2.74\%. Recuperado de https://gestion.pe/economia/bcr-mantiene-tasa-referencia-2-74-231398 
Gestión (2016). Perú apunta a convertirse en hub energético exportando electricidad a Ecuador y Chile. Recuperado de https://gestion.pe/economia/peru-apuntaconvertirse-hub-energetico-exportando-electricidad-ecuador-chile-144347

Godet M. (2000). La caja de herramientas de la prospectiva Estratégica (4⿳â..edición,). España.

Han, J., Park, H., Ock, J., \& Jang, H. (2014). An international competitiveness evaluation model in the global construction industry. KSCE Journal of Civil Engineering, 19(3), 464-477. doi:http://dx.doi.org/10.1007/s12204-012-0486-z

Honty, G. (2019). Panorama energético latinoamericano de la última década. Recuperado de https://www.alainet.org/es/articulo/201411

Instituto Nacional de Estadística e Informática [INEI]. (2018a). Comportamiento de la economía peruana en el primer trimestre de 2018. Recuperado de https://www.inei.gob.pe/media/principales_indicadores/02-informe-tecnicon02_pbi-trimestral_-itrim2018.PDF

Instituto Nacional de Estadística e Informática [INEI]. (2018b). Situación del mercado laboral en Lima Metropolitana: Trimestre móvil: Marzo-Abril-Mayo 2018. Recuperado de https://www.inei.gob.pe/media/principales_indicadores/06-informetecnico-n06_mercado-laboral-mar-abr-may2018.pdf

Jaramillo, V. (2018). Matriz energética de Centroamérica es cada vez más sostenible. Recuperado de https://www.estrategiaynegocios.net/lasclavesdeldia/1202342330/matriz-energ\%C3\%A9tica-de-centroam\%C3\%A9rica-es-cada-vezm\%C3\%A1s-sostenible

Kahatt, K. \& Azerrad, C. (2012). Evolución del Régimen Legal Ambiental para las actividades eléctricas. Recuperado de http://www.santivanez.com.pe/wpcontent/uploads/2012/07/06legal-ambiental.pdf

Kotler, P. \& Armstrong, G. (2017). Marketing. (16a. ed.). México D.F, México: Editorial Pearson

Marthans, J. (2017, diciembre 16). Crisis Política: ¿Qué impacto tendrá en la economía para el 2018? Diario Gestión, Perspectiva. Recuperado de https://gestion.pe/economia/crisis-politica-impacto-economia-2018-223428

Mendoza, M. \& Vallenas E. (2018). Plan Estratégico de Protección Ambiental S.A.C. EPA S.A.C. (Tesis para optar el grado de maestro en ciencias empresariales). Universidad San Ignacio de Loyola, Lima, Perú. Recuperado de http://repositorio.usil.edu.pe/bitstream/USIL/3011/1/2018_Mendoza_Empresa-deproteccion-ambiental.pdf 
Ministerio del Ambiente [MINAM] (2004). Ley General del Ambiente. Recuperado de http://www.minam.gob.pe/wp-content/uploads/2013/06/ley-general-delambiente.pdf.

Ministerio del Ambiente [MINAM] (2004). Marco legal y normativo. Recuperado de http://www.minam.gob.pe/pagcc/marco-legal-y-normativo/

Ministerio del Ambiente [MINAM] (2016). Ley del Sistema Nacional de Evaluación de Impacto Ambiental (Ley № 27446). Recuperado de http://www.minam.gob.pe/wpcontent/uploads/2017/04/Ley-N\%C2\%B0-27446.pdf

Ministerio del Ambiente [MINAM] (2018). Media Ambiente en la Empresa Recuperado de https://www.greenglobe.es/medio-ambiente-empresa/

Ministerio de Energía y Minas del Perú [MINEM]. (2014). Plan Energético Nacional 2014_2024. Recuperado de https://www.esan.edu.pe/conexion/actualidad/2016/03/30/perspectivas-del-sectorenergetico-peru/

Ministerio de Energía y Minas del Perú [MINEM]. (2016). la Inversión Pública en Electricidad. Dirección General de Electricidad Rural. Recuperado de http://www.osinergmin.gob.pe/seccion/centro_documental/Institucional/EstudiosEc onomicos/Libros/Osinergmin-Industria-Electricidad-Peru-24anios.pdf

Ministerio de Energía y Minas del Perú [MINEM]. (2016). Plan Estratégico Sectorial Multianual (PESEM) 2016 - 2021. Recuperado de http://www.ipen.gob.pe/transparencia/transp_doc/plan_org/planes_politicas/PESE M_2016_2021.pdf

Ministerio de Energía y Minas del Perú [MINEM]. (2018). Manual de Legislación. Recuperado de http://legislacionambientalspda.org.pe/index.php?option=com_content\&view=articl e\&id $=464 \&$ ltemid $=3480$

Ministerio de Energía y Minas del Perú [MINEM]. (2018b). Manual de Legislación. Recuperado de https://www.greenglobe.es/medio-ambiente-empresa/

Moll, E. (2017) Diseño de un Sistema de Control de Gestión para una empresa de Generación de Energía Eléctrica de Fuentes Renovables. (Tesis para obtener al grado de magister en control de gestión) Universidad de Chile. Recuperado de http://repositorio.uchile.cl/handle/2240/144379

Mongilardi (2017, septiembre 14). CCL: Tensión política afecta la inversión privada y empleo. El Comercio, Redacción. Recuperado de https://elcomercio.pe/economia/peru/ccl-tension-politica-afecta-inversion-privadageneracion-noticia-448112 
Nytimes (2019). La solución energética que América Latina necesita. Recuperado de https://revistaenergia.pe/la-solucion-energetica-que-america-latina-necesita/

Organismo Supervisor de la Inversión en Energía y Minería [OSINERGMIN]. (2016). La industria de la electricidad en el Perú: 24 años de aportes al crecimiento económico del país. Recuperado de http://www.osinergmin.gob.pe/seccion/centro_documental/Institucional/EstudiosEc onomicos/Libros/Osinergmin-Industria-Electricidad-Peru-24anios.pdf

Organismo Supervisor de la Inversión en Energía y Minería [OSINERGMIN]. (2018). Revisión del marco regulatorio del sector eléctrico. Recuperado de http://www.osinergmin.gob.pe/seccion/institucional/regulacion-tarifaria/procesosregulatorios/electricidad

Ortiz, M., Paredes, J., Romero, G., \& Sánchez, M. (2014) Plan estratégico del sector eléctrico (Tesis para obtener el grado de magíster en administración estratégica de empresas). Universidad Pontificia Católica del Perú, Lima, Perú. Recuperado de

http://dalessio.pearsonperu.pe/el_proceso_estrategico_3/recursos/7_sector_elec trico_de_peru.pdf

Perafan, J. (2013) Plan de empresa Ambientic S.A.S. Empresa de Consultoría Ambiental. Universidad Autónoma de Occidente, Santiago, Cali. Recuperado de https://red.uao.edu.co/bitstream/10614/4131/1/TCS01413.pdf

Perú 21 (2018) Inversión privada crecerá 4.4\% durante el 2018 y 7.4\% en 2019.

Recuperado de https://peru21.pe/economia/bcrp-inversion-privada-crecera-4-42018-7-4-2019-410402?foto=3Pontificia Universidad Católica del Perú (2018). Perú económico en el 2018.analisis de la economía. Recuperado de http://blog.pucp.edu.pe/blog/competenciayconsumidor/2018/01/

Porter, M. (2017) Ser Competitivo. $9^{\circ}$ Edición. Harvard Business Press. Editorial Deusto S.A. Ediciones.

Pontificia Universidad Católica del Perú [PUCP]. (2017). Perú económico en el 2017. Análisis de la economía peruana. Recuperado de http://blog.pucp.edu.pe/blog/competenciayconsumidor/2017/12/

Quintanilla, E. (2016) Crecimiento económico y expansión energética en Perú. Recuperado de https://www.esan.edu.pe/conexion/actualidad/2016/10/08/crecimiento-economicoy-expansion-energetica-en-peru/ 
Quintanilla, E. (2018) El futuro del sector energético peruano. Recuperado de https://www.esan.edu.pe/conexion/actualidad/2018/03/13/el-futuro-del-sectorenergetico-peruano/

Ríos, A. (2016). Perspectivas del sector energético en el Perú. Recuperado de https://www.esan.edu.pe/conexion/actualidad/2016/03/30/perspectivas-del-sectorenergetico-peru/

Rumelt, R. (1980). The evaluation of business strategy. New York, USA: Editorial McGraw-Hill

Santivañez, R. \& Sumar, P. (2012). Cuarenta años de evolución del marco legal peruano de la transmisión eléctrica. Recuperado de http://www.santivanez.com.pe/wpcontent/uploads/2012/07/04transmicion-electrica.pdfSociedad Nacional de Minería, Petróleo y Energía [SNMPE]. (2008, octubre). Informe Quincenal Octubre III.

Sistema de Integración Centroamérica [SICA]. (2017). Centroamérica puede duplicar energía limpia. Recuperado de https://www.sica.int/busqueda/Noticias.aspx? IDItem=109333\&IDCat=3\&IdEnt =1224\&Idm=1\&IdmStyle $=1$

Singh, Nanda (2018). Nuevas medidas del gobierno peruano promueven inversiones en el sector energético-minero: se definirán políticas que impulsan a las renovables. Recuperado de http://www.energiaestrategica.com/nuevas-medidas-de-gobiernoperuano-promueven-inversiones-en-el-sector-energetico-minero-y-definenpoliticas-que-impulsa-a-las-renovables/

Sotomayor, T., Maticorena, Ch., Moses I., \& Valdivieso, M. (201) Plan estratégico para la empresa Constructora San Jorge E.I.R.L. (Tesis para obtener el Grado de Magíster en Administración de Empresas). Pontificia Universidad Católica del Perú, Lima, Perú. Recuperado de http://tesis.pucp.edu.pe/repositorio/handle/123446789/8842

Tamayo, J., Salvador, J., Vásquez, A., \& Vilches, C. (2016). La industria de la Osinergmin. Lima World Economic Forum (2016, marzo 10). ¿Cómo la revolución digital transformará el sector energía? Diario Gestión. Redacción Gestión.

Recuperado de https://gestion.pe/economia/revolucion-digital-transformara-sectorenergia-113863

Viscidi, L. \& Yépez, A. (2018). La solución energética que América Latina necesita. Recuperado de https://www.nytimes.com/es/2018/02/02/opinion-energiasrenovables-america-latina/. 


\section{Apéndice $\mathrm{N}^{\circ} 1$}

\section{Entrevista en Profundidad a Gerente General de Hamek Ingenieros y Asociados}

S.A.C.

\section{FICHA TÉCNICA}

Técnica:

Entrevista en Profundidad

Instrumento:

Guía de entrevista

Muestra:

Objetivos:

Recopilar información de la empresa Hamek

Ingenieros Asociados S.A.C, para conocer su

trayectoria, fortalezas, debilidades, oportunidades y amenazas, sus tendencias, éxitos, sus retos, y quiénes son su competencia.

Entrevistador:

Melissa Burga Ruiz

Lugar:

La Molina

Fecha y hora:

16 Mayo 2018, 7pm

Duración:

1hora y 4 minutos

\section{FICHA DEL ENTREVISTADO}

Nombre:

Amadeo Carrillo Villena

Edad:

64

Nacionalidad: Peruano

Ocupación: Empresario

Profesión: Ing. Mecánico

Reseña Ingeniero mecánico colegiado, con estudios de post grado en

profesional/empresarial energía y medio ambiente en Alemania, Suecia y

del entrevistado: $\quad$ España, Maestría en Energética y Maestría en Proyectos de Inversión. Ha trabajado para el Ministerio de Energía y

Minas, Electroperú S.A., CENERGIA, PNUD, Comunidad 


\section{Europea y diversas empresas consultoras nacionales e internacionales; actualmente Gerente General de Hamek Ingenieros Asociados S.A.C.}

\section{FASE DE PRESENTACIÒN}

Buenas noches, soy estudiante de la MBA de la Escuela de Postgrado de la Universidad San Ignacio de Loyola. Como parte del desarrollo del Plan Estratégico de su empresa Hamek Ingenieros Asociados S.A.C., que nos ayudará a conocerla a profundidad, nos vemos con la necesidad de realizarle una entrevista, cabe señalar que toda la información recopilada será publicada para fines académicos.

Nos permitiría filmar o grabar, para agilizar la toma de información, y no perder detalles y para poder presentarlo en nuestro curso. ¿Tendría algún inconveniente de que la entrevista sea grabada o filmada?

\section{GUÍA DE ENTREVISTA}

Pregunta 1: ¿Quién fue el fundador de la empresa Hamek Ingenieros Asociados

$$
\text { S.A.C? }
$$

Respuesta: Buenas noches, yo soy el fundador de la empresa Hamek Ingenieros Asociados S.A.C.

Pregunta 2: ¿Nos podría comentar la historia de la empresa?

Respuesta: En abril del 2010, se constituye la empresa Hamek Ingenieros Asociados S.A.C., una empresa familiar, empezamos con dos personas, pero, yo ya había estado trabajando en este sector de energía, en la empresa Cenergia, donde obtuve mucha experiencia y conociendo el mercado, decidí formar mi empresa.

Pregunta 3: ¿ ¿Cuál fue el primer servicio que se ofreció en su empresa?

Respuesta: El primer servicio de energía, fue pruebas operativas de potencia efectiva.

Pregunta 4: ¿ ¿Cómo ve a la empresa dentro de 4 años?

Respuesta: $\quad$ En 4 años veo a Hamek Ingenieros Asociados S.A.C., 
intercionalizandose, posicionado en el mercado, siendo reconocida y con prestigio.

Pregunta 4: ¿Cuál son las principales debilidades de su empresa?

Respuesta: La principal debilidad es la falta de gobierno corporativo, es una empresa familiar, que no les permita soportar un crecimiento ordenado, puede afectar la sostenibilidad de la empresa, en la actualidad cuenta con una estructura gerencial reducida donde las funciones de administración, logística y personal se encuentran concentradas en la Gerencia de Administración, diferenciada de la Gerencia Técnica, cuya estructura está conformada por dos Jefaturas Técnicas de las líneas energéticas y medio ambiente que le reportan directamente al Gerente General.

La empresa no invierte mucho en publicidad, a pesar que existe un potencial de negocios y donde aún no se tiene mayor presencia, a pesar que la empresa participa en eventos del sector.

Tenemos una falta de modernización de los equipos tecnológicos, lo que nos lleva a una disminución de la gestión y productividad.

Falta de inversión en equipamiento tecnológico o en certificaciones que aumenten su prestigio y faciliten el ingreso en mercados regionales Existe una falta de política de retención, con el personal que labora, por lo que puede suceder como paso conmigo, que aprenden como es el negocio y se pueden volverse parte de la competencia.

Pregunta 6: ¿Cuál son las principales fortalezas de su empresa?

Respuesta: $\quad$ Sin Duda la principal fortaleza que tiene Hamek Ingenieros Asociados S.A.C., es su gran trayectoria en el sector lo que permite contar con una reputación elevada para enfrentar nuevos desafíos en el mercado local y regional.

Contamos con una experiencia Internacional en países como El Salvador y Chile lo que les permite incrementar su competitividad y su margen de rentabilidad. 
Tiene la empresa una solidez financiera, hasta el momento, no hemos requerido apalancamiento financiero y tiene la suficiente generación de caja para cubrir cualquier flujo futuro, aunque insuficiente para hacer adquisiciones de equipos de última generación.

La empresa cuenta con personal altamente calificado, y a la vez existe un sentido de pertenencia e identificación de los colaboradores con la empresa, porque se siente parte de ella.

Pregunta 7: ¿Cuándo y porqué se concibió la idea de constituir la empresa Hamek Ingenieros Asociados S.A.C.?

Respuesta: La idea surgió hace diez años, porque vi una oportunidad de negocio en el mercado poco abastecido, con alto crecimiento y porque contaba con el conocimiento y experiencia sobre el sector. Asimismo pretendía independizarme.

Pregunta 8: ¿En qué ciclo de vida se encuentra la empresa y cada uno de los servicios que ofrece?

Respuesta: La empresa se encuentra en crecimiento, tiene la rentabilidad necesaria para continuar avanzando y expandirse en el mercado internacional, la que se ve expresado en las ventas de los últimos nueve años.

En los servicios que se ofrecen en el área energética son más rentables, que los servicios que ofrece en el área del medio ambiente.

Los servicios de energía se encuentran en la etapa de crecimiento, siendo sus ventas una muestra representativa y por su incremento de utilidades.

Los clientes están fidelizados y se están abriendo nuevos mercados

El ciclo de vida del servicio que se ofrece en el área del medio ambiente, se encuentra en la etapa de madurez de su ciclo de vida, tiene como alta competencia con las empresas del sector, donde se característica la estabilización de las ventas.

Pregunta 9: $\quad$ El organigrama de su organización es conocido por todo el personal ¿Cómo se comunica? 
Respuesta: $\quad$ Si es conocido por todo el personal de la organización, personal que inicia a laborar con nosotros, se les entrega el reglamento interno, además se le brinda los alcances de la misión, visión, política y valores de la empresa. Tienen una inducción y se le capacita al personal, con el uso de los equipos.

Pregunta 10: ¿Cuáles son sus fuentes de búsqueda de los mejores talentos profesionales?

Respuesta: La fuente de búsqueda para los profesionales es a través de las redes sociales, por medio del linkedln; bolsas de empleo como laborum, computrabajo entre otros, también en las bolsas de trabajo de las mismas universidades.

Nuestros empleados son ingenieros eléctricos, electrónicos y ambientales, de las universidades prestigiosa como la Universidad Nacional de Ingeniería y la universidad Nacional Mayor de San Marcos.

Pregunta 11: ¿Cuál considera usted que es la misión de la empresa?

Respuesta: En el 2012, reformulamos nuestra misión, la cual es superar las expectativas de nuestros clientes en todos los servicios de consultora que brindamos en los temas de energía y medio ambiente, aplicando una ingeniería y tecnología de punta, conservando en nuestro personal una mística de innovación, superación continua y compromiso con el desarrollo sustentable de nuestro país.

Pregunta 12: ¿Cuál considera usted que es la visión de la empresa?

Respuesta: La visión actual de Hamek Ingenieros Asociados S.A.C., declarada desde el 2014 es alcanzar el liderazgo en la consultora nacional en los temas de energía y medio ambiente con presencia destacada en el ámbito internacional.

Pregunta 13: ¿Cuáles considera que son los principales valores de su empresa?

Respuesta: Actualmente, los valores que se promueven dentro de Hamek Ingenieros Asociados S.A.C. son:

Espíritu de servicio, responsabilidad, honestidad y trabajo en equipo. 
Pregunta 14: ¿Su equipo está comprometido con la misión, visión y valores de la empresa?

Respuesta: Los empleados de mi empresa si se encuentran comprometidos con la misión, valores y visión., ellos se encuentra identificados con la empresa.

Pregunta 14: ¿Existe un fomento de inversión privada por parte del Estado? ¿En qué sector existe mayor inversión de los dos sectores que ofrece su servicio Hamek Ingenieros Asociados S.A.C.?

Respuesta: El Estado promueve a inversión privada desde los años 90, la mayor inversión existe en el sector de energético y constituye una gran oportunidad para Hamek Ingenieros y Asociados S.A.C, para desarrollarse en el mercado local con sus servicios de asesoría, teniendo en cuenta el crecimiento del sector energético a nivel local, con el desarrollo de nuevos proyectos en las regiones del Sur, como Tacna, Arequipa y Cuzco, donde opera la mayoría de las empresas mineras, en vista que existe un gran consumo de energía en mineras .

Pregunta 16: ¿La calificación de riesgo país +BBB en el 2018 beneficia a la inversión?

Respuesta: La calificación del riesgo +BBB, si beneficia la inversión, porque en el extranjero ve a un país con la capacidad de cumplir con sus obligaciones financieras, y de acuerdo a ello obtiene una calificación crediticia internacional.

Pregunta 17: ¿Cómo es el marco normativo y regulatorio para sus servicios que ofrece su empresa?

Respuesta: El marco normativo y regulatorio es estable, transparente y adecuado, que es administrado por el Organismo Supervisor de la Inversión en Energía y Minería (OSINERGMIN), como organismo regulador independiente y autónomo del mercado eléctrico.

Pregunta 18: ¿La conservación del medio ambiente es una oportunidad o amenaza en los servicios que ofrece?

Respuesta: La conservación del medio ambiente es una oportunidad, para el servicio que ofrecemos, porque existen empresas que les obligan tener 
permisos, programas, procedimientos y estudios que deben ser desarrollados por profesionales del sector, es ahí que nuestra empresa es más demandada.

El Estado está empleando nuevas reglas y avances en el sector ambiental, desarrollando capacidades que promuevan, de manera efectiva, la conservación de recursos naturales y ambientales, esto nos favorece por los servicios que brindamos.

Pregunta 19: ¿Cuánto afecta la inestabilidad política a los proyectos de inversión?

Respuesta: Definitivamente afecta las decisiones que inversionistas puedan tomar para venir a invertir a nuestro país. La inversión privada repuntó en el 2018, sin embargo, las tensiones entre el Gobierno y el Congreso han vuelto a ser un factor de preocupación.

Pregunta 20: ¿En el sector de energía y medio ambiente la interferencia política es una amenaza?

Respuesta: Existen varios proyectos en el sector de energía y medio ambiente, por lo cual la interferencia política es una amenaza para ambos sectores, porque ante un riesgo político, pueden afectar la inversión extranjera y con ello rentabilidad del negocio.

Pregunta 21: ¿Las limitaciones de financiamiento por parte del FONAFE, afecta al sector eléctrico?

Respuesta: FONAFE dirige y aprueba el presupuesto de 12 empresas del sector de energía, por lo tanto, las decisiones políticas pueden llevar a limitaciones de financiamiento de proyectos.

Pregunta 22: ¿Sus servicios son estandarizados?

Respuesta: $\quad$ El sector es muy estandarizado. Los servicios tienen una leve diferenciación basado en los plazos y del uso de equipos con más tecnología y precisión.

Pregunta 23: ¿Considera que Hamek Ingenieros Asociados S.A.C tiene reconocimiento en el sector? ¿Por qué? 
Respuesta: $\quad$ Si considero que Hamek Ingenieros Asociados S.A.C, tiene reconocimiento en el sector, porque nuestros clientes nos avalan, con demandar nuestros servicios por varias veces consecutivas.

Pregunta 24: ¿Quiénes considera que son los líderes del mercado en consultoría en el sector energético orientado al cuidado del medio ambiente? Por qué?

Respuesta: Actualmente son pocas las empresas constituidas como consultoras calificadas por el COES, todas ellas son bastante similares en tamaño, productos y precios. Es por ello que Hamek Ingenieros Asociados S.A.C., es uno de los principales líderes a nivel nacional, su reputación en ampliamente conocida y valorada por los clientes.

La empresa CENERGIA cuenta con más trayectoria en el mercado y ha tecnificado más sus equipos para brindar sus servicios, respecto a lo precios ofertados son similares y regulados además están asociados a un nivel de servicio similar de allí que no hay diferenciación.

Respecto al mercado regional, tanto Cenergia como Hamek Ingenieros Asociados S.A.C., prestan servicios en varios países de la región, en el caso de Hamek Ingenieros Asociados S.A.C., presta servicios en El Salvador desde el 2014 y Chile desde el 2016 lo que finalmente le ha permitido incrementar sus ingresos totales del 2014 al 2018 en más de un $140 \%$.

Pregunta 24: ¿Qué hace diferente a Hamek Ingenieros Asociados S.A.C. de las demás empresas que brindan los mismos servicios?

Respuesta: El sector es muy estandarizado, los servicios que ofrece Hamek Ingenieros Asociados S.A.C., tienen una leve diferenciación basado en los plazos y del uso de equipos con más Tecnología y precisión. Lo que destacamos es nuestra calidad de servicio para la satisfacción de nuestros clientes. 


\section{Apéndice $\mathrm{N}^{\circ} 2$}

Entrevista en Profundidad a Gerente Administrativo de Hamek Ingenieros y

Asociados S.A.C.

\section{FICHA TÉCNICA}

Técnica:

Entrevista en Profundidad

Instrumento:

Guía de entrevista

Muestra:

Objetivos:

Conocer el funcionamiento de la empresa, su parte administrativa, a sus colaboradores, sus clientes y competidores, proveedores, sustitutos oportunidades y amenazas.

Entrevistador:

Melissa Burga Ruiz

Lugar:

La Molina

Fecha y hora:

14 de Junio de 2018, 8: 00 pm

Duración:

44 minutos

\section{FICHA DEL ENTREVISTADO}

Nombre:

Erika Carrillo Zelaya

Edad:

37

Nacionalidad: Peruano

Ocupación: Empresario

Profesión: Ing. Civil

Reseña Ingeniero Civil colegiado con 7 años de experiencia

profesional/empresarial profesional, con estudios de Maestría en Ingeniería Civil con del entrevistado: $\quad$ mención en Ingeniería Vial, con Diplomados en Gestión Vial y Administración de Empresas. Se ha desarrollado en proyectos viales, participando en estudios, supervisión de obras y mantenimiento vial, desenvolviéndome en diferente 
áreas en coordinación de proyectos, programación y control de proyectos, licitaciones, responsable del File de Calidad.

\section{FASE DE PRESENTACIONN}

Buenas noches, soy estudiante de la MBA de la Escuela de Postgrado de la Universidad San Ignacio de Loyola. Como parte del desarrollo del Plan Estratégico de su empresa Hamek Ingenieros Asociados S.A.C., que nos ayudará a conocerla a profundidad, nos vemos con la necesidad de realizarle una entrevista, cabe señalar que toda la información recopilada será publicada para fines académicos.

Nos permitiría filmar o grabar, para agilizar la toma de información, y no perder detalles y para poder presentarlo en nuestro curso. ¿Tendría algún inconveniente de que la entrevista sea grabada o filmada?

\section{GUÍA DE ENTREVISTA}

Pregunta 1: ¿ ¿Cuáles son tus fuentes de búsqueda de los mejores talentos profesionales?

Respuesta: Buenas noches, yo como gerente administrativo, me encargo de convocar a los nuevos talentos y entrevistarlos.

La fuente de búsqueda es a través del linkedln; bolsas de empleo como laborum, computrabajo entre otros, también se solicita en la bolsa de trabajo de dos prestigiosas universidades nacionales, de preferencia de las universidades Nacional de Ingeniería y la Universidad Mayor de San Marcos.

Los talentos que se solicitan deben tener quinto superior como requisito.

Pregunta 2: ¿Considera que las capacitaciones para el personal son importantes? ¿Por qué?

Respuesta: $\quad$ Por supuesto, la capacitación es algo realmente importante, porque permite mejorar los conocimientos, habilidades o conductas y actitudes del personal de una empresa.

Beneficia para obtener mejores resultados y mayores beneficios económicos. Capacitar al personal, también otorga una mejor imagen 
empresarial. Si contamos con un personal más preparado y competente, estaremos dando una imagen de empresa seria.

Pregunta 3: ¿Cómo has diseñado el proceso de acogida e integración de los nuevos miembros de su equipo?

Respuesta: $\quad$ El proceso de acogida se le da la bienvenida, se le hace entrega del reglamento interno, se le da información sobre la cultura organizacional, de la misión, visión, política y valores de la empresa.

Dándole la mayor información posible, es capacitado por uno de los empleados que laboran con nosotros.

Pregunta 4: ¿QQué cualidades del candidato considera en las entrevistas?

Respuesta: $\quad$ Entre las cualidades que se consideran en las entrevistas son:

- Capacidad para trabajar en equipo.

- Compromiso e implicación.

- Responsabilidad.

- Proactividad.

- Capacidad para tomar decisiones y resolver problemas.

- Capacidad para planificar, organizar y priorizar el trabajo.

- Actitud positiva.

- Capacidad de comunicación.

Pregunta 4: ¿Disponen de materiales de formación? ¿Cuáles? ¿Pueden utilizarlos?

Respuesta: $\quad$ No disponemos de materiales de formación, los nuevos ingresante a la empresa llevan capacitación.

Pregunta 6: ¿Cómo perciben la rotación del personal dentro de la empresa: alta, moderada, baja?

Respuesta: La empresa está conformada por 10 empleados, la rotación del personal es moderada, hay empleados que laboran con nosotros años.

Pregunta 7: $\quad$ A nivel de organización ¿Cuál crees que serían sus oportunidades y amenazas?

Respuesta: Las oportunidades son: hoy en día existe una orientación al cuidado del medio ambiente y ecosistema. La conservación del medio ambiente 
exige mayor necesidad de consultorías ambientales en todos los sectores productivos y de servicios.

El sector de energía ha crecido y el uso de Tecnología que permite la innovación constante en equipos de mayor precisión y conectividad. Aprovechar las nuevas tecnologías en referencia a los equipos de medición de equipos y el uso de software especializados que permiten una diferenciación ante la competencia

Marco Normativo y regulatorio estable y claro, por años no hay cambio Acuerdo energético de Perú con Brasil que permita abastecer de energía desde Perú y que apertura un mercado de integración

Amenazas: Existe inestabilidad Socio Cultural en forma de rechazo a la inversión pública y privada por parte de la población.

Oposición de las comunidades a los proyectos de generación hidráulica Conflictos culturales, sociales y medioambientales

Pregunta 8: ¿Se recibe beneficios adicionales de la empresa?

Respuesta: La empresa no reparte utilidades entre sus empleados, su único beneficio es de acuerdo a la ley.

Se programa en el transcurso del año salidas de camaradería, full day deportivo, actividad que ayudará a reforzar en vínculo de confianza entre todos los colaboradores de Hamek Ingenieros y Asociados S.A.C., con ello se busca fortalecer la amistad y la unión de todos los integrantes de la organización.

Pregunta 9: ¿Se ha definido e implantado un organigrama funcional en la empresa con sus funciones y responsabilidades?

Respuesta: $\quad \mathrm{Si}$, existe un organigrama funcional en la empresa con sus funciones y responsabilidades.

Pregunta 10: ¿Cuál es su factor diferenciador respecto a la competencia?

Respuesta: Su factor diferenciador respecto a la competencia, es la calidad de sus servicios, por su seguridad, credibilidad y responsabilidad. El cliente valora nuestro servicio, que vuelven a contratarnos, por la buena experiencia que han tenido. 
Pregunta 11: ¿Considera importante como factor clave de éxito, los plazos de atención en las empresas en el rubro de consultora dentro del sector? Por qué?

Respuesta: En los servicios que ofrecemos, los plazos de atención son muy importantes, porque aumenta la capacidad productiva, es necesario aumentar la efectividad de los procesos, para obtener la satisfacción de los clientes.

Pregunta 12: ¿Cómo se selecciona a los proveedores?

Respuesta: A los proveedores se selecciona, por su buena reputación, credibilidad, y rapidez en la entrega, es muy importante el tiempo pueden tardar desde que reciben una orden hasta que realizan la entrega del producto termina do.

Pregunta 13: ¿Cuáles son sus principales proveedores? ¿Existen muchos o pocos proveedores en su sector?

Respuesta: Los proveedores que tenemos, son empresas representantes de los equipos de medición energética y ambiental, en su gran mayoría son equipos importados.

Entre los principales proveedores son: Druck, Proviento Peru.

Existen pocos proveedores y por ser muy especializadas son pocas empresas que cuentan con estos equipos.

Pregunta 14: ¿Quiénes son sus clientes? ¿Cuántos? ¿Su poder de negociación es fuerte?

Respuesta: Hamek Ingenieros Asociados S.A.C., cuenta con clientes importantes del sector, son muchos, su poder de negociación es fuerte porque tenemos clientes locales e internacionales. Por temas de competencia no puedo dar nombres de nuestros clientes.

Pregunta 14: ¿Quiénes son sus productos sustitutos de Hamek Ingenieros Asociados S.A.C.? ¿Qué tan atractivo es en su sector?

Respuesta: Para la empresa es atractivo, porque en el sector no hay productos Sustitutos, los servicios que hacemos no tienen reemplazo por otros. Esta regidas y se respetan los procedimientos dictada por el COES. 
Pregunta 16: ¿Cuáles son o podrían ser sus competidores potenciales? ¿El ingreso es fácil o existe una barrera de entrada?

El competidor potencial es CENERGIA en el Perú, tiene mayor trayectoria en el mercado, ha tecnificado más sus equipos para brindar sus servicios, respecto a lo precios ofertados son similares y regulados además están asociados a un nivel de servicio similar de allí que no hay diferenciación.

Existen pocos competidores en el Perú, en El Salvador tiene diez competidores y en Chile existen ocho competidores.

Las barreras de ingreso son altas, el servicio es altamente calificada y estandarizada, lo cual resulta atractivo para Hamek Ingenieros y Asociados S.A.C.

Pregunta 17: ¿Qué tan involucrados están sus colaboradores?

Respuesta: El personal se encuentra involucrado y se siente parte de la familia Hamek Ingenieros y Asociados S.A.C, existe un elevado grado de compromiso e identificación con la empresa que crea un ambiente adecuado para el cambio, la innovación y la orientación hacia un modelo moderno de organización.

Pregunta 18: ¿Cómo describes el proceso que sigues para realizar promociones y despidos?

Respuesta: El proceso de promoción es por una estimación cuantitativa y cualitativa del grado de eficacia del personal, nos basamos en meritos y no favoritismo.

Generalmente no hay despidos sino finalización de contrato, a fin de evitar mayores consecuencias en los casos de despidos injustificados que pueden ser muy oneroso en para la compañía.

Pregunta 19: ¿Existen nuevas tecnologías o cambios en el marco regulatorio que su empresa puede aprovechar?

Respuesta: Existen nuevas tecnología en los equipos de medición, la existencia de un marco regulatorio que se mantiene en el tiempo y la tendencia al cuidado del medio ambiente lo que genera enormes oportunidades de brindar los servicios de asesoría en el sector energético y estudios 
técnicos referidos al uso eficiente de la energía y el cuidado del medio ambiente.

Pregunta 20: ¿Cómo califica la calidad de servicio de Hamek Ingenieros Asociados S.A.C, respecto a las empresas de la competencia?

Respuesta: La empresa Hamek Ingenieros Asociados S.A.C. en su calidad de servicios está mejor valorada en comparación de sus competidores directos, pero se percibe una desventaja en tecnología con la empresa CENERGIA, debido a que este, al ser una ONG, tiene beneficios de obtener mejores productos del extranjero con tecnología de punta; se observa una desventaja menor con la competencia en infraestructura por su espacio de sus instalaciones y en marketing en su imagen corporativa. 


\section{Apéndice $\mathrm{N}^{\circ} 3$}

\section{Entrevista en Profundidad a Experto del Sector Ambiental}

\section{FICHA TÉCNICA}

Técnica:

Instrumento:

Muestra:

Objetivos:

Entrevistador:

Lugar:

Fecha y hora:

Duración:

\section{Entrevista en Profundidad}

Guía de entrevista

Conocer las perspectivas de crecimiento del sector ambiental.

Erika Carrillo Zelaya

La Molina

17.06.2019

$38 \mathrm{~min}$

\section{FICHA DEL ENTREVISTADO}

Nombre: José Roncallo Miraval

Edad: $\quad 48$

Nacionalidad: Peruano

Ocupación: Ingeniero

Profesión: Ing. Geógrafo

Reseña

profesional/empresarial del entrevistado:

Especialista en Medio Ambiente y Recursos Naturales, con Maestría en Gestión Ambiental, con diecinueve (19) años de ejercicio profesional y experiencia en elaboración de EIA's, monitoreos ambientales, auditorías ambientales, planes de cierre y diversos servicios ambientales en proyectos energéticos, mineros, industriales; se encargará de la elaboración de la Línea Base Ambiental, la identificación y evaluación de los impactos ambientales, así como la 
elaboración del Plan de Manejo Socio Ambiental, tomando en cuenta las conclusiones obtenidas por los consultores de sus respectivas evaluaciones.

\section{FASE DE PRESENTACIÒN}

Buenas noches, soy estudiante de la MBA de la Escuela de Postgrado de la Universidad San Ignacio de Loyola. Como parte del desarrollo del Plan Estratégico de la empresa Hamek Ingenieros Asociados S.A.C., nos vemos con la necesidad de realizarle una entrevista, cabe señalar que toda la información recopilada será publicada para fines académicos.

Nos permitiría filmar o grabar, para agilizar la toma de información, y no perder detalles y para poder presentarlo en nuestro curso. ¿Tendría algún inconveniente de que la entrevista sea grabada o filmada?

\section{GUÍA DE ENTREVISTA}

\section{Pregunta 1: $\quad$ Existe una conciencia ambiental en el Perú}

Respuesta: En términos generales, se podría sostener que no existe en el país una opinión pública conductualmente comprometida con las causas ambientales. Sin embargo, se percibe que, en la última década, en el Perú se han difundido ideas, sucesos, normas, iniciativas empresariales y políticas gubernamentales alrededor del objeto ambiente. Los diversos actores han internalizado en sus discursos, y algunos en sus prácticas, las consideraciones ambientales. Aunque si se podría decir, existe un mayor conocimiento y una aparente buena disposición hacia lo que significa un mayor cuidado de nuestros paisajes, recursos naturales y ecosistemas.

Pregunta 2: ¿Cómo ha ido evolucionando los estudios de gestión ambiental en el Perú?

Respuesta: El Perú ha venido completando el conjunto de instrumentos de gestión ambiental necesarios para alcanzar los objetivos de política ambiental en el marco del Sistema Nacional de Gestión Ambiental, para ello se ha desarrollado varios programas nacionales en las áreas de biodiversidad, biocomercio, bioseguridad, cambio climático, calidad 
ambiental del ruido, biocumbustibe, etc, por otro lado, busca la prevención y producción limpia, para ella nace el ordenamiento ambiental del territorio (ZEE), El sistema de evaluación de impacto ambiental (SEIA), estandares de calidad ambiental y límites máximos permisibles (ECAs), límites máximos permisibles (LMP) aprobados para los sectores en minería y energía. Todos estos cambios han generado que todos los sectores se alienen a una misma exigencia de mejora sostenible ambiental.

Pregunta 3: De acuerdo a su experiencia en sector de Medio ambiental ¿Cómo describe la tendencia de este sector?

Respuesta: Las tendencias ambientales vienen tomando cuerpo en la gestión empresarial, observándose un esfuerzo sistemático para establecer políticas, procesos y presupuestos". Todo esto con el objetivo de integrarse al gran esfuerzo global hacia la conservación y aseguramiento futuro del medio ambiente.

"Las tendencias influyen en la gestión empresarial al demandar la incorporación de un operador ambiental que lidere el plan de trabajo que corresponda", señala el experto. "Esto requiere de presupuesto y formas adicionales para formular, evaluar y ver resultados económicos y financieros de actividades específicas". Estas últimas están relacionadas de manera directa con la gestión ambiental.

Por ello es importante contar con un sistema de gestión en la organización que vele por los riesgos, impactos, tratamientos, recomendaciones y otros relacionados al medio ambiente. Para esto hay que considerar una serie de normas, tratados, requisitos e inversión. Las funciones empresariales deben valerse de los principios y políticas que tenga la compañía en cuanto a la sostenibilidad.

Pregunta 4: $\quad$ Como se encuentra el sector ambiental del Perú, respecto a los países de la región.

Respuesta: $\quad$ Si bien en los últimos años el Perú ha mostrado un desarrollo, pues las exigencias a todos los sectores han crecido y se ha creado nuevos instrumentos de gestión ambiental, aún está muy lejos de igual por 
ejemplo al resto de países de la región. Por ejemplo, la ley del plástico en el Perú establece la reducción progresiva en producción local, importación, distribución y entrega de envases de bolsas de plástico de un solo uso, sorbetes, bolsas que no sean reutilizables y envases de Tecnopor. Además del impuesto, la ley establece medidas sobre estos materiales y botellas de plástico PET. A diferencia de la regulación de Chile, primer país que prohíbe las bolsas de plástico, el Perú incluye en su legislación la reducción de materiales contaminantes como el Tecnopor y las cañitas.

Pregunta 4: ¿ ¿Cuál cree usted que son las principales regulaciones que el estado ha establecido para el desarrollo del sector?

Respuesta Las principales regulaciones son: La ley general del ambiente, Código Penal D.L N 634 y Ley de Áreas Naturales Protegidas, Ley № 26834.

Pregunta 6: ¿En qué medida estas regulaciones obstaculizan el desarrollo de nuevos proyectos de ingeniería, proyectos mineros e industriales?

Respuesta: Obstaculizan mientras que las aprobaciones y la emisión de las resoluciones correspondientes se tomen mayor tiempo de lo establecido.

Pregunta 7: Que piensa sobre como maneja el estado sobre la difusión y la política ambiental, en el país.

Respuesta: La difusión que tienen el estado hacia el cuidado ambiental, se realiza a través de los ministerios y entidades ambientales con trípticos y folletos de cuidado ambiental e información de las actualizaciones de la normativa ambiental, sin embargo estas solo se pueden encontrar dentro de los locales, no existe una difusión radial ni en los canales locales.

Pregunta 8: ¿Por qué es importante contar con una política ambiental?

Respuesta: Tener una política ambiental es importante para conservar base de la naturaleza de los seres humanos y además de conseguir el desarrollo sostenible y eso que se debe proteger y preservar el medio ambiente de una nación.

Pregunta 9: ¿Cuál es la importancia de los estudios ambientales en los proyectos de ingeniería? 
Respuesta: Los estudios ambientales son imprescindibles ante el inicio de los proyectos de ingeniería pues con este estudio previo se identifica, previene y ayuda a minimizar los impactos ambientales que producirá un proyecto en su entorno en caso de ser ejecutado. Este procedimiento jurídico administrativo inicia con la presentación de la memoria resumen por parte del promotor, sigue con la realización de consultas previas a personas e instituciones por parte del órgano ambiental, y continúa con la realización del Estudio de Impacto Ambiental a cargo del promotor y su presentación al órgano sustantivo.

Pregunta 10: $\quad$ Existe una alta demanda de los servicios de estudios de gestión Ambiental

Respuesta: Podría decir que el crecimiento económico de un país se refiere al incremento de ciertos indicadores, como la producción de bienes y servicios, el mayor consumo de energía, el ahorro, la inversión, una balanza comercial favorable, el aumento de consumo de calorías per cápita, y en todas ellas interviene un estudio ambiental previo ante el inicios de sus operaciones, el PBI del Perú se mantiene en crecimiento a la fecha podríamos deducir que hay mayor inversión y en consecuencia también la demanda de estudios ambientales ha crecido.

Pregunta 11: Existen suficientes consultoras ambientales para cubrir la demanda en el país.

Respuesta: $\quad \mathrm{Si}$, en los últimos años las consultoras y laboratorios ambientales han crecido, la alta demanda de estos servicios ha hecho que haya que el mercado tenga muchas consultoras y profesionales independiente que ofrezcan sus servicios en este sector.

Pregunta 12: Que exigencias mínimas debe tener una consultora ambiental para que brinde los servicios ambientales.

Respuesta: Mínimamente debe estar inscrito en el SENACE y en los ministerios de cada sector.

Pregunta 13: Cuando hablamos de consultoras ambientales, cuál o cuáles son las más reconocidas a nivel nacional.

Respuesta: $\quad$ No podría especificar a una en particular, pues hay muchas en el mercado local. 
Pregunta 14: ¿Cuál cree usted que es su factor diferenciador respecto a los demás?

Respuesta: Uno de los factores hace que las consultoras se diferencien es la experiencia, contar con expertos de mucha trayectoria y equipos de monitoreo ambientales.

Pregunta 14: ¿Considera importante como factor clave de éxito la experiencia de las empresas en el rubro de consultoría dentro del sector? ¿Por qué?

Respuesta: Si claro. Porque la experiencia es un punto importante para tomar las decisiones y determinar que consultora se hará cargo del proyecto ambiental.

Pregunta 16: ¿Considera importante como factor clave de éxito una tarifa competitiva en las empresas en el rubro de consultoría dentro del sector? ¿Por qué?

Respuesta: Las tarifas competitivas siempre son determinantes, pues las evaluaciones no solamente son técnicas sino también económicas.

Pregunta 17: ¿Considera importante como factor clave de éxito los plazos de atención en las empresas en el rubro de consultoría dentro del sector? ¿Por qué?

Respuesta: Los plazos de atención que tienen las consultoras, es importante pues el plazo dentro de del tiempo previo a la entrega final de los informes, sería muy prejudicial, ya que lo plazos para la aprobación son más críticos en la etapa de revisión y conformidad por la entidad.

Pregunta 18: ¿Considera importante como factor clave de éxito la tecnificación de equipos de monitoreo ambiental? ¿Por qué?

Respuesta: Contar con equipos de monitoreo modernos no necesariamente estas son las mejores, pues si estas no estas acreditadas por INACAL, y aprobadas por las entidades como el ministerio del ambiente, no podrían formar parte del proyecto.

Pregunta 19: ¿Considera importante como factor clave de éxito el nivel de servicio / calidad para realizar un estudio, en las empresas en el rubro de consultoría dentro del sector? ¿Por qué? 
Respuesta: La calidad de los proyectos indica la satisfacción que se tiene con el proyecto, culminado.

Pregunta 20: ¿ ¿Considera importante como factor clave de éxito la participación de personal especializado, en las empresas en el rubro de consultoría dentro del sector? ¿Por qué?

Respuesta: Claro, contar con la participación de profesionales expertos en las diferentes especialidades que requiere un estudio de gestión ambiental es sumamente importante, ya que esta garantiza el éxito del estudio.

Pregunta 21: ¿Qué Factores relevantes impactan a los estudios de Gestión Ambiental a nivel local? (positivos y negativos)

Respuesta: El cambio a las normativas, así como la aparición de nuevas leyes en el sector, que podrían tener un fin positivo pero si estas forman parte de una reformar institucional donde haya menos burocracia que dilaten el tiempo de aprobación de los informes.

Pregunta 22: Usted que ha trabajado muchos años en el sector cuales creen que serían las ventajas y desventajas que se podría presentar para las consultoras ambientales.

Respuesta: Como ventaja, podríamos indicar que la aparición de nuevos proyectos mineros, las obras de infraestructura en general, y las reformas en el reglamento ambiental, han hecho que estas sean más exigentes en todos los sectores, la oportunidad que existe en el mercado es amplia, sin embargo para los servicios ambientales, se estaría corriendo el riego que estos sean dirigidos únicamente a los laboratorios y no para las consultoras, el decreto no está aprobado, sin embargo esta en evaluación, sería muy perjudicial para muchas consultoras por el gran equipamientos que tienen las empresas para el desarrollo de estos servicios.|

Pregunta 23: Tiene referencias o a trabajado con la empresa Hamek Ingenieros Asociados S.A.C

Respuesta: Si he trabajado con Hamek Ingenieros y Asociados S.A.C., he participado en un par de proyectos una para el sector minero y otra para en un plan de cierre de una central hidroeléctrica. 
Pregunta 24: Finalmente. Con la experiencia que posee en el sector ¿Qué propuesta de valor considera que podría ser clave y que sería apreciado por las empresas?

Respuesta: Sugeriría que las revisiones de parte de la comisión de las entidades que aprueban los informes de estudios ambientales sean en menos plazo, que cuenten con el personal suficiente para que las aprobaciones tomen menor tiempo y así no afecte al inicio de los proyectos. 


\section{Apéndice $\mathrm{N}^{\circ} \mathbf{4}$}

Entrevista en Profundidad a Especialista / Jefe del Área de Energía en la empresa Hamek Ingenieros Asociados S.A.C

FICHA TÉCNICA

Técnica:

Instrumento:

Muestra:

Objetivos:

Entrevistador:

Lugar:

Fecha y hora:

Duración:
Entrevista en Profundidad

Guía de entrevista

Recopilar información necesaria para conocer la opinión de un trabajador de la empresa, con la finalidad de proponer mejorar en los servicios y en la organización de Hamek Ingenieros Asociados

\section{S.A.C}

Julio Chávez Enciso

La Molina

11 de Julio del 2018, 12:00pm

90 minutos

\section{FICHA DEL ENTREVISTADO}

Nombre:

Edad:

Nacionalidad:

Ocupación:

Profesión:

\section{Reseña}

profesional/empresarial del entrevistado:

\section{Erly Fernández Andrade}

31

Peruano

Ingeniero

Ing. Mecánico Electricista

Auditor Peruano con especialidad en Ingeniería Mecánica Eléctrica, con más de siete (07) años de experiencia en el sector eléctrico, en el ámbito nacional y en el extranjero. En el campo de la energía he participado, para el caso de centrales termoeléctricas, en pruebas de potencia efectiva y rendimiento, pruebas de entrega o Performance Test de centrales Nuevas, Centrales de Reserva Fría, Centrales de Cogeneración, Centrales RER, Sistemas Aislados, en todas las centrales del Nodo Energético Sur Peruano, en centrales hidroeléctricas, pruebas de potencia efectiva. Todo ello en 
las centrales más importantes a nivel nacional. Actualmente se desempeña en el Área Técnica en empresa Hamek Ingenieros Asociados S.A.C. como Jefe del Área de Energía y Proyectos centrales del Nodo Energético Sur Peruano, en centrales hidroeléctricas, pruebas de potencia efectiva. Todo ello en las centrales más importantes a nivel nacional.

FASE DE PRESENTACIÒN

Buenas noches, soy estudiante de la MBA de la Escuela de Postgrado de la Universidad San Ignacio de Loyola. Como parte del desarrollo del Plan Estratégico de la empresa Hamek Ingenieros Asociados S.A.C., nos vemos con la necesidad de realizarle una entrevista, cabe señalar que toda la información recopilada será publicada para fines académicos.

Nos permitiría filmar o grabar, para agilizar la toma de información, y no perder detalles y para poder presentarlo en nuestro curso. ¿Tendría algún inconveniente de que la entrevista sea grabada o filmada?

\section{GUÍA DE ENTREVISTA}

Pregunta 1: ¿ ¿Cuál es su cargo y las funciones que usted desempeña en la empresa?

Respuesta: Actualmente me desempeño como Jefe del Área Técnica, específicamente en lo referido en Energía y proyectos.

Pregunta 2: $\quad$ Cuánto tiempo se encuentra laborando en Hamek Ingenieros Asociados S.A.C?

Respuesta: Desde el mes de Febrero del año 2011 hasta la actualidad.

Pregunta 3: ¿Cómo se siente trabajando en Hamek Ingenieros Asociados S.A.C.?

Respuesta: Bastante bien, aporto mi experiencia y aprendo de la mano del ingeniero empresa Hamek Ingenieros Asociados S.A.C.

Pregunta 4: ¿Conoce usted la estructura organizacional formal de la empresa? ¿Nos puede comentar al respecto?

Respuesta: $\quad$ Si claro, en la gerencia general se encuentra el Ingeniero Amadeo Carrillo Villena, y en la Gerencia de Administración la Ingeniero Erika Carrillo Zelaya, además existe un área técnica, estando yo a cargo de la Gerencia Técnica.

Pregunta 4: ¿Conoce la Visión, Misión y Valores de la empresa? 
Respuesta: No lo tengo tan claro, pero entiendo que tenemos como misión ser líderes ofreciendo soluciones técnicas que cubran las necesidades de los cliente locales

Pregunta 6: ¿Conoce usted las fortalezas de la empresa? ¿Por qué considera que son sus fortalezas?

Respuesta: Si las conozco, las principales son la experiencia que tiene como consultora en temas técnicos y de medio ambiente, el contar con expertos muy calificados con el Ingeniero Carrillo que tiene mucho reconocimiento y ello fortalece la reputación de la empresa

Pregunta 7: ¿Conoce usted las debilidades de la empresa? ¿Por qué considera que son debilidades?

Respuesta: Desde mi punto de vista, es una empresa que en el corto tiempo ha adquirido mucho protagonismo en el sector sin embargo aún está en la etapa de dejar de ser una empresa familiar y constituirse en una empresa con una estructura gerencial más sólida, en el rubro se requiere realizar inversiones técnicas y de equipamiento para seguir enfrentando los nuevos desafíos con mucho éxito.

Pregunta 8: ¿Cuál es la mayor ventaja competitiva de la empresa? ¿Por qué? La mayor ventaja podría ser su experiencia en el mercado local lo que le permite tener una importante participación de otro lado y de la mano del Ingeniero Carrillo con amplio reconocimiento profesional se han conseguido realizar varios estudios técnicos en países como Chile y El Salvador lo que refuerza su prestigio.

Pregunta 9: ¿ ¿Ha efectuado una acción nueva o corrección de un proceso que haya causado una mejora en la organización? Si fue así ¿qué le motivo a hacerlo? ¿Quiénes intervinieron? ¿Qué resultado se produjeron?

Respuesta: Constantemente se trabaja en optimizar los procesos técnicos para conseguir un estudio ingenieril que cubra las necesidades de los clientes, en estas mejoras participan toda el área técnica de la mano del Ingeniero Carrillo, y vuelco toda mi experiencia anterior referida a puestas en marchas de las principales centrales eléctricas a nivel local y alguna experiencia, los resultados permitieron concluir los estudios técnicos dentro de los plazos estimados y entregar las respectivas recomendaciones técnicas.

Pregunta 10: ¿Cuál sería la mayor desventaja o debilidad que tienen los servicios de Hamek Ingenieros Asociados S.A.C.? ¿Por qué? 
Respuesta: $\quad$ No observo mayor desventaja en Hamek Ingenieros y Asociados S.A.C. sin embargo considero que sería importante que se evalúe contar con certificaciones internacionales de los servicios brindados para incrementar más su prestigios de cara a una participación en procesos concursales en otros países, además debiera estar preparado de manera organizacional para un crecimiento mayor dado que la demanda de los servicios que brindan va en aumento como consecuencia de una mayor preocupación de las organizaciones públicas y privadas para la realización de estudios técnicos, ingenieriles y del impacto medio ambiental en la totalidad de proyectos energéticos que se vienen desarrollando o se desarrollaran.

Pregunta 11: ¿Emplea algún programa de innovación o mejora continua en su área?

Respuesta: Solo talleres de mejora pero no tengo entendido que se den dentro de un programa de innovación.

Pregunta 12: ¿Cómo visualiza usted a la empresa de acá a 4 años?

Respuesta: $\quad$ Como una empresa consolidada en el Perú pero además con presencia importante en varios países vecinos, el Perú es un país con muchos recursos, no solo naturales sino además con muchos profesionales altamente competentes y con una formación técnica muy alta que les permite brindar servicios, trabajar en Hamek Ingenieros y Asociados S.A.C. se convierte además en un oportunidad para los profesionales del rubro que adquieren mucho mayor experiencia, veo al Ingeniero Carrillo con un objetivo personal de trascender y comparte el conocimiento con sus profesionales, eso nos motiva a seguir creciendo con él.

Pregunta 13: ¿Considera usted que los servicios que ofrece son los apropiados para satisfacer a sus clientes? ¿Por qué?

Respuesta: $\quad$ Son los apropiados, puedo dar fe de que luego de realizar la entrega de los estudios técnicos solicitados, no existe un solo caso donde se haya solicitado reconsideración al estudio presentado, por el contrario el estudio viene acompañado de las recomendaciones para que se hagan los trabajos técnicos y mantenimientos, un tema importante a mencionar es que la empresas a las que anteriormente se les brindó el servicio recurren nuevamente a Hamek Ingenieros y Asociados S.A.C.en caso se requiera un nuevo servicio. 
Pregunta 14: ¿Cree que hay integración y coordinación entre sus compañeros del mismo nivel para la solución de tareas y problemas?

Respuesta: $\quad$ Si lo creo, en Hamek Ingenieros y Asociados S.A.C. se trabaja de forma coordinada con toda el área técnica para sacar adelante los proyectos en los que se involucra, la experiencia de cada uno de los profesionales se complementan de una forma armónica, es un punto destacable pues hay mucha identificación de los ingenieros de Hamek Ingenieros y Asociados S.A.C.para con la empresa y para con el Ingeniero Carrillo y eso facilita un trabajo coordinado,

Pregunta 14: ¿Cómo perciben la rotación del personal dentro de la empresa: alta, moderada, baja?

Respuesta: $\quad$ Es una rotación moderada, Hamek Ingenieros y Asociados S.A.C. incorpora jóvenes profesionales y los forma técnicamente, además el desarrollo de proyectos y estudios de ingeniería los afianza y les da mucha más experiencia, como recomendación debieran trabajar más la retención de los mejores cuadros, pues los profesionales se forman y luego parten para enfrentar más desafíos personales.

Pregunta 16: ¿Cómo se siente trabajando en Hamek Ingenieros Asociados S.A.C?

Respuesta: Me siento muy bien, aporto mi experiencia y tengo a cargo un equipo técnico de jóvenes profesionales en ingeniería eléctrica que permiten sacar adelante los proyectos técnicos que se me asignan, por otro lado, el desarrollo de estos proyectos me permiten además conocer además la legislación del sector eléctrico en otras realidades fuera del país además de la capacitación técnica constante que recibimos en el país y fuera del Perú.

Pregunta 17: ¿Cómo describe usted la demanda actual por el servicio que se brinda?

Respuesta: Una demanda en constante aumento. A nivel país y a nivel región existe una mayor demanda de energía eléctrica por el crecimiento poblacional que se proyecta y el contar con más redes de electrificación , además, los distintos países están preocupados además en desarrollar fuentes de energía renovable para no afectar el medio ambiente, en ese contexto las empresas y organizaciones son cada vez más exigentes en la puesta en marcha de estos proyectos energéticos que deben contar con estudios técnicos y de impacto del medio ambiente y ello se traduce en una mayor demanda de los 
servicios que brinda actualmente Hamek Ingenieros y Asociados S.A.C. y empresas del rubro.

Pregunta 18: ¿ ¿Qué hace diferente a Hamek Ingenieros Asociados S.A.C de las demás empresas que brindan los mismos servicios?

Respuesta: Lo resumiría en tres puntos relevantes, el primero, la experiencia adquirida en el mercado local y países vecinos, la segunda, la reputación adquirida lo cual le genera mucha relevancia en el sector, acá tiene mucho que ver el prestigio del Ingeniero Carrillo y lo tercero, el perfil profesional del equipo técnico a cargo de los proyectos, profesionales con experiencia y que están en permanente capacitación técnica para estar actualizados en temas técnicos y en normativas vigentes.

Pregunta 19: ¿Qué mejoraría en Hamek Ingenieros Asociados S.A.C para que la empresa sea más reconocida en el sector?

Respuesta: Lo comente anteriormente, preparar la organización para el crecimiento futuro, formular líneas de crecimiento profesional o una línea de carrera para retener a los mejores profesionales y buscar contar con certificaciones internacionales de los servicios brindados para aumentar más su competitividad, sobre todo con empresas que brinden servicios en la región donde ya se han realizados los primeros trabajos de una forma óptima.

Pregunta 20: ¿Referente al crecimiento de la empresa? ¿Cuál es su opinión al respecto?

Respuesta: Falta prepararse para un crecimiento, mayor inversión por ejemplo en infraestructura, contar con una estructura gerencial más robusta, actualmente solo se cuenta con el Gerente General y la Gerente de Administración, el desarrollo de líneas de carrera para los profesionales más competentes, un crecimiento de los negocios debe venir acompañado de un crecimiento de la estructura organizativa, finalmente conseguir certificaciones internacionales para avalar más los servicios ofrecidos.

Pregunta 21: ¿ ¿Cómo enfrenta Hamek Ingenieros Asociados S.A.C a sus competidores?

Respuesta: $\quad$ En la mayoría de casos, Hamek Ingenieros y Asociados S.A.C. participa en procesos concursales acreditando que está apto para postular, en las evaluaciones se toma en cuenta varias dimensiones, 
entre ellas, la trayectoria de la empresa, la experiencia de sus profesionales, la dimensión de los clientes a los cuales Hamek Ingenieros y Asociados S.A.C. les ha prestado sus servicios anteriormente y el ámbito geográfico por eso se valora la experiencia en otros países del continente americano.

Pregunta 22: ¿Considera usted que existe un crecimiento de la industria?

Respuesta: Como lo mencioné anteriormente, el crecimiento de la industria se dará, a nivel de Sudamérica y Centroamérica existe una mayor demanda de energía eléctrica por el crecimiento poblacional la necesidad de ampliar la redes de electrificación, además, además hay un mayor preocupación de los países por desarrollar fuentes de energía renovable y esto es una enorme posibilidad de crecimiento para Hamek Ingenieros y Asociados S.A.C. 


\section{Apéndice $\mathrm{N}^{\circ} 5$}

\section{Entrevista en Profundidad a Experto del Sector Energético - Cliente COES}

\section{FICHA TÉCNICA}

Técnica:

Instrumento:

Muestra:

Objetivos:

Entrevistador:

Lugar:

Fecha y hora:

Duración:

\section{Entrevista en Profundidad}

Guía de entrevista

Conocer las fortalezas y debilidades que tienen el sector energético y como Hamek Ingenieros y Asociados S.A.C. se encuentra ubicado en el mercado.

Erika Carrillo Zelaya

La Molina

20 de Junio de 2018, 4:00pm

30 minutos

\section{FICHA DEL ENTREVISTADO}

Nombre: $\quad$ José Geiner Tafur Grández

Edad: $\quad 32$

Nacionalidad: Peruano

Ocupación: Ingeniero24

Profesión: Ing. Electricista

Reseña Consultor del sector de una empresa privada y con personería profesional/empresarial de Derecho Público, se ha desempeñado las funciones de del entrevistado: medición y diagnóstico de la calidad de energía, pozos de tierra, auditoria energética. Elaboración del Plan de Manejo Socio Ambiental, tomando en cuenta las conclusiones obtenidas por los consultores de sus respectivas evaluaciones. 


\section{FASE DE PRESENTACIONN}

Buenas noches, soy estudiante de la MBA de la Escuela de Postgrado de la Universidad San Ignacio de Loyola. Como parte del desarrollo del Plan Estratégico de la empresa Hamek Ingenieros Asociados S.A.C., nos vemos con la necesidad de realizarle una entrevista, cabe señalar que toda la información recopilada será publicada para fines académicos.

Nos permitiría filmar o grabar, para agilizar la toma de información, y no perder detalles y para poder presentarlo en nuestro curso. ¿Tendría algún inconveniente de que la entrevista sea grabada o filmada?

\section{GUÍA DE ENTREVISTA}

Pregunta 1: ¿Cómo ve el desarrollo del sector energético en los últimos años?

Respuesta: Durante las dos últimas décadas la economía peruana registró el más prolongado ciclo de alto crecimiento de su historia, este crecimiento no solo se debe a incremento de inversiones y de la oferta energética, sino que estas hicieron posible que la economía se consolide.

En el caso peruano la constante durante las dos últimas décadas fue la duplicación de la oferta energética cada 10 años, resultado que se dio en virtud de una participación activa en el desarrollo de la infraestructura tanto por parte del Estado como de los inversionistas.

Pregunta 2: ¿ ¿Considera que el Estado fomenta la inversión privada en el sector energético? ¿Por qué?

Respuesta: $\quad$ Si, la iniciativa como la promulgación de la la Ley 28832 han permitido aumentar la generación eficiente de energía, pero los clientes aún tienen dificultades en el acceso a mejores precios que deberían resolverse a la brevedad. Las políticas implementadas por el Estado para orientar el desarrollo energético en una dirección determinada y cumplir objetivos nacionales, como el acceso de la población a energía de buena calidad y precio razonable.

Pregunta 3: ¿Considera que existe un marco normativo y regulatoria adecuado que permita mejorar el estándar del servicio? ¿Podría indicar las más relevantes normas? 
Respuesta: $\quad$ No, la normativa en el Perú dificulta el acceso de los usuarios a mejores precios en el mercado local.

En este contexto, es importante que los clientes puedan acceder a oportunidades en el sector, sin que sean restringidos a buscar los mejores precios. La Ley 28832 permite que un cliente libre acceda a los precios del mercado spot, pero un reglamento redujo ese acceso a solo el $10 \%$ de la demanda.

Pregunta 4: Respecto al uso de la energía renovable, ¿está desarrollada en el país? ¿Considera adecuado su uso? ¿Por qué?

Respuesta: El uso de energía renovable en el Perú es muy emergente aún.

EI Perú tradicionalmente produce energía hidroeléctrica y pertenece a los países con una alta tasa de energías renovables. Buenos ejemplos son la central hidroeléctrica Gallito Ciego, o la enorme Central Hidroeléctrica Mantaro, una obra maestra que, con una capacidad de más de $1 \mathrm{GW}$, suministra aproximadamente $14 \%$ de toda la electricidad al Sistema Eléctrico Interconectado Nacional (SEIN).

Pregunta 4: Respecto al uso de la energía renovable, ¿cuál considera que tiene el mayor potencial de crecimiento? ¿Por qué?

Respuesta: El Perú cuenta con un importante potencial de fuentes renovables revelado en diversos estudios: las fuentes hídricas alcanzan a los 70,000 MW, el potencial eólico a los 23,000 MW, el potencial solar con aprovechamientos diversos mayormente en el sur con niveles de radiación entre 6.0 y $6.4 \mathrm{kWh} / \mathrm{m} 2$, además del potencial de la biomasa y de las fuentes geotérmicas.

Pregunta 6: ¿Considera que los conflictos socio cultural y medio ambiental afectan el desarrollo del sector? ¿Por qué?

Respuesta: Los conflictos socio cultural y medio ambiente atrasan y en muchos casos se cierran proyectos afectando a todos los sectores, incluyendo al energético, pues las inversiones privadas y del estado ante conflictos tienen que dialogar y esto puede tomar mucho tiempo.

Pregunta 7: ¿Considera que la inestabilidad política experimentada en los últimos tiempos afecta el desarrollo del sector? ¿Por qué? 
Respuesta: La inestabilidad política y la incertidumbre que se generan por el enfrentamiento entre los poderes del Estado están afectando la dinámica económica del país. Las inversiones privadas comienzan a detenerse ante la incertidumbre y son ellas las que constituyen un elemento clave si queremos mantener nuestro crecimiento.

Pregunta 8: ¿ ¿Cuál considera que es la principal oportunidad en el sector energético?

Respuesta: Para el 2019 se esperan inversiones de hasta 2280 millones de dólares en el sector energético. Una de las grandes oportunidades se encuentra en las energías renovables. El Perú siempre ha sido un país con un potencial notable en disponibilidad de recursos hídricos y de gas natural, tanto en la región como a nivel mundial.

Pregunta 9: ¿Cuál considera que es la principal amenaza en el sector energético?

Respuesta: El principal problema que el sector tienen es que hay sobreoferta comercial de electricidad lo que se está traduciendo en una guerra de precios entre las generadoras, esto podría generar la sobrecontratación que tienen las distribuidoras eléctricas.

Pregunta 10: Dentro del rubro de consultorías, ¿Quiénes consideran que son los líderes del mercado? ¿Por qué?

Respuesta: Como consultoras, podríamos decir que existen muchas pero que por servicios unas destacan más que otras, hay consultoras expertas exclusivamente en estudios de operatividad y otras consultoras expertas en auditorías energéticas en esta última podría mencionar a Cenergia y Hamek Ingenieros y Asociados S.A.C.

Pregunta 11: ¿Cuál considera que es el principal factor clave de éxito de una empresa de consultoría del sector energético? ¿Por qué?

Respuesta: El factor clave de éxito de una empresa en este rubro, es contar con los profesionales expertos y equipamiento adecuado.

Pregunta 12: ¿Considera como factor clave de éxito la trayectoria de una empresa en el rubro de consultoría dentro del sector? ¿Por qué? ¿Qué empresas son las más destacadas? 
Respuesta: Por supuesto la trayectoria es importante pues es la experiencia en el campo un punto importante para ser reconocida, sin embargo, si estas no van de la mano con los expertos adecuados entonces no están en competencia.

Pregunta 13: ¿Considera como factor clave de éxito el contar con una tarifa competitiva en el rubro de consultoría dentro del sector? ¿Por qué? ¿Qué empresas son las más destacadas?

Respuesta: Tener una tarifa competitiva es muy importante, pues como todo negocio para la evaluación de una propuesta se evalúan, la técnica y económica, en la primera se evalúan la experiencia y calidad del servicio que ofrecerá, mientras que en la económica evalúan que está dentro del mercado y de acuerdo al presupuesto de las entidades.

Pregunta 14: ¿Considera como factor clave de éxito una atención rápida y oportuna en el rubro de consultoría dentro del sector? ¿Por qué? ¿Qué empresas son las más destacadas?

Respuesta: Es muy importante para nosotros los clientes, que ante cualquier solicitud, estas puedan tener una buena y rápida atención, para nuestra área no tener una información correcta y a tiempo nos puede generar mucho tiempo perdido pues muchos de las datos no conllevan a otra. Por ello nuestra comunicación debe ser atendida oportunamente por los especialistas.

En cuanto a comunicación podemos indicar que de las cuatro empresas registradas para los anexos 16 y 17, Hamek Ingenieros y Asociados S.A.C. es una de las consultoras que destaca por tener una rápida respuesta.

Pregunta 14: ¿Considera como factor clave de éxito la tecnificación de equipos para realizar un estudio en el rubro de consultoría dentro del sector? ¿Por qué?

¿Qué empresas son las más destacadas?

Respuesta: $\quad$ Por supuesto contar con equipos de alta tecnología es importante, sin embargo, para el éxito de un proyecto es también poder contar con los expertos adecuados, pues no solo se trata de un buen equipamiento sino también del equipo de profesionales de elaborar el servicio. 
En cuanto a modernización de los equipos para las pruebas de potencia efectiva Cenergía cuenta con un buen equipamiento.

Pregunta 16: ¿Considera como factor clave de éxito el nivel de servicio / calidad para realizar un estudio en el rubro de consultoría dentro del sector? ¿Por qué?

¿Qué empresas son las más destacadas?

Respuesta: El factor clave no solo en el rubro energéticos sino en todos los sectores es la calidad de sus servicios, que se miden por la capacidad de la empresa en realizar los proyectos antes de plazo, con un buen equipamiento, con profesionales idóneos, buen precio y con mejoras en sus propuestas técnicas.

Pregunta 17: ¿Considera como factor clave de éxito la participación de personal especializado en el rubro de consultoría dentro del sector? ¿Por qué?

¿Qué empresas son las más destacadas?

Respuesta: Sí, creo que el factor principal que conlleva al éxito de todos los proyectos es contar con personal adecuado, que cuente con la experiencia necesaria para el servicio. Sobre las empresas más destacadas en el rubro de energía, podemos mencionar a varias, pero los servicios del procedimiento del anexo 17 y 16 del COES, podemos considerar a Hamek Ingenieros y Asociados S.A.C. en Pruebas de potencias en centrales termoeléctricas y a Energía para Hidroeléctricas.

Pregunta 18: De los factores claves de éxito mencionados anteriormente, ¿cuáles considera que son los más relevantes? ¿Por qué?

Respuesta: Los más relevantes para encontrar el éxito es con profesionales expertos y con el equipamiento de alta tecnología.

Pregunta 19: ¿Hay algún factor clave en el rubro de consultorías dentro del sector energético que considera que debe ser tomado en cuenta? ¿Por qué?

¿Qué empresas son las más destacadas?

Respuesta: El equipamiento, pues contar con equipos de alta tecnología ayuda en que los resultados tengan mayor precisión, si hablamos en los servicios 
de auditorías del anexo 16 y 17 del coes, la consultora cenergia se destaca en ello.

Pregunta 20: Dentro del rubro de consultorías en el sector energético ¿cuál considera es la principal fortaleza y la principal debilidad de Hamek Ingenieros Asociados S.A.C?

Respuesta: Como Fortaleza de Hamek Ingenieros y Asociados S.A.C., podríamos indicar que la calidad de sus servicios, y la comunicación directa con los especialistas. Como debilidad podríamos indicar que aún no cuenta con servicios múltiples en el sector.

Pregunta 21: Dentro del rubro de consultorías en el sector energético ¿cuál considera es la principal fortaleza y la principal debilidad de Cenergía?

Respuesta: La mayor fortaleza que tiene Cenergia son los años de experiencia y trayectoria en el mercado, y ser especialistas en servicios de energía y medio ambiental, la incursión en energía renovable es un plus que tiene la empresa. Como debilidad es que las comunicaciones se hacen muchas veces con los asistentes esto hace que el tiempo de respuesta no sea inmediata.

Pregunta 22: Dentro del rubro de consultorías en el sector energético ¿cuál considera es la principal fortaleza y la principal debilidad de Alfa Plus?

Respuesta: Alfa Plus tiene como fortaleza los años de trayectoria sin embargo en los servicios especializados de Prueba de potencia efectiva ya no se presentan muy seguido, Como debilidad es que ya no cuentan con expertos en su staff de profesionales, para poder concursar.

Pregunta 23: Dentro del rubro de consultorías en el sector energético ¿cuál considera es la principal fortaleza y la principal debilidad de Global Energy?

Respuesta: No puedo opinar por que no he trabajado con Global Energy, sé que está inscrito en el COES porque se encuentra en la lista de consultora habilitada para brindar servicios de potencia efectiva, pero no he tenido la oportunidad de trabajar con ellos. Hace algunos años que no se presentan.

Pregunta 24: ¿Existe alguna empresa del sector consultorías en el sector energético que no hemos mencionado? Desde su perspectiva, ¿cuál considera que es su principal fortaleza y su principal debilidad? 
Respuesta: No. Como expertos en Prueba de Potencia Efectica son solo esas cuatro consultoras mencionadas.

Pregunta 24: Para concluir, ¿cuál es su opinión general de Hamek Ingenieros Asociados S.A.C?

Respuesta: $\quad$ Creo que es una buena empresa, tiene buenos profesionales, sin embargo pienso que deberían invertir más en equipamiento y arriesgarse en ingresar en nuevos servicios. 


\section{Apéndice $\mathrm{N}^{\circ} 6$}

\section{Entrevista en Profundidad al Cliente}

\section{FICHA TÉCNICA}

Técnica:

Instrumento:

Muestra:

Objetivos:

Entrevistador:

Lugar:

Fecha y hora:

Duración:
Entrevista en Profundidad

Guía de entrevista

Conocer las empresas del sector, a la competencia, a los servicios que ofrecen en las consultoras, como el sector energético ha ido evolucionando, cuales son las empresas más demandas por sus servicios.

Melissa Burga Ruiz

La Molina

28 de Junio 2018, 6:00 pm

30 minutos

\section{FICHA DEL ENTREVISTADO}

Nombre: $\quad$ Luis Alaya

Edad: $\quad 34$

Nacionalidad: Peruano

Ocupación: $\quad$ Coordinador de Mantenimiento de ENGIE

Profesión: Ing. Mecánico Electrico

Reseña Ing. Mecánico Electricista, de la Universidad Nacional de profesional/empresarial Ingeniería, con 9 años de experiencia en el sector de energía, del entrevistado: $\quad$ se a desempeñado como coordinador de mantenimiento en ENERSUR, GDF SUEZ y actualmente labora en ENGIE 


\section{FASE DE PRESENTACIONN}

Buenas noches, soy estudiante de la MBA de la Escuela de Postgrado de la Universidad San Ignacio de Loyola. Como parte del desarrollo del Plan Estratégico de la empresa Hamek Ingenieros Asociados S.A.C., nos vemos con la necesidad de realizarle una entrevista, cabe señalar que toda la información recopilada será publicada para fines académicos.

Nos permitiría filmar o grabar, para agilizar la toma de información, y no perder detalles y para poder presentarlo en nuestro curso. ¿Tendría algún inconveniente de que la entrevista sea grabada o filmada?

\section{GUÍA DE ENTREVISTA}

Pregunta 1: ¿Cómo ve el desarrollo del sector energético en los últimos años?

Respuesta: Nuestro país tiene un gran potencial en el sector energético.

En los últimos años el sector energético ha crecido más del cien por ciento, nuestro país tiene un gran potencial y con el surgimiento de energía renovable no convencionales como solar y fotovoltaica.

En los países latinoamericanos están realizando inversiones importantes en energía

Pregunta 2: ¿ ¿Detecta alguna oportunidad de mejora en el sector energético? ¿Cuál sería esta oportunidad?

Respuesta: Gracias al favorable panorama económico, se han potenciado las oportunidades de expansión de la demanda respecto al uso de este importante recurso.

Los cambios tecnológicos dan oportunidades al desarrollo de las energías renovables no convencionales, la ampliación de la cobertura energética y la reducción de los impactos sociales y ambientales, hacen que las empresas que brindan este servicios sean favorecidos.

Pregunta 3: ¿Cómo considera que afecta este desarrollo en su sector / empresa? ¿Por qué? 
Respuesta: La necesidad de generar electricidad de cualquier forma conlleva un impacto medioambiental catastrófico a nivel mundial, es por este motivo que debemos conseguir energía más sostenible.

La instalación de grandes parques eólicos tiene un impacto medioambiental que recae directamente en la fauna local y el empobrecimiento del suelo.

Pregunta 4: ¿Considera que el servicio que recibe actualmente cubre sus expectativas? ¿Por qué?

Respuesta: Si cubre mis expectativas, he recibido un buen servicio, con alta calidad

Pregunta 4: ¿Ha escuchado acerca de la energía renovable? ¿Está Ud. Interesado en recibir más información?

Respuesta: Si escuchado, son fuentes de energía limpia, inagotable y crecientemente competitiva, pero sobre todo en que no producen gases de efecto invernadero causantes del cambio climático, ni emisiones contaminantes.

Claro me gustaría recibir información, porque la energía renovable tendrá efecto económico muy positivo.

Pregunta 6: ¿Estaría dispuesto a utilizar energía renovable en su sector / negocio? ¿Por qué lo haría? o ¿Por qué no lo haría?

Respuesta: Si estoy dispuesto, de utilizar energía renovable, la cual abrirá con el tiempo una ventana autoconsumo eléctrico, donde cada edificio o empresa, tengan sus propias placas solares, lo cual permitirá una mayor eficiencia energética y un mayor control sobre el consumo de cada hogar o edificio.

Pregunta 7: ¿Sabía que en países como Chile, Argentina, México y Brasil y se cuentan con proyectos en curso referidos a la generación de energía eólica o solar? ¿Cuál es su opinión? ¿Por qué?

Respuesta: Los países latinoamericanos, están invirtiendo en energía eólica y solar porque en unos años se convertirá en la más barata.

América Latina, después de haber reestructurado sus sectores de electricidad para dar un papel más destacado a la propiedad privada de 
las instalaciones de generación, también se enfrenta al reto de atraer inversión privada en energía eólica.

Pregunta 8: ¿Conoce de alguna experiencia exitosa a nivel local de uso de energía renovable? ¿Quiere saber respecto a ello?

Respuesta: Las energías renovables permiten a las localidades más aisladas aprovechar los recursos naturales para generar su propia energía. Especialmente aquellas donde no llega la red eléctrica tradicional. Es más fácil instalar paneles solares que una central nuclear en una pequeña localidad aislada.

Pregunta 9: $\quad$ Sobre empresas del rubro de consultorías en el sector energético, ¿Qué servicios considera que debieran brindar para cubrir sus necesidades?

Respuesta: Los servicios que deberían brindar, deben ser aquellos diseñados para mejorar el desempeño energético de nosotros los clientes.

Pregunta 10: ¿Conoce empresas dedicadas al rubro de consultorías en al sector energético?? ¿Le interesa saber de ellas? ¿Por qué?

Respuesta: $\quad$ Si conozco, como a Cenergia y Hamek Ingenieros Asociados S.A.C., me gustaría saber qué cambios se verán con la tecnología, en el sector energético.

Pregunta 11: ¿Cuál considera que es el principal factor clave de éxito de una empresa de consultoría del sector energético? ¿Por qué?

Respuesta: El principal éxito de una empresa consultora es atender bien a su cliente, ofreciendo los mejores servicios.

Independientemente de cuán grandioso sea el servicio o cuán talentoso sea tu personal, una de las cosas que más recuerdan los clientes es la interacción directa que tienen con tu empresa.

Pregunta 12: Dentro del rubro de consultorías, ¿Para Ud. una empresa con mayor trayectoria en el rubro le podría dar un mejor servicio? ¿Por qué? ¿Qué empresas son las más destacadas?

Respuesta: Las empresas de gran trayectoria ya tienen una excelente relación con sus clientes, aunque no es necesario tener muchos años en el sector, 
hay empresas que son nuevas y buscan constantemente oportunidades para mejorar su atención al cliente.

Las más destacadas son Cenergia y Hamek Ingenieros Asociados S.A.C.

Pregunta 13: Dentro del rubro de consultorías, ¿Para Ud. una empresa que cuente con tarifas competitivas para brindar este servicio podría ser tomada en cuenta por Ud.? ¿Por qué? ¿Qué empresas son las más destacadas?

Respuesta: Los precios competitivos en el mercado son importantes, en las empresas consultoras los precios de las empresas no varían mucho, todas ellas son bastante similares en tamaño, productos y precios.

Las empresas más destacadas es Hamek Ingenieros Asociados S.A.C. y Cenergia

Pregunta 14: Dentro del rubro de consultorías, ¿Para Ud. una empresa que responda dentro de los plazos resulta relevante como parte del servicio? ¿Por qué? ¿Qué empresas son las más destacadas?

Respuesta: Es importante que una empresa responda dentro de los plazos, para el cliente es satisfactorio tener una propuesta a tiempo.

Las empresa más destacada es Hamek Ingenieros Asociados S.A.C.

Pregunta 14: Para Ud. ¿una empresa con una adecuada tecnificación de equipos para realizar estudios en el rubro de consultoría le inspira confianza o le resulta irrelevante? ¿Por qué? ¿Qué empresas son las más destacadas?

Respuesta: Los quipos con una adecuada tecnificación me inspira confianza, la tecnología es muy importante, entre la que destaca por su equipos con alta tecnología es la empresa Cenergia, ya que ellos debido, al ser una ONG, tiene beneficios de obtener mejores productos del extranjero con tecnología de punta.

Pregunta 16: ¿Qué tan importante sería para Ud. tener un nivel de servicio / calidad sobre otros factores a tomar en cuenta? ¿Por qué? ¿Qué empresas son las más destacadas?

Respuesta: La calidad es muy importante, para garantizar la rentabilidad y el éxito de cualquier empresa. Además de contribuir con la lealtad del 
consumidor hacia un servicio, garantiza la viabilidad y éxito de la compañía dentro del mercado competitivo que existe en la actualidad.

La empresa más destaca en la calidad de su servicio es Hamek Ingenieros Asociados S.A.C.

Pregunta 17: ¿Para Ud. un personal especializado en el rubro de consultoría dentro del sector le genera más valor o es irrelevante? ¿Por qué? ¿Qué empresas son las más destacadas?

Respuesta: Por supuesto que contar con los profesionales expertos y especializados dentro del sector genera más valor y de éxito de una empresa en este rubro.

Las empresas más destacadas son Cenergia y Hamek Ingenieros Asociados S.A.C.

Pregunta 18: De los factores claves de éxito mencionados anteriormente, ¿cuáles considera que son los más relevantes? ¿Por qué?

Respuesta: El factor clave para el éxito es la calidad, contar con profesionales expertos y tener unos equipos con alta tecnología, porque garantiza el éxito de la empresa, gracias al cliente.

Pregunta 19: ¿Hay algún factor clave en el rubro de consultorías dentro del sector energético que considera que debe ser tomado en cuenta? ¿Por qué? ¿Qué empresas son las más destacadas?

Respuesta: El factor clave en el rubro de consultoría es la tecnología, que en estos tiempos avanza muy rápido, y los servicios que ofrecen las consultoras deben tener equipos de alta tecnología.

La más destacada es la empresa Cenergia

Pregunta 20: Dentro del rubro de consultorías en el sector energético ¿conoce a Hamek Ingenieros Asociados S.A.C? ¿Identifica la principal fortaleza y la principal debilidad de ellos?

Respuesta: $\quad$ Por supuesto que conozco a la empresa Hamek Ingenieros Asociados S.A.C., entre sus fortaleza es su calidad en sus servicios, su rapidez en la atención y debilidades es que aún no ofrece servicios múltiples de atención. 
Pregunta 21: Dentro del rubro de consultorías en el sector energético ¿conoce a Cenergía? ¿ldentifica la principal fortaleza y la principal debilidad de ellos?

Respuesta: También la conozco, he trabajado con ambas empresas, entre su fortaleza, es su trayectoria en el mercado, ellos ya están incursionando en energía renovable, entres sus debilidades es el tiempo de respuesta.

Pregunta 22: Dentro del rubro de consultorías en el sector energético ¿conoce a Alfa Plus? ¿ldentifica la principal fortaleza y la principal debilidad de ellos?

Respuesta: La empresa Alfa Plus, tiene años de trayectoria menos que Cenergia, ya no concursa mucho en algunos servicios, tiene como debilidad que no cuenta con profesionales especializados.

Pregunta 23: Dentro del rubro de consultorías en el sector energético ¿conoce a Global Energy? ¿Identifica la principal fortaleza y la principal debilidad de ellos?

Respuesta: No los conozco, no he trabajado con ellos.

Pregunta 24: ¿Existe alguna empresa del sector consultorías en el sector energético que no hemos mencionado? Desde su perspectiva, ¿cuál considera que es su principal fortaleza y su principal debilidad?

Respuesta: Todas las empresas del sector de consultoría en el sector energético me han mencionado.

Pregunta 24: Para concluir, ¿cuál es su opinión general de Hamek Ingenieros Asociados S.A.C?

Respuesta: La empresa Hamek Ingenieros Asociados S.A.C, está siendo reconocida, en el sector, lo que deberían hacer es invertir más en tecnología. 


\section{Apéndice $\mathrm{N}^{\circ} 7$}

Entrevista en Profundidad Especialista Estudios Técnicos / Servicios Externos para la empresa Hamek Ingenieros Asociados S.A.C

FICHA TÉCNICA

Técnica:

Instrumento:

Muestra:

Objetivos:

Entrevistador:

Lugar:

Fecha y hora:

Duración:
Entrevista en Profundidad

Guía de entrevista

Recopilar información necesaria para conocer la opinión de un trabajador de la empresa, con la finalidad de proponer mejorar en los servicios y en la organización de Hamek Ingenieros Asociados S.A.C

Julio Chávez Enciso

La Molina

14 de Marzo del 2018 - 3:00pm

74 minutos

\section{FICHA DEL ENTREVISTADO}

Nombre:

Edad:

Nacionalidad:

Ocupación:

Profesión:

\section{Reseña}

profesional/empresarial del entrevistado:

\section{Alex Atalaya Tafur}

33

Peruano

Ingeniero

Ing. Mecánico Electricista

Ingeniero Mecánico CIP y coach con más de 7 años de experiencia laboral, consultor especialista en energía y proyectos, supervisión, consultoría y estudios según procedimientos COES, OSINERGMIN, MINEM, participación de trabajos en diversos campos de estudios, proyectos energéticos y ambientales, nacionales e internacionales. Con conocimiento del marco normativo y regulatorio del sector energético, instalaciones eléctricas de baja y media tensión, energías renovables. Conocimientos en administración comercial, elaboración de propuestas y licitaciones. 


\section{FASE DE PRESENTACIÒN}

Buenas noches, soy estudiante de la MBA de la Escuela de Postgrado de la Universidad San Ignacio de Loyola. Como parte del desarrollo del Plan Estratégico de la empresa Hamek Ingenieros Asociados S.A.C., nos vemos con la necesidad de realizarle una entrevista, cabe señalar que toda la información recopilada será publicada para fines académicos.

Nos permitiría filmar o grabar, para agilizar la toma de información, y no perder detalles y para poder presentarlo en nuestro curso. ¿Tendría algún inconveniente de que la entrevista sea grabada o filmada?

\section{GUÍA DE ENTREVISTA}

Pregunta 1: ¿ ¿Cuál es su cargo y las funciones que usted desempeña en la empresa?

Respuesta: En la actualidad me desempeño como especialista externo para realizar pruebas de estudios de potencia efectiva a demanda para Hamek Ingenieros y Asociados S.A.C.

Pregunta 2: $\quad$ Cuánto tiempo se encuentra laborando en Hamek Ingenieros Asociados S.A.C?

Respuesta: $\quad$ Trabaje en Hamek Ingenieros y Asociados S.A.C., hasta el año 2018, actualmente les presto servicios externos, a la par me desempeño como consultor en estudios de energía, elaboración de informes, preparación de perfiles de proyectos y supervisión de proyectos y estoy ejerciendo la docencia desde el 2018 en gestión de proyectos

Pregunta 3: ¿Cómo se siente trabajando en Hamek Ingenieros Asociados S.A.C.?

Respuesta: Me gustaba el trabajo encomendado, me permitió desarrollar mis habilidades y vertir mi experiencia en el desarrollo de proyectos energéticos y ambientales, con la experiencia adquirida decidí incursionar como consultor, en la actualidad le brindo servicios a Hamek Ingenieros y Asociados S.A.C., a las empresas que demanden mis servicios siempre en el sector energía y ambiente.

Pregunta 4: ¿Conoce usted la estructura organizacional formal de la empresa? ¿Nos puede comentar al respecto?

Respuesta: Hamek Ingenieros y Asociados S.A.C. tiene una organización muy reducida, el gerente general es el Ingeniero Amadeo Carrillo Villena, y la Gerente de Administración y demás temas es la Ingeniero Erika 
Carrillo Zelaya, existe un área técnica que tiene dos áreas específicas, el área de Energía y Medio Ambiente, que son las dos líneas de negocios más representativas que tienen.

Pregunta 4: ¿ ¿Conoce la Visión, Misión y Valores de la empresa?

Respuesta: Como misión se tenía ofrecer un servicio de consultoría que supere las expectativas de los clientes y contribuir con ello a un desarrollo sostenible del país, estos servicios basados en recursos profesionales y tecnológicos necesarios para desarrollar los estudios técnicos en tiempo y forma.

Pregunta 6: ¿Conoce usted las fortalezas de la empresa? ¿Por qué considera que son sus fortalezas?

Respuesta: La experiencia como consultora en energía y medio ambiente, la participación en el mercado local, sobretodo en el sector energía, contar con especialistas altamente calificados a cuales forman y capacitan constantemente que además generan sentimiento de pertenencia entre ellos para con Hamek Ingenieros y Asociados S.A.C..

Pregunta 7: ¿Conoce usted las debilidades de la empresa? ¿Por qué considera que son debilidades?

Respuesta: Desde mi punto de vista una debilidad importante es el manejo de Hamek Ingenieros y Asociados S.A.C. como una empresa familiar, esto obedece a que es una empresa con poco tiempo de constituida que ha experimentado un crecimiento importante, las inversiones se darán cuando se genere la oportunidad, por ejemplo para contar con un local adhoc para el trabajo, también se considera como debilidad no contar con un área específica para realizar análisis de los mercados regionales para ofrecer sus servicios aprovechando que ya tienen experiencia internacional anterior.

Pregunta 8: ¿Cuál es la mayor ventaja competitiva de la empresa? ¿Por qué? La mayor ventaja competitiva sigue siendo el prestigio que tiene Hamek Ingenieros y Asociados S.A.C., dada la experiencia del Ingeniero Carrillo, además de contar con profesionales altamente calificados lo que les ha permitido capitalizar su crecimiento en el sector energía y brindar sus servicios fuera del país, el prestigio que tiene Hamek Ingenieros y Asociados S.A.C., es un diferencial frente a los retadores. 
Pregunta 9: $\quad$ ¿Ha efectuado una acción nueva o corrección de un proceso que haya causado una mejora en la organización? Si fue así ¿qué le motivo a hacerlo? ¿Quiénes intervinieron? ¿Qué resultado se produjeron?

Respuesta: No, dado que desde el 2018 ya no laboro en Hamek Ingenieros y Asociados S.A.C., sin embargo en los estudios técnicos donde se me ha convocado, aprovechamos para incorporar mejoras en los procesos de pruebas de potencia efectiva que implican un elevado estándar de exactitud, estos procesos de mejora se hacen en coordinación con el equipo técnico de Hamek Ingenieros y Asociados S.A.C. buscando superar las expectativas que tienen los clientes sobre el servicio prestado.

Pregunta 10: ¿Cuál sería la mayor desventaja o debilidad que tienen los servicios de Hamek Ingenieros Asociados S.A.C.? ¿Por qué?

Respuesta: Un desventaja que observe es que la línea de energía está muy desarrollada y eso se evidencia con una importante participación a nivel local sin embargo en la línea ambiental Hamek Ingenieros y Asociados S.A.C. no tiene tanta presencia, considerando que cada vez existe una mayor preocupación por el impacto de proyectos energéticos en el medio ambiente, debiera esforzarse en desarrollar mucho más esta línea, para ello se debe incorporar más especialistas del sector y realizar un mayor estudio de mercado para poder detectar nuevas oportunidades en esta última línea.

Pregunta 11: ¿Emplea algún programa de innovación o mejora continua en su área? Respuesta: $\quad$ Siempre se está actualizando a los especialistas, la capacitación es constante para llevar a cabo los futuros proyectos técnicos, la preocupación de Hamek Ingenieros y Asociados S.A.C. es contar con profesionales de alto rendimiento, por otro lado la innovación se hace necesaria para mejorar los procesos sin necesidad de que exista como un programa.

Pregunta 12: ¿Cómo visualiza usted a la empresa de acá a 4 años?

Respuesta: Hamek Ingenieros y Asociados S.A.C. seguirá consolidándose en el mercado local con una mayor participación, solo el competidor CENERGIA está al mismo nivel y ambas empresas han empezado a realizar estudios técnicos y de consultoría en el extranjero con relativo éxito, a futuro Hamek Ingenieros y Asociados S.A.C. también tendrá una expansión de sus servicios en la línea ambiental y se verá obligado 
a contar con un mayor número de profesionales competentes para enfrentar su crecimiento como compañía.

Pregunta 13: ¿Considera usted que los servicios que ofrece son los apropiados para satisfacer a sus clientes? ¿Por qué?

Respuesta: $\quad$ Como lo mencioné anteriormente, Hamek Ingenieros y Asociados S.A.C., se ha desarrollado mucho en los estudios técnicos en el Área de Energía donde supera la expectativa de las empresas que toman o adjudican los servicios técnicos diversos, sin embargo debe desarrollar mucho más su Área Ambiental a nivel local, Respecto a la calidad de los servicios ofrecidos, cumple con todos los estándares exigidos para la entrega de un estudio técnico, ahora, en el desarrollo de la generación de energía limpia empuja a Hamek Ingenieros y Asociados S.A.C., a desarrollarse también en esta línea de energía que incluye estudios sobre el impacto ambiental al momento de desarrollar estos proyectos.

Pregunta 14: ¿Cree que hay integración y coordinación entre sus compañeros del mismo nivel para la solución de tareas y problemas?

Respuesta: Cuando se encomienda un estudio técnico a Hamek Ingenieros y Asociados S.A.C., se establece un responsable de proyecto y el equipo de profesionales que se integran al mismo, se definen las tareas de cada uno y los plazos de atención que se tienen teniendo muy en cuenta a fecha definida para el entregable, todo ello dentro de un Gantt de actividades, además se establecen reuniones rápidas para evaluar avances de todos a cargo del jefe de proyecto, al tratarse de estudios técnicos e ingenieriles, todos entienden claramente su rol en el desarrollo del mismo, por otro lado, el personal es altamente especializado y en permanente capacitación lo que favorece de manera significativa en la ejecución de la tarea encomendada.

Pregunta 14: ¿Cómo perciben la rotación del personal dentro de la empresa: alta, moderada, baja?

Respuesta: Los profesionales de Hamek Ingenieros y Asociados S.A.C., tienen una permanencia de 2 a 3 años en promedio, son profesionales técnicos con experiencia en proyectos, sobretodo energéticos que además adquieren más experiencia en el tiempo que permanecen en Hamek Ingenieros y Asociados S.A.C., como indique antes, Hamek Ingenieros y Asociados S.A.C., no cuenta con una política de retención de cuadros 
por lo tanto, los profesionales normalmente no permanecen por más tiempo, sin embargo, Hamek Ingenieros y Asociados S.A.C., puede volver a solicitar sus servicios, bajo la modalidad de contratación de servicios externos, cuando existe un crecimiento de la demanda en los servicios que ofrece, como es mi caso dado que desde el 2018 ya no laboro en Hamek Ingenieros y Asociados S.A.C.

Pregunta 16: ¿Cómo se siente trabajando en Hamek Ingenieros Asociados S.A.C? Respuesta: En el tiempo que laboré en Hamek Ingenieros y Asociados S.A.C., me sentí muy bien, muy a gusto sacando adelante proyectos y aprendiendo más, definitivamente es una experiencia enriquecedora para mí y es una de las razones por la cuales cuando me llaman para colaborar en alguno de ellos , participo de forma activa, trabajar en Hamek Ingenieros y Asociados S.A.C., implica además, un constante aprendizaje no solo de parte técnica sino además de la normativa vigente del sector y de otras industrias afines como la minería que también tiene proyectos energéticos importantes para poder autogenerar energía para el consumo propio del proyecto y además poder contrastarlo con la legislación que se tiene en otros países como El Salvador, donde también se han prestado servicios anteriormente.

Pregunta 17: ¿Cómo describe usted la demanda actual por el servicio que se brinda? Respuesta: Una demanda en constante aumento. A nivel país y a nivel región existe una mayor demanda de energía eléctrica por el crecimiento poblacional que se proyecta y el contar con más redes de electrificación, además, los distintos países están preocupados además en desarrollar fuentes de energía renovable para no afectar el medio ambiente, en ese contexto las empresas y organizaciones son cada vez más exigentes en la puesta en marcha de estos proyectos energéticos que deben contar con estudios técnicos y de impacto del medio ambiente y ello se traduce en una mayor demanda de los servicios que brinda actualmente Hamek Ingenieros y Asociados S.A.C. y empresas del rubro.

Pregunta 18: ¿Qué hace diferente a Hamek Ingenieros Asociados S.A.C de las demás empresas que brindan los mismos servicios?

Respuesta: Hamek Ingenieros y Asociados S.A.C., es una de las empresas pioneras en la elaboración de estudios técnicos e ingenieriles para el sector energía y el Ingeniero Carrillo es un profesional muy reconocido 
en el medio lo que ha permitido que la empresa tenga un gran reconocimiento, además la trayectoria de Hamek Ingenieros y Asociados S.A.C., la he llevado a tener un crecimiento importante en el mercado local donde tiene una participación superior al $40 \%$ de todos los procesos concursales, referidos a energía, el Know how que tiene Hamek Ingenieros y Asociados S.A.C., lo diferencia de la mayoría de competidores.

Pregunta 19: ¿Qué mejoraría en Hamek Ingenieros Asociados S.A.C para que la empresa sea más reconocida en el sector?

Respuesta: Comenzaría por aumentar la participación activa en congresos y conclaves técnicos que se presenten para estar al tanto de las novedades en los sectores de interés como energía y minería y otros sectores relacionados, por otro lado se hace necesario contar con un especialista cuya función permanente sea la búsqueda de nuevas oportunidades de servicios, investigaciones nuevas y concursos técnicos donde Hamek Ingenieros y Asociados S.A.C., podría participar, estudio de las normativas vigentes locales y de los países donde Hamek Ingenieros y Asociados S.A.C., podría participar y gestionar para ser considerada como una empresa apta para participar en futuras convocatorias, aprovechando que ya cuenta con experiencia en algunos países de la región.

Pregunta 20: ¿ ¿Referente al crecimiento de la empresa? ¿Cuál es su opinión al respecto?

Respuesta: Hamek Ingenieros y Asociados S.A.C., ha conseguido un crecimiento importante, en el Perú, en muy poco tiempo, detectó la oportunidad de negocio y se certificó como una empresa apta para prestar los servicios de estudios técnicos sobre todo en proyectos energéticos, además ha conseguido incursionar en otros países de la región con mucho éxito, espero que el crecimiento se siga dando y Hamek Ingenieros y Asociados S.A.C., se siga consolidando en este sector cuya demanda seguirá creciendo dado que el sector energía está en franco crecimiento en la región.

Pregunta 21: ¿Considera usted que existe un crecimiento de la industria?

Respuesta: La información actual habla del desarrollo del sector energía eléctrica en la Sudamérica y Centromérica a una mayor velocidad que el crecimiento mundial, además las exigencias son cada vez mayores 
para todos los proyectos energéticos que se desarrollen y eso constituye una gran oportunidad para que empresas como Hamek Ingenieros y Asociados S.A.C., tengan un crecimiento mayor pues existirá mayor demanda de los servicios de asesoría y consultoría técnica, de lo anterior es importante que Hamek Ingenieros y Asociados S.A.C., esté lista para capitalizar este mayor crecimiento de la demanda. 


\section{Apéndice $\mathrm{N}^{\circ} 8$}

\section{Entrevista en Profundidad a Representante COES}

Pregunta : $\quad$ En una escala del 1 al 4 ¿Qué tan importante para el sector es el fomento de la inversión privada por parte del Estado?

\section{RPTA:4}

Pregunta: $\quad$ En una escala del 1 al 4 ¿Qué tan importante para el sector es la Calificación Riesgo País acompañado de proyección de crecimiento del PBI?

\section{RPTA:4}

Pregunta : $\quad$ En una escala del 1 al 4 ¿Qué tan importante para el sector es que Perú tenga un acuerdo energético con Brasil?

\section{RPTA:4}

Pregunta : $\quad$ En una escala del 1 al 4 ¿Qué tan importante para el sector es que Perú se constituya como Hub energético para países vecinos, como Ecuador, Chile y Bolivia?

\section{RPTA:4}

Pregunta: $\quad$ En una escala del 1 al 4 ¿Qué tan importante para el sector es que el Marco Normativo y Regulatorio sea estable?

\section{RPTA:4}

Pregunta: En una escala del 1 al 4 ¿Qué tan importante para el sector es la incorporación de tecnología para mejora de equipos de medición?

\section{RPTA:4}

Pregunta: En una escala del 1 al 4 ¿Qué tan importante para el sector es incremento de parque eólico /solar - energía renovable?

\section{RPTA:3}

Pregunta: En una escala del 1 al 4 ¿Qué tan importante para el sector es un incremento exigencias gubernamentales y empresariales?

\section{RPTA:4}


Pregunta : $\quad$ En una escala del 1 al 4 ¿Qué tan preocupante para el sector sería una inestabilidad política que frene Proyectos de Inversión?

\section{RPTA:4}

Pregunta : $\quad$ En una escala del 1 al 4 ¿Qué tan preocupante para el sector sería una Interferencia /Injerencia política en el sector eléctrico?

\section{RPTA:4}

Pregunta: $\quad$ En una escala del 1 al 4 ¿Qué tan preocupante para el sector sería la existencia de limitaciones de financiamiento por parte del FONAFE?

\section{RPTA:4}

Pregunta: $\quad$ En una escala del 1 al 4 ¿Qué tan preocupante para el sector sería una guerra comercial entre China y EEUU? afectaría el crecimiento del sector?

\section{RPTA:4}

Pregunta: $\quad$ En una escala del 1 al 4 ¿Qué tan preocupante para el sector sería el impacto negativo de factores climáticos en desarrollo del sector?

\section{RPTA:4}




\section{Apéndice $\mathbf{N}^{\circ} \mathbf{9}$}

Entrevista en Profundidad a Gerente General de Hamek Ingenieros y Asociados

S.A.C.

Pregunta: En una escala del 1 al 4 ¿Qué tan importante para el sector es Rpta.:

el fomento de la inversión privada por parte del Estado?

Pregunta: En una escala del 1 al 4 ¿Qué tan importante para el sector es Rpta.:

la Calificación Riesgo País acompañado de proyección de crecimiento del PBI?

Pregunta: En una escala del 1 al 4 ¿Qué tan importante para el sector es Rpta.: que Perú tenga un acuerdo energético con Brasil?

Pregunta: En una escala del 1 al 4 ¿Qué tan importante para el sector es Rpta.: que Perú se constituya como Hub energético para países vecinos, como Ecuador, Chile y Bolivia?

Pregunta: En una escala del 1 al 4 ¿Qué tan importante para el sector es que el Marco Normativo y Regulatorio sea estable?

Rpta.:

Pregunta: En una escala del 1 al 4 ¿Qué tan importante para el sector es la incorporación de tecnología para mejora de equipos de medición?

Pregunta: En una escala del 1 al 4 ¿Qué tan importante para el sector es el incremento de parque eólico /solar - energía renovable?

Rpta.:

Rpta::

Pregunta: En una escala del 1 al 4 ¿Qué tan importante para el sector es Rpta.: un incremento exigencias gubernamentales y empresariales?

Pregunta: En una escala del 1 al 4 ¿Qué tan preocupante para el sector Rpta.: sería una inestabilidad política que frene Proyectos de Inversión?

Pregunta: En una escala del 1 al 4 ¿Qué tan preocupante para el sector Rpta:: sería una Interferencia /Injerencia política en el sector eléctrico?

Pregunta: En una escala del 1 al 4 ¿Qué tan preocupante para el sector Rpta.: sería la existencia de limitaciones de financiamiento por parte del FONAFE? 
Pregunta: En una escala del 1 al 4 ¿Qué tan preocupante para el sector Rpta.: sería una guerra comercial entre China y EEUU?

Pregunta: En una escala del 1 al 4 ¿Qué tan preocupante para el sector Rpta.: sería el impacto negativo de factores climáticos?

Pregunta: En una escala del 1 al 4 ¿Qué tanto afecta a Hamek Ingenieros y Asociados S.A.C., el fomento de la inversión privada por parte del Estado?

Pregunta: En una escala del 1 al 4 ¿Qué tanto afecta a Hamek Ingenieros y Asociados S.A.C., es la Calificación Riesgo País acompañado de proyección de crecimiento del PBI?

Rpta::

Rpta::

Pregunta: En una escala del 1 al 4 ¿Qué tanto afecta a Hamek Ingenieros y Asociados S.A.C., que Perú tenga un acuerdo energético con Brasil?

Rpta.:

Pregunta: En una escala del 1 al 4 ¿Qué tanto afecta a Hamek Ingenieros y Asociados S.A.C., que el Perú se constituya como Hub energético para países vecinos como Ecuador, Chile y Bolivia?

Pregunta: En una escala del 1 al 4 ¿Qué tanto afecta a Hamek Ingenieros y Asociados S.A.C., que el Marco Normativo y Regulatorio sea estable?

Rpta::

Rpta::

Pregunta: En una escala del 1 al 4 ¿Qué tanto afecta a Hamek Ingenieros Rpta.: y Asociados S.A.C., la incorporación de tecnología para mejora de equipos de medición?

Pregunta: En una escala del 1 al 4 ¿Qué tanto afecta a Hamek Ingenieros Rpta.: y Asociados S.A.C., el incremento de parque eólico /solar energía renovable?

Pregunta: En una escala del 1 al 4 ¿Qué tanto afecta a Hamek Ingenieros Rpta.: y Asociados S.A.C., un incremento exigencias gubernamentales y empresariales?

Pregunta: En una escala del 1 al 4 ¿Qué tanto afectaría a Hamek Rpta.: Ingenieros y Asociados S.A.C., una inestabilidad política que frene Proyectos de Inversión? 
Pregunta: En una escala del 1 al 4 ¿Qué tanto afectaría a Hamek

Rpta.:

Ingenieros y Asociados S.A.C., una Interferencia /Injerencia

política en el sector eléctrico?

Pregunta: En una escala del 1 al 4 ¿Qué tanto afectaría a Hamek Rpta.: Ingenieros y Asociados S.A.C., la existencia de limitaciones de financiamiento por parte del FONAFE?

Pregunta: En una escala del 1 al 4 ¿Qué tanto afectaría a Hamek Rpta.: Ingenieros y Asociados S.A.C., una guerra comercial entre China y EEUU? afectaría su crecimiento?.

Pregunta: En una escala del 1 al 4 ¿Qué tanto afectaría a Hamek Rpta.: Ingenieros y Asociados S.A.C., sería el impacto negativo de factores climáticos en desarrollo del sector? 
Apéndice $\mathrm{N}^{\circ} 10$

Tabulación Respuestas de Entrevista en Profundidad para determinación pesos y valores de Matriz MEFE

\begin{tabular}{|c|c|c|c|c|c|}
\hline & & \multicolumn{3}{|c|}{ INDUSTRIA } \\
\hline & & & EXPERTO1COES & EXPERTO 2 & TOTAL \\
\hline \multirow{8}{*}{$\begin{array}{l}0 \\
0 \\
0 \\
z \\
\partial \\
0 \\
0 \\
0 \\
0 \\
0\end{array}$} & 1 & $\begin{array}{l}\text { QQué tan importante para el sector es el fomento } \\
\text { de la inversión privada por parte del Estado? }\end{array}$ & 4 & 3 & 7 \\
\hline & 2 & $\begin{array}{l}\text { Qué tan importante para el sector es la } \\
\text { Calificación Riesgo País acompañado de } \\
\text { proyección de crecimientodel PBI? }\end{array}$ & 4 & 3 & 7 \\
\hline & 3 & \begin{tabular}{|l|} 
¿Qué tan importante para el sector es Perú tenga \\
un acuerdo energético con Brasil?
\end{tabular} & 4 & 3 & 7 \\
\hline & 4 & \begin{tabular}{|l|} 
QQué tan importante para el sector es que perú se \\
constituya en un hub energetico en la región?
\end{tabular} & 4 & 4 & 8 \\
\hline & 5 & \begin{tabular}{|l|} 
¿Qué tan impottante para el sector es que el \\
Marco Normativo y Regulatorio sea estable? \\
\end{tabular} & 4 & 4 & 8 \\
\hline & 6 & 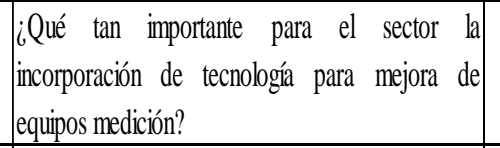 & 4 & 3 & 7 \\
\hline & 7 & $\begin{array}{l}\text { QQué tan importante para el sector es el } \\
\text { incremento del parque eolico / solar de energía } \\
\text { renovable }\end{array}$ & 3 & 3 & 6 \\
\hline & 8 & $\begin{array}{l}\text { QQué tan importante para el sector es un } \\
\text { incremento exigencias gubernamentales y } \\
\text { empresaraiales? }\end{array}$ & 4 & 4 & 8 \\
\hline \multirow{5}{*}{ 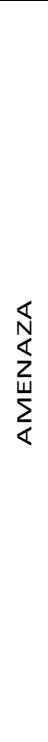 } & 8 & $\begin{array}{l}\text { Qué tan preocupante para el sector sería una } \\
\text { inestabilidad politica que frene Proyectos de } \\
\text { Inversión? }\end{array}$ & 2 & 4 & 6 \\
\hline & 9 & $\begin{array}{l}\text { QQué tan preocupante para el sector sería una } \\
\text { Interferencia Injerencia politica en el sector } \\
\text { eléctrico? }\end{array}$ & 3 & 3 & 6 \\
\hline & 10 & $\begin{array}{l}\text { QQué tan preocupante para el sector sería la } \\
\text { existencia de limitaciones de financiamiento por } \\
\text { parte delFONAFE? }\end{array}$ & 3 & 3 & 6 \\
\hline & 11 & $\begin{array}{l}\text { QQué tan preocupante para el sector sería un } \\
\text { cambio de condiciones de servicio por parte del } \\
\text { COES? }\end{array}$ & 3 & 3 & 6 \\
\hline & 12 & $\begin{array}{l}\text { QQué tan preocupante para el sector sería el } \\
\text { impacto negativo de factores climáticos en } \\
\text { desarrollo del sector? }\end{array}$ & 4 & 3 & 7 \\
\hline
\end{tabular}

\begin{tabular}{|c|c|}
\hline & VALOR HAMEK \\
\hline PESO RELATIVO & GTEGRAL \\
\hline 0.05 & 3 \\
\hline 0.05 & 3 \\
\hline 0.06 & 3 \\
\hline 0.08 & 4 \\
\hline 0.08 & 4 \\
\hline 0.07 & 3 \\
\hline 0.04 & 3 \\
\hline 0.08 & 4 \\
\hline 0.09 & 4 \\
\hline 0.09 & 3 \\
\hline 0.09 & 3 \\
\hline 0.09 & 3 \\
\hline 0.13 & 3 \\
\hline
\end{tabular}




\section{Anexo №1}

\section{Consultores inscritos en el COES}

Hamek Ingenieros Asociados S.A.C., se encuentra acreditada por el COES SINAC, máxima entidad de regulación eléctrica a nivel nacional, como consultoras especializada en realizar el servicio en ejecución de los ensayos de potencia efectiva y rendimiento de las unidades térmicas y potencia efectiva de las centrales hidráulicas.

Como se visualiza en la página web del COES, y en la lista de consultoras registradas.
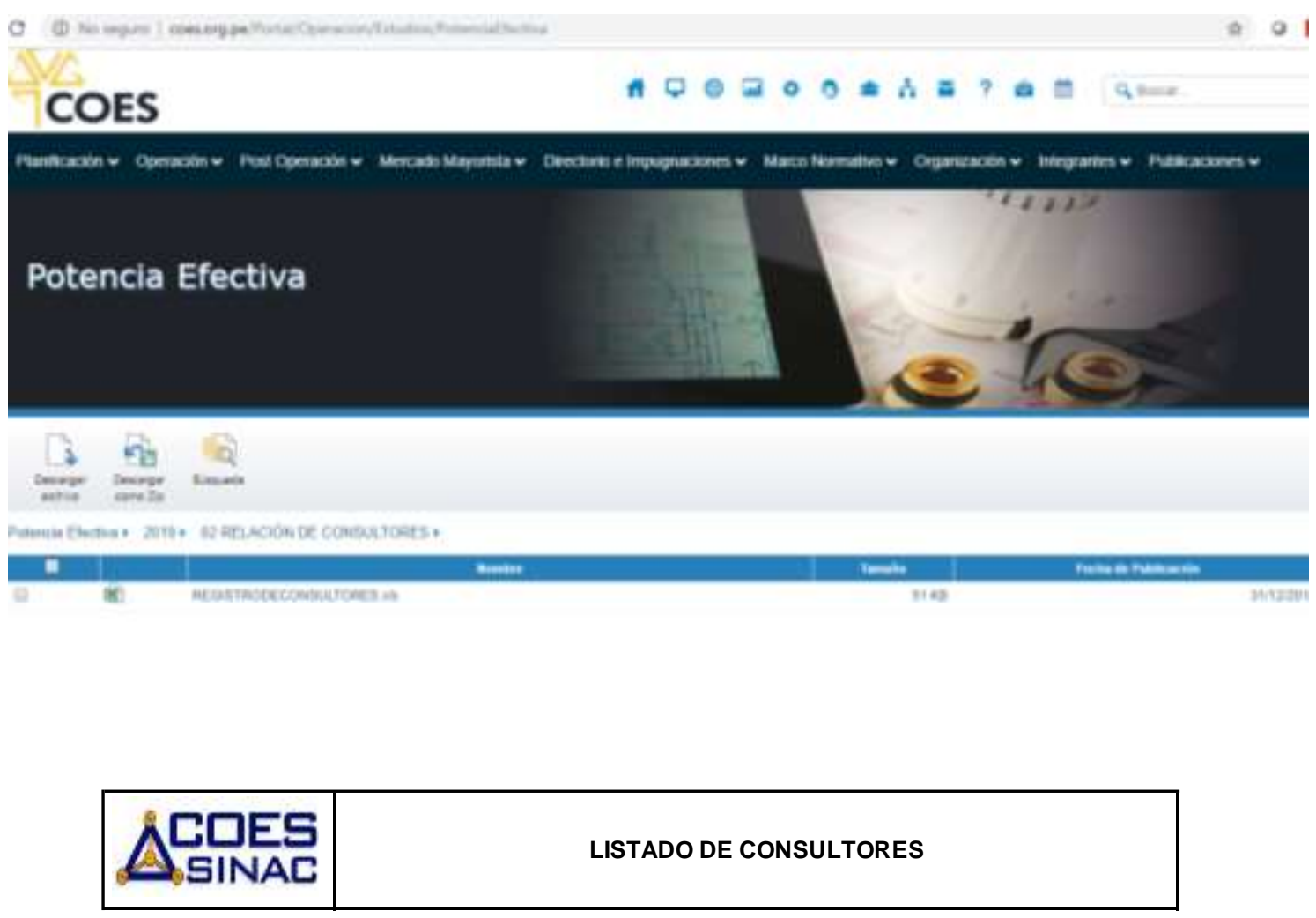

\begin{tabular}{c|c|l|l|c|}
\begin{tabular}{|c|c} 
N \\
N
\end{tabular} & \multicolumn{2}{c}{ PROVEEDOR } & \multicolumn{1}{c|}{ TIPO } & $\begin{array}{l}\text { FECHA } \\
\text { INSCRIPC. }\end{array}$ \\
\hline 1 & P3.14 & $\begin{array}{l}\text { CENTRO DE CONSERVACION DE ENERGIA Y DEL } \\
\text { AMBIENTE (CENERGIA) }\end{array}$ & $\begin{array}{l}\text { CONSULTORIAY } \\
\text { ASESORIA GRAL. }\end{array}$ & 11.12 .2012 \\
\hline 2 & P1.10 & ALFA PLUS S.A.C. & $\begin{array}{l}\text { CONSULTORIAY } \\
\text { ASESORIA GRAL. }\end{array}$ & 28.04 .2014 \\
\hline 3 & P8.5 & $\begin{array}{l}\text { GLOBAL ENERGY ENVIRONMENTAL AND } \\
\text { ECONOMIC CONSULTING S.A. }\end{array}$ & $\begin{array}{l}\text { CONSULTORIAY } \\
\text { ASESORIA GRAL. }\end{array}$ & 26.03 .2012 \\
\hline 4 & P9.5 & HAMEK INGENIEROS ASOCIADOS & $\begin{array}{l}\text { CONSULTORIAY } \\
\text { ASESORIA GRAL. }\end{array}$ & 12.05 .2014 \\
\hline
\end{tabular}




\section{Anexo №2}

La empresa está inscrita en la UT Unidad de Transacción de EI Salvador

En el ámbito internacional, cuenta con la inscripción en la UT Unidad de Transacción de EI Salvador, ente similar al COES, como se muestra en su página web. Con este registro la empresa se encuentra habilitada como experto en Pruebas de Potencia efectiva en generadoras en El Salvador, Guatemala y Honduras.
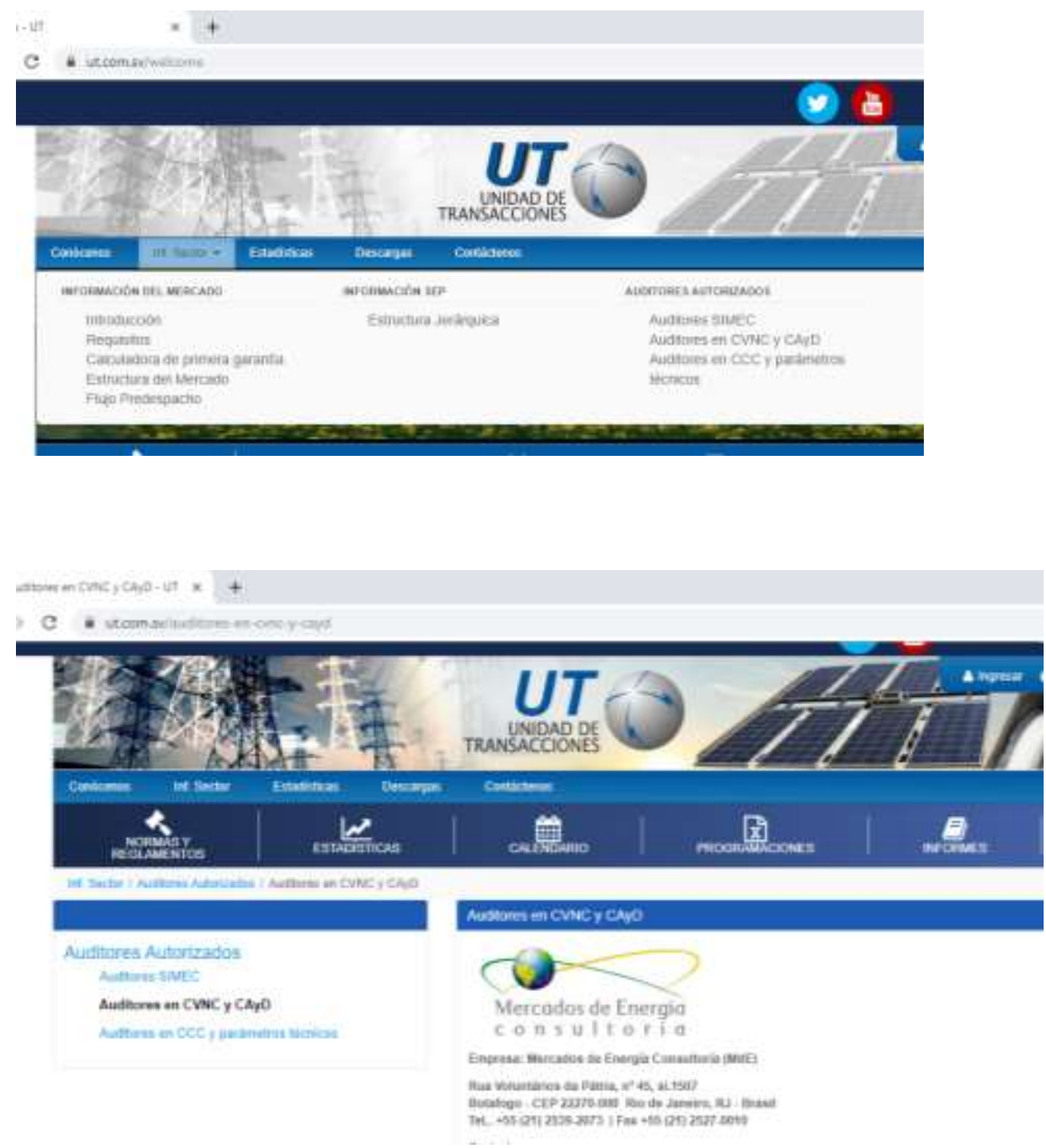

\section{Hamek}


En Chile, Hamek Ingenieros Asociados S.A.C., se encuentra registrada como proveedor en las principales generadoras Engie Energía Chile S.A., Enel Generación Chile S.A. y Aes Gener S.A., quien son los intermediarios ante el Coordinador Eléctrico Nacional (CEN), para ser convocados para participar en las licitaciones y brindar los servicios de Consumo Especifico de Unidades Generadoras. 


\section{Anexo № 3}

\section{Características de las pequeñas empresas en el Perú}

Las pequeñas empresas están definidas por la ley peruana como aquellas que tiene un nivel de ventas totales equivalente al valor entre 140 y 1700 unidades impositivas tributarias (UIT). [22]

Hamek Ingenieros Asociados S.A.C., está clasificada de acuerdo a sus ventas anuales como una pequeña empresa, tamaño designado de acuerdo a las características determinadas por la SUNAT, como se observa en el cuadro adjunto. Al cierre del 2018, las ventas anuales no han superado los 1700 (UIT). A través de esta definición, se observa en la siguiente tabla extraída de la página de la SUNAT que las pequeñas empresas tienen un rango de ventas mayor a las microempresas.

\section{CARACTERÍSTICAS DE LA MICRO Y PEQUEÑAS EMPRESAS:}

Las MYPES deben reunir las siguientes características recurrentes:

\begin{tabular}{|c|c|}
\hline \multicolumn{2}{|c|}{ MICROEMPRESA } \\
\hline $\begin{array}{c}\text { NÚMERO DE } \\
\text { TRABAJADORES }\end{array}$ & De uno (1) hasta diez (10) trabajadores inclusive. \\
\hline VENTAS ANUALES & Hasta el monto máximo de 150 Unidades Impositivas \\
& Tributarias (UIT) (*)
\end{tabular}

\begin{tabular}{|c|c|}
\hline \multicolumn{2}{|c|}{ PEQUEÑA EMPRESA } \\
\hline NÚMERO DE TRABAJADORES & De uno (1) hasta cien (100) trabajadores \\
inclusive.
\end{tabular}

(*) Monto de la UIT para el 2019 es de S/4200 nuevos soles. 


\section{Anexo № 4}

Carta de Acreditación del COES a Hamek Ingenieros Asociados S.A.C como empresa calificada para realizar Ensayos de Potencia Efectiva en Unidades Térmicas e Hidráulicas.

\section{$\triangle$ S므를

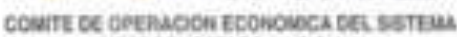 MTInCONECTAOO NuCiones \\ San isidro, 21 de octubre de 2010}

\section{COESID - 706-2010}

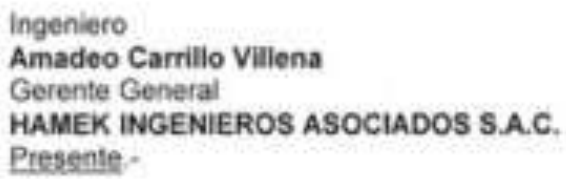

Aeanto

INSCRIPCION EN EL. REGISTRO DE ENTIDADES AUTORIZADAS PARA ELABORAR ESTUDIOS DE POTENCIA EFECTIVA $Y$ RENDIMIENTO

Bet.

De mi consideración:

Me dirio a usted, con relacion a su carta de la referencia, mediante la cual nos solicita la inscripcion en los registros de entidades autorizadas para elaborar estudios de potencia efectiva y rendimiento de las unidades térmicas y polencia efectiva de las centrales hidraulicas.

Al respecto, se reviso la informeción tecnica presentada por ustedes y consideramos que cuenta con perscnal calificado y de experiencia en el rubro solicitado, asi como. disponen de los equipos de medicion que normalmente son uticicados para los fines antes sefalados.

Por io tanto, mandestamos que HAMEK INGENIEROS ASOCIADOS S.A.C, esta calificada para tealizar Ensayos de Potencia Electiva y Rendimiento de unidades termicas y Ensayos de Potencia Efectiva de centrales hidrdulicas y, a partir de la fecha de emisión dol presenta documento, formara parte de la relación de consultoras calificadas para tal fin

Sin otro particular, hago propicia la ocasion para saludarto

Atentamente.

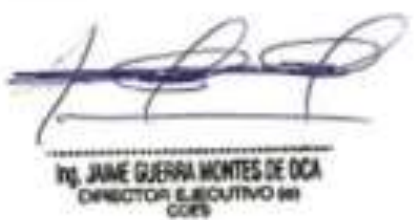




\section{Anexo №5}

\section{Beta por Sector}

\begin{tabular}{|c|c|c|c|c|c|c|c|c|c|c|}
\hline Betas by sector & $\begin{array}{c}\text { Number of } \\
\text { firms }\end{array}$ & Beta & D/E Ratio & $\begin{array}{c}\text { Effective } \\
\text { Tax rate }\end{array}$ & Unlevered beta & Cash/Firm value & $\begin{array}{c}\text { Unlevered beta corrected for } \\
\text { cash }\end{array}$ & HiLo Risk & $\begin{array}{l}\text { Standard } \\
\text { deviation } \\
\text { of equity }\end{array}$ & \begin{tabular}{|c}
$\begin{array}{c}\text { Standard } \\
\text { deviation } \\
\text { in }\end{array}$ \\
operating \\
income \\
(last 10 \\
years)
\end{tabular} \\
\hline \begin{tabular}{|l|} 
Advertising \\
\end{tabular} & 40 & 1.15 & $73.87 \%$ & $6.38 \%$ & 0.74 & $5.80 \%$ & 0.78 & 0.631 & $80.95 \%$ & $15.30 \%$ \\
\hline Aerospace/Defense & 87 & 1.08 & $18.46 \%$ & $11.59 \%$ & 0.95 & $4.33 \%$ & 0.99 & 0.4893 & $49.06 \%$ & $12.87 \%$ \\
\hline Air Transport & 17 & 1.01 & $71.00 \%$ & $24.57 \%$ & 0.66 & $2.67 \%$ & 0.67 & 0.4148 & $40.20 \%$ & $92.29 \%$ \\
\hline Apparel & 51 & 1.02 & $34.18 \%$ & $10.35 \%$ & 0.81 & $5.16 \%$ & 0.85 & 0.4998 & $59.71 \%$ & $22.55 \%$ \\
\hline Auto \& Truck & 18 & 1.2 & $148.09 \%$ & $8.15 \%$ & 0.56 & $4.88 \%$ & 0.59 & 0.6051 & $38.59 \%$ & $209.62 \%$ \\
\hline Auto Parts & 62 & 1.04 & $28.30 \%$ & $7.71 \%$ & 0.85 & $7.19 \%$ & 0.92 & 0.5423 & $56.74 \%$ & $53.93 \%$ \\
\hline Bank (Money Center) & 11 & 0.64 & $157.26 \%$ & $27.31 \%$ & 0.29 & $9.94 \%$ & 0.32 & 0.1462 & $33.37 \%$ & NA \\
\hline Banks (Regional) & 612 & 0.5 & $58.68 \%$ & $25.57 \%$ & 0.35 & $10.04 \%$ & 0.39 & 0.1809 & $32.08 \%$ & NA \\
\hline Beverage (Alcoholic) & 28 & 1.33 & $26.14 \%$ & $10.12 \%$ & 1.11 & $1.20 \%$ & 1.12 & 0.5387 & $50.14 \%$ & $32.58 \%$ \\
\hline Beverage (Soft) & 35 & 0.7 & $23.06 \%$ & $6.41 \%$ & 0.6 & $4.46 \%$ & 0.63 & 0.585 & $45.33 \%$ & $13.03 \%$ \\
\hline Broadcasting & 27 & 1.12 & $112.17 \%$ & $17.18 \%$ & 0.6 & $7.16 \%$ & 0.65 & 0.4085 & $52.30 \%$ & $20.47 \%$ \\
\hline Brokerage \& Investment Banking & 42 & 1.24 & $219.92 \%$ & $14.56 \%$ & 0.46 & $14.84 \%$ & 0.54 & 0.4586 & $42.48 \%$ & $36.49 \%$ \\
\hline Building Materials & 39 & 1.11 & $21.46 \%$ & $23.34 \%$ & 0.95 & $3.30 \%$ & 0.99 & 0.3135 & $41.01 \%$ & $55.46 \%$ \\
\hline Business \& Consumer Services & 169 & 1.17 & $27.44 \%$ & $11.09 \%$ & 0.97 & $3.94 \%$ & 1.01 & 0.5442 & $49.45 \%$ & $19.49 \%$ \\
\hline Cable TV & 14 & 0.92 & $53.05 \%$ & $22.23 \%$ & 0.66 & $1.67 \%$ & 0.67 & 0.4154 & $36.33 \%$ & $35.61 \%$ \\
\hline Chemical (Basic) & 38 & 1.2 & $41.28 \%$ & $9.76 \%$ & 0.91 & $5.52 \%$ & 0.96 & 0.5297 & $59.39 \%$ & $40.60 \%$ \\
\hline Chemical (Diversified) & 7 & 2.03 & $27.19 \%$ & $11.66 \%$ & 1.69 & $6.07 \%$ & 1.79 & 0.3952 & $68.62 \%$ & $36.93 \%$ \\
\hline Chemical (Specialty) & 99 & 1.11 & $29.00 \%$ & $9.64 \%$ & 0.91 & $3.71 \%$ & 0.95 & 0.4598 & $59.69 \%$ & $20.92 \%$ \\
\hline Coal \& Related Energy & 30 & 1.25 & $45.41 \%$ & $4.94 \%$ & 0.93 & $10.94 \%$ & 1.04 & 0.593 & $90.61 \%$ & $226.93 \%$ \\
\hline Computer Services & 111 & 1.1 & $30.83 \%$ & $9.40 \%$ & 0.89 & $5.49 \%$ & 0.94 & 0.5432 & $48.53 \%$ & $12.54 \%$ \\
\hline Computers/Peripherals & 58 & 1.01 & $18.17 \%$ & $5.03 \%$ & 0.89 & $4.44 \%$ & 0.93 & 0.5296 & $61.38 \%$ & $44.58 \%$ \\
\hline Construction Supplies & 49 & 1.12 & $32.47 \%$ & $17.36 \%$ & 0.9 & $5.64 \%$ & 0.95 & 0.3347 & $45.67 \%$ & $28.97 \%$ \\
\hline Diversified & 24 & 1.19 & $32.49 \%$ & $12.09 \%$ & 0.96 & $5.48 \%$ & 1.01 & 0.437 & $26.82 \%$ & $22.28 \%$ \\
\hline Drugs (Biotechnology) & 459 & 1.44 & $15.83 \%$ & $1.36 \%$ & 1.29 & $5.27 \%$ & 1.36 & 0.5569 & $94.78 \%$ & $59.98 \%$ \\
\hline Drugs (Pharmaceutical) & 185 & 1.21 & $14.63 \%$ & $2.11 \%$ & 1.09 & $3.65 \%$ & 1.13 & 0.5754 & $85.70 \%$ & $9.32 \%$ \\
\hline Education & 34 & 1.15 & $38.83 \%$ & $8.24 \%$ & 0.89 & $7.06 \%$ & 0.96 & 0.473 & $53.59 \%$ & $25.37 \%$ \\
\hline Electrical Equipment & 118 & 1.08 & $15.85 \%$ & $5.06 \%$ & 0.97 & $5.49 \%$ & 1.02 & 0.6021 & $66.17 \%$ & $15.61 \%$ \\
\hline Electronics (Consumer \& Office) & 24 & 1.09 & $6.94 \%$ & $5.98 \%$ & 1.04 & $3.85 \%$ & 1.08 & 0.5949 & $70.22 \%$ & $257.32 \%$ \\
\hline Electronics (General) & 167 & 0.94 & $14.97 \%$ & $8.34 \%$ & 0.84 & $7.80 \%$ & 0.91 & 0.5125 & $60.25 \%$ & $28.33 \%$ \\
\hline Engineering/Construction & 49 & 1.27 & $29.72 \%$ & $13.37 \%$ & 1.04 & $8.14 \%$ & 1.13 & 0.413 & $53.02 \%$ & $11.78 \%$ \\
\hline Entertainment & 90 & 1.15 & $33.74 \%$ & $5.45 \%$ & 0.92 & $4.23 \%$ & 0.96 & 0.6323 & $54.94 \%$ & $20.36 \%$ \\
\hline Environmental \& Waste Services & 87 & 0.88 & $34.87 \%$ & $4.45 \%$ & 0.69 & $0.93 \%$ & 0.7 & 0.605 & $65.74 \%$ & $12.70 \%$ \\
\hline Farming/Agriculture & 34 & 0.74 & $55.54 \%$ & $7.69 \%$ & 0.52 & $6.02 \%$ & 0.56 & 0.4842 & $42.57 \%$ & $25.17 \%$ \\
\hline Financial Svcs. (Non-bank \& Insuran & 264 & 0.61 & $1032.19 \%$ & $19.89 \%$ & 0.07 & $2.38 \%$ & 0.07 & 0.2561 & $36.63 \%$ & $53.82 \%$ \\
\hline
\end{tabular}




\section{Anexo №6}

Tasa de Mercado y Tasa Libre de Riesgo

\begin{tabular}{|c|c|c|c|c|c|c|c|c|c|c|c|c|}
\hline \multicolumn{4}{|c|}{ Annual Returns on Investments in } & \multicolumn{6}{|c|}{ Compounded Value of $\$ 100$} & \multirow[b]{2}{*}{$\begin{array}{ll}\text { Stocks } & - \\
\end{array}$} & \multirow[b]{2}{*}{ Stocks -} & \multirow[b]{2}{*}{ Historic: $\mathrm{r}$} \\
\hline Year & S\&P 500 (include & 3-month T.Bill & Returno $=$ & & cks & & Bills & & nds & & & \\
\hline 1928 & $43.81 \%$ & $3.08 \%$ & $0.84 \%$ & $\mathrm{~S} /$ & 143.81 & $\mathrm{~S} /$ & 103.08 & $\mathrm{~S} /$ & 100.84 & $40.73 \%$ & $42.98 \%$ & \\
\hline 1929 & $-8.30 \%$ & $3.16 \%$ & $4.20 \%$ & $\mathrm{~S} /$ & 131.88 & S/ & 106.34 & $\mathrm{~S} /$ & 105.07 & $-11.46 \%$ & $-12.50 \%$ & \\
\hline 1930 & $-25.12 \%$ & $4.55 \%$ & $4.54 \%$ & $\mathrm{~S} /$ & 98.75 & $\mathrm{~S} /$ & 111.18 & $\mathrm{~S} /$ & 109.85 & $-29.67 \%$ & $-29.66 \%$ & \\
\hline 1931 & $-43.84 \%$ & $2.31 \%$ & $-2.56 \%$ & $\mathrm{~S} /$ & 55.46 & $\mathrm{~S} /$ & 113.74 & $\mathrm{~S} /$ & 107.03 & $-46.15 \%$ & $-41.28 \%$ & \\
\hline 1932 & $-8.64 \%$ & $1.07 \%$ & $8.79 \%$ & $\mathrm{~S} /$ & 50.66 & $\mathrm{~S} /$ & 114.96 & $\mathrm{~S} /$ & 116.44 & $-9.71 \%$ & $-17.43 \%$ & \\
\hline 1933 & $49.98 \%$ & $0.96 \%$ & $1.86 \%$ & $\mathrm{~S} /$ & 75.99 & S/ & 116.06 & $\mathrm{~S} /$ & 118.60 & $49.02 \%$ & $48.13 \%$ & \\
\hline 1934 & $-1.19 \%$ & $0.32 \%$ & $7.96 \%$ & $\mathrm{~S} /$ & 75.09 & S/ & 116.44 & S/ & 128.05 & $-1.51 \%$ & $-9.15 \%$ & \\
\hline 1935 & $46.74 \%$ & $0.18 \%$ & $4.47 \%$ & $\mathrm{~S} /$ & 110.18 & $\mathrm{~S} /$ & 116.64 & $\mathrm{~S} /$ & 133.78 & $46.57 \%$ & $42.27 \%$ & \\
\hline 1936 & $31.94 \%$ & $0.17 \%$ & $5.02 \%$ & $\mathrm{~S} /$ & 145.38 & S/ & 116.84 & $\mathrm{~S} /$ & 140.49 & $31.77 \%$ & $26.93 \%$ & \\
\hline 1937 & $-35.34 \%$ & $0.30 \%$ & $1.38 \%$ & $\mathrm{~S} /$ & 94.00 & $\mathrm{~S} /$ & 117.19 & S/ & 142.43 & $-35.64 \%$ & $-36.72 \%$ & \\
\hline 1938 & $29.28 \%$ & $0.08 \%$ & $4.21 \%$ & $\mathrm{~S} /$ & 121.53 & $\mathrm{~S} /$ & 117.29 & $\mathrm{~S} /$ & 148.43 & $29.21 \%$ & $25.07 \%$ & \\
\hline 1939 & $-1.10 \%$ & $0.04 \%$ & $4.41 \%$ & $\mathrm{~S} /$ & 120.20 & $\mathrm{~S} /$ & 117.33 & $\mathrm{~S} /$ & 154.98 & $-1.14 \%$ & $-5.51 \%$ & \\
\hline 1940 & $-10.67 \%$ & $0.03 \%$ & $5.40 \%$ & $\mathrm{~S} /$ & 107.37 & $\mathrm{~S} /$ & 117.36 & $\mathrm{~S} /$ & 163.35 & $-10.70 \%$ & $-16.08 \%$ & \\
\hline 1941 & $-12.77 \%$ & $0.08 \%$ & $-2.02 \%$ & $\mathrm{~S} /$ & 93.66 & $\mathrm{~S} /$ & 117.46 & S/ & 160.04 & $-12.85 \%$ & $-10.75 \%$ & \\
\hline 1942 & $19.17 \%$ & $0.34 \%$ & $2.29 \%$ & $\mathrm{~S} /$ & 111.61 & $\mathrm{~S} /$ & 117.85 & $\mathrm{~S} /$ & 163.72 & $18.84 \%$ & $16.88 \%$ & \\
\hline 1943 & $25.06 \%$ & $0.38 \%$ & $2.49 \%$ & $\mathrm{~S} /$ & 139.59 & $\mathrm{~S} /$ & 118.30 & $\mathrm{~S} /$ & 167.79 & $24.68 \%$ & $22.57 \%$ & \\
\hline 1944 & $19.03 \%$ & $0.38 \%$ & $2.58 \%$ & $\mathrm{~S} /$ & 166.15 & $\mathrm{~S} /$ & 118.75 & $\mathrm{~S} /$ & 172.12 & $18.65 \%$ & $16.45 \%$ & \\
\hline 1945 & $35.82 \%$ & $0.38 \%$ & $3.80 \%$ & $\mathrm{~S} /$ & 225.67 & S/ & 119.20 & $\mathrm{~S} /$ & 178.67 & $35.44 \%$ & $32.02 \%$ & \\
\hline 1946 & $-8.43 \%$ & $0.38 \%$ & $3.13 \%$ & $\mathrm{~S} /$ & 206.65 & $\mathrm{~S} /$ & 119.65 & $\mathrm{~S} /$ & 184.26 & $-8.81 \%$ & $-11.56 \%$ & \\
\hline 1947 & $5.20 \%$ & $0.57 \%$ & $0.92 \%$ & $\mathrm{~S} /$ & 217.39 & $\mathrm{~S} /$ & 120.33 & $\mathrm{~S} /$ & 185.95 & $4.63 \%$ & $4.28 \%$ & \\
\hline 1948 & $5.70 \%$ & $1.02 \%$ & $1.95 \%$ & $\mathrm{~S} /$ & 229.79 & S/ & 121.56 & $\mathrm{~S} /$ & 189.58 & $4.68 \%$ & $3.75 \%$ & \\
\hline 1949 & $18.30 \%$ & $1.10 \%$ & $4.66 \%$ & $\mathrm{~S} /$ & 271.85 & S/ & 122.90 & $\mathrm{~S} /$ & 198.42 & $17.20 \%$ & $13.64 \%$ & \\
\hline 1950 & $30.81 \%$ & $1.17 \%$ & $0.43 \%$ & $\mathrm{~S} /$ & 355.60 & $\mathrm{~S} /$ & 124.34 & $\mathrm{~S} /$ & 199.27 & $29.63 \%$ & $30.38 \%$ & \\
\hline 1951 & $23.68 \%$ & $1.48 \%$ & $-0.30 \%$ & $\mathrm{~S} /$ & 439.80 & $\mathrm{~S} /$ & 126.18 & $\mathrm{~S} /$ & 198.68 & $22.20 \%$ & $23.97 \%$ & \\
\hline 1952 & $18.15 \%$ & $1.67 \%$ & $2.27 \%$ & $\mathrm{~S} /$ & 519.62 & $\mathrm{~S} /$ & 128.29 & $\mathrm{~S} /$ & 203.19 & $16.48 \%$ & $15.88 \%$ & \\
\hline 1953 & $-1.21 \%$ & $1.89 \%$ & $4.14 \%$ & $\mathrm{~S} /$ & 513.35 & S/ & 130.72 & S/ & 211.61 & $-3.10 \%$ & $-5.35 \%$ & \\
\hline 1954 & $52.56 \%$ & $0.96 \%$ & $3.29 \%$ & $\mathrm{~S} /$ & 783.18 & S/ & 131.98 & S/ & 218.57 & $51.60 \%$ & $49.27 \%$ & \\
\hline 1955 & $32.60 \%$ & $1.66 \%$ & $-1.34 \%$ & $\mathrm{~S} /$ & $1,038.47$ & $\mathrm{~S} /$ & 134.17 & $\mathrm{~S} /$ & 215.65 & $30.94 \%$ & $33.93 \%$ & \\
\hline 1956 & $7.44 \%$ & $2.56 \%$ & $-2.26 \%$ & $\mathrm{~S} /$ & $1,115.73$ & $\mathrm{~S} /$ & 137.60 & $\mathrm{~S} /$ & 210.79 & $4.88 \%$ & $9.70 \%$ & \\
\hline 1957 & $-10.46 \%$ & $3.23 \%$ & $6.80 \%$ & $\mathrm{~S} /$ & 999.05 & $\mathrm{~S} /$ & 142.04 & S/ & 225.11 & $-13.69 \%$ & $-17.25 \%$ & \\
\hline 1958 & $43.72 \%$ & $1.78 \%$ & $-2.10 \%$ & $\mathrm{~S} /$ & $1,435.84$ & $\mathrm{~S} /$ & 144.57 & $\mathrm{~S} /$ & 220.39 & $41.94 \%$ & $45.82 \%$ & \\
\hline 1959 & $12.06 \%$ & $3.26 \%$ & $-2.65 \%$ & $\mathrm{~S} /$ & $1,608.95$ & $\mathrm{~S} /$ & 149.27 & $\mathrm{~S} /$ & 214.56 & $8.80 \%$ & $14.70 \%$ & \\
\hline 1960 & $0.34 \%$ & $3.05 \%$ & $11.64 \%$ & $\mathrm{~S} /$ & $1,614.37$ & S/ & 153.82 & $\mathrm{~S} /$ & 239.53 & $-2.71 \%$ & $-11.30 \%$ & $0.10 \%$ \\
\hline
\end{tabular}




\begin{tabular}{|c|c|c|c|c|c|c|c|c|c|c|c|}
\hline 1961 & $26.64 \%$ & $2.27 \%$ & $2.06 \%$ & $\mathrm{~S} /$ & $2,044.40$ & 157.30 & $\mathrm{~S} /$ & 244.46 & $24.37 \%$ & $24.58 \%$ & $0.11 \%$ \\
\hline 1962 & $-8.81 \%$ & $2.78 \%$ & $5.69 \%$ & $\mathrm{~S} /$ & $1,864.26$ & 161.67 & $\mathrm{~S} /$ & 258.38 & $-11.59 \%$ & $-14.51 \%$ & $0.10 \%$ \\
\hline 1963 & $22.61 \%$ & $3.11 \%$ & $1.68 \%$ & $\mathrm{~S} /$ & $2,285.80$ & 166.70 & $\mathrm{~S} /$ & 262.74 & $19.50 \%$ & $20.93 \%$ & $0.11 \%$ \\
\hline 1964 & $16.42 \%$ & $3.51 \%$ & $3.73 \%$ & $\mathrm{~S} /$ & $2,661.02$ & 172.54 & $\mathrm{~S} /$ & 272.53 & $12.91 \%$ & $12.69 \%$ & $0.12 \%$ \\
\hline 1965 & $12.40 \%$ & $3.90 \%$ & $0.72 \%$ & $\mathrm{~S} /$ & $2,990.97$ & 179.28 & $\mathrm{~S} /$ & 274.49 & $8.50 \%$ & $11.68 \%$ & $0.12 \%$ \\
\hline 1966 & $-9.97 \%$ & $4.84 \%$ & $2.91 \%$ & $\mathrm{~S} /$ & $2,692.74$ & 187.95 & $\mathrm{~S} /$ & 282.47 & $-14.81 \%$ & $-12.88 \%$ & $0.11 \%$ \\
\hline 1967 & $23.80 \%$ & $4.33 \%$ & $-1.58 \%$ & $\mathrm{~S} /$ & $3,333.69$ & 196.10 & $\mathrm{~S} /$ & 278.01 & $19.47 \%$ & $25.38 \%$ & $0.13 \%$ \\
\hline 1968 & $10.81 \%$ & $5.26 \%$ & $3.27 \%$ & $\mathrm{~S} /$ & $3,694.23$ & S/ $\quad 206.41$ & $\mathrm{~S} /$ & 287.11 & $5.55 \%$ & $7.54 \%$ & $0.13 \%$ \\
\hline 1969 & $-8.24 \%$ & $6.56 \%$ & $-5.01 \%$ & $\mathrm{~S} /$ & $3,389.77$ & 219.96 & $\mathrm{~S} /$ & 272.71 & $-14.80 \%$ & $-3.23 \%$ & $0.13 \%$ \\
\hline 1970 & $3.56 \%$ & $6.69 \%$ & $16.75 \%$ & $\mathrm{~S} /$ & $3,510.49$ & 234.66 & $\mathrm{~S} /$ & 318.41 & $-3.12 \%$ & $-13.19 \%$ & $0.12 \%$ \\
\hline 1971 & $14.22 \%$ & $4.54 \%$ & $9.79 \%$ & $\mathrm{~S} /$ & $4,009.72$ & S/ 245.32 & $\mathrm{~S} /$ & 349.57 & $9.68 \%$ & $4.43 \%$ & $0.12 \%$ \\
\hline 1972 & $18.76 \%$ & $3.95 \%$ & $2.82 \%$ & $\mathrm{~S} /$ & $4,761.76$ & 255.01 & $\mathrm{~S} /$ & 359.42 & $14.80 \%$ & $15.94 \%$ & $0.13 \%$ \\
\hline 1973 & $-14.31 \%$ & $6.73 \%$ & $3.66 \%$ & $\mathrm{~S} /$ & $4,080.44$ & 272.16 & $\mathrm{~S} /$ & 372.57 & $-21.03 \%$ & $-17.97 \%$ & $0.12 \%$ \\
\hline 1974 & $-25.90 \%$ & $7.78 \%$ & $1.99 \%$ & $\mathrm{~S} /$ & $3,023.54$ & 293.33 & $\mathrm{~S} /$ & 379.98 & $-33.68 \%$ & $-27.89 \%$ & $0.11 \%$ \\
\hline 1975 & $37.00 \%$ & $5.99 \%$ & $3.61 \%$ & $\mathrm{~S} /$ & $4,142.10$ & 310.90 & $\mathrm{~S} /$ & 393.68 & $31.01 \%$ & $33.39 \%$ & $0.12 \%$ \\
\hline 1976 & $23.83 \%$ & $4.97 \%$ & $15.98 \%$ & $\mathrm{~S} /$ & $5,129.20$ & S/ $\quad 326.35$ & $\mathrm{~S} /$ & 456.61 & $18.86 \%$ & $7.85 \%$ & $0.12 \%$ \\
\hline 1977 & $-6.98 \%$ & $5.13 \%$ & $1.29 \%$ & $\mathrm{~S} /$ & $4,771.20$ & 343.09 & $\mathrm{~S} /$ & 462.50 & $-12.11 \%$ & $-8.27 \%$ & $0.12 \%$ \\
\hline 1978 & $6.51 \%$ & $6.93 \%$ & $-0.78 \%$ & $\mathrm{~S} /$ & $5,081.77$ & 366.87 & $\mathrm{~S} /$ & 458.90 & $-0.42 \%$ & $7.29 \%$ & $0.12 \%$ \\
\hline 1979 & $18.52 \%$ & $9.94 \%$ & $0.67 \%$ & $\mathrm{~S} /$ & $6,022.89$ & S/ 403.33 & $\mathrm{~S} /$ & 461.98 & $8.58 \%$ & $17.85 \%$ & $0.13 \%$ \\
\hline 1980 & $31.74 \%$ & $11.22 \%$ & $-2.99 \%$ & $\mathrm{~S} /$ & $7,934.26$ & S/ $\quad 448.58$ & $\mathrm{~S} /$ & 448.17 & $20.52 \%$ & $34.72 \%$ & $0.15 \%$ \\
\hline 1981 & $-4.70 \%$ & $14.30 \%$ & $8.20 \%$ & $\mathrm{~S} /$ & $7,561.16$ & S/ $\quad 512.73$ & $\mathrm{~S} /$ & 484.91 & $-19.00 \%$ & $-12.90 \%$ & $0.14 \%$ \\
\hline 1982 & $20.42 \%$ & $11.01 \%$ & $32.81 \%$ & $\mathrm{~S} /$ & $9,105.08$ & S/ $\quad 569.18$ & $\mathrm{~S} /$ & 644.04 & $9.41 \%$ & $-12.40 \%$ & $0.13 \%$ \\
\hline 1983 & $22.34 \%$ & $8.45 \%$ & $3.20 \%$ & $\mathrm{~S} /$ & $11,138.90$ & S/ $\quad 617.26$ & $\mathrm{~S} /$ & 664.65 & $13.89 \%$ & $19.14 \%$ & $0.14 \%$ \\
\hline 1984 & $6.15 \%$ & $9.61 \%$ & $13.73 \%$ & $\mathrm{~S} /$ & $11,823.51$ & S/ $\quad 676.60$ & $\mathrm{~S} /$ & 755.92 & $-3.47 \%$ & $-7.59 \%$ & $0.14 \%$ \\
\hline 1985 & $31.24 \%$ & $7.49 \%$ & $25.71 \%$ & $\mathrm{~S} /$ & $15,516.60$ & 727.26 & $\mathrm{~S} /$ & 950.29 & $23.75 \%$ & $5.52 \%$ & $0.14 \%$ \\
\hline 1986 & $18.49 \%$ & $6.04 \%$ & $24.28 \%$ & $\mathrm{~S} /$ & $18,386.33$ & 771.15 & $\mathrm{~S} /$ & $1,181.06$ & $12.46 \%$ & $-5.79 \%$ & $0.14 \%$ \\
\hline 1987 & $5.81 \%$ & $5.72 \%$ & $-4.96 \%$ & $\mathrm{~S} /$ & $19,455.08$ & 815.27 & $\mathrm{~S} /$ & $1,122.47$ & $0.09 \%$ & $10.77 \%$ & $0.14 \%$ \\
\hline 1988 & $16.54 \%$ & $6.45 \%$ & $8.22 \%$ & $\mathrm{~S} /$ & $22,672.40$ & S/ 867.86 & $\mathrm{~S} /$ & $1,214.78$ & $10.09 \%$ & $8.31 \%$ & $0.15 \%$ \\
\hline 1989 & $31.48 \%$ & $8.11 \%$ & $17.69 \%$ & $\mathrm{~S} /$ & $29,808.58$ & S/ $\quad 938.24$ & $\mathrm{~S} /$ & $1,429.72$ & $23.37 \%$ & $13.78 \%$ & $0.15 \%$ \\
\hline 1990 & $-3.06 \%$ & $7.55 \%$ & $6.24 \%$ & $\mathrm{~S} /$ & $28,895.11$ & S/ 1,009.08 & $\mathrm{S} /$ & $1,518.87$ & $-10.61 \%$ & $-9.30 \%$ & $0.15 \%$ \\
\hline 1991 & $30.23 \%$ & $5.61 \%$ & $15.00 \%$ & $\mathrm{~S} /$ & $37,631.51$ & S/ 1,065.69 & $\mathrm{S} /$ & $1,746.77$ & $24.62 \%$ & $15.23 \%$ & $0.15 \%$ \\
\hline 1992 & $7.49 \%$ & $3.41 \%$ & $9.36 \%$ & $\mathrm{~S} /$ & $40,451.51$ & S/ 1,101.98 & $\mathrm{S} /$ & $1,910.30$ & $4.09 \%$ & $-1.87 \%$ & $0.15 \%$ \\
\hline 1993 & $9.97 \%$ & $2.98 \%$ & $14.21 \%$ & $\mathrm{~S} /$ & $44,483.33$ & S/ 1,134.84 & $\mathrm{S} /$ & $2,181.77$ & $6.98 \%$ & $-4.24 \%$ & $0.15 \%$ \\
\hline
\end{tabular}




\begin{tabular}{|c|c|c|c|c|c|c|c|c|c|c|c|}
\hline 1994 & $1.33 \%$ & $3.99 \%$ & $-8.04 \%$ & $\mathrm{~S} /$ & $45,073.14$ & S/ 1,180.07 & $\mathrm{S} /$ & $2,006.43$ & $-2.66 \%$ & $9.36 \%$ & $0.16 \%$ \\
\hline 1995 & $37.20 \%$ & $5.52 \%$ & $23.48 \%$ & $\mathrm{~S} /$ & $61,838.19$ & S/ 1,245.15 & $\mathrm{S} /$ & $2,477.55$ & $31.68 \%$ & $13.71 \%$ & $0.16 \%$ \\
\hline 1996 & $22.68 \%$ & $5.02 \%$ & $1.43 \%$ & $\mathrm{~S} /$ & $75,863.69$ & S/ 1,307.68 & $\mathrm{S} /$ & $2,512.94$ & $17.66 \%$ & $21.25 \%$ & $0.17 \%$ \\
\hline 1997 & $33.10 \%$ & $5.05 \%$ & $9.94 \%$ & $\mathrm{~S} /$ & $100,977.34$ & S/ 1,373.76 & $\mathrm{S} /$ & $2,762.71$ & $28.05 \%$ & $23.16 \%$ & $0.18 \%$ \\
\hline 1998 & $28.34 \%$ & $4.73 \%$ & $14.92 \%$ & $\mathrm{~S} /$ & $129,592.25$ & $\mathrm{~S} / 1,438.70$ & $\mathrm{~S} /$ & $3,174.95$ & $23.61 \%$ & $13.42 \%$ & $0.19 \%$ \\
\hline 1999 & $20.89 \%$ & $4.51 \%$ & $-8.25 \%$ & $\mathrm{~S} /$ & $156,658.05$ & S/ 1,503.58 & $\mathrm{S} /$ & $2,912.88$ & $16.38 \%$ & $29.14 \%$ & $0.20 \%$ \\
\hline 2000 & $-9.03 \%$ & $5.76 \%$ & $16.66 \%$ & $\mathrm{~S} /$ & $142,508.98$ & S/ 1,590.23 & $\mathrm{S} /$ & $3,398.03$ & $-14.79 \%$ & $-25.69 \%$ & $0.19 \%$ \\
\hline 2001 & $-11.85 \%$ & $3.67 \%$ & $5.57 \%$ & $\mathrm{~S} /$ & $125,622.01$ & S/ 1,648.63 & $\mathrm{S} /$ & $3,587.37$ & $-15.52 \%$ & $-17.42 \%$ & $0.18 \%$ \\
\hline 2002 & $-21.97 \%$ & $1.66 \%$ & $15.12 \%$ & $\mathrm{~S} /$ & $98,027.82$ & S/ 1,675.96 & $\mathrm{S} /$ & $4,129.65$ & $-23.62 \%$ & $-37.08 \%$ & $0.16 \%$ \\
\hline 2003 & $28.36 \%$ & $1.03 \%$ & $0.38 \%$ & $\mathrm{~S} /$ & $125,824.39$ & S/ 1,693.22 & $\mathrm{S} /$ & $4,145.15$ & $27.33 \%$ & $27.98 \%$ & $0.17 \%$ \\
\hline 2004 & $10.74 \%$ & $1.23 \%$ & $4.49 \%$ & $\mathrm{~S} /$ & $139,341.42$ & S/ $1,714.00$ & $\mathrm{~S} /$ & $4,331.30$ & $9.52 \%$ & $6.25 \%$ & $0.17 \%$ \\
\hline 2005 & $4.83 \%$ & $3.01 \%$ & $2.87 \%$ & $\mathrm{~S} /$ & $146,077.85$ & S/ 1,765.59 & $\mathrm{S} /$ & $4,455.50$ & $1.82 \%$ & $1.97 \%$ & $0.17 \%$ \\
\hline 2006 & $15.61 \%$ & $4.68 \%$ & $1.96 \%$ & $\mathrm{~S} /$ & $168,884.34$ & S/ $1,848.18$ & $\mathrm{~S} /$ & $4,542.87$ & $10.94 \%$ & $13.65 \%$ & $0.18 \%$ \\
\hline 2007 & $5.48 \%$ & $4.64 \%$ & $10.21 \%$ & $\mathrm{~S} /$ & $178,147.20$ & S/ 1,933.98 & $\mathrm{S} /$ & $5,006.69$ & $0.84 \%$ & $-4.73 \%$ & $0.18 \%$ \\
\hline 2008 & $-36.55 \%$ & $1.59 \%$ & $20.10 \%$ & $\mathrm{~S} /$ & $113,030.22$ & S/ 1,964.64 & $\mathrm{S} /$ & $6,013.10$ & $-38.14 \%$ & $-56.65 \%$ & $0.15 \%$ \\
\hline 2009 & $25.94 \%$ & $0.14 \%$ & $-11.12 \%$ & $\mathrm{~S} /$ & $142,344.87$ & S/ 1,967.29 & $\mathrm{S} /$ & $5,344.65$ & $25.80 \%$ & $37.05 \%$ & $0.16 \%$ \\
\hline 2010 & $14.82 \%$ & $0.13 \%$ & $8.46 \%$ & $\mathrm{~S} /$ & $163,441.94$ & S/ 1,969.84 & $\mathrm{S} /$ & $5,796.96$ & $14.69 \%$ & $6.36 \%$ & $0.17 \%$ \\
\hline 2011 & $2.10 \%$ & $0.03 \%$ & $16.04 \%$ & $\mathrm{~S} /$ & $166,871.56$ & S/ 1,970.44 & $\mathrm{S} /$ & $6,726.52$ & $2.07 \%$ & $-13.94 \%$ & $0.16 \%$ \\
\hline 2012 & $15.89 \%$ & $0.05 \%$ & $2.97 \%$ & $\mathrm{~S} /$ & $193,388.43$ & S/ 1,971.42 & $\mathrm{S} /$ & $6,926.40$ & $15.84 \%$ & $12.92 \%$ & $0.17 \%$ \\
\hline 2013 & $32.15 \%$ & $0.07 \%$ & $-9.10 \%$ & $\mathrm{~S} /$ & $255,553.31$ & S/ 1,972.72 & $\mathrm{S} /$ & $6,295.79$ & $32.08 \%$ & $41.25 \%$ & $0.18 \%$ \\
\hline 2014 & $13.52 \%$ & $0.05 \%$ & $10.75 \%$ & $\mathrm{~S} /$ & $290,115.42$ & S/ 1,973.77 & $\mathrm{S} /$ & $6,972.34$ & $13.47 \%$ & $2.78 \%$ & $0.19 \%$ \\
\hline 2015 & $1.38 \%$ & $0.21 \%$ & $1.28 \%$ & $\mathrm{~S} /$ & $294,115.79$ & S/ 1,977.91 & $\mathrm{S} /$ & $7,061.89$ & $1.17 \%$ & $0.09 \%$ & $0.19 \%$ \\
\hline 2016 & $11.77 \%$ & $0.51 \%$ & $0.69 \%$ & $\mathrm{~S} /$ & $328,742.28$ & $\mathrm{~S} / 1,988.00$ & $\mathrm{~S} /$ & $7,110.65$ & $11.26 \%$ & $11.08 \%$ & $0.19 \%$ \\
\hline 2017 & $21.64 \%$ & $1.39 \%$ & $2.80 \%$ & $\mathrm{~S} /$ & $399,885.98$ & S/ 2,015.63 & $\mathrm{S} /$ & $7,309.87$ & $20.25 \%$ & $18.84 \%$ & $0.20 \%$ \\
\hline
\end{tabular}

\begin{tabular}{|c|c|c|}
\hline Años & Tasa de mercado & Tasa Libre de Riesgo \\
\hline $1928-2017$ & $12.59 \%$ & $3.77 \%$ \\
\hline $1968-2017$ & $12.44 \%$ & $4.10 \%$ \\
\hline $2008-2017$ & $12.25 \%$ & $2.92 \%$ \\
\hline
\end{tabular}


Anexo N7

Riesgo Región

\begin{tabular}{|c|c|c|c|c|c|c|c|c|c|c|c|}
\hline \multicolumn{12}{|c|}{ LATIN EMBIG Países Latinoamericanos - EMBIG Perú (pbs) } \\
\hline MIESES & 2007 & 2008 & 2009 & 2010 & 2011 & 2012 & 2013 & 2014 & 2015 & 2016 & 2017 \\
\hline Enero & 183 & 298 & 718 & 355 & 343 & 460 & 320 & 425 & 561 & 663 & 463 \\
\hline Febrero & 180 & 311 & 711 & 376 & 348 & 415 & 330 & 456 & 539 & 685 & 442 \\
\hline Marzo & 187 & 335 & 704 & 331 & 364 & 372 & 346 & 408 & 521 & 588 & 431 \\
\hline Abril & 167 & 314 & 624 & 310 & 371 & 392 & 347 & 372 & 488 & 559 & 431 \\
\hline Mayo & 165 & 290 & 0 & 383 & 379 & 425 & 347 & 365 & 470 & 552 & 419 \\
\hline Junio & 168 & 283 & 484 & 401 & 388 & 444 & 414 & 343 & 504 & 541 & 430 \\
\hline Julio & 203 & 323 & 452 & 388 & 368 & 416 & 404 & 336 & 527 & 495 & 435 \\
\hline Agosto & 249 & 345 & 408 & 362 & 417 & 375 & 408 & 373 & 567 & 473 & 435 \\
\hline Septiembre & 243 & 413 & 386 & 373 & 470 & 360 & 404 & 391 & 586 & 463 & 416 \\
\hline Octubre & 220 & 696 & 365 & 345 & 483 & 353 & 401 & 443 & 582 & 453 & 407 \\
\hline Noviembre & 264 & 739 & 369 & 346 & 464 & 367 & 418 & 454 & 553 & 490 & 422 \\
\hline Diciembre & 270 & 777 & 361 & 350 & 454 & 333 & 602 & 516 & 594 & 482 & 419 \\
\hline Prom. Anual & 208 & 427 & 465 & 360 & 404 & 393 & 395 & 407 & 541 & 537 & 429 \\
\hline
\end{tabular}

Fuente: www.bcrp.gob.pe/docs/Estadisticas/Cuadros-Estadisticos/NC_037.xls

\begin{tabular}{|l|c|}
\hline \multirow{2}{*}{ Promedio Riesgo País } & $\mathbf{4 3 6}$ \\
\cline { 2 - 2 } & $\mathbf{4 . 3 6} \%$ \\
\hline
\end{tabular}




\section{Anexo N8}

Inflación Perú e Inflación Estados Unidos

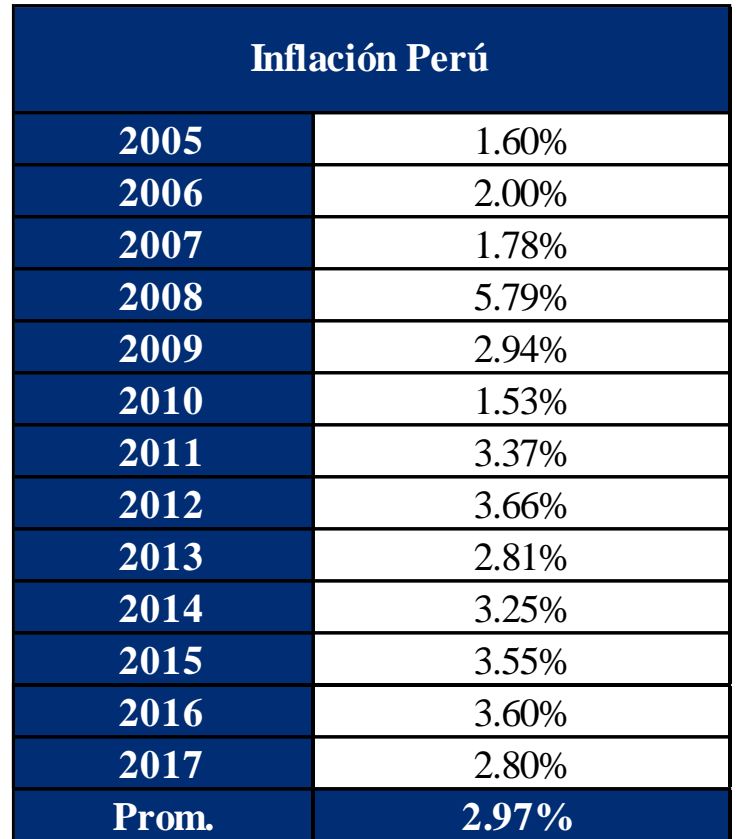

Fuente:

datos.bancomundial.org/indicador/FP.CPI.

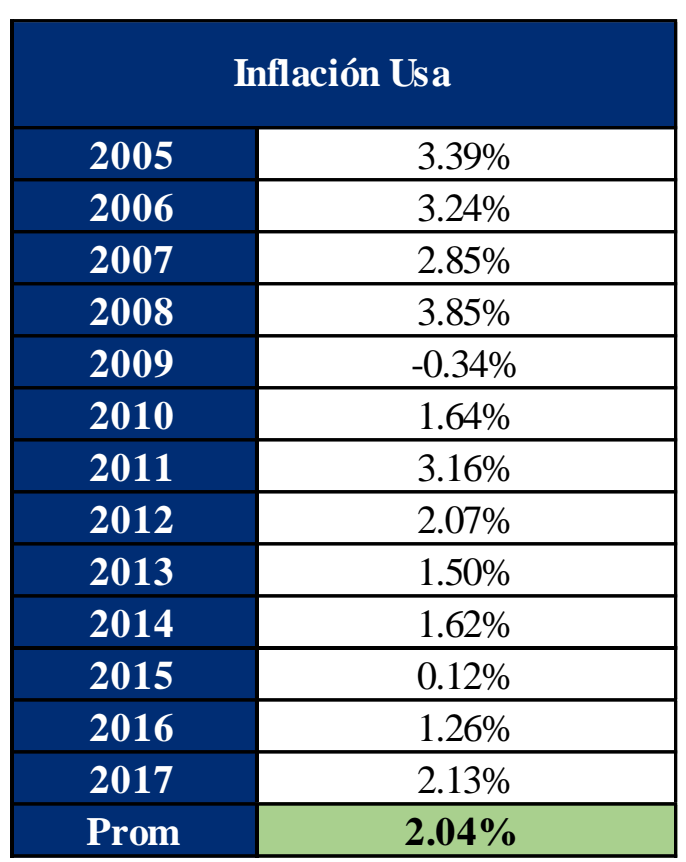

Fuente:http://inflationdata.com/inflatio n/Inflation_Rate/HistoricalInflation.as px 


\section{Anexo N9}

Riesgo País Perú

\begin{tabular}{|c|c|c|c|c|c|c|c|c|c|c|c|}
\hline \multicolumn{12}{|c|}{ Riesgo País Spread - EMIBIG Perú (pbs) } \\
\hline MESES & 2007 & 2008 & 2009 & 2010 & 2011 & 2012 & 2013 & 2014 & 2015 & 2016 & 2017 \\
\hline Enero & 123 & 195 & 460 & 180 & 146 & 219 & 110 & 177 & 202 & 266 & 157 \\
\hline Febrero & 127 & 209 & 419 & 200 & 146 & 200 & 127 & 183 & 183 & 282 & 152 \\
\hline Marzo & 132 & 221 & 409 & 158 & 157 & 166 & 140 & 167 & 184 & 227 & 141 \\
\hline Abril & 118 & 182 & 360 & 144 & 192 & 154 & 133 & 154 & 177 & 210 & 149 \\
\hline Mayo & 110 & 154 & 292 & 202 & 187 & 180 & 133 & 149 & 166 & 208 & 141 \\
\hline Junio & 104 & 160 & 258 & 207 & 192 & 188 & 180 & 145 & 177 & 210 & 144 \\
\hline Julio & 129 & 198 & 274 & 187 & 171 & 163 & 175 & 147 & 187 & 184 & 142 \\
\hline Agosto & 169 & 195 & 240 & 157 & 200 & 133 & 191 & 157 & 217 & 170 & 156 \\
\hline Septiembre & 156 & 258 & 226 & 167 & 237 & 124 & 182 & 150 & 234 & 162 & 144 \\
\hline Octubre & 139 & 475 & 193 & 157 & 232 & 108 & 173 & 170 & 226 & 147 & 140 \\
\hline Noviembre & 175 & 479 & 191 & 152 & 214 & 123 & 182 & 165 & 219 & 168 & 139 \\
\hline Diciembre & 175 & 524 & 179 & 157 & 217 & 117 & 222 & 182 & 236 & 165 & 136 \\
\hline Prom. Anual & 138 & 271 & 292 & 172 & 191 & 156 & 162 & 162 & 201 & 200 & 145 \\
\hline
\end{tabular}

Fuente: www.bcrp.gob.pe/docs/Estadisticas/Cuadros-Estadisticos/NC_037.xls 